\title{
Close Encounters of Various Kinds. Empirical Studies of Customer-Firm Interactions
}

Citation for published version (APA):

van Dolen, W. M. (2002). Close Encounters of Various Kinds. Empirical Studies of Customer-Firm Interactions. [Doctoral Thesis, Maastricht University]. Uni Network Consultancy BV. https://doi.org/10.26481/dis.20020607wd

Document status and date:

Published: 01/01/2002

DOI:

$10.26481 / d i s .20020607 w d$

Document Version:

Publisher's PDF, also known as Version of record

\section{Please check the document version of this publication:}

- A submitted manuscript is the version of the article upon submission and before peer-review. There can be important differences between the submitted version and the official published version of record.

People interested in the research are advised to contact the author for the final version of the publication, or visit the DOI to the publisher's website.

- The final author version and the galley proof are versions of the publication after peer review.

- The final published version features the final layout of the paper including the volume, issue and page numbers.

Link to publication

\footnotetext{
General rights rights.

- You may freely distribute the URL identifying the publication in the public portal. please follow below link for the End User Agreement:

www.umlib.nl/taverne-license

Take down policy

If you believe that this document breaches copyright please contact us at:

repository@maastrichtuniversity.nl

providing details and we will investigate your claim.
}

Copyright and moral rights for the publications made accessible in the public portal are retained by the authors and/or other copyright owners and it is a condition of accessing publications that users recognise and abide by the legal requirements associated with these

- Users may download and print one copy of any publication from the public portal for the purpose of private study or research.

- You may not further distribute the material or use it for any profit-making activity or commercial gain

If the publication is distributed under the terms of Article $25 \mathrm{fa}$ of the Dutch Copyright Act, indicated by the "Taverne" license above, 


\section{Close Encounters of Various Kinds}

Empirical Studies of Customer-Firm Interactions 
- 2002, Willemijn M. van Dolen, Maastricht.

All rights reserved. No part of this publication may be reprinted or utilized in any form or by any electronic, mechanical or other means, now known, or hereafter invented, including photocopying and recording, or in any information storage or retrieval system, without written permission from the copyright owner.

Support provided by: Uni Network Consultancy B.V., Amsterdam

Cover designed by: Jochem Harteveld

ISBN:

90-9015873-1 


\title{
Close Encounters of Various Kinds
}

\author{
Empirical Studies of Customer-Firm Interactions
}

\section{PROEFSCHRIFT}

\author{
ter verkrijging van de graad van doctor \\ aan de Universiteit Maastricht,
}

op gezag van de Rector Magnificus, Prof. Dr. A.C. Nieuwenhuijzen Kruseman, volgens het besluit van het College van Decanen, in het openbaar te verdedigen op vrijdag 7 juni 2002 om 14.00 uur

door

Willemijn Maria van Dolen 
Promotoren:

Prof. 1)r. J.C. de Ruyter

Prof. Dr. J.G.A.M. I.emmink

\section{Beoordelingscommissie:}

Prof. Dr. P.J.J. Herings (voorzitter)

Prof. Dr. W.H. Gijselaers

Prof. J.M. Carman, Ph.D. (University of California, Berkeley) 
Voor mijn vader en moeder 



\section{Acknowledgements}

Vier jaar geleden kwam ik tot de conclusie dat mijn toenmalige baan in het bedrijfsleven niet leidde tot volle tevredenheid. Er ontbrak iets. Het was Luci Moorman die mij op dat moment wees op een AIO-plaats in Maastricht. En dat bleek een schot in de roos. Het zijn vier jaren geweest van diep nadenken, leren, lijnen uitzetten en vooral hard werken. Ik heb het met groot plezier gedaan, vooral ook omdat ik algauw tot de conclusie kwam dat het wetenschappelijke werk mij uitdaagt en veel voldoening geeft.

Tijdens mijn sollicitatiegesprek maakte ik kennis met mijn promotoren Ko de Ruyter en Jos Lemmink. Door de jaren heen hebben beiden op hun eigen wijze een belangrijke bijdrage geleverd aan de totstandkoming van dit proefschrift. Ko is een echte motivator die in staat is het beste in een AIO naar boven te halen. Ik heb met name goede herinneringen aan onze leerzame discussies, en aan zijn onafgebroken zoektocht naar bruikbaar materiaal voor mijn onderzoek. Keer op keer kwam hij enthousiast mijn kamertje binnenlopen: "Ik heb nóg een interessant papertje voor je gevonden". En dat, terwijl de hele kamer al bezaaid lag met artikelen, die we hadden verzameld. Jos is het luisterende oor. Ik klopte veelvuldig op zijn deur, en telkens weer was hij een aandachtige luisteraar, die mij van bruikbare adviezen diende. Daarnaast kon hij een prettige, vaderlijke zorg tentoonspreiden als de druk op de ketel opliep. Zowel Ko als Jos hebben me de ruimte gegeven mijzelf te ontplooien en ik dank hen voor het vertrouwen dat daaruit sprak.

I also would like to thank the members of the graduation committee, Prof. Dr. P.J.J. Herings, Prof. Dr. W.H. Gijselaers, and Prof. J.M. Carman, Ph.D. for the effort and time they have put into reading the dissertation. I would like to pay a special tribute to Jim Carman. Prof. Dr. Hans Kasper introduced me to the University of California, Berkeley and the kindness with which Jim responded ("I would be delighted to host, sponsor, and help Willemijn") turned out to be typical for him during my stay in the Bay Area. Jim did not only provide me his academic wisdom, but he also taught me about American history, about important matters as Dutch Gin, and, not forgetting, he provided me with a new name: 'Willa'. I would like to thank him and his wife Carol for taking care of Erik and me by inviting us to many social events like lunches, dinners, sporting events ("Go Bears, Go Cal!"), and to their chalet in Kirkwood.

Next to Jim, I was very lucky to get to know another Professor in the United States: Pratibha Dabholkar. Last year, we have been working together and I gained a lot of knowledge from her valuable and wise feedback. Our work-related discussions but also our talks about topics like religion, the relativity of time, and reincarnation made my visit to her and her husband Earl in Knoxville, Tennessee, an enriching experience.

Natuurlijk wil ik ook mijn collega's van de sectie marketing \& marktonderzoek bedanken voor de prettige werksfeer waaraan ieder een bijdrage heeft geleverd. Met name Marcel van Birgelen vervulde daarbij een belangrijke rol als geduldige kamergenoot. Hij stond mij bij met raad en daad tijdens de afronding van deze 
dissertatie. Maar hij heeft me ook leren 'kallen' op z'n Limburgs, bij hem heb ik voor het eerst Limburgs zuurvlees gegeten en daarbij genoten van zijn eigen gebrouwde Limburgse bier. Samen hebben we bewezen dat een Hollander en een Limburger het wel degelijk goed met elkaar kunnen vinden.

De dataverzameling voor deze dissertatie was gevarieerd en complex. We hebben mensen 'achtervolgd' in meubelzaken, gefilmd in een reisbureau, web-sites gebouwd en een chat-applicatie vormgegeven en geïmplementeerd. Ik wil alle bedrijven, managers en studenten die mij hierbij hebben geholpen van harte bedanken.

Daarnaast is er een aantal mensen dat geen directe invloed heeft gehad op mijn proefschrift, maar die het leven naast het werk erg aangenaam voor me hebben gemaakt. Dat zijn al mijn vrienden, van wie ik speciaal Nynke Driesens wil noemen. Ik zou haar willen omschrijven als "no-nonsense-ik-sta-altijd-voor-je-klaar"-Nynke, op wie ik te pas en te onpas kan bouwen. Verder wil ik Luci bedanken voor haar bovengenoemde "gouden tip", die mijn leven een andere wending heeft gegeven, voor de eerste opvang in Maastricht en voor de aanhoudende belangstelling die zij heeft getoond.

Naast vrienden vervullen mijn familieleden een belangrijke rol. Mijn broer Joost heeft een goed gevoel voor humor en van zijn relativeringsvermogen kan ik op zijn tijd veel leren. Mijn vader is altijd attent en zorgzaam in de breedste zin van het woord. Waar hij ook is en ongeacht waar ik ben, hij houdt me op de hoogte via lange en vooral geestige e-mails, kaartjes en brieven. Verder kan ik rekenen op uitgebreide lunchpakketten voor de 'reis' Amsterdam-Maastricht en leest hij met veel precisie mijn werk na. Mijn moeder is er altijd op de momenten dat het nodig is en toont steevast veel interesse in mijn werk en sociale leven. Dat laatste is in het bijzonder prettig omdat ik regelmatig overloop van de verhalen. Dan spui ik bij haar en spring van de hak op de tak waarop zij uiteindelijk antwoordt met een keurig gestructureerd overzicht inclusief alle details. Heerlijk en absoluut noodzakelijk. Het gevoel dat ik onvoorwaardelijk op alledrie kan rekenen is voor mij van onschatbare waarde.

Tot slot, als ik het heb over plezier in het leven, dan gaan mijn gedachten meteen naar mijn man Erik uit: Never a dull moment with Erik! Het leven met hem is een feest en in stijl met mijn proefschrift wil ik hem graag op z'n 'chats' laten weten:

U2MeREvrythng $\bullet \bullet$ Dy By Dy \& $\$$ !

Willemijn van Dolen Amsterdam, voorjaar, 2002 


\section{Table of Contents}

Acknowledgements

1 Introduction

1.1 Customer Satisfaction

1.2 Customer-Firm Encounters

1.3 Motivation

1.4 Objectives

1.4.1 Objectives Chapter 2

1.4.2 Objectives Chapter 3

1.4.3 Objectives Chapter 4

1.4.4 Objectives Chapter 5

1.5 Outline of this Dissertation

2 Customer-Sales Employee Encounters: A Dyadic Perspective

2.1 Introduction

2.2 A Dyadic Perspective on Satisfaction

2.2.1 Actor Effects in the Sales Encounter

2.2.2 Partner Effects in the Sales Encounter

2.2.3 Agreement in Perceptions between Customers and Employees

2.2.4 Uniqueness versus Consensus and Consistency in Perceptions

2.3 An Empirical Study

2.3.1 Method

2.3.2 Procedure

2.3.3 Sample

2.3.4 Questionnaire Development 22

2.4 Multi-Level Analysis and Model Building 24

2.4.1 Analysis Strategy 26

2.5 Results 27

2.5.1 Uniqueness versus Consensus and Consistency in Perceptions 291

2.5.2 Actor and Partner Effects on Customer Encounter Satisfaction 29

2.5.3 Actor and Partner Effects on Employee Encounter Satisfaction 31

2.5.4 Agreement in Perceptions between Customers and Employees 31

2.6 Discussion 31

2.6.1 Actor Effects in the Sales Encounter: Uniqueness versus Consensus and 32

2.6.2 Partner Effects in the Sales Encounter: Uniqueness versus Consensus and 33 Consistency

Consistency

2.6.3 Agreement in Perceptions between Customers and Employees 34

2.6.4 Conclusion 34

2.6.5 Suggestions for Future Researcb 35 
3 The Impact of Humor in Face-to-Face and Electronic Encounters 37

$\begin{array}{lll}3.1 & \text { Introduction } & 38\end{array}$

3.2 Literature Review 39

3.2.1 Conceptualizations of Humor 39

3.2.2 Types of Humor 41

3.2.3 Effects of Humor $\quad 42$

3.2.4 Customer Evaluations of Service Encounters 43

3.3 Hypotheses Development 44

3.4 Experiment 1: Face-to-Face Encounters 47

$\begin{array}{lll}3.4 .1 & \text { Method } & 47\end{array}$

$\begin{array}{ll}3.4 .2 & \text { Procedure }\end{array}$

$\begin{array}{lll}3.4 .3 & \text { Pre-Test } & 49\end{array}$

3.4.4 Sample 49

3.4.5 Questionnaire Development 49

3.4.6 Results 50

3.5 Experiment 2: Electronic Encounters 53

3.5.1 Method 53

$\begin{array}{ll}3.5 .2 & \text { Procedure } \\ 3.5 .3\end{array}$

3.5.3 Pre-Test $\quad 54$

3.5.4 Sample $\quad 54$

3.5.5 Questionnaire Development 54

3.5.6 Results $\quad 55$

3.6 Discussion $\quad 58$

3.6.1 Suggestions for Future Research 60

3.6.2 Managerial Implications $\quad 62$

$4 \quad$ Moderated Group Chat: An Empirical Investigation of a New 63

4.1 Introduction 64

4.2 IRC as a Marketing Instrument 65

4.3 Development of a Theoretical Research Model 68

4.3.1 Consumer Characteristics $\quad 69$

$\begin{array}{lll}\text { 4.3.2 Group Characteristics } & 71\end{array}$

4.3.3 Advisor Characteristics $\quad 73$

4.3.4 Refinement of the Theoretical Research Model 74

$\begin{array}{lll}4.4 & \text { An Empirical Study } & 78\end{array}$

$\begin{array}{lll}\text { 4.4.1 Method } & 78\end{array}$

$\begin{array}{ll}\text { 4.4.2 Procedure } & 78\end{array}$

$\begin{array}{lll}4.4 .3 \text { Pre-Test } & 80\end{array}$

$\begin{array}{lll}4.4 .4 & \text { Sample } & 81\end{array}$

4.4.5 Questionnaire Development 81 
4.5 Multi-Level Analysis and Model Building

4.6 Results

4.6.1 Consumer Characteristics

4.6.2 Group Characteristics

4.6.3 Advisor Characteristics

4.6.4 Research Questions Results

4.6.5 Summary

4.7 Discussion

4.7.1 Consumer Characteristics

4.7.2 Group Characteristics

4.7.3 Advisor Characteristics

4.7.4 Complementary Roles

4.7.5 Suggestions for Future Research

4.7.6 Managerial Implications

$5 \quad$ Moderated Group Chat: An Investigation of Alternative Models of 95 Satisfaction

5.1 Introduction

5.2 The Domain of Commercial IRC

5.3 Development of a Conceptual Foundation

5.3.1 Attribute-Based Model

5.3.2 Overall Affect Model

5.3.3 Group Characteristics Model

5.3.4 Refinement of the Conceptual Foundation.

$5.4 \quad$ An Empirical Study

5.4.1 Method

5.4 .2 Procedure

5.4.3 Pre-Test

5.4.4 Sample

5.4.5 Questionnaire Development

5.5 Multi-Level Analysis and Model Building

5.6 Results

5.6.1 Attribute-Based Model

5.6.2 Overall Affect Model

5.6.3 Group Characteristics Model

5.6.4 Research Questions Results 
5.7 Discussion

5.7.1 A Comparison of Models

5.7.2 Individual-and Group-Level Effects

5.7.3 Style of the Advisor

5.7.4 Attribute-Based Model

5.7.5 Overall Affect Model

\subsubsection{Group Characteristics Model}

5.7.7 Suggestions for Future Research

5.7.8 Managerial Implications

6.1 Synopsis

6.2 Main Conclusions of the Chapters

6.2.1 Chapter 2

6.2.2 Chapter 3

6.2.3 Chapter 4

6.2.4 Chapter 5

6.3 An Integrated Perspective 128

6.3.1 Interpersonal Influence $\quad 128$

$\begin{array}{ll}\text { 6.3.2 Social and Task Antecedents } & 129\end{array}$

6.3.3 Unique and Shared Experiences 130

6.3.4 Role of the Employee 130

6.3.5 Nuances in Electronic Experiences 131

6.3.6 The Future of Electronic Encounters 132

6.4 Suggestions for Future Research 133

References 135

Appendix A: Humor Treatment for Face-to-Face Encounters 149

Appendix B: Humor Treatment for Electronic Encounters 150

Nederlandse Samenvatting $\quad 153$

Curriculum Vitae 
Chapter 1

\section{Introduction}




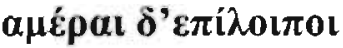

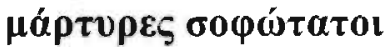

\author{
(Pindarus, Olympic Odes, 1, 53-54)
}

In this chapter, we first offer a brief description of the field this dissertation has relevance to and the aims it attempts to achieve. Next, we discuss the motivation underlying our study and the specific objectives of the several chapters. Finally, this chapter concludes with an outline of the remainder of this dissertation.

\subsection{Customer Satisfaction}

Pindarus' adagio that the days to come are the sharpest witnesses (cf., van Dolen 2000), seems to be more true than ever in today's economy. For present-day companies, operating in highly competitive markets, concurrently accompanied by more demanding customers, indicators of future performance are of utmost importance. It is generally acknowledged that managers cannot manage effectively while relying solely on backward-looking measures. In fact, focusing only on these measures is like lnoking at the present through a rear-view mirror and marching backwards into the future (McLuhan and Fiore 1997). Managers need to know, or at least have an indication of, what lies ahead. Such an indication of future performance is customer satisfaction (Anderson and Fornell 2000).

In the contemporary marketing literature, there exists a general agreement about the importance of customer satisfaction for both consumers and firms (Oliver 2000; Oliver 1997; Price et al. 1995a; Westbrook and Oliver 1991). Shemwell et al. (1998 p. 155) state that in today's competitive milieu, "having satisfied customers is viewed as indispensable for gaining a sustainable advantage." Customer satisfaction's role as a leading indicator of financial and economic performance is directly linked to behavioral and economic benefits to the firm (Anderson et al. 1994). Financial measures of performance, such as profitability and return on equity, provide us with information about the quantity of consumption, and are fundamental to evaluating the past performance of a firm. However, they provide the firm limited information about future viability (Kaplan and Norton 1992). For instance, a productive sales force may be a liability if customers are only marginally satisfied. Customer satisfaction measures tell us about the quality of consumption and provide a leading indicator of financial health (Anderson and Fornell 2000).

Concretely, customer sarisfaction has been found to affect several desirable outcomes for firms. It leads to customer loyalty and consequently secures repeat business, and minimizes the likelihood to loose customers in case of a failure (e.g., Anderson and Sullivan 1993; Bolton 1998; Fornell 1992). Through increasing loyalty, it reduces the costs of future transactions (Reicheld and Sasser 1990) and decreases price elasticities (Anderson 1996). Furthermore, customer satisfaction results in positive worth of mouth and this lowers the costs of attracting new customers and 
positively influences the reputation of the firm (Anderson 1998; Fornell 1992). Overall, empirical work indicates that firms increasing customer satisfaction and providing quality enjoy higher economic returns (Aaker and Jacobson 1994; Anderson et al. 1997). As such, increasing attention is given to customer satisfaction as a corporate goal, in addition to traditional financial measures of success.

From a customer's perspective satisfying experiences may provide pleasure and meet desires; the origins of satisfaction begin with the necessity to fulfill basic needs and from the earliest times people have been assessing life outcomes against requirements or desires (Oliver 2000). Oliver (1997) suggests three reasons why consumers want a satisfying experience. First, satisfaction itself is a desirable end state of consumption; it is a reinforcing, pleasurable experience. Secondly, satisfaction obviates the need to take additional redress action or to suffer the consequences of a bad decision. There is no need to return products or to complain about a service. Finally, satisfaction reaffirms the consumer's decision-making prowess. The consumer proofs to be able to make satisfying decisions.

From a management perspective, one of the challenges facing many retail organizations is to continuously review their capacity to provide outcomes that satisfy their customers. As a result of intensified competition, improvements in technical product attributes have been realized and an increasing number of sales organizations attempt to use strategies based on differentiating buyer-seller interaction processes to increase customer satisfaction. They strive to create a competitive advantage in selling by new channels like web-sites, by improving interpersonal processes in the form of personalization, and by providing higher levels of service.

A vital aspect of a firm's performance is its capability to create satisfying experiences whenever customers and firms interact. In order to reflect the interactive nature of these contacts we have adopted the term close encounters in the title of this dissertation. Originally, the term was applied by the NASA to describe encounters between Earth and objects from outer space. Specifically, close encounters of the $3 \mathrm{rd}$ kind involve real-time interaction between human beings and unidentified species. This theme prominently features in the famous movie by Steven Spielberg 'Close Encounters of the Third Kind'. The theme of real-time contact is also central to this dissertation in which we study the formation of customer satisfaction in close encounters of various kinds between customers and firms.

Customer satisfaction is often determined by the quality of these individual encounters (Bitner et al. 1990) and consequently the customer-firm encounter is essentially the key to success or failure of many firms (Czepiel et al. 1985; Grönroos 1997). As Czepiel (1990 p. 13) states "an encounter is the point on which both today's and tomorrow's business success hinges." Customer encounter satisfaction is defined as a customer's evaluation of a particular product or service experience (Bitner and Hubert 1994). 


\subsection{Customer-Firm Encounters}

From the customer's point of view, the most immediate evidence of a firm's quality occurs in the encounter when the customer interacts with the firm (Bitner et al. 1994). In many retail settings, this customer-seller encounter plays a decisive and crucial role in optimizing customer sarisfaction (Bitner et al. 1994) and is consequently referred to as the 'moment of truth'. Some researchers define the customer-firm encounter broadly in terms of the moment of interaction between the customer and the firm (e.g., Shostack 1985). These researchers include all aspects of the firm with which the customer may interact, like the employee, technology, and other visible objects. They in fact suggest that customer-firm encounters can occur without any human interaction element. Others focus on the customer-firm encounter as an interpersonal, face-to face interaction between a buyer and a seller (e.g., Bitner et al. 1990; Solomon et al. 1985). For instance, Czepiel et al. (1985 p. 3) defines this encounter as "one human being interacting with another." In this dissertation, we refer to the customer-firm encounter as "a period of time during which a consumer directly interacts with a firm."

Encounters can be characterized by the extent of customer participation. As Risch Rodie and Schultz Kleine (2000 p. 113) state: "Customer participation is a behavioral concept that refers to the actions and resources supplied by customers for service production and/or delivery." It includes mental, physical, and emotional inputs (Hochschild 1983; Larsson and Bowen 1989). An encounter may require high participation (e.g., guitar lessons, home remodeling, defining goals for an investment portfolio) as well as low participation (e.g., opera attendance). Furthermore, encounters may be characterized by the level of customer contact, e.g., the percentage of time that the customer is present in the service delivery relative to the total service time (Chase 1978). For example, in getting a haircut the level of customer contact is high, whereas in bringing in a car for repair services the level is relatively low. Finally, the encounter can be characterized by involvement, e.g., a customer's personal interest in the service or product. For instance, a customer who is doing routine grocery shopping might be relatively low involved, whereas a customer who is contemplating the potential of investment services following a major inheritance might be relatively high involved (Risch Rodie and Schultz Kleine 2000).

To date, stveral furces are irreversible changing the nature of the encounter between customers and firms. For instance, the difference between products and services is disappearing. That is, services and physical goods are becoming more and more similar in nature (Grönroos 2000). Webster (1994) goes even further by stating that every business is a service business and Grönroos (1997) suggests that today's competition in many situations can be characterized as service competition, regardless whether the core of the offering to the market is services or goods. Oliver (2000) indicates that the satisfaction mechanisms in the context of service provision do not differ qualitatively from those existing in a product model. It might be that the nature of service consumption will cause some mechanisms to be more important in the satisfaction judgment and others to be less so. In many retail firms, customer-firm encounters become combined sales-service encounters, in which salespeople have to 
sell a product and to deliver the service during the encounter. This increases the intensity of the interaction between customers and the firm (Evans et al. 1999).

Furthermore, technological developments change the nature of the encounter. The number of technological applications offered by firms is substantial and growing, and impact service delivery and selling (e.g., Meuter and Bitner 1998; Lovelock 1995). An important consequence of the technological innovations like the Internet is that it provides salespeople as well as customers with much more information and knowledge. As a consequence, the face-to-face encounter between the firm and the customer can no longer be regarded as a transaction of knowledge, products and services from the firm towards the customer. It becomes more and more an interaction, comprised of contributions from both the customer's and the firm's side of the dyad.

Until recently, customer-firm encounters were viewed as person-to-person, faceto-face encounters between a customer and an employee at a site where they are both physically present and are able to communicate in person. Such encounters have traditionally been conceptualized as 'high touch, low-tech'. Yet, the explosive growth of the Internet has led to new forms of customer service and interaction, i.e., electronic encounters. These are interactions via the computer between the customer and the firm, in which the latter is an employee communicating via his or her keyboard or a web-site used by customers to buy or to provide service themselves. In the literature, the latter form is referred to as technology-based selfservice; customers can use the Internet to buy a product or provide service for themselves. This form is common in e-retailing and includes e-commerce activities like on-line banking, buying books on a web-site, and on-line brokerage services (Bitner et al. 2000; Dabholkar 1996). Although this dissertation focuses on technology-based self-service on the Internet, services like automated hotel check-out, self-service gas stations, automated photography service, and automated teller machines are defined as technology-based self-services too (Meuter et al. 2000).

An important consequence of self-service in electronic encounters is that interpersonal contact is limited or eliminated. Although it may be effective for some services and products to create a 'low touch, high tech' environment, new technologies are not only applied to replace the human provider. It is also acknowledged that in other situations it might be more effective and desirable to accompany the focus on 'high tech' by an emphasis on 'high touch' (Naisbitt et al. 2001). Some customers need social interaction, may want customization of service or product, and addressing of special needs in a person-to-person encounter (Barnes et al. 2000; Prendergast and Marr 1994). The call of customers for the integration of technology with human touch aspects is notable (Business Week 2001; Levine et al. 2000). As Albrecht and Zemke (2001 p. 21) note: "The more retail e-commerce websites there are, the more consumers desire live, human contact with the company as a value-added option." Also, others describe how consumers expect interaction with the company's staff during on-line interactions: "They know our experts are just behind the curtain and they want to ask the experts for more information." (Information Week 2001). In other words, customers are demanding real-time integration and human service in addition to automated cyber sale transactions and software agents. 
To respond to this call of on-line customers, firms explore interactive and collaborative e-business functionalities, which allow customers to interact with technology and employees. Examples are service provision and selling via e-mail, voice over IP, and Internet Relay Chat. We define these interpersonal encounters as moderated electronic encounters; interactions between the customer and the contact employee, in which both communicate via their computer, synchronously (e.g., chat) or non-synchronously (e.g., e-mail). It is reported that especially synchronous, interpersonal interaction on the Internet is important for business success in terms of customer loyalty, information targeting, product/service customization, real-time feedback gathering, and cross-selling (Business Week 2001; Kenny and Marshall 2000; Muniz and O'Guinn 2001; Rifkin 2000; Sivadas et al. 1998; Spiegelman 2000; Wolfinbarger and Gilly 2001). Figure 1-1 presents the conceptualization of face-to-face and electronic encounters as used in this dissertation.

Figure 1-1: Categories of Face-to-Face and Electronic Encounters

\begin{tabular}{|c|c|c|}
\hline Mode Structure & Dialogue & 'Multi-logue' \\
\hline Face-to-face & $\begin{array}{l}\text { 1) Examples. buying furniture at the store, booking } \\
\text { a trip at the travel agency, getting financial advice } \\
\text { at the bank. }\end{array}$ & $\begin{array}{l}\text { 3) Examples: Tupperware parties, guided group- } \\
\text { traveling, financial seminars. }\end{array}$ \\
\hline Electronic & $\begin{array}{l}\text { 2) Examples of self-service: buying books on- } \\
\text { line, getting account information, booking a flight, } \\
\text { and electronic banking. } \\
\text { Examples of moderated encounters: getting } \\
\text { shipping and product information via chat, e- } \\
\text { mailing about a sales proposal or specific needs. }\end{array}$ & $\begin{array}{l}\text { 4) Examples of self-service: auctions, sharing } \\
\text { tips on bulletin boards about buying cars, diet } \\
\text { products, stocks. } \\
\text { Examples of moderated encounters: customers } \\
\text { chat on-line with other customers and a pets } \\
\text { expert, on-line financial seminars. }\end{array}$ \\
\hline
\end{tabular}

The rows represent the mode of the encounter, face-to-face versus electronic. The columns represent the structure of the interaction. Dialogue is defined as a dyadic interaction between the customer and the firm. 'Multi-logue' (Newell and Newell 2001) is defined as a many-to-many interaction between the customer, the firm, and another party/other parties (for instance other customers or another firm).

The first cell represents the prototypical dyadic encounter. It includes both the customer and the contact employee in a face-to-face setting. The second quadrant is also dyadic, but the customer and the firm interact via a computer. This might be selfservice or a moderated electronic encounter. The third quadrant represents those encounters which take place with more than two parties in a face-to-face setting. In retailing, the most widespread use of these encounters are those in which an employee and several customers participate. The setting of several customers and several salespersons might be more common in a business-to-business setting. During the many-to-many interactions of the fourth quadrant the firm and customers interact through a computer. As with the dyadic electronic encounter, this might be self-service, i.e., the firm is represented by a web-site. For instance, the web-site provides information about a certain product and enables customers to share 
information and to swap tips about this product. It also might be moderated, i.e., a real employee is involved in the electronic group interaction. One growing use of this type of encounters is Moderated Group Chat (MGC). MGC enables shoppers to purchase products and services on-line with the possibility to consult synchronously a service employee and other customers.

A challenge for many firms is to design an encounter between the customer and the firm that is satisfying. Marketing managers at many retail organizations acknowledge the importance of the encounter, but do not know how to manage it (Boles and Babin 1996; Gutek 2000; Hartline and Ferrell 1996). They have to move forward to meet the expectations of technologically proficient customers, without neglecting technology-resistant customers who prefer a face-to-face encounter (e.g., Barret 1997). They must depend on contact employees, technology, or a combination of both to deliver services or products to their customers. It is well known that the attitudes and behaviors of employees, the attributes of the technology, and the aspects related to interpersonal on-line interactions can greatly influence customers' perceptions of the encounter and the firm (Bowen and Schneider 1985; Dabholkar 1996). Knowledge of the effectiveness of ways of organizing customer-firm encounters is crucial for further improvements and management of these encounters. Firms need strategic direction regarding what customers want from face-to-face and on-line interactions, so they can design and promote encounters accordingly.

\subsection{Motivation}

The overall motivation behind the writing of this dissertation is driven by the importance of encounters in daily life, for firms as well as for customers. Each day millions of encounters across companies and across industries take place. For example, Bitner et al. (2000) report that one strategic business unit within IBM Canada has 70.000 encounters with customers each day. Disney and Federal Express manage millions of encounters daily. Océ-UK, the British subsidiary of a large European office equipment manufacturer, handles approximately 4800 inbound calls from customers, issues 2600 outbound calls (i.e., company-initiated), and has 1100 customer site visits each day. For many consumers, encounters with service employees and salespersons are a daily event, and at least happen on a frequent base. Czepiel et al. (1985) state that service encounters affect the quality of everyday life. With the sheer number of these interactions and their consequences, it is imperative to know how to best manage these encounters, face-to-face as well as electronic.

It is evident that the face-to-face encounter will continue to be a critical channel to deliver services and to sell products. The emphasis in academic research on face-toface encounters underlines its importance in marketing research (e.g., Beatty et al. 1996; Bettencourt and Gwinner 1996; Bitner et al. 1990; Goodwin and Gremler 1996; Hartline and Ferrell 1996). Many studies focused on antecedents of customers' evaluations of the encounter and considerable proof has already been. accumulated that face-to-face encounters between customers and firms are important for both 
customers and firms (Bitner et al. 1990; Winsted 1997). However, the call for gathering information for the purpose of enhancing the customer's encounter experience is still recognized (e.g., Cappella 1997; Grayson 1998; Grove et al. 1998; Gupta and Vajic 2000; Gutek et al. 1999). In fact, despite the research aimed at understanding face-to-face encounters there has been a steady decline in satisfaction with services (Fornell et al. 1996; Leaf 1998). These downward trends indicate that there is still much to be learned about face-to-face encounters (Bitner et al. 2000). Especially, in-depth investigations of underlying mechanisms of interpersonal interaction and specific tools to create customer satisfaction with face-to-face encounters are needed.

In contrast to face-to-face interactions, electronic encounters are a relatively new form of service delivery and selling, and there is much to be learned. It is increasingly clear that on-line interactions between company and customers will continue to be a strategic aspect of customer-firm interactions. Meuter et al. (2000) expect technologybased interactions to become a key criterion in long-term business success. The rise of electronic interactions raises questions about how customers perceive these encounters. Although many academic researchers have acknowledged a need for greater understanding in this area (Bitner et al. 2000; Hoffman 2001), little is known how electronic encounters influence customers perceptions of satisfaction.

\subsection{Objectives}

In this dissertation, we focus on the customer-firm encounters of the first, second and fourth quadrant of figure 1-1. The encounters under study may be characterized as high with respect to customer participation, customer contact, and customer involvement. The separate chapters related to these encounters clearly discuss the relevant literature, their objectives, and their theoretical and managerial contribution. Nonetheless, it is important to outline the overall objective of this dissertation and how the aims of the chapters are related to this central objective.

The overall aim of this dissertation is to uncover antecedents that are important in enhancing customer encounter satisfaction in face-to-face and electronic settings in a retail context. To gain in-depth insight into encounters between the customer and the firm, and to address this overall objective effectively from a variety of perspectives, we develop more specific aims for the different chapters along our general objective.

\subsubsection{Objectives Chapter 2}

In Chapter 2, we focus on the dyadic, face-to-face encounter. We endeavor to break new ground by introducing a novel approach to examining encounters based on interpersonal perception research, a theoretical lens developed for the study of dyadic interactions in the field of social psychology (Kenny 1996a). This approach underscores the exploration of interpersonal encounters as a true interpersonal system and from both perspectives (therefore, employee encounter satisfaction is 
included in this study as a dependent variable in addition to customer encounter satisfaction). Based on this theoretical lens, the specific objectives of this chapter are to: 1) investigate to what extent customer satisfaction is influenced by the customer's own experience and by the employee's experience of the encounter and vice versa, and 2) study whether customers' and employees' perceptions are based on their own unique experience during the encounter or that these perceptions are based on stable characteristics of the employee.

\subsubsection{Objectives Chapter 3}

In Chapter 3, we study the influence of humor on customers' evaluations of the dyadic, face-to-face encounter and the self-service electronic encounter. Within the customer satisfaction literature, there is recently a growing attention to the importance of hedonic aspects of the service encounter. One important way to increase the hedonic quality of the shopping experience as well as the positive evaluation of the product or service itself is the use of humor (Childers et al. 2001; Dabholkar 1996; Perry and Jenzowsky 1997). With respect to face-to-face and electronic self-service encounters, the incremental value of humor as a potential source of enjoyment and determinant of customers' evaluations is scarcely researched. Consequently, the specific objectives of the chapter are to: 1) discuss the conceptualization of humor and to hypothesize it's influence on customer encounter evaluations (the experimental research design of this study allows us to focus on customer enjoyment and behavioral intentions, in addition to customer satisfaction), and 2) empirically test our hypotheses while taking contingencies, like the outcome of the service encounter, into account.

\subsubsection{Objectives Chapter 4}

In Chapter 4, we study many-to-many, electronic encounters. Specifically, we focus on MGC in a commercial context. Based on literature review, we discern three types of antecedents that may influence customer satisfaction in these encounters: consumer characteristics, group characteristics, and the behavior of the moderator in the group. Within this examination, we take two unique contingencies of multi-way interaction into account. First, we study how relationships between antecedents and customer satisfaction are influenced by the style of the advisor. Secondly, we explicitly consider how predictor-criterion relationships may vary between individual. perceptions and group-level (shared) perceptions of customers. The objectives of this chapter are to: 1) develop a theoretical research model, grounded in several research fields, that explains customer satisfaction with MGC in a commercial context, and 2) empirically test this theoretical research model while taking the contingencies into account. 


\subsubsection{Objectives Chapter 5}

Also in Chapter 5, we study many-to-many, electronic encounters. In this chapter, we propose three alternative models of satisfaction with MGC: an attribute-based model, an overall affect model, and a group characteristics model. We replicate the attribute-based model and the overall affect model of Dabholkar (1996). The attribute-based model is based on a cognitive approach to decision-making where customers evaluate relevant attributes associated with their experience with MGC. The overall aflect model is based on an affective approach where consumers would use overall predispositions. In addition, based on group decision-making literature, we propose a group characteristics model, which includes cognitive variables, affective variables, and communication-oriented variables, related to the group. Furthermore, we take into account the same contingencies as in Chapter 4, the style of the advisor and group-level processes. Specific objectives of this chapter are to: 1) replicate and extend earlier research on technology-infused encounters to the context of $M G C, 2)$ develop a group characteristics model, grounded in the group decision-making literature, and 3) empirically test all three models while taking the contingencies into account.

\subsection{Outline of this Dissertation}

This dissertation explores different theoretical issues, contributes to different research streams, it combines different theoretical backgrounds, and it employs different data gathering and analysis methodologies. At the same time, all chapters are designed to explain the same key construct, customer encounter satisfaction. The dispersion over different domains allows us to isolate specific topics as well as to generate extensive models, which is very fruitful, especially in underdeveloped areas of research which many-to-many electronic encounters are. Furthermore, although the four chapters explore different theoretical issues, they are linked as well.

In Chapter 2 and 3, we apply a specific idea from another discipline or context to the customer-firm encounter. Given that the academic literature has focused on general models of face-to-face encounters (e.g., Bitner et al. 1990; Sharma 1997; Weitz et al. 1986), as well as technology-based self-service encounters (Bitner et al. 2000; Dabholkar 1994, 1996; Meuter et al. 2000), we take a more detailed focus in these chapters. In Chapter 2, the focus is determined by the theoretical lens of interpersonal perception, whereas in (hipter 3, the focus is on the concept of humor. In addition to this specific focus, we attempt to obtain an in-depth understanding in both chapters by taking multiple dependent variables into account.

In contrast to this specific focus, we develop broad theoretical frameworks in Chapter 4 and 5. We theorize on factors that might influence customer satisfaction with a new marketing channel, while we adopt a number of theoretical lenses and review the literature from marketing, computer-mediated communication, group dynamics, leadership, and (consumer) decision-making. To our knowledge, no 
academic study has appeared yet, that has focused on MGC within a commercial context and consequently, there is much to be learned.

Aside from their difference in broadness, Chapter 2 and 4 have common characteristics as well. In both chapters, we assume that a classical dichotomy is underlying the antecedents: task-related versus social-related (Beatty et al. 1996; Forsyth 1999; Waldersee et al. 1995). Task-related antecedents refer to the goal of the interaction and social-related antecedents to the social aspects of the interaction. In Chapter 2, we make this distinction with respect to employee performance, and in Chapter 4, we assume this dichotomy with respect to the characteristics of the employee, the customer, and the group.

Chapter 3, 4, and 5 all focus on electronic interactions, though Chapter 3 focuses on electronic self-service encounters and Chapter 4 and 5 explore moderated electronic encounters. The latter two chapters explore an innovative way to provide service, which makes optimal use of the nature of new technologies by creating high levels of interactivity. Chapter 3 focuses on perhaps the most widespread and wellknown application of e-commerce. However, the option of self-service via web-sites does often not take full advantage of the possibilities to create high levels of interactivity.

With respect to the methods employed, in Chapter 2, 4, and 5, we have hierarchical data-sets which are analyzed by multi-level analyses. A hierarchical datastructure implies that individual perceptions are grouped at different levels. In Chapter 2, we do not group the perceptions of a real, existing, group but we bundle individual perceptions that have a common characteristic. In Chapter 4 and 5, individual perceptions are grouped based on the fact that the individuals belong to the same, existing, group. Although data-analytically this does not result in a difference, theoretically this difference is fundamental. In Chapter 3, 4, and 5, we use student samples and include experimental manipulations in our study, whereas in Chapter 2, we collected our data in the field.

Finally, Chapter 6 presents a summary of our main conclusions and provides suggestions for future research. Figure 1.2 offers a summary of the outline of the thesis. 
Figure 1-2: Outline of the Dissertation

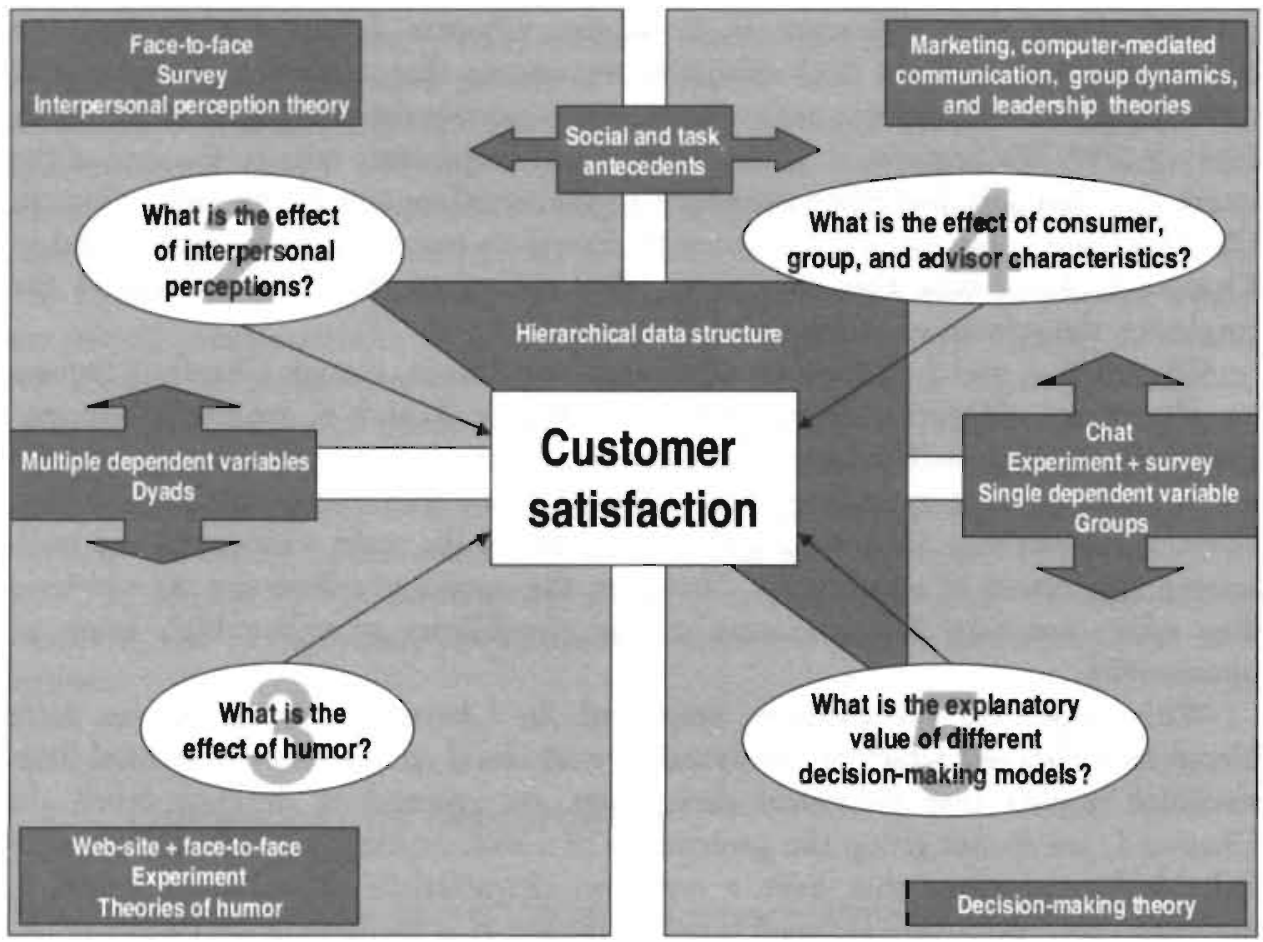




\title{
Chapter 2
}

\section{Customer-Sales Employee Encounters: A Dyadic Perspective ${ }^{1}$}

\begin{abstract}
Although researchers have suggested that the performance of the salesperson during sales encounters is critical, many of the underlying mechanisms that govern the interaction between salespersons and customers are still unclear. In this research, we investigate sales encounters from a new approach based on the research field of interpersonal perception. Results demonstrate that drivers of customer satisfaction may also be satisfying for the contact employee. Additionally, we find that customer satisfaction is not only determined by the customer's own perceptions, but also by the perceptions of the employee. Similarly, employee satisfaction is driven by the customer's perceptions. Finally, our study identifies that perceptions of employee performance and satisfaction do not only reflect the unique interaction between the customer and the employee, but also relatively stable characteristics of the employee.
\end{abstract}




\subsection{Introduction}

There is a growing belief among academics and practitioners on the importance of turning each customer-firm encounter into a satisfying experience (Gupta and Vajic 2000; Pine and Gilmore 1999). Where the contact between employees and customers is particularly intense, such as in consumer durables, this recognition of the importance of satisfying experiences draws attention to the need for a better understanding of the individual encounters. Although researchers have suggested that the success or failure of an individual encounter is dependent on the performance of the contact employee, there is little guidance regarding the underlying mechanisms that govern the interaction (Cappella 1997; Gupta and Vajic 2000).

We endeavor to break new ground in three ways based on the approach of interpersonal perception, a theoretical lens developed for the study of dyadic interactions in the field of social psychology (e.g., Barnes 1995; Kenny 1996a). First, we analyze the encounter from both the customer as well as the employee focus employing the constructs of customer and employee satisfaction (Bettencourt and Brown 1997; Hartline and Ferrell 1996). To the authors' knowledge, these constructs have hardly been considered in parallel at the individual encounter level. Little is known, for example, whether behaviors of the employee that lead to customer encounter satisfaction are the same behaviors that drive employee encounter satisfaction.

Secondly, we introduce partner effects. Dyadic data measurements reflect not only the characteristics of the person providing the data, but also those of the partner (Kenny and Cook 1999). For example, customer encounter satisfaction may be influenced by the customer's own perceptions of employee performance as well as by the employee's perception of employee performance. Yet, researchers have scarcely examined the influence of customer and employee perceptions simultaneously. We designed this study to introduce this perspective.

Thirdly, we focus on the difference berween uniqueness, consensus, and consistency in perceptions thereby addressing a long-standing issue in social psychology research. In the present context, uniqueness refers to the extent to which customer's or employee's perceptions are exclusive to their personal interaction (Kenny et al. 1998). Consensus reflects the degree to which customers agree in their perceptions of the employee. Consistency reflects the extent to which employees are consistent in their perceptions across different customer encounters (Kenny 1996a). As such, consensus and consistency may reflect a relatively stable employee characteristic. Focusing on individual encounters, the question is whether the customer's and the employee's evaluations of performance and satisfaction are primarily determined by the unique interaction between the employee and the customer, by consensus and consistency, or by a combination of these elements.

This chapter is structured as follows. First, we review the relevant literature on key conceptual issues. Secondly, we develop and test a multi-level model to determine which performance attributes influence customer and employee encounter satisfaction. We conclude with a discussion of the results and implications. 


\subsection{A Dyadic Perspective on Satisfaction}

Customer encounter satisfaction may be influenced by the customer's evaluation of employee performance as well as by the employee's perception of his or her own performance. We call the first effect an actor effect; the second effect is a partner effect (figure 2-1). Similarly, employee encounter satisfaction may be influenced by the employee's evaluation of his or her own performance (i.e., an actor effect) as well as by the customer's perception of employee performance (i.e., a partner effect). In the next section, we first discuss the actor effects for the customer and employee dyad, and subsequently we elaborate on the phenomenon of partner effects.

Figure 2-1: Conceptual Model of Actor and Partner Effects in Encounters
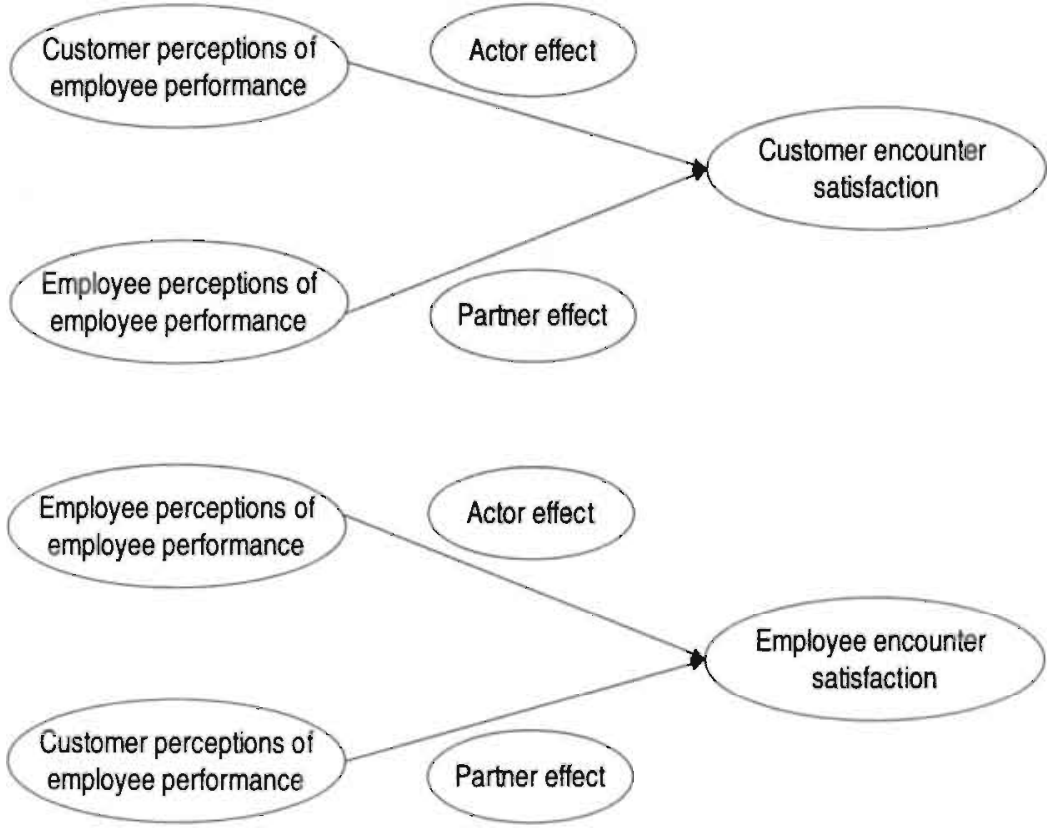

\subsubsection{Actor Effects in the Sales Encounter}

The influence of customers' perceptions of employee performance on customer satisfaction has received considerable attention in the marketing literature and practice in recent years. It has been reported consistently that the behavior of the contact employee plays a critical role in shaping customers' perceptions of the interaction (Bitner et al. 1990; van Dolen et al. 2001; Spiro and Weitz 1990). Employee performance can be grouped into two types, core task and socio-emotional 
aspects (Czepiel 1990; Price et al. 1995a; Winsted 1997). Core task aspects include product knowledge, fulfilling customer service needs and helping customers to achieve their goals. Socio-emotional aspects comprise those employee behaviors that foster interpersonal relationships and satisfy customers' emotional needs. These facilitate interactions and create a positive evaluation by being friendly, enthusiastic, attentive, and showing empathy for the customer (Beatty et al. 1996; Rafaeli 1993). Customers' perceptions of both aspects of employee performance have been found to be important drivers of customer satisfaction (Price et al. 1995b; Winsted 1997). Therefore, we hypothesize that:

\section{$H_{l}: \quad$ Customer perceptions of both employee task and social competence will positively contribute to customer encounter satisfaction.}

Compared to customer satisfaction, limited research has been done on employee satisfaction with individual encounters. This is remarkable since many researchers have emphasized the importance of satisfied employees to a firm's success (e.g., Hartline and Ferrell 1996). From the relatively scarce empirical evidence, we conclude that employee encounter satisfaction is influenced by the employee's perceptions of his or her task-oriented performance as well as by interpersonal and social aspects (Beatty et al. 1996; Czepiel 1990). It has been argued that contact employees are genuinely concerned and have a strong desire to provide their customers a good service or sale (Bitner et al. 1994; Schneider 1980). Beatty et al. (1996) state that successful sales employees attempt to tackle customer problems as if they were their own, display a personal involvement, and like to establish a bond with customers. Consequently, we expect that the extent to which employ'es see themselves as capable to deliver the service and to make the interaction enjoyable as well as sociable will influence their evaluation of the encounter. This results in the following hypothesis:

H2: Employee perceptions of his or ber task and social competence will positively contribute to employee encounter satisfaction.

\subsubsection{Partner Effects in the Sales Encounter}

To the authors' knowledge no marketing studies are reported that depart from an explicit focus on partner effects (i.e., in addition to actor effects). Therefore, we turn to other research disciplines for guidance. Psychologists Kenny and Cook showed in 1999 that a person's perceived control is negatively influenced by another person's perceived assertiveness and positively by perceived cooperativeness. They also found that one person's speech characteristics are not independent of his or her partner's speech. Bui et al. (1996) report partner effects in a study on relationship commitment. The rationale is that much of what we think and feel is not only determined by our own evaluations, but also by the evaluations of whom we are with (Felson 1992; 
Kenny and Cook 1999; Kenny 1996b). With partner effects, a person is in some way, verbally or non-verbally, influenced by a characteristic, behavior, or perception of the orher. It is well known that people are sensitive to, and monitor cues and reactions of others (DePaulo and Rosenthal 1982; Mead 1986). In general, there seems to be a common interest in people about what others perceive (Kenny 1996a). Put differently, people try to get 'into other people's head' and to 'read their minds.'

It is important to note that the partner effect of the employee on customer satisfaction reflects a different process than the partner effect of the customer on employee satisfaction. The general question underlying the first effect is whether a person's perceptions (e.g., the customer) are influenced by the way his or her interaction partner (e.g., the employee) sees him or herself. The second effect reflects the issue whether the perceptions of a person (e.g., the employee) are influenced by the way in which the interaction partner (e.g., the customer) views him or her. The importance of the latter influence of perceptions has been acknowledged in several contexts and disciplines varying from psychology to anthropology (e.g., DePaulo 1992; Goffman 1959; Kenny 1996a; Mead 1934; Snodgrass 1992). Several studies in a service or sales context exist which provide insight in the possible influences of partner effects.

With respect to the influence of employee perceptions on customers' evaluations, Hartline and Ferrell (1996) found that employees' perceptions of their own abilities and job satisfaction increase customers' perceptions of service quality. Also, Schlesinger and Zornitsky (1991) showed that employees' perceptions of their capability strongly related to customers' perceptions of the service. In addition, Schneider and Bowen (1985) have substantiated the conclusion that the way employees experience their work environment is reflected in customers' perceptions of service quality.

Despite the above, we note that these studies did not focus on individual encounters. Studies of individual encounters suggest that customers might be influenced by the experience of the employee (e.g., Beatty et al. 1996). Gremler and Gwinner (2000) found that customers might strongly care about an employee, feel genuine interest and a bond with an employee, and also look forward to seeing him or her. Beatty et al. (1996) and Price et al. (1995a) describe how customers can wonder how an employee is feeling or what (s)he is thinking. Whereas Price et al. (1995a) state that this interest will be likely in extended encounters, others suggest that this also might occur in briefer or single encounters (Czepiel 1990; Gremler and Gwinner 2000). It is well known that partner effects might be created by a concern of people with the experiences of the interaction partner (Kenny and Cook 1999). In addition to this concern, there might be contagion; one may feel satisfied when those around you are feeling good (Hatfield et al. 1993). Drawing on the studies, we contend that the perceptions of the employee might influence customer encounter satisfaction. This results in the following hypothesis:

H3: Employee perceptions of bis or her task and social competence will positively contribute to customer encounter satisfaction. 
With respect to the influence of customers' perceptions on employee satisfaction, the findings of a number of studies suggest this influence to be positive; the rationale being that if the customer likes the performance of the employee, this will increase the satisfaction felt by the employee. For instance, Beatty et al. (1996) found how personally and profoundly rewarded salespersons felt in helping and serving customers. In their research, the positive reinforcement provided by customers provides satisfaction to sales employees. Also, other studies report that employees have respect for customers, are concerned about their feelings, and are pleased with the appreciation showed by them (Goodwin and Gremler 1996; Price et al. 1995a). Sometimes employees even describe their relationship with customers as camaraderie and friendship, and they are genuinely concerned about how the customers think of them (Gremler and Gwinner, 2000). During interactions employees frequently look for cues that tell them how customers receive their service and modify their behavior accordingly (Bitner et al. 1994). Beatty et al. (1996) as well as Ramsey and Sohi (1997) found that successful salespeople sense incoming (verbal and non-verbal) stimuli from the customer. It might be that the customer's perception is important to the employee because the employee feels a bond with the customer (Beatty er al. 1996; Price et al. 1995a). A complementary explanation may be reflecting impression management, i.e., the employee may attempt to control his or her image towards the customer (e.g., Grayson and Shulman 2000). In either case, the employee's interest in the customer's perceptions might explain a partner effect. Therefore, we hypothesize:

\section{H: Customer perceptions of both employee task and social competence will positively contribute to employee encounter satisfaction.}

\subsubsection{Agreement in Perceptions between Customers and Employees}

Although there may be partner effects on encounter satisfaction, this does not necessarily imply that customers and employees agree in their perceptions of the employee performance. For instance, it might be that the employee derives satisfaction from experiencing that the customer perceives him or her as competent, but at the same time, (s)he might think that his or her performance was not up to standard in that particular interaction. In dyadic research, the extent to which one person (e.g., the employee) perceives him- or herself as others do (e.g., the customer) is referred to as 'self-other agreement' (Kenny 1996a; Shrauger and Schoeneman 1979). This agreement and the related accurate employee understanding of a customer's perception of employee performance enables the employee to adjust his or her behavior appropriately to the customer's needs (Bitner et al. 1994).

Academic marketing research correlating customer and employee views is thin and does not always focus on self versus other perceptions. For instance, Schneider and Bowen (1985) found high correlations, but they focused on employee and customer perceptions of overall service quality. Brown and Swartz (1989) gathered data on patient experiences with their physicians and compared them with the physician's perceptions of their patients' experiences. The differences they found were rather large and inversely related to patient satisfaction. In a qualitative study, 
Bitner et al. (1994) focused on the customer's and the employee's perspective of events leading to customer (dis)satisfaction and found similarities as well as differences.

It has also been reported that customer service professionals consistently rated the importance of specific service skills and competencies and their actual performance higher than customers rated the same skills and competences (Services Marketing Newsletter 1989). Studies in the field of interpersonal perception find different levels of self-orher agreement, ranging from negative (e.g., Albright et al. 1988), to zero (e.g., Borkenau and Liebler 1992), to very high (e.g., Kenny et al. 1992). In addition, the level of self-other agreement has been found to differ for separate constructs and found to be positively related to the level of acquaintance (Park and Judd 1989; Paulhus and Bruce 1992). Based on these findings, we would expect to find a certain level of self-other agreement. Therefore, we hypothesize:

\section{Hs: There will be a level of agreement between customers and employees about employee task and social competence during the interaction.}

In the next section, we elaborate on interpersonal influence during interactions by developing two research questions about the difference between uniqueness, consensus, and consistency in perceptions.

\subsubsection{Uniqueness versus Consensus and Consistency in Perceptions}

Consensus in customers' perceptions is defined as the agreement among customers on the performance of the employee (Kenny 1996a) and it suggests a consistency in the behavior of the employee. A unique perception is exclusively related to a single customer (Kenny 1996a) and this might reflect unique behaviors of the employee, a trait of the customer, or an extraneous factor like the mood of the customer. To separate these conceptually different factors, we employ a research design in which an employee participates in more than one encounter. In the investigation of interpersonal phenomena, some researchers studied how persons participate in multiple dyads (e.g., Albright et al. 1997; Levesque 1997).

In the present context, consider a customer's perception of the employee's empathy during an encounter. If an employee participates in only one encounter, then the perception of empathy may not necessarily represent unique empathy. In other words, a high empathy score from the customer may be due to the fact that the employee is empathic with every customer. Similarly, it may be that the empathy is determined interpersonally and that the rating of empathy within this encounter is unique. The degree to which an employee is emphatic can be assessed by looking at the empathy scores of multiple customers. This may reflect a tendency on the part of the employee to be seen as empathic across all of his or her customers, i.e., an across encounter effect. What makes the feature quasi-objective is the fact that there is consensus among several customers in their perceptions of employee performance. Similarly, if over and above the employee's tendency to empathize, one customer especially empathizes with the employee, there is evidence that empathy is uniquely determined by the specific interaction, i.e., a unique encounter effect (Kenny et al. 1998). 
In the same way, the employee's perceptions of his or her performance can be evaluated. With multiple encounters, the tendency for the employee to see him or herself consistently across all interaction partners can be assessed. In line with the terminology used for the customer perceptions, we label this as an across encounter effect. Comparable to the customer's evaluations, there might be a unique encounter effect for an employee that is uniquely determined by a specific customer interaction. This results in the following research question:

\section{$R Q_{1:}$ Will there be an across encounter effect in customer and employee perceptions of employee performance, or will these perceptions primarily be determined by the unique interaction between the customer and the employee?}

Unique as well as across encounter effects may influence customer and employee satisfaction (de Jonge et al. 1999). A study of this influence in a design in which an individual (i.e., the employee) participates in multiple interactions with different others (i.e., customers) implies a hierarchical structure of data. We refer to a hierarchy as consisting of units grouped at different levels. The lower level contains all interactions and the upper level contains the employee or, in methodological terms, customers/encounters are nested within an employee. For this data structure, multi-level statistical techniques (Bryk and Raudenbush 1992) can help to disentangle the unique encounter effects (leading to within salespeople differences) from the across encounter effects (leading to between salespeople differences). Consistent with the terms used in most multi-level analysis research, we refer to the first (unique encounter) effect as the individual-level effect and to the latter (across encounter) as the group-level effect. In this study, we use individual and group assessments for all performance dimensions to determine whether performance data at the group-level explain variance to individual customer and employee satisfaction. In this way, we examine which part of the explained variance of customer or employee satisfaction is attributable to unique perceptions and which part to some more objective characteristics of the employee. This is reflected in the following research question:

\section{$R_{2}:$ Will both individual-level and group-level indicators of employee performance influence customer and employee encounter satisfaction?}

Regarding the linkage between customer characteristics and its influence on evaluations of employee performance and satisfaction, it was not possible to apply a design in which customer's perceptions of multiple encounters were evaluated. Therefore, we do not assess separately the degree to which a customer's ratings are consistent across all of his or her interactions with several employees. 


\subsection{An Empirical Study}

\subsubsection{Method}

A field study was conducted among customers and contact employees of a large furniture company operating two retail stores. The company's retail outlets were selected because of the kind of encounters between customers and contact employees that take place in these stores; these are extended, interactive encounters, designed to enhance the customer's experience. The selling of furniture is often combined with services regarding home remodeling and home decoration in a setting simulating the home situation. Furthermore, the interactions are intense and customers are highly involved; customers need information about materials, style, and maintenance. In addition, customer participation is often high as customers provide information about their requirements.

\subsubsection{Procedure}

Customers and contact employees both completed the questionnaire in the store immediately after the interaction had taken place. Due to the limited number of salespersons, all employees were included in our study, 59 in total. Customers were randomly approached in the store to fill out a questionnaire. To match the customer's evaluation of the interaction with that of the contact employee, we asked customers with whom they had interacted. Then, the contact employee was approached to fill out the questionnaire with respect to that specific interaction.

For all contact employees, seven different customer encounters were collected. This resulted in 413 questionnaires filled out by both customers and by the 59 employees. We matched the questionnaires of the employee and the customer. In case of missing data of an encounter, either caused by the customer questionnaire or by the employee questionnaire, both questionnaires related to that encounter were excluded (Kenny 1996a). After this matching, 754 questionnaires remained for further analysis. Although contact employees of both stores participated, no significant differences between the two groups were found.

\subsubsection{Sample}

On the demographics for customers, our respondents consisted of $51 \%$ women and $49 \%$ men. Their age ranged from 25 to 66 with an average of 40 years. The level of respondent education was high, as $40 \%$ had completed college while another $45 \%$ had followed vocational education. According to customer databases provided by the retailer, the sample proved representative of its overall population of customers. With regards to the contact employees, the sample consisted of $39 \%$ men and $61 \%$ women. Their age ranged from 21 to 59 with an average of 42 years. Additionally, $61 \%$ of the employees had more than five years experience selling furniture. 


\subsubsection{Questionnaire Development}

The items were measured on a 7-point Likert-scale ranging from 'totally disagree' to 'totally agree". Table 2-1 presents all items as used in the study. Each contact employee completed a questionnaire largely identical to the questionnaire that the customer completed. In some parts of the questionnaire, statements were transformed from the customer's to the employee's perspective and demographic questions were changed.

Table 2-1: Results of Confirmatory Factor Analysis

\begin{tabular}{|c|c|c|}
\hline Measures & Factor loadings & t-value \\
\hline \multicolumn{3}{|c|}{$\begin{array}{l}\text { Fit indices: }(\mathrm{GFl}=.90 ; \mathrm{AGF}=.86 ; \mathrm{RMSEA}=.037 ; \mathrm{NNFI}=.97 ; \mathrm{CF}=.98) \text { " } \\
\text { Customer perceptions } \\
\text { Task competence }(\mathrm{n}=6 ; \alpha=.87)\end{array}$} \\
\hline The employee was capable & .57 & 10.18 \\
\hline The employee was efficient & .83 & 16.17 \\
\hline The employee was organized & .78 & 14.48 \\
\hline The employee was thorough & .87 & 17.25 \\
\hline The employee met my needs & .80 & 1.98 \\
\hline The employee performed as I expected & .51 & 8.76 \\
\hline \multicolumn{3}{|l|}{ Social competence $(n=9 ; \alpha=.92)$} \\
\hline The employee connected to my life/experiences & .69 & 12.98 \\
\hline The employee revealed personal information & .74 & 14.28 \\
\hline The employee invited me to reveal personal information & .93 & 20.66 \\
\hline The employee paid special attention to me & .84 & 17.18 \\
\hline The employee went out of his/her way & .80 & 15.95 \\
\hline The employee gave me a break (something special) & .78 & 15.41 \\
\hline The employee was truly out of the ordinary & .54 & 9.58 \\
\hline The employee was his/her own person & .76 & 14.77 \\
\hline The employee was genuine & .50 & 8.72 \\
\hline \multicolumn{3}{|l|}{ Employee perceptions } \\
\hline \multicolumn{3}{|l|}{ Task competence ( $n=6 ; a=.86$ ) } \\
\hline I was capable & .53 & 9.46 \\
\hline I was efficient & .53 & 8.12 \\
\hline I was organized & .81 & 15.79 \\
\hline I was thorough & .89 & 18.50 \\
\hline I met the customer's needs & .71 & 13.50 \\
\hline I performed as I expected & .54 & 9.69 \\
\hline \multicolumn{3}{|l|}{ Social competence ( $n=9 ; \alpha=94)$} \\
\hline I connected to the customer's life/experiences & .74 & 14.29 \\
\hline I revealed personal information & .77 & 14.65 \\
\hline I invited the customer to reveal personal information & 92 & 20.00 \\
\hline I paid special attention to the customer & .88 & 18.54 \\
\hline I went out of my way & .89 & 18.78 \\
\hline I gave the customer a break (something special) & .81 & 16.02 \\
\hline I was truly out of the ordinary & .65 & 12.18 \\
\hline I was my own person & .65 & 12.10 \\
\hline I was genuine & .69 & 13.28 \\
\hline
\end{tabular}

a GFI=Goodness of fit index; AGFl=Adjusted goodness of fit index; RMSEA=Root mean squared error of approximation; $\mathrm{NNFl}=$ Non-normed fit index (Tucker-Lewis index); CFl=Comparative fit index. 
Encounter satisfaction. Encounter satisfaction items were measured with a scale developed by Oliver (1997), i.e., This was one of the best encounters I could bave had; This encounter was exactly what I needed; I am satisfied with this encounter; I have truly enjoyed this encounter; This encounter was a good experience; I am not happy with this encounter (reverse coded). The statements were exactly the same for the customers and the employees. Cronbach's alpha coefficient for our sample was .88 for the customer scale and .84 for the employee scale.

Contact employee performance. Employee performance was measured with nine items reflecting the socio-emotional aspects of employee performance and six items reflecting task core aspects as suggested by Price et al. (1995b). The task competence scale includes items that deal with employee performance of fulfilling product or service needs and accomplishing goals during the sales encounter. The social competence scale captured the perceived genuineness of the employee, the special concern of the employee towards the customer, and their mutual understanding.

Two techniques were employed to test the factor structure and item loadings of the employee performance scale. We initially examined coefficient alphas and the factor structure through principal component analysis (varimax rotation) for all scale items simultaneously (customers' and employees' perceptions of task and social competence). A four-factor structure was achieved with items loading on the a priori dimensions. In addition, the items were subjected to confirmatory factor analysis (CFA) using LISREL (Jöreskog and Sörbom 1993) to assess the critical measurement properties of the scales. The fit indices of the proposed four-factor model, construct reliabilities of the scales, and confirmatory factor loadings with $t$-values for each item are represented in table 2-1. The indices of the proposed factor model provided a good fit $(G F I=.90 ; A G F I=.86 ; \quad R M S E A=.037 ; \mathrm{NNFI}=.97 ; \mathrm{CFI}=.98$ ), revealing unidimensionality of the scales. Construct reliabilities of the scales were tested by means of Cronbach's alpha. Coefficients of all measures were at least .86 , which implies that reliability is deemed acceptable.

Next, we examined within-method convergent validity by investigating the significance and magnitude of the item loadings. All items loaded significantly on their respective construct (minimum t-value $=8.12$ ) where all items had a standardized loading of at least .50 . In addition, discriminant validity was evaluated by testing whether pairs of constructs were correlated less than unity. Chi-square difference tests with one degree of freedom were used to test for unity between pairs of constructs. All tests were significant by at least the .05 level.

Control variables. The variables age, gender $(\operatorname{men}=0$, women $=1)$, and sales experience of the contact employee served as control variables for the employee. For the customer sample age, gender (men=0, women $=1$ ), education, and actual purchase served as control variables. This latter variable requires explanation. Because some customers come to the store just to get advice and not to buy, two outcome questions were asked: What was the goal of your visit? 1) oricntation/information or 2) to buy, and Did you achieve this goal? 1) yes or 2) no. Thus, a variable of purchase versus no purchase had to be constructed by conditioning the second question on the first. Consequently, the control variable is buy versus no buy and not whether their goal was achieved. This is because $90.4 \%$ of the customers reported they achieved their goal. 


\subsection{Multi-Level Analysis and Model Building}

The investigation of hierarchically ordered structures has been of interest in a number of disciplines for some time. Using conventional statistical techniques, like ordinary regression analysis, would result in unreliable results because customers in the same 'group' share common influences (they interacted with the same employee). Therefore, the assumption of independent observations required for ordinary regression analysis would be violated (Bryk and Raudenbush 1992). ANOVA and covariance analysis have shortcomings in presenting geometric relationships.

In the light of these difficulties, a hierarchical linear model, called the multi-level model, has been derived to deal with hierarchically nested data structures (Hofmann 1997; Raudenbush 1993). For a multi-level approach with our data, the analysis takes into account the hierarchical data structure (customers within employees) (Bryk and Raudenbush 1992; Snijders and Bosker 1999). A multi-level model is a form of the general linear model that combines the characteristics of ANOVA and multiple regression analysis with dummy variables, taking into consideration within-group variability as well as between-groups variability. It differs from the usual regression model in that the equation defining the hierarchical linear model contains more than one error term: one for each level.

In multi-level modeling, the dependent variable, $Y$ has an individual as well as a group aspect. This carries through also for other individual-level predictor variables, $\mathrm{X}_{\mathrm{ij}}$. An $\mathrm{X}_{\mathrm{ij}}$ variable, although it is a variable at the individual-level, may also contain a group, $\mathrm{X}_{\mathrm{i}}$, aspect. The mean, $\mathrm{X}_{\mathrm{i}}$, in one group may be different from the mean in another group. In other words, $\mathrm{X}_{\mathrm{ij}}$ may have a significant within-group variance as well as a significant between-groups variance. The hierarchical linear model is comparable to a regression, but also includes random effects to represent the unexplained differences between groups. Fixed effects are entered into the model on the basis of theoretical considerations, as in multiple regression analysis.

In this dissertation, we designed multi-level models for random variation among contact employees in the intercept (e.g., groups may differ randomly in their overall level on the dependent variable) as well as in the regression coefficients (e.g., the coefficients are allowed to vary across groups). This requires a simultaneous estimation of two models: one modeling relationships within each of the individuallevel units and a second modeling how these relationships within units vary between units. The individual-level and the group-level models for customer encounter satisfaction are formulated as follows:

For the individual-level, there is:

CUSTSATISFACTION $N_{i}=\beta_{0}+\beta_{1}$ AGECUST $_{i}+\beta_{2}$ GENDERCUST $_{i}+\beta_{3}$ EDUCUST $_{i}+\beta_{4}$ PURCUST $_{i}+\beta_{5}$ TASKCUST $_{i}+$ $\beta_{6}$ SOCIALCUST $_{i}+\beta_{7}$ TASKEMPLi $_{4}+\beta_{8}$ SOCIALEMPL $_{i}+e_{17}$

For the group-level, we estimate: 
where $i$ stands for individuals; $j$ indicates groups (e.g., employees); CUSTSATISFACTION $_{i}$ refers to the degree of satisfaction of customer $i(i=1, \ldots n c)$ who interacted with employee $j(j=1, \ldots n))$; AGECUST, GENDERCUST $_{i}$, EDUCUST, PURCUST are age, gender, education, and actual purchase of the customer at the individual-level, respectively; AGECUST, GENDERCUST, EDUCUST, PURCUST are age, gender, education, and actual purchase of the customer at the group-level, respectively; TASKCUST, SOCIALCUST, TASKEMPL, SOCIALEMPL are customer perceived task competence, customer perceived social competence, employee perceived task competence, and employee perceived social competence at the individual-level, respectively; TASKCUST, SOCIALCUST, TASKEMPL, SOCIALEMPL are customer perceived task competence, customer perceived social competence, employee perceived task competence, and employee perceived social competence at the group-level, respectively. Substituting equations A2a-A2i in equation A1 yields the following multi-level model:

\section{CUSTSATISFACTION $=\gamma_{100}+\gamma_{10}$ AGECUST $_{i}+\gamma_{20}$ GENDERCUST $_{i}+\gamma_{30}$ EDUCUST $_{i}+\gamma_{40}$ PURCUSTi $_{i}+\gamma_{50}$ TASKCUST $_{i}+$ $\gamma_{60}$ SOCIALCUST $_{i}+\gamma_{70}$ TASKEMPL $_{i}+\gamma_{00}$ SOCIALEMPL $_{i}+\gamma_{01}$ AGECUST $_{i}+\gamma_{02}$ GENDERCUST $_{i}+$ $\gamma_{00}$ EDUCUST $_{1}+\gamma_{04}$ PURCUST $_{1}+\gamma_{05}$ TASKCUST $_{1}+\gamma_{06}$ SOCIALCUST $_{j}+\gamma_{01}$ TASKEMPL $_{1}+$

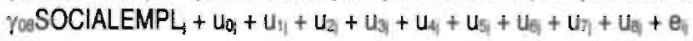

The section of the model incorporating the regression coefficients $\gamma_{00}, \ldots \gamma 08$ is called the fixed part of the model because the coefficients are not stochastic. The remaining part, $u_{0}, \ldots u_{i}+e_{i j}$ is the random part of the model. The individual-level error term $e_{i j}$ is normally distributed with a mean of 0 and variance $\sigma^{2}$. The random effects $u_{y j}$ $(q=0, \ldots 8)$ are multivariate normal distributed over groups with an expected value of 0 , variance $\left(u_{q j}\right)=\tau_{q q}$ and covariance $\left(u_{q j}, u_{q i} i\right)=\tau_{q q^{\prime}}\left(q, q^{\prime}=0, \ldots 8\right)$. $u_{q j}$ is the unique deviation of group $j$ (e.g., employee) from the overall effect on the intercept $\left(\beta_{0}\right)$ while controlling for the group-level predictor variables.

In addition, we also estimated a model for employee encounter satisfaction. Apart from the control variables, model and parameter specification are similar to the customer encounter satisfaction model. This multi-level model is formulated as follows: 
where EMPLSATISFACTION, refers to the degree of satisfaction with a single encounter $i(i=1, \ldots n E N)$ as perceived by employee $j(j=1, \ldots n E)$; AGEEMPL, GENDEREMPL, EXPEMPL, are age, gender, and experience of employee at the group-level, respectively ${ }^{2}$.

For the data analysis, we used the computer program MlwiN (Goldstein et al. 1998), a program that performs multi-level analysis of data with $n$ levels. The analysis is also possible with the MIXED procedure in SAS. Size variations among groups pose no problem for this technology.

\subsubsection{Analysis Strategy}

In our study, the group-level variables of employee performance are defined as the mean over all individual-level units (encounters), within a given group (employee). This implies that the individual customer's perceptions of employee performance during the encounter are aggregated to the group-level, i.e., to the single employee's group. In the same way, for the employee data, the employee's perceptions of his or her own performance during encounters are aggregated to the group-level, i.e., to the single employee's group. To disentangle the unique encounter effects (leading to within-group differences) from the across encounter effects (leading to betweengroups differences), we divided all performance variables into the group mean and the within-group deviation variable (individual score minus group mean) (van Yperen and Snijders 2000). The regression coefficient of the group mean is the betweengroups regression coefficient, whereas the coefficient of the deviation variable is the within-group coefficient. If these two coefficients are significant and equal, the variable functions at the individual-level (i.e., encounter), while there is no separate main effect at the group-level (i.e., employee). Secondly, if the coefficient is significant for the group mean, but not significant for the within-group deviation, the effect emerges only at the group-level. For this study, this would mean that there is an across encounter effect, but not a unique encounter effect. Thirdly, if the coefficient is significant at the individual-level and not significant for the group mean, the effect is solely based on the subjective experience of the customer. For this study, this would mean that there is a unique encounter effect, but not an across encounter effect. Fourthly, if both group mean and the within-group coefficient are significant, but different from each other, there exists both an individual effect and an independent group-level effect (van Yperen and Snijders 2000).

To examine within-group agreement (e.g., across encounter effect) and therefore justification for aggregation of the variables to the group mean, the variance of all variables was decomposed into variance at the group-level, true variance at the individual-level, and error variance. Error variance was defined as [1-Cronbach's alpha] (van Yperen and Snijders 2000). The ratio of group-level variance to the total variance (e.g., group-level plus individual-level variance) is the intra-class correlation

\footnotetext{
${ }^{2}$ Control variables in the customer model are included at the individual-level and at the group-level. Control variables in the employee model could only be introduced at the group-level; the employee defines the group-level and consequently the employee control variables are group-level variables by definition in our model.
} 
coefficient. This expresses the degree of resemblance between individual-level units belonging to the same group-level unit. For the customer data, this reflects the level of consensus among customers (e.g., across encounter effect). For the employee data, it reflects the tendency for the employee to see him or herself consistently across all interaction partners (e.g., across encounter effect). If there is considerable resemblance, aggregation to the group mean is allowed. Also for the dependent variable, we decomposed variance in group-level and individual-level variance. This represents the (unexplained) variation of the outcome variable (i.e., customer or employee encounter satisfaction) at each level (individual and group). If there is considerable variation at the group-level, multi-level analysis is appropriate.

Social and task competence are so-called 'mixed' variables-the measurements contain both the within salespeople effect (e.g., unique encounter effect) and the between salespeople effect (e.g., across encounter effect). With mixed variables, the analyst should test the assumption about the homogeneity of within regression lines by introducing the random term of individual-level variables at the group-level (e.g., random-slope model). When these random coefficients are insignificant, the regression lines of individual-level parameters do not vary across groups. If the random coefficient is significant (e.g., heterogeneity), it should be tested whether the variety in the regression slopes is dependent on the group mean of the intercept. Therefore, covariance terms are specified between the random intercept term uoj and the random terms of the individual-level variables ui at the group-level (Snijders and Bosker 1999). Non-significance of covariance terms indicates that the relationship between the predictor variables and the outcome variable is not dependent on the group mean of the intercept.

The predictive power of the models can be compared by a likelihood ratio test (Bryk and Raudenbush 1992). We tested for multivariate significance of effects by computing the increase in model fit compared to the previous step. The increase in model fit is represented by a decrease in deviance, where deviance is defined as $-2 \ln$ (likelihood). The difference between the deviance statistics ( $\Delta$ Deviance) has a $\chi^{2}$. distribution (with the number of added predictors as degrees of freedom) under $\mathrm{H}_{0}$ that the model does not predict significantly better than the previous model (starting with an intercept-only-model). Finally, the fixed effects of single predictor variables in multi-level models are comparable to regression coefficients in ordinary regression analysis. These were tested by means of two-tailed $t$-tests, the test statistic being the coefficient divided by its standard error.

\subsection{Results}

Table 2-2 reflects the percentages of variance attributed to across encounter and unique encounter effects. The results indicate that for customer and employee encounter satisfaction a major portion may be attributed to between-groups variance. This finding indicates that a multi-level approach is correct. Correlations between the variables on the individual- and the group-level are presented in table 2-3. 
Table 2-2: Variance Attributed to Across-Encounter and Unique-Encounter Effects

\begin{tabular}{lccc}
\hline & $\begin{array}{c}\text { Group-leveV } \\
\text { across encounter effect }\end{array}$ & $\begin{array}{c}\text { Individual-level } \\
\text { unique encounter effect }\end{array}$ & Intraclass correlation * \\
\hline $\begin{array}{l}\text { Variables } \\
\text { Customer perceptions }\end{array}$ & $22 \%$ & & \\
Encounter satisfaction & $10 \%$ & $65 \%(13)$ & .25 \\
Task competence & $14 \%$ & $76 \%(14)$ & .11 \\
Social competence & $39 \%$ & $80 \%(6)$ & .15 \\
Employee perceptions & $45 \%$ & $52 \%(9)$ & .43 \\
Encounter satisfaction & $54 \%$ & $47 \%(8)$ & .48 \\
Task competence & $43 \%(3)$ & .56 \\
Social competence & & 48 & \\
\hline
\end{tabular}

Note: Values between parentheses: percentage of the individual-level variance attributed to measurement error. a ICC-coefficients are corrected for unreliability.

Table 2-3: Correlations between Study Variables

\begin{tabular}{|c|c|c|c|c|c|c|c|c|}
\hline & \multicolumn{4}{|c|}{ Customer perceptions } & \multicolumn{4}{|c|}{ Employee perceptions } \\
\hline & \multicolumn{4}{|c|}{ Competence } & \multicolumn{4}{|c|}{ Competence } \\
\hline & \multicolumn{2}{|c|}{ Individual-level } & \multicolumn{2}{|c|}{ Group-level } & \multicolumn{2}{|c|}{ Individual-level } & \multicolumn{2}{|c|}{ Group-level } \\
\hline & Task & Social & Task & Social & Task & Social & Task & Social \\
\hline \multicolumn{9}{|l|}{ Customer perceptions } \\
\hline $\begin{array}{l}\text { Customer satisfaction } \\
\text { Individual-level }\end{array}$ & .46 & .34 & .44 & .44 & .03 & .21 & .04 & .04 \\
\hline \multicolumn{9}{|l|}{ Task competence } \\
\hline Social competence & .50 & & & & & & & \\
\hline \multicolumn{9}{|l|}{ Group-level } \\
\hline Task competence & .00 & .00 & & & & & & \\
\hline Social competence & .00 & .00 & .64 & & & & & \\
\hline \multicolumn{9}{|l|}{ Employee perceptions } \\
\hline \multicolumn{8}{|l|}{ Individual-level } & .45 \\
\hline Task competence & .10 & .10 & .00 & .00 & & & & \\
\hline Social competence & .21 & .20 & .00 & .00 & .47 & & & \\
\hline \multicolumn{9}{|l|}{ Group-level } \\
\hline Task competence & .00 & .00 &. .01 & .02 & .00 & .00 & & \\
\hline Social competence & .00 & .00 & .07 & .20 & .00 & .00 & .61 & \\
\hline
\end{tabular}

Note: All correlations $>.09$ are significant at $p<.05$ (two-tailed).

Table 2-4 presents the results of our multi-level analyses. Separate analyses were conducted for customer and employee encounter satisfaction. First, the control variables were included into the model (step 1). Secondly, the within-group deviation scores of social and task competence (as perceived by the customer and the employee) were added to the model (step 2). Finally, the group means of social and task competence (as perceived by the customer and the employee) were included (step 3). The $\Delta$ Deviance is significant (except for the control variables) at each step and this indicates a good model fit. Multi-level models are considered as models that may be subject to multi-collinearity. Therefore, ordinary regression analyses were conducted to investigate multi-collinearity by means of the Variance Inflation Factor (VIF). The VIF's of the predictor variables were lower than 1.6 for the separate analyses, hence 
no severe multi-collinearity problems were to be expected (Kleinbaum et al. 1988). Since the findings with respect to $R Q_{1}$ are related to the discussion of the hypotheses results, we first discuss the findings with respect to this research question.

\subsubsection{Uniqueness versus Consensus and Consistency in Perceptions}

Our results in table 2-2 show consensus among customers for their perceptions of employee performance; for task and social competence there is an across encounter effect. In interpersonal perception research, 10 percent of the variance at the grouplevel is considered an acceptable level to conclude that consensus exists among respondents (Kenny 1996a). The largest part of variance is individual-level variance, however, indicating a unique encounter effect. Furthermore, it appears that the between-groups variance for employees' perceptions is considerable higher relative to customers' perceptions. For employee perceptions there is a unique encounter effect, although a substantial part of the variance reflects an across encounter effect $\left(R Q_{1}\right)$.

\subsubsection{Actor and Partner Effects on Customer Encounter Satisfaction}

Table 2-4 shows that employee's social and task competence, as perceived by the customer, are significant in explaining variance in customer encounter satisfaction. Therefore, $\mathrm{H}_{1}$ is accepted. Task and social competence have a significant effect for both the within-group deviation score and the group mean. The group-level coefficient is significantly higher than the within-group deviation effect in explaining customer satisfaction ${ }^{3}$. With respect to the influence of task and social competence as perceived by the employee on customer satisfaction, the results only indicate a partner effect for social comperence at the individual-level. We partly accept $\mathrm{H}_{3}$. Finally, the findings of the control variables age, gender, education, and purchase show only a significant impact of the customer age at the individual-level. In addition, we tested for each individual-level variable to determine whether the inclusion of the variance term of its group-level random parameter led to a significant improvement in model fit (e.g., random slopes; Snijders and Bosker 1999). For most predictors the introduction of these variance terms did not lead to that result. Hence, the regression coefficients of these predictors can be perceived as equal across groups (e.g., employees). Only the inclusion of the group-level variance term of customer age resulted in a significant increase in model fit $\left(\chi^{2}(1)=6.31 ; p<.05\right)$. This means that the individual-level effect of customer age on customer encounter satisfaction significantly differs among groups (e.g., employees). Finally, we tested to determine whether this variance across groups is dependent on the group mean of the intercept. The inclusion of the covariance term did not result in a significantly better model fit.

\footnotetext{
${ }^{3}$ To test whether within-group and between-groups regressions; are different, the significance of the group

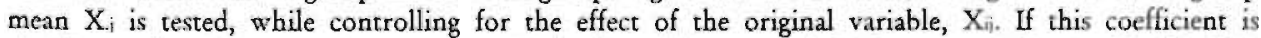
significant, then it is convenient to replace $\mathrm{X}_{\mathrm{i}}$ by the within-group deviation score, defined as $\mathrm{X}_{\mathrm{i}}-\mathrm{X}_{\mathrm{i}}$. This deviation score, together with the group mean, can be used to test if the within-group or between-groups: regressions are O (Snijders and Bosker 1999).
} 
Apparently, the direction of the regression line of customer age is not related to the average degree of customer encounter satisfaction of a given group.

From the results as discussed in relation to the hypotheses, we conclude that customer satisfaction is influenced by unique encounter (e.g., individual-level) as well as across encounter (e.g., group-level) effects $\left(R_{2}\right)$.

\section{Table 2-4: Results of the Multi-Level Analyses}

\begin{tabular}{|c|c|c|}
\hline & Customer encounter satisfaction & Employee encounter satisfaction \\
\hline & Coefficient (SE) a & Coefficient $(\mathrm{SE})^{\lrcorner}$ \\
\hline \multicolumn{3}{|l|}{ Step 1 (control variables) } \\
\hline \multicolumn{3}{|c|}{ Control variables customer } \\
\hline Age (individual) & $.14(.07)^{c}$ & \\
\hline Gender (individual) & $-.07(.10)$ & \\
\hline Education (individual) &. $.04(.07)$ & \\
\hline Purchase (individual) & $-.13(.11)$ & \\
\hline Age (group) & $-.01(.14)$ & \\
\hline Gender (group) & $-.07(.29)$ & \\
\hline Education (group) & $.07(.19)$ & \\
\hline Purchase (group) & $-.02(.33)$ & \\
\hline \multicolumn{3}{|c|}{ Control variables employee } \\
\hline Age (group) & & $-.01(.01)$ \\
\hline Experience (group) & & $.01(.01)$ \\
\hline Gender (group) & & $-.02(.15)$ \\
\hline Increase in model fit & $\chi^{2}(12)=19.3$ & $x(3)=1.2$ \\
\hline \multicolumn{3}{|l|}{ Step 2 (individualunique) ${ }^{b}$} \\
\hline \multicolumn{3}{|l|}{ Customer perceptions } \\
\hline Task competence & $.44(.06)^{d}$ & $.12(.04)^{d}$ \\
\hline Social competence & $.19(.06)^{d}$ & $-.09(.06)$ \\
\hline \multicolumn{3}{|l|}{ Employee perceptions } \\
\hline Task competence & $-.11(.07)$ & $.36(.08)^{d}$ \\
\hline Social competence & $.17(.08)^{c}$ & $.26(.08)^{6}$ \\
\hline Increase in model fit & $\chi^{2}(8)=116.7^{\theta}$ & $x^{2}(8)=97.90$ \\
\hline \multicolumn{3}{|l|}{ Step 3 (group/across) } \\
\hline \multicolumn{3}{|l|}{ Customer perceptions } \\
\hline Task compelence & $.68(.16)$ & $-.21(.17)$ \\
\hline Social competence & $.63(.15)^{\downarrow}$ & $.30(.15)^{\mathrm{d}}$ \\
\hline \multicolumn{3}{|l|}{ Employee perceptions } \\
\hline Task competence & $.01(.09)$ & $.54(.11)^{\mathrm{d}}$ \\
\hline Social competence & $-.08(.09)$ & $.25(.10)^{\mathrm{d}}$ \\
\hline Increase in model fit & $x^{2}(4)=57.7$ & $\chi^{2}(4)=50.5^{\circ}$ \\
\hline
\end{tabular}

Note: " Unstandardized coefficients with their standard errors; " Within-group deviation score $X-X_{i} ; " p<.05$ (two-tailed); ${ }^{2} p<.01$ (two-tailed); $p<.05$. 


\subsubsection{Actor and Partner Effects on Employee Encounter Satisfaction}

Table 2-4 shows a significant positive impact of task and social competence on employee encounter satisfaction, so we accept $\mathrm{H}_{2}$. Task competence has a significant effect for both the within-group deviation score and the group mean. The group-level coefficient is significantly higher compared to the within-group deviation effect, indicating an across encounter as well as a unique encounter effect in explaining employee satisfaction. Social competence also has an individual- as well as a grouplevel effect, though the deviation score and the group mean have about the same regression coefficient, so social competence has a unique encounter effect without evidence for an independent across encounter effect.

With respect to the influence of employee's task and social competence as perceived by the customer on employee satisfaction, the results indicate a partner effect for task competence at the individual-level and for social competence at the group-level. We accept $\mathrm{H}_{4}$. The findings of the control variables age, gender, and experience show no significant impact on employee encounter satisfaction.

Incorporating the variance terms of the group-level random parameters for all individual-level variables yielded a significant increase in model fit for employee perceived task competence $\left(\chi^{2}(1)=5.66 ; p<.05\right)$ and employee perceived social competence $\left(\chi^{2}(1)=6.52 ; p<.05\right)$. These findings indicate that the unique encounter effect of employee perceived task and social competence on his or her encounter satisfaction significantly varies between groups (i.e., employee). The inclusion of covariance terms did not improve the model fit. Hence, the direction of the regression lines of both employee perceived task and social competence is not dependent on the average level of employee encounter satisfaction of a given group.

From the results as discussed, we conclude that employee satisfaction is influenced by unique encounter as well as across encounter effects $\left(\mathrm{RQ}_{2}\right)$.

\subsubsection{Agreement in Perceptions between Customers and Employees}

The significant correlations in table 2-2 between customer and employee perceptions of the employee's social competence at both levels indicate self-other agreement between the customer and the employee with respect the employee performance. Also, the small but significant, correlation between customer and employee perceptions of the employee's task competence at the individual-level indicates selfother agreement between the customer and the employee. Consequently, we accept $\mathrm{H}$ s.

\subsection{Discussion}

Our purpose in this research was to explore the customer-employee encounter in three ways; from both perspectives, considering employees' and customers' perceptions simultaneously, and taking the different drivers of evaluations (uniqueness, consensus, and consistency) into account. Our main findings are: 
1) Uniqueness, customers' consensus, and employee's consistency in perceptions are important influencers of customer and employee satisfaction.

2) Customer satisfaction is partly determined by employee perceptions and employee satisfaction partly by customer perceptions (e.g., partner effects).

A detailed overview of our main findings is given in table 2-5. We discuss the findings for customers and employees separately.

Table 2-5: Summary of Results

\begin{tabular}{|c|c|c|c|c|c|c|c|c|}
\hline & \multicolumn{4}{|c|}{ Customer satisfaction } & \multicolumn{4}{|c|}{ Employee satisfaction } \\
\hline & \multicolumn{4}{|c|}{ Competence } & \multicolumn{4}{|c|}{ Competence } \\
\hline & Task & Social & Task & Social & Task & Social & Task & Social \\
\hline Across & .28 & .28 & & & .41 & $.20^{\mathrm{a}}$ & & .16 \\
\hline Unique & .36 & .14 & & .10 & .26 & .17 & .12 & \\
\hline
\end{tabular}

Note: The numbers are standardized coefficients of the significant effects; a This effect is not independent of the unique encounter eflect.

\subsubsection{Actor Effects in the Sales Encounter: Uniqueness versus Consensus and Consistency}

\section{Customer Satisfaction}

It can be concluded that customer satisfaction is influenced by the customer's unique (e.g., individual-level) as well as shared perceptions (e.g., group-level) of the employee's task and social competence. With respect to the group-level perceptions, our results show that there is consensus among customers on the social and task competence of the employee they were interacting with. This suggests that both aspects of performance may be considered as relarively enduring and consistent characteristics that an employee (inevitably) brings to every encounter. This is in line with earlier research that suggests that task competence is an attribute of the contact employee (Crosby et al. 1990; Weitz et al. 1986) and that some salespersons may possess social skills or traits (e.g., positive, warm, outgoing personalities) that others may not have or to a lesser extent (Beatty et al. 1996).

At the same time, a substantial part of customers' perceptions of both social and task competence is unique (e.g., individual-level) to the specific encounter with the employee. This uniqueness can be caused by several sources (Kenny 1996a). First, two customers may see the same behavior, but they may attach different meanings to the event; the customer may bring a trait to the encounter, so one customer may perceive behavior as more social than another. Secondly, a customer may integrate external information, such as his or her mood, in the rating. Thirdly, it also may be that the employee takes on different roles with different customers, depending on the expectations and on the questions of the customer, e.g., the notion of adaptive selling. Finally, uniqueness may reflect the personal preferences of the employee. It has been demonstrated that employees may treat customers differently, for example, by giving some customers more special attention than others (e.g., Beatty et al. 1996). 
Finally, we found that older customers are more satisfied. This influence of customer age on satisfaction is stronger for some employees than for others. The variable purchase versus no purchase was not significant. This implies that the satisfaction of customers is not influenced by the fact whether they bought something during their visit or not.

\section{Employee Satisfaction}

It can be concluded that employee satisfaction is influenced by the unique (e.g., individual-level) and consistent (e.g., group-level) perceptions of task competence, and by the unique (e.g., individual-level) perceptions of social competence. Interestingly, our results indicate that for some employees these unique experiences are more important in creating satisfaction than for others.

The consistency in the employee's perceptions of his or her performance across several customers is in line with research that states that people make consistent selfjudgments across interactions (Felson 1992). The effect also suggests that differences exist between employees in these perceptions; some employees perceive themselves as more competent than others do. Generalized self-efficacy beliefs may explain this (Bandura 1986; van Yperen 1998). In addition to this perceptual explanation, there may be a behavioral rationale as well. An employee may behave more competently across all encounters with customers compared to other employees.

Employees also perceive their performance differently for each encounter, e.g., uniqueness (e.g., individual-level effect). It may be that the employee performs differently in every encounter. It is well known that when people interact with different people one at a time their behavior really differs from partner to partner and people are aware of that (Reno and Kenny 1992). However, it also may be that (s) he just perceives his or her performance differently. This latter may be caused by external sources like the employee's mood, the feedback of the manager, the customer or a colleague.

\subsubsection{Partner Effects in the Sales Encounter: Uniqueness versus Consensus and Consistency}

\section{Customer Satisfaction}

If the employee perceives him or herself as social competent in an interaction with a particular customer, this has a positive influence on customer satisfaction. This effect may reflect a truly dyadic influence process, i.e., the employee may let the customer know, verbally or non-verbally, that (s)he perceives that (s)he socially connects to the customer and this results in a favorable judgment on the part of the customer. This implies that the customer cares about the employee; if (s)he feels good, I am happy.

The influence is only related to the unique experiences of the employee in a particular interaction. It might be that the uniqueness of his or her perception creates a need to express this to the customer. It is well known from the interpersonal perception literature that perceptions are 'telegraphed' during interaction, verbally, by body language or intonation (e.g., DePaulo and Rosenthal 1982). The employee's perception of his or her task competence does not influence customer satisfaction. 
The employee may perceive task competence as a normal thing to do and consequently feels no need to communicate it. It also might be that the employee does communicate his or her task competence perceptions, but that a customer does not pick up the signal or is not influenced by it.

\section{Employee Satisfaction}

The results show that the customer's perceptions of employee's task as well as social competence influence employee satisfaction. The effect of task competence is related to the customer's unique perceptions. Again, it might be that the employee thinks that task competence is standard and (s)he is only influenced by a unique task experience of the customer. Regarding social competence, it seems that the employee is influenced when several customers see him or her as social competent. This clearly suggests that salespersons are aware of the importance to relate to every customer during each interaction (e.g., Bitner et al. 1994).

A unique partner effect with respect to social competence might have been reasonable to expect. This would imply that the employee was influenced by unique feelings of the customer with respect to their social connection and mutual understanding. However, this does not seem to be the case. It may be that employees have become so indoctrinated in the customer relationship management standards that all customers become significant others in that respect. The influence of the perception of significant others on a person's perceptions has been well documented (e.g., Snodgrass 1992).

\subsubsection{Agreement in Perceptions between Customers and Employees}

We conclude that the customer and employee agree in their perceptions of employee performance, especially with respect to the social competence of the employee. The correlations are moderate, which is in line with other research at this level of acquaintance (Park and Judd 1989; Paulhus and Bruce 1992). Also, the moderate effect might be explained by the fact that others often use different cues than the self uses in evaluations. Customers' perceptions are largely limited to observable behavior during the encounter. Self-ratings may be based on information like the past and company standards of performance, and less on observable behaviors (Kenny 1996a).

\subsubsection{Conclusion}

Overall, we conclude that the interaction between the customer and the employee is a true interpersonal system subject to a number of important nuances in mutual perceptions. Whether the customer and employee are satisfied is determined not only by what they see of themselves, but also by the perceptions of those with whom they are interacting. Therefore, it is important for firms to focus not only on the management of customer perceptions, but also on the management of employees' perceptions of their own performance.

In addition, the unique experience of the customer and the employee during the interaction is important in creating satisfaction for both parties. This indicates that an 
understanding of the unique fit between the custorner and the employee may further enhance satisfaction. Therefore, it may be worthwhile to consider a policy in which customers are related to specific employees by introducing what might be called interaction routing based on a proven fit congruence between employee and customer. Management may want to provide customers with the possibility to pre-register a profile on-line, or to call for an appointment, so (returning) customers can be easily matched with their preferred employee and problems like wait time are avoided. This can already be witnessed in many business-to-business settings and account management principles. It seems that both, the customer and the employee, may well benefit from such an approach.

Furthermore, it can be concluded that the influence of employee performance is not only unique, but also seems to reflect a stable form of employee behavior. This suggests that hiring and training policies for employees focusing on task and social competence profiles could be valuable for the sake of customer and employee satisfaction, contributing thereby to sales and employee success.

\subsubsection{Suggestions for Future Research}

Several limitations to our research project have to be recognized. These may point to future research issues. The first limitation relates to the way of data collection. A study incorporating multiple sample groups and performing one-to-one measures is complex to execute and has a number of potential causes for biases. Customers and contact employees completed the questionnaires in the store, immediately after an interaction. This might cause feelings of unease with customers, because they have to evaluate the person they have just spoken to and who is still in the store. Furthermore, by measuring after a particular encounter, we implicitly assume that this is a reliable sample of how contact employees are generally perceived by the customer and by themselves in an encounter. However, the employee may act differently because the customers are evaluating them. In addition, a consequence of our design was that employees had to fill out the same questionnaire several times, which can be boring. To minimize this bias, we divided our study over several weeks. Overall, these issues indicate that future research should investigate if another approach of data collection, like participant observation or an experiment, could produce the same results.

Secondly, our focus on a single industry may raise concerns about limited external validity. Constraining the study to a single industry eliminates problems associated with the effects of industry differences (e.g., Hartline and Ferrell 1996), but future research will have to reveal whether the results are generalizable to other retail settings.

Thirdly, further work in partner effects is also required since these effects are perhaps the quintessential indicators of interpersonal processes (Kenny and Cook 1999). Little research is done with respect to these effects in the marketing context. Although the influence of employee perceptions has received attention (e.g., Schneider and Bowen 1985), the surface has been barely scratched at the encounter level. Future research may lastly wish to consider which processes are operating behind the influence of partner effects. 
Additionally, research that examines the linkage between customer characteristics and their influence on evaluations of employee performance and satisfaction may prove valuable. We measured unique perceptions and consensus among several customers, but not the tendency of customers to see several employees in the same way. Yet, such effects may provide important information with respect to the influence of stereotypes (Kenny 1996a).

Furthermore, the model's explanatory power is limited to its included constructs. Obviously other constructs could affect customer and contact employee encounter satisfaction. The effects of role stress, primary rewards or the personality of the contact employee on employee encounter satisfaction were, for example, not examined. Likewise, we did not include the influence of factors like attributions or service quality on customer encounter satisfaction. 


\section{Chapter 3}

\section{The Impact of Humor in Face-to-Face and Electronic Encounters}

In this study, we attempt to nuance the intricate interplay between the use of humor and the outcome of the service in establishing customers' evaluations of face-to-face and electronic encounters. Experiments with manipulation of type of humor (related versus unrelated) and outcome of the service encounter were used to investigate relationships between aforementioned variables and satisfaction, enjoyable interaction, and behavioral intentions. The results suggest that a related humor process increases the likelihood of a positive service evaluation by customers in a face-to-face encounter. This is not the case in electronic encounters. Furthermore, we find that the outcome of the service is an important determinant of customers' evaluations in face-to-face encounters as well as in electronic encounters. It is found that the impact of the type of humor used in a face-to-face encounter is more important than the outcome of the service encounter, whereas in electronic encounters, the impact of the outcome of the service encounter is more important than the type of humor. In addition, we report interaction effects for the setting of the electronic encounter signifying that in these encounters, related humor might compensate partly for an unfavorable service outcome. 


\subsection{Introduction}

Academics and practitioners agree that the underlying premise of customer-firm encounters is to make them memorable and satisfying (Gupta and Vajic 2000; Pine and Gilmore 1999). This focus on creating memorable experiences by blending functionality, fulfillment, and fun has recently drawn attention to the importance of hedonic aspects of the service encounter. In general, these hedonic aspects refer to the enjoyment resulting from the fun and play arising during the experience (Hirschman and Holbrook 1982) which has been represented in the retail context by the theme of 'shopping as fun' (Babin et al. 1994; Bloch and Bruce 1984; Sherry 1990). This theme has serious consequences, for it has been argued that gauges of the hedonic quality of the experience reflect future economic performance (Anderson and Fornell 1994).

One important way to increase the hedonic quality of the shopping experience as well as the positive evaluation of the product or service itself is the use of humor (Childers et al. 2001; Dabholkar 1996; Perry and Jenzowsky 1997). To date, most research on the use of humor in a marketing context has been conducted in the area of mass communication channels. It has been demonstrated that humor in advertising may be used to create product and service awareness as well as a favorable image and to stimulate customer purchase behavior (Alden et al. 1993; Hanna et al. 1994; Spotts et al. 1997). Moreover, it has been demonstrated that advertising and promotion that incorporates humor does not only lead to positive product evaluations and buying intentions, but also seems to have a positive effect on the way in which people enjoy the viewing experience. For instance, Perry and Jenzowsky (1997 p. 395) report that they find "strong support for the use of humorous commercials to boost program enjoyment levels."

With respect to service delivery formats, varying from traditional face-to-face to technology-based self-service delivery modes, the picture of the incremental value of humor as a potential source of enjoyment and as a determinant of customers' evaluations is less clear. From research in the social sciences, there is strong evidence that humor may serve different functions in face-to-face contact (Chapman and Foot 1976; Wilson 1979), varying from the communication of a person's attitude in social interactions to the transformation of negative emotions into positive ones and the development of a basis for relationships between people (Locke 1996). Furthermore, there is an accumulating body of evidence that humor is also important in electronic channels (Babin et al. 1994; Bloch and Bruce 1984; Childers et al 2001; Sherry 1990). For instance, it has been suggested that the use of humor in e-mail campaigns has a positive effect on sales (Kaye 1999) and it has been argued that for on-line customers "the best experiences will sparkle with humor" (McKeown 2002 p. 256). Therefore, we investigate the influence of humor on customers' evaluations with respect to two service delivery formats.

In the investigation, we take two important contingencies into account: the nature of the service ourcome (e.g., favorable versus unfavorable) and the type of humor. It is well established that customers' evaluations of services depend both on the service process and outcome (Brown and Swartz 1989; Grönroos 1984). To date, the service marketing literature has focused extensively on service process (Dabholkar and Walls 
1999). Only recently, researchers have begun to explore the role of service outcome in service evaluation (Johnson et al. 1998; Powpaka 1996). An obvious and important issue is to determine the relative importance of process and outcome in service evaluations as well as the effect of the interaction between process and outcome. With respect to process, in face-to-face encounters humor is primarily associated with the attitude and behavior of the service employee, while in electronic encounters humor is an integral part of the (virtual) design of the service process.

Furthermore, in the humor research literature frequently a distinction has been made between related and unrelated humor (e.g., Zillman and Bryant 1983). In the context of learning and advertising, studies have demonstrated that the use of related humor has more positive effects than the use of unrelated humor (Spotts et al. 1997; Zillman and Bryant 1983). However, no studies are reported with respect to the effect of related versus unrelated humor in service encounters. The purpose of our study is to investigate how the interplay between the type of humor and the outcome of the service determines customers' evaluations of face-to-face and electronic encounters.

The remainder of this chapter is structured as follows. First, we review previous research on key conceptual issues. We subsequently discuss the results of two experiments designed to provide empirical evidence on the relationship between type of humor and service outcome in the formation of customers' evaluations of face-toface and electronic service delivery. We conclude with a discussion of a number of theoretical and managerial implications of our results.

\subsection{Literature Review}

\subsubsection{Conceptualizations of Humor}

Humor is an integral part of the human condition and yet many have struggled to come up with an exact conceptualization. Humor can be verbal, as in "the repartee that sharply levels drama and life to a sheen of verbal wit" (Sypher 1956 p. 29). It can also be physical and visual, as in "physical mishaps, pratfalls, and loud collisions" (Sypher 1956 p. 29). The benefits of humor have been underscored in several disciplines; humor has the ability to help people's understanding of key points, to aid building relationships, and to relax people in moments of anxiety and increased tension. But what exactly is humor? We attempt to answer this question by reviewing the literature with regards to the mechanisms that underlie humor and the benefits that may result from the use of humor.

As the exact nature of humor is yet to be resolved, it is not surprising that no comprehensive theory of humor has emerged (Spotts et al. 1997). Consequently, different views of humor's underlying mechanisms have been developed. Some theorists assumed that laughter was either a necessary or sufficient condition for humor to occur (Martin and Lefcourt 1984). While laughter is an important behavioral response to humor, and humor and laughter are often presented as inseparable (Chapman and Foot 1976; Mulkay 1988; Suls 1983), it has also been 
recognized that one can appreciate a joke without actually laughing and that laughter may be induced by many circumstances not directly related to humor (Bremmer and Roodenburg 1997; Suls 1983). People may laugh because they are uncomfortable, they may laugh at someone, and they may laugh because they are physiologically induced to do so. Alternatively, scholars have explored the evolutionary basis of humor in an attempt to verify whether humor is a learned behavior or a natural characteristic of all people. For instance, Weisfeld (1993) believes that humor is an evolved behavior and defines humor as an emotion or affect. Others have speculated that what we find humorous depends on which belief patterns we hold and comes from the ability to rapidly switch from one viewpoint to another (LaFollette and Shanks 1993).

While there is consensus about the fact that humor is multi-dimensional in nature, few humor researchers agree on the exact dimensions (Martin and Lefcourt 1983; Svebak 1974; Thorson and Powell 1993). Solomon (1996 p. 250) underscores this by summing the synonyms of humor: "farce, wit, jocularity, tease, laugh, snicker, zany, joke, ludicrous, satire, mirth, pun, jeer, glee, and giggle." She defines humor as a three-step process consisting of arousal, problem solving, and resolution. Shade (1996) proposes five elements related to humor that are always present in a person's sense of humor; humor appreciation, humor identification, humor comprehension, humor mirth response, and humor production. Although there is no unified, generally accepted taxonomy for humor, Spotts et al. (1997) suggest that the mechanisms that govern humor can be grouped into three broad categories: cognitive, affective, and social (McGhee 1974; Speck 1987, 1991; Wicker et al. 1980). These categories are reflective of three parallel theoretical perspectives on humor.

Cognitive mechanisms are related to the structure of the message and this focus is dominated by incongruity theory. It suggests that something is humorous because the event (e.g., joke, body movement, statement) is incompatible with our expectations, when circumstances do not fit or when they are illogical to us (Endlich 1993). Some hold the view that incongruity alone is sufficient, but others, the so-called incongruity-resolution theorists, suggest that incongruity must be accompanied with resolution in order to be considered humorous (Suls 1983). Affective mechanisms are closely related to Freud's relief theory. It supposes that humor diverts attention from seriousness to lightness, offering a release from the rigor of rationality and as such humor is seen as a healthy adaptive behavior (Freud 1905, 1960). Humor enables people to experience positive feelings of pleasure, even in environments of suffering. Each person experiences situations in which (s)he feels uncomfortable, afraid, or embarrassed, and via humor one can release this stress in a way that is socially acceptable. In line with Freud, 'freedom theorists' suggest that pleasure stems from the violation of uniform standards (Mindness 1971), and tension-release and arousal theorists suggest that pleasure derives from release of tension/arousal (Berlyne 1972; Rapp 1947). The social mechanisms refer to the social context in which humor arises. An example is superiority theory, the origins of which can be traced back to Plato. This perspective suggests that humor results from superior people looking at the inadequacies of inferiors (Lefcourt and Martin 1986). We laugh at others because we feel superior and because we are relieved that it is not us (LaFave 1972). By laughing 
at others, people communicate that they belong with the laughing social group rather than the ridiculed group. From this viewpoint laughter serves to identify with other people, to solidify the social bonds (Martineau 1972), to boost one's ego, and to create a sense of self-worth. These cognitive, affective, and social mechanisms together embody what is generally believed to drive humor.

\subsubsection{Types of Humor}

The aforementioned underlying mechanisms of humor provide a conceptual rather than an operational starting point for studying humor (Spotts et al. 1997). In order to develop a basis suitable for empirical study, various authors have suggested techniqueoriented and descriptive typologies of humor, in addition to its mechanisms (Speck $1987,1991)$. One frequently used typology is that of related versus unrelated humor. Related humor is defined as humor that is pertaining to the particular situation, message, or product, while unrelated humor is not (c.f. Zillman and Bryant 1983). In general, it is has been suggested that adult audiences (as opposed to children) respond well to humor that is integrated and related (Coleman 1992; Zillmann and Bryant 1983; Ziv 1988), but the findings with respect to unrelated humor remain conflicting and are not conclusive. It has been argued that people do not respond to humor that has no apparent connections to the message and is obviously interspersed to liven things up. For instance, with respect to books, it was found that related humor made them appear more interesting and promoted the desire to read them, whereas unrelated humor did not have these effects (Klein et al. 1982). It also has been suggested that unrelated humor may be even perceived as inconsequential or distracting and may be met with impatience, if not with annoyance, whereas related humor can be an effective way to help remember examples of content (Zillmann and Bryant 1983). In another study (Hezel et al. 1982), it was found that teachers who use related and relevant humor were judged to be more interesting, entertaining, and enjoyable than those who used unrelated humor. In general, these authors concluded that teachers using unrelated humor may well be perceived as being funny and possibly gain appeal in the sense of being liked, but at the same time the use of unrelated humor was detriment to rapport and to be most harmful to the assessment of the teacher's competence. Furthermore, it may create a loss in attentiveness and ultimately result in reduced information acquisition from messages.

These findings are confirmed by several studies on the use of humor in advertising (Assael 1995; Spotts et al. 1997). It has been argued that the relatedness of humor to the ad, product, or service is an important aspect that influences the effectiveness of humor in advertising. Moreover, it is concluded that the most important advantage of related humor is that the customer's attention remains focused on the core product or service, which is not the case with unrelated humor. Also, others suggest that humor related to the product is superior to unrelated humor (e.g., Schiffman and Kanuk 1994). Scott et al. (1990) found that humor is only effective when it is related to the product, service, and event. Their results supported that related humor enhances patronage activity, but unrelated humor has either no impact or a negative impact. An overall conclusion drawn from advertising literature is that humor is more likely 
to enhance recall, evaluation, and purchase intention when the humorous message is related to the product. Under such circumstances, humor is more likely to "secure audience attention, increase memorability, overcome sale resistance and enhance message persuasiveness" (Scott et al. 1990 p. 498; also Alden et al. 1993; Krishnan and Chakravarti 1990).

\subsubsection{Effects of Humor}

Generalizations about the effects of humor have been rare, since many factors are of influence by the use of humor, like the (humorous) message, the nature of the product, audience factors, communication goals, humor relatedness, humor style, and humor placement (Weinberger and Gulas 1992). Studies on the effects of humor have been conducted in different fields involving various communication modes. In the field of advertising, previous research has shown that the outcomes of the use of humor in advertising vary (Alden and Hoyer 1993; Chattopadhyay and Basu 1990; Hanna et al. 1994). Many firms have turned to humor as a primary element in their marketing communications and researchers suggest that the positive effects tend to relate to humor as an attention-getter, a message-acceptance-facilitator, and a popular persuasion technique (Assael 1995; Hanna et al. 1994; Madden and Weinberger 1984; Schiffman and Kanuk 1994). At the same time, it is well known that there are also risks involved in using humor as a communication device. For example, if humor is too dominating, it may have a negative effect on message comprehension and may fail to communicate the product or service benefits (Assael 1995).

Some argue that humor cannot be used for serious purposes, as it is directly associated with joking and laughter. They believe serious topics require serious discourse with no laughing allowed (Witkin 1999). However, several studies have shown that humor is frequently used as a resource for accomplishing certain types of difficult interaction and thus can coexist with the serious (e.g., Mulkay 1988). For example, the use of humor in medical encounters can be the patient's defense against getting in touch with his or her pain or sadness (Molnos 1998).

In the educational setting, humor may uniquely impact teacher-student rapport. A teacher who is regarded as entertaining and being funny attracts students to his or her classroom and can enliven an otherwise boring lecture (Zillman and Bryant 1983; Witkin 1999). For years, humor has been proven effective in the workplace, where it facilitates communication (Blocklyn 1988), makes people feel more comfortable and productive (Boruch 1995; Swift and Swift 1994), and provides a coping mechanism for dealing with on-the-job stress (Vinton 1989).

Beck (1997) summarizes the benefits of humor as physiological, psychological, cognitive, and social. Included in the physiological effects are its stimulation of the circulatory and respiratory systems, and relaxation of the muscles. (e.g., Williams 1986). Psychologically, humor helps to strengthen one's self-esteem and to decrease stress by providing a safe and acceptable outlet of emotions. It functions as a coping mechanism to screen the individual from negative stimuli and reactions, it may create a positive mood, and it may give a sense of control (Burbach and Babbitt 1993; Moran and Massam 1999; Witkin 1999). Cognitively, humor facilitates the learning process 
by capturing and maintaining attention, and by increasing memory (e.g., Leiber 1986). Finally, humor appears to have an important social function as it has the capability of enhancing interpersonal relationships. According to Cohen (1990) laughter is the shortest distance between people and the use of humor can enhance feelings of closeness, togetherness, warmth, and friendliness (Parse 1993). Chapman (1983) states that these social functions may even be the most crucial for modern man. Humor might reveal group allegiances, communicate attitudes, and aid members of small groups to engage in smooth interactions. Expression of humor can foster rapport and attraction between people and create intimacy (Hampes 1992; Wilson 1979). Humor promotes group cohesion and provides social control (Witkin 1999). Finally, humor can boost friendship by showing common sentiment and reduce a person's prevailing hostilities and anxiecies (Wilson 1979).

The effects of humor have mainly been studied in the context of advertising. and interpersonal, face-to-face interactions (primarily outside the marketing domain), and so far there has been little work on humor in the context of computer-mediated interactions (Danet et al 1995; Fox 1993). The few studies on computer-mediated interactions, though, found positive effects of humor. Baym (1995) state that humor can be accomplished in computer-mediated communication and can be critical to creating social meaning on-line. In her study, she shows how humor creates group solidarity, group identity, and also individual identity in on-line encounters. Research concerning computer-mediated interactions in the context of education found a significant positive effect of humor on the feelings of the students toward the content, but no significant differences with respect to acquisition or retention of information (Snetsinger and Grabowski 1994a, 1994b).

From the different studies on humor we conclude that humor may not only serve purposes of entertainment and amusement, but may also form a basis for turning interactions between people into memorable experiences (Brown and Bryant 1983; Mulkay 1988; Wilson 1979). Moreover, the use of humor is generally associated with enjoyment and fun (e.g., Bryant et al. 1980). As such, it is certainly of interest to examine the role of humor and the hedonic quality in the service encounter.

\subsubsection{Customer Evaluations of Service Encounters}

With respect to customers' evaluations of service encounters, the focus in our study is on satisfaction, enjoyable interaction, and behavioral intentions. It is well established these three constructs are critical measures of face-to-face and electronic service encounters (Bitner et al. 1990, Meuter et al. 2000; Gremler and Gwinner 2000; Keaveney and Parthasarathy 2001; Szymanski and Hise 2000). The concept of customer satisfaction bears relevance to both single, discrete encounters and to relationships. In this study, the focus is on single encounter satisfaction. According to Bitner and Hubbert (1994 p. 76), this reflects "the customer's feelings about a discrete interaction with the firm and will result from the evaluation of the events and behaviors that occur during that definable period of time."

A second evaluative judgment concerns enjoyable interaction. Enjoyable interaction might be interpreted as an aspect of hedonic quality. With respect to 
enjoyable interaction, several researchers identified its importance in positively influencing customers' judgments in off-line (e.g., Babin et al. 1994; Gremler and Gwinner 2000; O'Guinn and Faber 1989) and on-line (e.g., Childers et al 2001; Hoffman and Novak 1996) encounters. A service provider might use different strategies to create an enjoyable interaction. For example, the firm may use humor, build a colorful design, include sufficient sensory information into web-sites, increase flexibility of navigation, and personalize the service (e.g., Childers et al. 2001; Dabholkar 1996; Gremler and Gwinner 2000).

A final construct that needs to be incorporated is behavioral intentions, i.e., the intention of the customer to return to the (e-)service and to make recommendations. An initial contact between two parties might result in an ongoing relationship and consequently result in a customer's return (Beatty et al. 1996). It has been suggested that given the essence of customer choice in services, it is imperative to examine customers' behavioral intentions with respect to returning to the firm and positive word-of-mouth communications (Ustrom and Iacobucci 1995; Zeithaml and Bitner 1996).

Although the three dependent measures are well documented in off-line contexts (e.g., Oliver 1997), recent studies suggest satisfaction, enjoyable interaction, and customer loyalty to be important in on-line environments as well (Shankar et al. 2000; Szymanski and Hise 2000; Wolfinbarger and Gilly 2001). In summary, it can be argued that the service encounter is positively evaluated when encounter satisfaction is high, customers experience an enjoyable interaction and have positive behavioral intuntions. In the next section, we develop our research hypotheses.

\subsection{Hypotheses Development}

In this research, we study the effects of the service process (e.g., the use of related versus unrelated humor) and the service outcome on the customer's evaluation of both the face-to-face and electronic encounter. Service process reflects the way the service is delivered to the customer and evaluating the process, several dimensions may be taken into account, such as the reliability, responsiveness, assurance, and empathy of the service provider (e.g., Parasuraman et al. 1985). It has frequently been argued that a favorable process increases a positive evaluation (Grönroos 1984; Iacobucci et al. 1994). In this study, we focus on the use of humor, i.e., the service process pertains to the fact whether the provider is using humor during the encounter with the customer. From previous studies it becomes clear that, when humor is properly used, it might have benefits for both provider and customer. Specifically, these studies indicate that in general, the use of related humor results in more positive effects than the use of unrelated humor (Assael 1995; Spotts et al. 1997; Zillman and Bryant 1983). Therefore, we hypothesize: 


\section{$H_{1}: \quad$ Respondents will evaluate services encounters in which related humor is used more positively than service encounters in which unrelated bumor is used, in terms of the following criteria: 1) Satisfaction, 2) Enjoyable interaction, and 3) Belsavioral intintions.}

It is well known that evaluations of services are based on what customers receive as outcome as well as on how the process of service delivery takes place, off-line (Lapierre 1996; Swartz and Brown 1991) as well as on-line (Zeithaml et al. 2000). Both aspects are considered important (e.g., Grönroos 1984; de Ruyter and Wetzels 1998) and, therefore, in our study we focus on outcome in addition to process. Outcome refers to an evaluation of what the customer received from encounters with the firm, whereas process refers to how the outcome is performed. Outcome essentially refers to the instrumental performance of a service. It can be viewed as an end-state, which may or may not be the intended effect of a service process. For instance, when booking a holiday, the concept of service outcome pertains to the fact whether the provider is able to book the vacation or not. Since service outcome may influence the encounter evaluation as well (Brown and Swartz 1989; Grönroos 1984; Johnson et al. 1998; Lapierre 1996), we expect that a favorable service outcome will lead to more positive encounter evaluations than an unfavorable service outcome. Therefore, we hypothesize:

\section{H2: Respondents will evaluate services encounters with a favorable outcome more positively than service encounters with an unfavorable outcome, in terms of the following criteria: 1) Satisfaction, 2) Enjoyable interaction, and 3) Behavioral intentions.}

Despite the main effects of outcome and type of humor on customers' evaluative judgments, both are an integral part of the service encounter and the interaction between outcome and process should be examined. Although to the authors" knowledge no studies are reported that depart from an explicit focus on the interaction effects between humor and outcome in face-to-face or electronic encounters in a marketing context, several studies in a service or sales context exist which provide insight in the possible intricate interplay between process and outcome. Therefore, we turn to these studies for guidance.

It has been frequently suggested in the services marketing literature that the way the service is delivered may be a more important antecedent of customers' evaluations than the service outcome (e.g., Brown and Swartz 1989). Furthermore, Iacobucci et. al. (1994) state that a favorable outcome might not increase the chance of positive evaluative judgments by customers, while a positive and favorable process may. Also, Bopp (1990) concludes that a good outcome may not be sufficient to foster perceptions of high service quality, satisfaction, and loyalty. Grönroos (1984) contends that outcome-related aspects may not be a sufficient but necessary condition for a positive encounter evaluation. Swan and Comb (1976) found that customers become dissatisfied with a service when they perceive the outcome to be satisfactory 
but the process unsatisfactory. In addition, de Ruyter and Wetzels (1998) showed that customers who experienced a favorable outcome and favorable process evaluated the service encounter more positively than customers who experienced a favorable outcome and an unfavorable process. Since related humor is supposed to be more positive than unrelated humor (e.g., Assael 1995; Spotts et al. 1997; Zillman and Bryant 1983) and in line with service research, we hypothesize:

H3: A service encounter with a favorable outcome in which related bumor is used will be evaluated more positively than a service encounter with a favorable outcome in which unrelated humor is used, in terms of the following criteria: 1) Satisfaction, 2) Enjoyable interaction, and 3) Behavioral intentions.

It has been argued that particularly in the case of an unfavorable outcome, process variables are important determinants of evaluative judgments. For instance, Lytle and Mokwa (1992), in a study of medical encounters, demonstrated that when customers experienced an unsuccessful outcome, elements pertaining to the service process were considered important and significantly influenced evaluative judgments. In a retail context, Lemmink and Mattsson (1998) found that in case of non-delivery (e.g., an unfavorable outcome), being pleasant and helpful still led to positive evaluations of the encounter. Lazare et al. (1975) report that the interaction of an unfavorable outcome and positive process perceptions may still result in a positive overall assessment of the service; a positive process seems to compensate for an unfavorable outcome. In line with this, it might be that a process with related humor (partly) makes up for an unfavorable outcome. Concerning the interaction between service outcome and type of humor in the service process, we hypothesize:

H4: A service encounter with an unfavorable outcome in which related bumor is used will be evaluated more positively than a service encounter with an unfavorable outcome in which unrelated bumor is used, in terms of the following criteria: 1) Satisfaction, 2) Enjoyable interaction, and 3) Behavioral intentions.

Finally, it has been suggested that humor with no apparent connection to the message and just included to entertain, might cause irritation. Unrelated humor may have a devastating effect on the perceptions of a provider's intelligence and may prompt appraisals of inferior informedness (Zillman and Bryant 1983). We argue that this effect might be especially strong in case of an unfavorable outcome. For example, in case a customer cannot make a reservation at a travel agency, while at the same time the service employee is just performing as the jolly entertainer, this might result in an extra negative evaluation. Therefore, we expect that the relative difference between a favorable outcome and an unfavorable outcome will be larger with the use of unrelated humor. We hypothesize: 


\section{Hs: The relative difference between service encounters with a favorable outcome and service encounters with an unfavorable outcome will be larger in case of unrelated humor than in the case of related bumor, in terms of the following criteria: 1) Satisfaction, 2) Enjoyable interaction, and 3) Behavioral intentions.}

We test these hypotheses for the face-to-face and the electronic encounter. In the next section, we describe two experiments designed to test the hypotheses.

\subsection{Experiment 1: Face-to-Face Encounters}

\subsubsection{Method}

The setting of our experiment was the travel business. To determine an appropriate research setting, we chose a service that is well known in an off-line and on-line setting. The travel business was chosen for two reasons. First of all, almost everyone has experience with this service so respondents do not find it very difficult to imagine themselves in such a situation. Secondly, booking travel trips is a successful application of e-commerce (Bloch and Segev 1996).

An experimental approach using a between-subjects, fixed-effects factorial design consisting of two factors was chosen to test the proposed hypotheses. Type of humor (service process) used by the provider was manipulated on two levels: related humor and unrelated humor. The outcome of the service interaction was manipulated on two levels: favorable outcome and unfavorable outcome. Consequently, we arrived at a 2 × 2 factorial design.

\subsubsection{Procedure}

As stimuli for evoking responses for the face-to-face encounter, we developed a videoscenario of a customer's visit to a travel agency with the aim of booking a skiing holiday. Respondents viewed the video and were asked to imagine that they were the customer. This method has been proven to be useful in service research (Lemmink and Mattsson 1998). Results of literature study show that only few studies can be found in which service encounters are analyzed with video-taped situations as a point of departure. Particularly, the use of experimental methods like video-taped service encounters is supported in a marketing context (Bitner 1990; 1992). Audio-visual presentations are most likely superior in conveying service attributes compared to written scenarios which are more often used. Several arguments can be given in support of this. First, compared to written scenarios, the information in audio-visual format is easier for respondents to process in a way that fits the holistic character (gestalt) of a service. Secondly, it is possible to show environmental conditions instead of verbal descriptions of the environment, which is more close to the aesthetical and sensational aspects of such environments. Thirdly, because of validity reasons it is 
important that stimuli will be offered as realistically as possible to customers; dynamic audio-visual information is more realistic than static conceptual information. Nasar (1989) postulated that the environmental psychology tradition has shown that simulated environments work well in achieving generalizable results. An experimental design with service encounters can be operationalized by describing e.g., procedures, environmental settings, and employee scripts. Subsequently, this information can be combined into video recordings.

The respondents were told that they had already informed themselves with the help of some travel brochures about the different possibilities and made a priority list with which they went to the travel agency. The purpose of the video was to let the respondents experience the situation in order to test our hypotheses.

We filmed the encounter in an existing travel agency to increase the realism of the video. For the role of the service provider, we trained an actress to act as a travel agent, to use either related or unrelated humor and to communicate the outcome. Regarding the use of related humor, the service provider made jokes and comic remarks related to the skiing holiday and in the unrelated condition jokes and comic remarks unrelated to skiing or any other aspect of the holiday were made. With respect to the service outcome the holiday could be booked (favorable outcome) or the holiday could not be booked (unfavorable outcome).

Four video films were composed based on the combination of the manipulated variables. In order to standardize the behavior of the service provider apart from the type of humor and outcome, a script was developed for the advisor and the customer for each encounter. These scripts were different for type of humor and service outcome, but the same for the other behaviors of the employee and the customer. So, each respondent was exposed to a similar encounter, aside from the experimental manipulations. For the role of customer, a student was hired. We filmed the customer only from behind, to make it easier for the respondents to identify with the customer in the filmed service encounter and to enable to experience the encounter literally through the eyes of the customer. Various samples of the scripts are included in Appendix A.

The respondents were randomly assigned to one of the four conditions. As we expected large effects for all treatments and as we anticipated the dependent variables to be intercorrelated, a sample size of approximately 25 would suffice to achieve a power $(1-\beta)$ of .80 at an alpha $(\alpha)$ of .05 . Each respondent received a booklet, which included an instruction and the questionnaire. Furthermore, manipulations checks were added to assess whether the state intended by the two independent variables was induced (Perdue and Summers 1986). Respondents were told to read the instruction and to watch the video. Next, they were asked to indicate their overall evaluation of the face-to-face encounter by rating the satisfaction, enjoyable interaction, and behavioral intentions measures. Finally, demographic measures were presented to the respondents (gender, age, and Internet experience). 


\subsubsection{Pre-Test}

Using simple random sampling, 15 students were selected for the pre-test in order to: 1) assess whether the desired state was induced by the manipulations of the independent variables, and 2) assess the reliability of the dependent measures. The subjects responded to a series of items assessing the validity of the manipulations immediately after exposure to the manipulation. Additionally, they were interviewed (Perdue and Summers 1986). The pre-test revealed that the manipulations were successful in creating the desired treatment effect. Only minor adaptations were necessary for the script. Furthermore, preliminary analyses indicated that the dependent measures showed sufficient reliability in terms of Cronbach's alpha.

\subsubsection{Sample}

Hundred-twenty business students from a large Dutch University participated in our study. They received course credits for their participation. The effective sample size ${ }^{1}$ of this study is 102 respondents. The sample consisted of $53 \%$ men and of $47 \%$ women. The age ranged from 19 to 24 with an average of 22 . Regarding Internet experience, measured by years of use, $47 \%$ of all respondents had experience for $2-3$ years, $27 \%$ between $4-5$ years, and $26 \%$ between $1-2$ years.

\subsubsection{Questionnaire Development}

All items were measured on a 7-point Likert-type scale using 'totally agree' and 'totally disagree' as anchors. Satisfaction with the encounter was operationalized by eight items as suggested by Oliver (1997). The five enjoyable interaction items were adapted from a scale developed by Gremler and Gwinner (2000). The behavioral intentions scale consisted of four items describing the customer's intention to recommend the provider and to return to the travel agency. The items were measured using an existing scale developed by Oliver and Swan (1989). We performed a series of confirmatory factor analysis (CFA) to assess the unidimensionality, reliability, and validity of the dependent variables used in our study. From table 3-1, we can conclude that the dependent variables used in our study exhibit a high degree of unidimensionality and reliability. With regard to the validity of the variables, we investigated whether within-method convergent and discriminant validity was present. Within-method convergent validity was assessed testing the significance and magnitude of each indicator's coefficient (cf., Anderson and Gerbing 1988). We found that all items, except one item for satisfaction, loaded higher than .50 on their respective constructs with minimum t-values of 4.45 . Discriminant validity was evaluated by testing whether pairs of constructs were correlated less than unity. We used chi-square difference tests with one degree of freedom to test for unity between the constructs. All tests were significant at the .05 significance level, thereby supporting the existence of discriminant validity.

\footnotetext{
'In total 18 observations were classified as outliers and consequently deleted from the analysis.
} 
Table 3-1: Results of Confirmatory Factor Analyses for the Face-to-Face Encounter

\begin{tabular}{|c|c|c|}
\hline Measures & Factor loadings & t-value \\
\hline \multirow{2}{*}{\multicolumn{3}{|c|}{$\begin{array}{l}\text { Fit indices: (GFl=.98; AGFl=.93; RMSEA=.040; NNFl=.93; CFl=.99) } \\
\text { Satisfaction }(n=8 ; \mathbf{a}=.92)\end{array}$}} \\
\hline & & \\
\hline I am satisfied with my interaction with the service employee & .87 & 12.24 \\
\hline The encounter with the service employee was a good experience & .85 & 11.68 \\
\hline I am satisfied with the information I got from the service employee & .61 & 7.43 \\
\hline I am not happy with the encounter with the service employee a & .80 & 10.64 \\
\hline I regret that i went to this travel agency " & .83 & 11.27 \\
\hline My choice for this travel agency was a good one & 89 & 12.67 \\
\hline In general, I am satisfied with the performance of the service employee & .86 & 11.98 \\
\hline In general, I arn satisfied with this travel agency & .39 & 4.45 \\
\hline \multicolumn{3}{|l|}{ Enjoyable interaction ( $n=5 ; \alpha=.86$ ) } \\
\hline The service employee had a good sense of humor & .67 & 8.18 \\
\hline I enjoyed interacting with this service employee & .71 & 8.84 \\
\hline I built a harmonious relationship with this ernployee & .73 & 9.16 \\
\hline I was cornfortable interacting with this employee & .87 & 11.87 \\
\hline The employee created a feeling of 'warmth' during the encounter & .74 & 9.36 \\
\hline \multicolumn{3}{|l|}{ Behavioral intentions $(n=4 ; a=.95)$} \\
\hline I would recommend this service employee to others & .91 & 13.20 \\
\hline I would return to this travel agency & .90 & 12.88 \\
\hline I would recommend this travel agency to others & .90 & 13.01 \\
\hline I say positive things about this travel agency to others & .94 & 13.96 \\
\hline
\end{tabular}

- Reverse coded.

\subsubsection{Results}

\section{Manipulation Checks}

Manipulation checks were executed in order to assess whether the intended manipulations were understood by the respondents. We can conclude that there are differences between the related humorous service process and the unrelated humorous service process $\left(\mathrm{F}_{1,100}=76.81, \mathrm{p}<.001\right)$, and the favorable service outcome

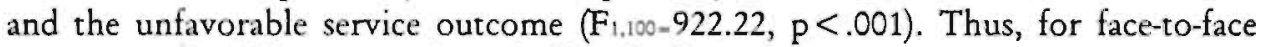
encounters the differences as intended by the design exist.

\section{Multivariate Analysis of Variance (MANOVA)}

To analyze the data of our experiment we performed a multivariate analysis of variance. Before we performed our actual MANOVA we conducted some preceding analyses to detect outliers, to assess the assumptions underlying MANOVA, and to assess the correlations among our dependent variables.

\section{Preliminary Analyses}

Outlier detection is a highly necessary first step as MANOVA is particularly sensitive to outliers. Following Tabachnik and Fidell (1996), we performed tests for univariate and multivariate outliers for each separate cell of the design. In total we detected 18 outliers, which were subsequently deleted from the analysis. The first assumption underlying MANOVA relates to the presence of a multivariate distribution. To make 
inferences about the presence of a multivariate normal distribution we tested the data for univariate and bivariate normality (cf., Johnson and Wichern 1998). Univariate normality was examined by means of histograms, Q-Q plots, skewness, kurtosis, and proportional chance analysis for each dependent variable for each cell. Bivariate normality was assessed using scatterplots. The analysis showed slight departures from a standard normal distribution. However, as MANOVA has shown to be robust against violations of the multivariate normal distribution, we continued our analysis with the variables in their original form. The second assumption that needs to be tested is the equality of the variance-covariance matrices. This assumption can be assessed by means of the Box's $M$ statistic for homogeneity of dispersion matrices. However, the Box's $M$ test is not very useful in this case as it is extremely sensitive to departures from a multivariate normal distribution (Tabachnick and Fidell 1996). Thirdly, MANOVA assumes linear relationships among all pairs of dependent variables, all pairs of covariates, and all dependent variable-covariate pairs in each cell (Tabachnick and Fidell 1996). Deviation from this third assumption leads to a reduction in the power of the statistical tests. Plots of all dependent variable pairs and dependent variable-covariate pairs indicated that linear relationships are present.

If the dependent variables are uncorrelated, applying MANOVA is superfluous and the hypotheses can be tested by performing a series of univariate ANOVAs. Inspection of the pooled within-group correlation matrix indicated significant correlation coefficients between the dependent variables (table 3-2).

Table 3-2: Pooled Within-Group Correlation Matrix *

\begin{tabular}{lccc}
\hline & Satisfaction & Enjoyable interaction & Behavioral intentions \\
\hline Satisfaction & 1.00 & & \\
Enjoyable interaction & .37 & 1.00 & \\
Behavioral intentions & .60 & .47 & 1.00 \\
\hline
\end{tabular}

All correlations are significant at the .05 level.

\section{Hypotheses Testing}

The results of the omnibus MANOVA tests are summarized in table 3-3. We find that type of humor exhibits a significant main effect $\left(V=.41 ; F_{3,96}=22.55, p<.001\right)$ and service outcome exhibits a significant main effect $\left(V=.28 ; F_{3,96}=12.29, p<.001\right)$. Moreover, we find an effect for the interaction between type of humor and service outcome $\left(\mathrm{V}=.09 ; \mathrm{F}_{3,96}=3.28, \mathrm{p}=.024\right)$. Comparing the partial effect sizes, we see that type of humor (partial $\eta^{2}=.41$ ) explains a larger portion of the variance in the dependent variables than service outcome (partial $\eta^{2}=.28$ ). We used univariate analyses to further explore the relationships uncovered by the omnibus MANOVA test (cf., Bray and Maxwell 1993). The results of the omnibus ANOVA tests for the 
dependent variables are presented in table $3-4^{2}$ and the cell means in table $3-5$. With regard to $H_{1}$, we find that respondents who experience a service encounter with related humor evaluate the service encounter more favorably than respondents who experience a service encounter in which unrelated humor is used, in terms of satisfaction ( $\left.t_{100}=8.53, p<.001\right)$, enjoyable interaction $\left(t_{100}=4.13, p<.001\right)$, and behavioral intentions $\left(t_{100}=9.10, p<.001\right)$. Concerning $\mathrm{H}_{2}$, we find that respondents who experience a service encounter with a favorable outcome will experience the service encounter more positively than respondents who experience an unfavorable outcome on all three evaluative criteria. More specifically, the results are as follows: customer satisfaction ( $\left.t_{100}=6.21, p<.001\right)$, enjoyable interaction $\left(t_{100}=5.80, p<.001\right)$, and behavioral intentions ( $\left.\mathrm{t}_{100}=7.66, \mathrm{p}<.001\right)$. Consequently, we accept $\mathrm{H}_{3}$.

Table 3-3: Results of Omnlbus MANOVA Tests for the Face-to-Face Encounter

\begin{tabular}{lcccc}
\hline Effect & Pillal-Bartlett trace $(\boldsymbol{N})$ & $\boldsymbol{F}_{3,96}$ & p-value! & Partial $\eta^{2}$ \\
\hline Main effects & .41 & 22.55 & & \\
Humor & .28 & 12.29 & $<.001$ & .41 \\
Outcome & .09 & 3.28 & $<.001$ & .28 \\
Two-way Interaction & Humor"outcome & .024 & .09 \\
\hline
\end{tabular}

Table 3-4: Results of Omnibus ANOVA Tests for the Face-to-Face Encounter

\begin{tabular}{|c|c|c|c|c|}
\hline Dependent variables & Effect & $F_{1,98}$ & p-value & Partial $\eta^{2}$ \\
\hline \multicolumn{5}{|l|}{ Satisfaction } \\
\hline \multirow[t]{2}{*}{ Main effects } & Humor & 44.99 & $<.001$ & .32 \\
\hline & Outcome & 19.11 & $<.001$ & .16 \\
\hline Two-way interaction & Humor"outcome & .06 & .809 & .00 \\
\hline \multicolumn{5}{|l|}{ Enjoyable Interaction } \\
\hline \multirow[t]{2}{*}{ Main effects } & Humor & 4.95 & .028 & .05 \\
\hline & Outcome & 20.99 & $<.001$ & .18 \\
\hline Two-way interaction & Humor"outcome & 1.11 & .296 & .01 \\
\hline \multicolumn{5}{|l|}{ Behavioral intentions } \\
\hline \multirow[t]{2}{*}{ Main effects } & Humor & 58.52 & $<.001$ & .37 \\
\hline & Outcome & 31.83 & $<.001$ & .25 \\
\hline Two-way interaction & Humor"outcome & 3.38 & .069 & .03 \\
\hline
\end{tabular}

Regarding $\mathrm{H}$, we find that a service encounter with a favorable outcome in which related humor is used is evaluated more positively than a service encounter with a favorable outcome in which unrelated humor is used in terms of satisfaction and behavioral intentions (satisfaction: $t 50=4.73, p<.001$; behavioral intentions: $t 50=9.40$, $\mathrm{p}<.001$ ). Thus, for two out of the three evaluative criteria $\mathrm{H}_{3}$ is accepted. In line with the relationship assumed under $\mathrm{H}_{4}$, we find that a service encounter with an

${ }^{2}$ Although Umesh et al. (1996) caution researchers for using the omnibus $F$ test for interactions testing for differences between cell means, they also state that $2^{*} 2$ ANOVA constitutes a special case in that respect (cf. Keppel 1991). 
unfavorable outcome in which related humor is used is evaluated more positively than a service encounter with an unfavorable outcome in which unrelated humor is used in terms of all evaluative criteria (satisfaction: $t+8=6.26, p<.001$; enjoyable interaction: $t 48=2.28, p=.029$; behavioral intentions: $t 48=4.50, p<.001)$. Thus, for the face-to-face encounter $\mathrm{H}_{4}$ is accepted. We would like to stress that the cell means we used to test $\mathrm{H}_{3}$ and $\mathrm{H}_{4}$ include both main effects and interactions effects. Since the interaction effect between type of humor and service outcome is not significant for all three dependent variables, the cell means can be interpreted as main effects (Umesh et al. 1996). $\mathrm{H}_{5}$ tests the presence of interaction effects (without including main effects) between type of humor and service outcome. Based on the results of the omnibus ANOVA tests we reject $\mathrm{H}_{5}$ as there are no statistically significant interaction effects.

Table 3-5: Cell Means for the Face-to-Face Encounter

\begin{tabular}{lrr}
\hline & Related humor & Unrelated humor \\
\hline \multirow{3}{*}{ Favorable outcome } & Satisfaction: $5.30(1.13)$ & Satisfaction: $4.02(.65)$ \\
& Enjoyable interaction: $4.73(.86)$ & Enjoyable interaction: $4.50(.74)$ \\
& Behavioral intentions: $5.19(.90)$ & Behavioral intentions: $3.46(.35)$ \\
& & \\
Unfavorable outcome & Satisfaction: $4.49(.66)$ & Satisfaction: $3.11(.85)$ \\
& Enjoyable interaction: $4.04(1.08)$ & Enjoyable interaction: $3.40(.86)$ \\
& Behavioral intentions: $3.83(.82)$ & Behavioral intentions: $2.76(.89)$ \\
\hline
\end{tabular}

\subsection{Experiment 2: Electronic Encounters}

\subsubsection{Method}

The setting and the design of experiment 2 were identical to that of experiment 1 . Thus, a between-subjects, fixed-effects factorial design consisting of two factors was chosen to test the proposed hypotheses. Related humor versus unrelated humor and favorable outcome versus unfavorable outcome were manipulated resulting in a $2 \times 2$ factorial design.

\subsubsection{Procedure}

The procedure was identical to that of Experiment 1. Hundred-twenty business students were randomly assigned to one of the four conditions. Each respondent received a booklet, which included an instruction, the questionnaire, and manipulations checks. As stimuli for evoking responses for the electronic encounters, the respondents surfed on a, for this study developed, web-site of a travel agency to book a skiing holiday. Students were told to read the instruction and to explore the web-site carefully. Next, they rated the satisfaction, enjoyable interaction, behavioral intentions, and demographic measures. In the related humor condition, we included one cartoon about skiing to the web-site, a humorous, animated picture about snow 
and skiing, winter sport related funnies, and a joke of the day related to skiing. The unrelated humor web-site included a cartoon, an animated picture, funnies (like smileys), and a joke of the day which were not related to any aspect of the holiday. With respect to the service outcome, the respondent had to fill out a booking form and after submitting this form the respondent got the message that the holiday could be booked (favorable outcome) or could not be booked (unfavorable outcome). The use of cartoons and jokes to express humor in our study was based on a review of humor research and experiments (e.g., LaFolette and Shanks 1993; Scott et al. 1990; Moran 1996). Four web-sites were composed based on the combination of the manipulated variables. Various samples of the stimulus material are included in Appendix B.

\subsubsection{Pre-Test}

As with Experiment 1, 15 students were selected for the pre-test. The subjects responded to a series of items assessing the validity of the manipulations and were interviewed. The pre-tests revealed that the manipulations were successful in creating the desired treatment effect. Only minor adaptations were necessary and the dependent measures showed sufficient reliability.

\subsubsection{Sample}

The effective sample size ${ }^{3}$ of this study was 114 respondents. The sample consisted of $45 \%$ men and of $55 \%$ women. The age ranged from 18 to 26 with an average of 23 . Regarding the respondents' Internet experience, $52 \%$ has $2-3$ years experience, 30\% 45 years, and $18 \% 1-2$ years.

\subsubsection{Questionnaire Development}

All items were measured on a 7-point Likert-type scale using 'totally agree' and 'totally disagree' as anchors, and operationalized as described for the face-to-face encounter in paragraph 3.4.5. Table 3-6 presents all items as used in the study. Like in experiment 1, we performed a series of confirmatory factor analysis (CFA). From table 3-6, we can conclude that the dependent variables used in our study exhibit a high degree of unidimensionality and reliability (Cronbach's alpha). All originally specified items remained in the analyses, except for one item of enjoyable interaction. With regard to the validity of the variables, we found that all items loaded higher than .50 on their respective constructs with minimum t-values of 5.84. Furthermore, discriminant validity was evaluated by using chi-square difference tests with one degree of freedom to test for unity between the constructs. All tests were significant at the .05 significance level, thereby supporting the existence of discriminant validity.

\footnotetext{
'In total 6 observations, were classified as outliers and consequently deleted from the analysis.
} 
Table 3-6: Results of Confirmatory Factor Analyses for the Electronic Encounter

\begin{tabular}{|c|c|c|}
\hline Measures & Factor loadings & I-value \\
\hline \multicolumn{3}{|l|}{$\begin{array}{l}\text { Fit indices: (GFI=.91; AGFI=.88; RMSEA=.045; NNFI=,96; CFl=.97) } \\
\text { Satisfaction }(n=8 ; a=.95)\end{array}$} \\
\hline I am satisfied with my visit to the web-site & .88 & 12.13 \\
\hline The visit to the web-site was a good experience & .89 & 12.31 \\
\hline I am satisfied with the information I got during my visit to the web-site & .68 & 8.28 \\
\hline I am not happy with my visit to the web-site & .84 & 11.34 \\
\hline I regret that I went to the web-site of this virtual travel agency 3 & .70 & 8.60 \\
\hline My choice for the web-site of this virtual travel agency was a good one & .90 & 12.73 \\
\hline In general, I am satisfied with the web-site & .85 & 11.41 \\
\hline In general, I am salisfied with this virtual travel agency & .89 & 12.31 \\
\hline \multicolumn{3}{|l|}{ Enjoyable interaction ( $n=4 ; \alpha=.77$ ) } \\
\hline The web-site is humorous & .52 & 5.84 \\
\hline l enjoyed visiting this web-site & .62 & 7.14 \\
\hline I was comfortable visiting this web-site & .63 & 7.38 \\
\hline | felt at ease using this web-site & .92 & 12.25 \\
\hline \multicolumn{3}{|l|}{ Behavioral intentions $(n=4 ; \alpha=.95)$} \\
\hline I would recommend this web-site to others & .93 & 13.34 \\
\hline I would return to this web-site & .89 & 12.43 \\
\hline I would recommend this virtual travel agency to others & .94 & 13.59 \\
\hline I say positive things aboul this virtual travel agency to others & .90 & 12.56 \\
\hline
\end{tabular}

a Reverse coded.

\subsubsection{Results}

\section{Manipulation Checks}

Concerning the electronic encounter we find significant differences between the related humorous service process and the unrelated humorous service process $\left(\mathrm{F}_{1.112}=43.25, \mathrm{p}<.001\right)$, and between the favorable service outcome and the unfavorable outcome $\left(\mathrm{F}_{t, 112}=2491.60, \mathrm{p}<.001\right)$. Thus, the intended differences exist.

\section{Multivariate Analysis of Variance (MANOVA)}

To analyze the data of our experiment we performed a multivariate analysis of variance. Before we performed our actual MANOVA we conducted the same preceding analyses as described for the face-to-face encounter in paragraph 3.4.6.

\section{Preliminary Analyses}

In total we detected 6 outliers, which were subsequently deleted from the analysis. In addition, the analysis showed slight departures from a standard normal distribution, but we continued our analysis with the variables in their original form as MANOVA has shown to be robust against violations of the multivariate normal distribution. The Box's M test is in this case not very useful as described in paragraph 3.4.6. Furthermore, plots of all dependent variable pairs and dependent variable-covariate pairs indicated that there are linear relationships present. Inspection of the pooled within-group correlation matrix (table 3-7) indicated significant correlation coefficients between the dependent variables. 
Table 3-7: Pooled Within-Group Correlation Matrix ${ }^{\text {a }}$

\begin{tabular}{lccc}
\hline & Satisfaction & Enjoyable interaction & Behavioral intentions \\
\hline Satisfaction & 1.00 & & \\
Enjoyable interaction & .24 & 1.00 & \\
Behavioral intentions & .56 & .36 & 1.00 \\
\hline
\end{tabular}

" All correlations are significant at the .05 level.

\section{Hypotheses Testing}

In table 3-8, the results for the omnibus MANOVA test are presented. Based on these results we can state that there exists a slightly significant interaction effect between type of humor and service outcome $\left(\mathrm{V}=.07 ; \mathrm{F}_{3,108}=2.68, \mathrm{p}=.051\right)$. Furthermore, we may conclude that only service outcome exhibits a significant main effect $(\mathrm{V}=.83$; $F_{3,108}=178.576, p<.001$ ). Thus, for the electronic encounter service outcome explains the largest proportion of variance in the set of dependent variables (partial $\eta^{2}=.83$ ). Again, we performed univariate tests to further explore the relationships revealed by the omnibus MANOVA test. The results of the omnibus ANOVA tests for the dependent variables are presented in table 3-9 and the cell means in table 3-10.

Table 3-8: Results of Omnibus MANOVA Tests for the Electronic Encounter

\begin{tabular}{lcrrr}
\hline Effect & Pillai-Bartlett trace $(\mathrm{V})$ & $\mathbf{F}_{3,100}$ & p-value & Partial $\eta^{2}$ \\
\hline Main effects & & & & \\
Humor & .04 & 1.58 & .198 & .04 \\
Outcome & .83 & 178.58 & $<.001$ & .83 \\
$\begin{array}{l}\text { Two-way interaction } \\
\text { Humor"outcome }\end{array}$ & .07 & 2.68 & .051 & .07 \\
\hline
\end{tabular}

Table 3-9: Results of Omnibus ANOVA Tests for the Electronic Encounter

\begin{tabular}{llrrr}
\hline Dependent variables & Effect & $\mathbf{F}_{1,110}$ & p-value & Partial $\eta^{2}$ \\
\hline Satisiaction & & & & .02 \\
Main effects & Humor & 2.36 & .127 & .78 \\
& Outcome & 388.03 & $<.001$ & .02 \\
Two-way interaction & Humor"outcome & 2.45 & .120 & .03 \\
Enjoyable interaction & & & .091 & .62 \\
Main effects & Humor & 2.90 & $<.001$ & .05 \\
& Outcome & 180.89 & .015 & .03 \\
Two-way interaction & Humor"outcome & 6.06 & .077 & .79 \\
Behavioral intentions & & & $<.001$ & .04 \\
Main effects & Humor & 3.18 & .029 & \\
& Outcome & 401.39 & & \\
Two-way interaction & Humor"outcome & 4.88 & &
\end{tabular}

With regard to $\mathrm{H}_{1}$, we find that there are no significant differences in service encounter evaluation between respondents who experienced a service encounter with related humor and respondents who experienced a encounter in which unrelated 
humor was used. Hence, we have to reject $\mathrm{H}_{\mathrm{t}}$. Regarding $\mathrm{H}$, we may conclude that respondents who experienced a service encounter with a favorable outcome, evaluate the service encounter more positively on all evaluative criteria than respondents who experienced a service encounter with an unfavorable outcome. The results are as follows: satisfaction ( $t 112=19.44, \mathrm{p}<.001)$, enjoyable interaction $\left(\mathrm{t}_{112}=12.91, \mathrm{p}<.001\right)$, and behavioral intentions $\left(\mathrm{t}_{12}=17.91, \mathrm{p}<.001\right)$. We accept $\mathrm{H}_{2}$.

Table 3-10: Cell Means for the Electronic Encounter

\begin{tabular}{lrr}
\hline & Related humor & Unrelated humor \\
\hline Favorable outcome & Satisfaction: $5.89(.75)$ & Satisfaction: $5.89(.54)$ \\
& Enjoyable interaction: $5.45(.64)$ & Enjoyable interaction: $5.45(.91)$ \\
& Behavioral intentions: $5.66(.54)$ & Behavioral intentions: $5.66(.73)$ \\
Unfavorable outcome & Satisfaction: $3.43(.98)$ & Satisfaction: $3.01(.46)$ \\
& Enjoyable interaction: $3.77(.87)$ & Enjoyable interaction: $3.15(.61)$ \\
& Behavioral intentions $2.95(1.04)$ & Behavioral intentions: $2.35(.86)$ \\
\hline
\end{tabular}

The relationship stated under $\mathrm{H}_{3}$ does not hold. We find no significant differences in evaluative criteria between respondents who experienced a service encounter with a favorable outcome in which related humor is used and respondents who experienced a service encounter with a favorable outcome in which unrelated humor is used. Therefore, $\mathrm{H}_{3}$ is rejected. Concerning $\mathrm{H}_{4}$, we find small but statistically significant differences between the groups. In this case, respondents who experienced a service encounter with an unfavorable outcome in which related humor was used evaluate the service encounter more positively than respondents who experienced a service encounter with an unfavorable service outcome in which unrelated humor was used in terms of enjoyable interaction and behavioral intentions (enjoyable interaction: $t_{52}=2.72, \quad p=.009$; behavioral intentions: $t_{52}=2.10, p=.042$ ). Consequently, we accept $\mathrm{H}_{4}$ for two out of the three evaluative criteria. As described above, the cell means we used for the testing of $\mathrm{H}_{3}$ and $\mathrm{H}_{4}$ consist of both main and interaction effects. Since there is no significant main effect for type of humor, the differences between the cell means as found in testing $\mathrm{H}_{4}$ can be interpreted as interaction effects. Concerning $\mathrm{H}_{5}$, we find that there is a significant interaction effect (without including main effects) between type of humor and the outcome of a service encounter for the variables enjoyable interaction $\left(\mathrm{F}_{1,110}=6.06, \mathrm{p}=.015\right)$ and behavioral intentions $\left(\mathrm{F}_{1,110}=4.88, \mathrm{p}=.029\right)$. As can be clearly observed from figure 3-1 and 3-2, the relative difference between service encounters with a favorable and an unfavorable outcome is smaller in terms of enjoyable interaction and behavioral intentions when related humor is used than when unrelated humor is used. 
Figure 3-1: Graph of the Cell Means for Enjoyable Interaction in the Electronic Encounter

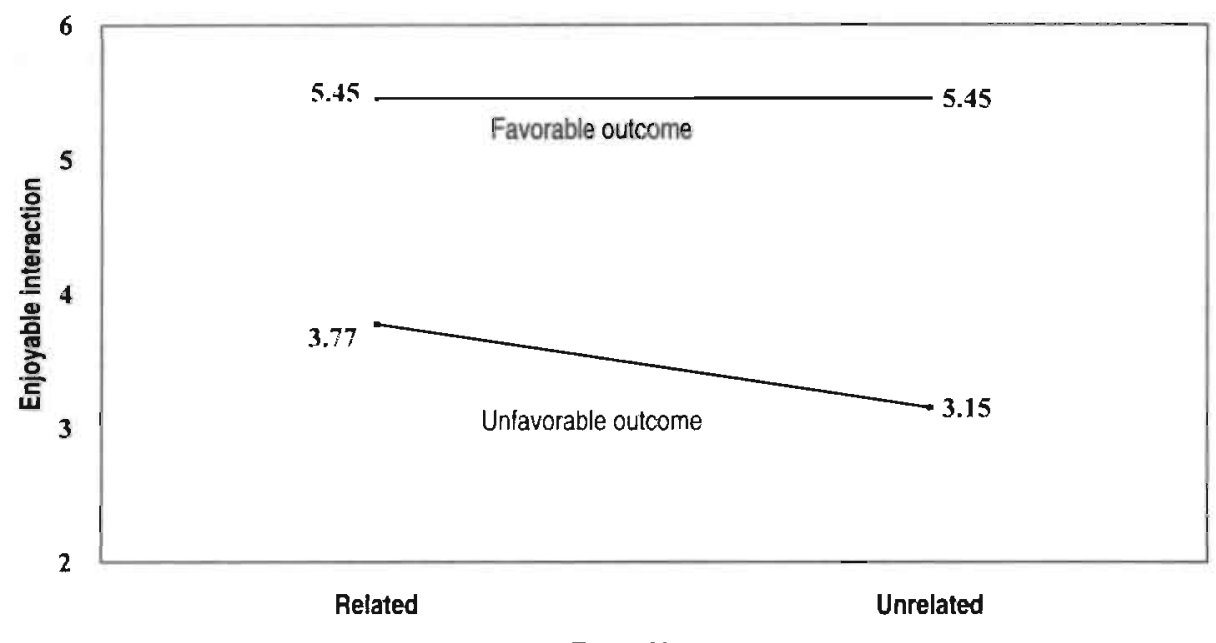

Type of humor

Figure 3-2: Graph of the Cell Means for Behavioral Intentions in the Electronic Encounter

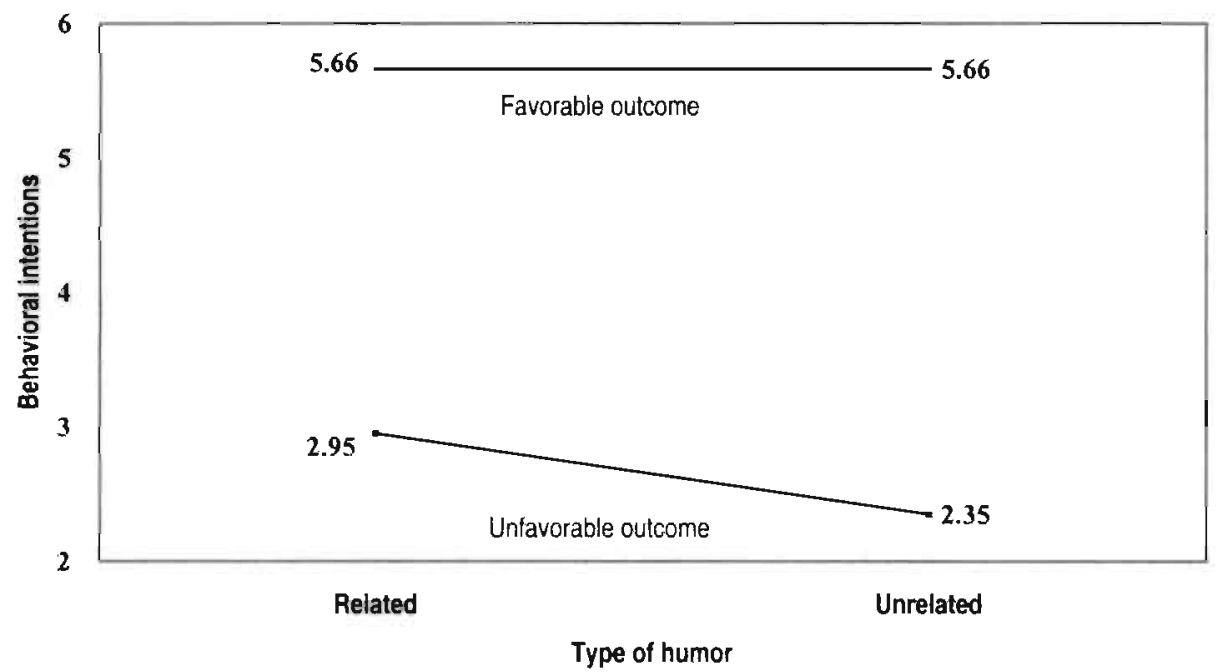

\subsection{Discussion}

This study was aimed at nuancing the intricate interplay between the type of humor used and the outcome of the service encounter in establishing customers' evaluations of face-to-face and electronic encounters. Various observations can be drawn from our results. Consistent with research on humor in the context of advertising and 
education (Spotts et al. 1997; Zillman and Bryant 1983), the results suggest that a related humor process increases the likelihood of a positive service evaluation by customers in a face-to-face encounter. With respect to the electronic encounter, we found that type of humor is not significant. This implies that there is no difference in effect for related and unrelated humor on customers' evaluations. Furthermore, in line with previous research in the area of services marketing, we find that the outcome of the service is an important determinant of customers' evaluations in faceto-face encounters (e.g., Brown and Swartz 1989; Lapierre 1996) as well as in electronic encounters. The relevant importance of outcome and process differ for the two modes of service delivery. Specifically, it is found that the impact of type of humor in a face-to-face encounter is more important than the outcome of the service encounter, whereas in electronic encounters, the impact of the outcome of the service encounter is more important than the type of humor.

The results for the face-to-face encounter support research that argues that process variables are considered as more important antecedents of customers' evaluations than service outcome dimensions in face-to-face service encounters (e.g., Brown and Swartz 1989). However, for enjoyable interaction a reverse result was found in the face-to-face encounter, i.e., outcome is more important than the type of humor. Gremler and Gwinner (2000) state that enjoyable interaction is an assessment of the relational aspects of service. They suggest three strategies to achieve an enjoyable interaction: 1) relating to a customer's needs, 2) caring about the customer's service outcome, and/or 3) using humor to place the customer at ease. As it appears from our study, humor does not influence enjoyable interaction, though these other strategies might be of influence. The relative importance of outcome in our study may be an indication of the importance of the second strategy. Also, Johnson and Zinkhan (1991) demonstrate that service outcome may trigger affective reactions. Finally, with respect to the relatively small effect of type of humor on enjoyable interaction, it might well be that the sense of humor of the respondents has a moderating effect on this relationship. Previous studies have shown that various individual characteristics may differently determine humor's effectiveness (Moran and Massam 1999; Myers et al. 1997). In line with this, Kirsner (1997) describes how an on-line service provider even uses humor to categorize users into particular types and to delliver appropriate personalization on their web-site.

The finding that the impact of the outcome of the service encounter is more important than the type of humor for on-line customers might have to do with the mode of service provision. It has been argued that on-line shopping in its present. stage is more likely to be goal-focused and driven by utilitarian motives rather than. experiential and hedonic. Goal-focused shoppers are transaction-oriented, they shop only when they have a specific purpose in mind, and they desire to purchase what. they want quickly (Wolfinbarger and Gilly 2001). Consequently, the occurrence of the desired outcome may be especially important.

With respect to interaction effects, we failed to find them for the face-to-face encounter. This implies that type of humor and service outcome do not strengthen or weaken each other in their effect on customers' evaluations. One explanation for the lack of interaction effects might be the type of service. In the context of our study, a 
customer can effectively separate his or her process and outcome evaluations, as the interpersonal and outcome elements of the travel service encounter are relatively distinct (as opposed to, for instance, medical services) (cf., Gremler and Gwinner 2000). Hence, it is possible for a customer to appreciate the process (e.g., related humor), but to rate the outcome negatively (and vice versa). While related humor is an important determinant of evaluative judgments in face-to-face encounters, it does not weaken the negative effect of an unfavorable outcome. Therefore, humor may be a value-added feature but may not be a substitute for outcome.

In electronic encounters, the effects of type of humor and outcome strengthen each other with respect to customers' evaluative judgments. This suggests that the nature of the outcome of an encounter influences the way in which the humor is evaluated. The relative difference in enjoyable interaction and behavioral intentions between service encounters with a favorable outcome and an unfavorable outcome is smaller when related humor is used. This might indicate that related humor can partly compensate for an unfavorable service outcome. So, although on-line customers may be likely focused on the occurrence of a favorable outcome, in case of an unfavorable outcome, the use of related humor (compared to unrelated humor) may weaken the negative effect of the unfavorable outcome. It might be that because of the unfavorable outcome, the customer focuses more on the site and its design, and the fun experience caused by the service-related comic strips and cartoons may create some positivity. In the same line of reasoning, we might conclude that in case of an unfavorable outcome the use of unrelated humor creates lower evaluative judgments than related humor. This might support research in the context of education which states that unrelated humor might cause annoyance (Hezel et al. 1982) and consequently magnifies the effects of an unfavorable outcome. It should be noted, however, that these patterns do not appear to apply to customer satisfaction. In other words, an unfavorable outcome lowers customer satisfaction and this effect can not be offset and/or will not be maximized by the type of humor used. Apparently, this type of customer evaluative judgment differs from the enjoyable interaction and behavioral intentions criteria. So, in case of an unfavorable outcome, the customer is less satisfied and the type of humor used does not influence this. However, in these circumstances, related humor does create a more enjoyable interaction and increase the intertions of the customer to return and to recommend the web-site.

\subsubsection{Suggestions for Future Research}

Several limitations to our research project have to be recognized. These may point to future research issues. The first limitation relates to our design. It pertains to a 'laboratory experiment' and consequently, the generalizability of the findings is limited with regards to senings outside the laboratory. Furthermore, the use of an experimental design is subject to a possible lack of realism. Even though the results of the manipulation checks show desired treatment effects of type of humor and outcome, there may be a difference between simulation and real experience, affecting the way in which respondents react to the situation. Future research extending our findings to experimental designs that make use of existing web-sites and real service 
employees in real service settings may yield additional insight into external validity.

Also, future research should explore the issues introduced in our study over a broader set of services, as the focus was limited to the travel industry only. Ir may be that the impact of type of humor as well as output behaves differently depending on the type of service and an important question is whether the humor and outcome dimensions are significant in every service industry (Powpaka 1996). For example, in our study it is possible to evaluate the outcome of the service accurately, but in case of experience and credence services this is much more difficult (Ford et al. 1988). Also, the measurement of personal characteristics such as sense of humor might yield a further insight into the relationships between the variables that were introduced in our research design.

Our study was limited to the role of type of humor and outcome. However, it can be argued that customer perceptions of satisfaction, enjoyable interaction, and behavioral intentions may be influenced by more than just humor and outcome. Also, the impact of other marketing mix variables, such as price, should be taken into account to investigate drivers of consumer return intentions and actual behavior.

Furthermore, based on advances in attribution theory (e.g., Bitner et al. 1990; Meuter et al. 2000), it can be argued that customers' inferences concerning the cause of an unfavorable outcome during encounters may considerably moderate customers' evaluations. For instance, in electronic encounters, the customer might interpret an unfavorable outcome caused by a server break-down differently from a nonavailability of the product or service. Future research should take the impact of such attributions into account.

In addition, more research is needed with respect to the determinants of enjoyable interaction. Gremler and Gwinner (2000) suggest three strategies. Whereas we find that type of humor is hardly of influence, we find an indication of the importance of caring about the customer's service outcome. However, we did not measure customers' perceptions of these strategies directly. Therefore, an important contribution to the understanding of creating an enjoyable interaction could be made by exploring the customers' perceptions of these strategies.

Future research also may investigate other dimensions of humor. In addition to related versus unrelated humor, some research has focused on the relevance of humor. Relevant humor helps to make a critical point (Hezel et al. 1982). Although this distinction might be more useful in interactions with an instructional character, it might be important to services too.

Finally, we could not make comparisons between the face-to-face and the electronic encounter, as the experimental conditions of the two encounters are not the same. For the face-to-face encounter, subjects watched a video and 'passively' experienced the service. The electronic encounter was different in that respect and perhaps more a realistic situation as the respondent was actually sitting behind the computer and could experience the service him or herself. Future research which uses video-tapes for both modes of service delivery or allow respondents to experience both modes actively might avoid this problem. 


\subsubsection{Managerial Implications}

Our findings have several managerial, implications. Our study identifies that service outcome is an important dimension in assessing customers' evaluations of face-to-face and electronic encounters. Therefore, managers should focus on strategies to ensure that employees can deliver a favorable service outcome by for example training, and design of systems and organizational structures. Especially in electronic encounters, it is of utmost importance to make sure that the technology works and that the service or product as offered is available. Although it has been suggested that the more enjoying, hedonic aspects of the electronic encounter play a crucial role too (Childers et al. 2001), this has not been found in our study. This suggests that design characteristics must focus on the creation of a favorable outcome. Web-sites that are efficient, well-structured, and reliable might be helpful to this. In addition, customers sometimes require help to get the desirable outcome. Call-centers, e-mail, or chat assistance may help to satisfy this need.

While the instrumental aspects of the electronic encounter are the most important predictors of on-line evaluations, the type of humor included at the web-site may play a role too. Those firms that include humor at their web-sites should focus on related humor. That is, compared to unrelated humor, related humor may partly compensate for an unfavorable outcome and it does not influence a favorable outcome (either negative or positive). As in our experiment, this could be accomplished by including comic strips, cartoons, a joke of the day, and funnies. However, it is of crucial importance to design humorous aspects that are related to the service, otherwise the negative effect of an unfavorable outcome is maximized.

In contrast to electronic encounters, in face-to-face encounters the type of humor plays an important role and has even a stronger impact than outcome on customers' evaluations of satisfaction and behavioral intentions. Therefore, managers should encourage employees to use related humor in their service encounters with customers. Since it has been suggested that sense of humor is largely innate, it is important for employees to adapt their humorous behavior to the needs and sense of humor of the customer. With respect to this, training focusing on 'adaptive behavior' as suggested by Spiro and Weitz (1990) might be useful. Role-playing exercises in which the employee is trained to make jokes and funny remarks that are related to the service (s)he provides might be a practical tool to enhance this behavior. Furthermore, since an employee has a sense of humor which is innate too, it follows that employee selection should be considered carefully (Prince and Davies 2001). The employee's use of humor should be considered in conjunction with a focus on outcome. 


\section{Chapter 4}

\section{Moderated Group Chat: An Empirical Investigation of a New Marketing Tool}

This chapter introduces the idea of moderated group chat (MGC). MGC is defined as on-line, real-time interactions between groups of customers with an active role for a company representarive and a commercial goal. Based on theories from the fields of marketing, computer-mediated communication (CMC), group dynamics, and leadership, we develop a theoretical research model and examine empirically which factors determine customer satisfaction with MGC. Specifically, we focus on the influence of characteristics of consumers and the group, and we take into account two relevant contingencies: 1) the style of the advisor, and 2) group-level processes. While our findings indicate a positive influence of consumer and group characteristics on satisfaction, the exact nature of the predictor-criterion relationships varies across style and levels. This suggests that during chat sessions the role of the advisor is of paramount importance and that certain processes operating at the group-level influence chat session satisfaction. 


\subsection{Introduction}

Despite the critical impact of communication and information technology on the marketing strategy of companies, it is increasingly acknowledged that the focus on 'high tech' needs to be accompanied by an emphasis on 'high touch' (Naisbitt et al. 2001). As a result, firms are gradually moving away from both the emphasis on disintermediated transactions and the elimination of sales and service representatives and other middlemen, which has been characteristic of e-commerce business models so far (Albrecht and Zemke 2001). Following many bad service and sales reports, web-customers are demanding real-time integration and human service in addition to automated cyber sale transactions and software agents. More and more companies are responding to the help-seeking behavior of on-line customers by exploring interactive and collaborative e-business functionalities as part of what might be called a 'servicemediated e-commerce strategy'. The success of such a strategy depends largely on the orchestration of innovative real-time customer contact options and interactive technology, such as 'call-back' options, direct messaging, message board tools, software that enables co-browsing with friends and sales reps, and Internet Relay Chat (IRC) sessions (Murphy and Collins 1999). As a consequence, there has been a massive increase, not only in interaction between company and customers, but also among customers themselves, who are drawn together by mutual interest in a commercial endeavor (Hagel and Armstrong 1997). Therefore, businesses need to consider the implications of the extended scale and scope of dialogue in the electronic market place by exploring the web's potential for this so-called multi-way interaction (Bressler and Gantham 2000; Rothaermel and Sugiyama 2001).

Many e-commerce sites have been experimenting with IRC. The on-line unit of catalog retailer Lands' End, for instance, has introduced a chat service that allows customers to interact with fashion and retail experts. Investment banks like Merrill Lynch and Citibank have launched IRC services in which investors communicate with each other and portfolio specialists in Q\&A sessions or in on-line financial seminars (Information Week 2001). The growing customer segment that manages its assets on-line expects their financial service provider to provide the convenience of these on-line seminars. It is reported that real-time human interaction is the finishing touch, the difference between closing a sale and closing a web-site (Spiegelman 2000). Companies report that visitor to buyer conversion is considered above average for those companies with the possibility to chat on their web-site (Business Week 2001). Other frequently mentioned commercial benefits of real-time interaction are customer loyalty, information targeting, product/service customization, real-time feedback gathering, and cross-selling (Kenny and Marshall 2000; Muniz and O'Guinn 2001; Rifkin 2000; Sivadas et al. 1998; Wolfinbarger and Gilly 2001). However, these high hopes still need to be substantiated and nuanced empirically. IRC has also been associated with electronic chit-chat, uninhibited behavior, group think, and privacy and security concerns (Curtis 1997; McWilliam 2000). In order for IRC to become an effective marketing tool, companies face the challenge of creating a user-friendly, secure and collaborative environment (Hoffman 2001).

So far, substantive research on IRC has pertained almost exclusively to non- 
commercial settings and remained predominantly exploratory in nature (Garcia and Jacobs 1999; Vronay et al. 1999). To the authors' knowledge, systematic research regarding commercial chat is sparse and companies adopting IRC may find themselves in uncharted waters. Therefore, we need to closely examine customer's evaluative judgments in order to be able to correctly assess the effectiveness of this new channel (McWilliam 2000). In such an examination, it seems specifically relevant to take two unique contingencies of multi-way interaction of commercial IRC into account. First, since IRC involves group communication and forms a social environment, predictor-criterion relationships may vary between individual perceptions and group-level (shared) perceptions. Therefore, we need to explicitly consider the influence of higher-level constructs on individual-level judgments (Kozlowsky and Klein 2000). Secondly, since marketing applications of commercial IRC are frequently company-hosted and moderated, we need to examine the influence of the moderator on customers' evaluations. As research in computermediated communication (CMC) and off-line groups has shown, the behavior (or style) of moderators has a decisive influence on group performance parameters (Fiedler and House 1988; Forsyth 1999). Taking these issues into account, the objective of this chapter is to investigate which factors determine customer's evaluative judgments with on-line chat sessions in a commercial context. It is structured as follows. Based on a synthesis of the literature on key issues, we develop a theoretical research model for explaining customers' evaluations in commercial chat groups and delineate a series of hypotheses and research questions. Next, we assess this framework empirically, using multiple levels of analysis. We conclude the chapter with a discussion of the results, and the theoretical and managerial implications.

\subsection{IRC as a Marketing Instrument}

Chat sessions provide an on-line social environment in which computer-mediated interactions between people take place. They allow for synchronous information exchange and social interactions. Communication consists usually of written text, but may also be audio-visual. Chat sessions are scheduled or unscheduled, take place in real-time and, therefore, enable conversation that feels more genuine, more substantial, and more human than many other Internet channels (Levine et al. 2000). These features make IRC appropriate for service-mediated e-commerce strategies. Recently, the need for real-time customer contact has catalyzed a variety of IRC applications aimed at enhancing electronic selling and service environments.

In the first place, IRC has been implemented to help customers in case they have questions and problems with finding information or ordering. Mostly, these sessions are dyadic and customer-initiated. Companies that use this type of customer serviceoriented IRC are Berries.com, ESL Federal Credit Union and Dealergain (e.g., Business Week 2001). Customer service representatives provide customers with realtime info in response to individual questions. For instance, using chat at Lands' End's 
site, a customer can get: quick answers to questions about products, shipping, costs and delivery time. Appropriately termed software like 'Humanclick' and 'Livelink' allows for co-browsing, and a service representative can send screens of information to the customer. Furthermore, companies can watch visitors and push a dialog box to them at any time, giving information or advice. For example, a relatively new service called 'Icontact' tracks consumer's movements through web-sites and employees step in if they believe they are needed. Wolfinbarger and Gilly (2001) report that this service increased sales at the Marriott site by $400 \%$ in the first two months of use.

Secondly, IRC takes place in groups in open virtual chat rooms, which are frequently part of company-hosted virtual communities. The interaction during these chat sessions is customer-initiated with a reactive and passive role for the company. The sessions are often user- or interest-based; groups of customers chat together and share information about common interests. Many of these groups are unmoderated and have limited commerce abilities. In fact, their notion of sharing may often be antithetical to commerce (Wolfinbarger and Gilly 2001). Although company-hosted, these chat rooms often present a social environment. The commercial relevance is determined by the extent to which companies use the sessions to build communities and to extract relevant information about products or services. For instance, Petsmart.com allows pets lovers to exchange tips and to share their affection for pets. Orher examples can be found at Garden.com, Travel-o-city, and E"trade (Walsh and Godfrey 2000). An increasing number of firms is analyzing 'multi-logues' of open chat rooms to identify trends before they take shape (McKeown 2002).

A third application of IRC are training sessions and seminars which are organized on-line. These sessions have the form of one-to-many communication, initiated by the company, and are less interactive. This application is analogous to the off-line situation of commercial group meetings, like financial seminars. The on-line sessions take place for several purposes like promotion, pre-sales, training, and advice, and can be free or subscription-based. They are organized in business-to-consumer as well as business-to-business settings by companies like Merill Lynch and Mail Boxes Etc. (New York Times 1998). IBM used this form of IRC to guide the launch of a new hardware product to 2000 industrial customers worldwide. VictoriaSecret.com invites customers to join their on-line fashion show (Walsh and Godfrey 2000).

A final category of commercial IRC is moderated group chat (MGC). MGC is company-initiated, with an active role for the company representative as well as for all other participants. It has a many-to-many communication structure, similar to web conferencing. The sessions are scheduled discussions in which participants share their experiences with peers. There is a host who sets the agenda, offers expert advice, and moderates the discussion. The analogous off-line situation are commercial meetings like Tupperware parties. The advisor uses the group meetings to gain trust and interest in the product from prospects as well as from existing customers and to sell directly or to get an appointment for further interaction. Pristine Real Time Trading, which organizes an on-line trading room, is an example of MGC; customers subscribe for the service and in return they can participate in sessions to receive tips from the company, as well as from fellow investors (New York Times 1998). Another example of this IRC application can be found at Petsmart.com, which organizes 
group chars moderated by an expert in pet-care in addition to the open chat sessions, as described above.

In this chapter, we focus on the latter application of IRC. It is the blending of controlled group interaction with commercial interests, which may provide a company with a unique and an effective marketing tool. MGC combines two important features; it is moderated and it has an interactive, communal nature. This combination results in a unique set of advantages. First, the moderation creates a controlled environment, which may provide security and trust (Handy 1995). In addition, the lack of a concealed identity in combination with a common interest and commitment may avoid privacy concerns and disadvantages, like uninhibited behavior.

Secondly, information shared in a group may have greater credibility. Opinions and testimonials voiced by other customers are likely to be judged as trustworthy, as they come from sources which have no vested interest in the product nor intentions to manipulate the other customers (Bickart and Schindler 2001). It has been argued that particularly in the e-commerce arena audiences mistrust predictable and remote corporate messages, and that credibility increases when corporate content is complemented by customer content (Levine et al. 2000; Tidwell and Wickre 2001). The credibility of the moderator will be positively influenced by the fact that (s) he 'risks' a presentation in a group, with a chance of critical comments by customers in front of everyone.

Thirdly, information will be more relevant as the discussion is focused by the moderator. Multiple perspectives related to the topic are discussed with little possibility for chit-chat, as could happen in other forms of IRC. Relevance of information is suggested to be an important determinant of sharing behavior on the web and of customers' evaluations (Barua et al. 1997; Hagel and Armstrong 1997; Maltz and Kohli 1996). This increase in relevant information also reduces information asymmetry between advisor and consumer.

Fourthly, chatting in groups has a great ability to generate enjoyment among participants. Research demonstrates that other customers may have a positive impact on the atmosphere during the interaction (e.g., Grönroos 1990; Grove and Fisk 1997) and the ability to create a vicarious and personal experience (Deighton et al. 1989). Also, the joys of a particular product described by one cuscomer could directly generate similar feelings in the mind of others (Bickhart and Schindler 2001). A company can use this for setting up a group promotion based on group affiliation. When customers are reluctant, it may be feasible to change their views through the use of social pressure by having them see that others are favorably disposed (Grikscheit et al. 1993).

Finally, it may be cost-effective for companies; the advisor can deliver his or her message to more people in the time (s)he has available. If the advisor masters the principles of promoting to (chat) groups, the sales volume may increase (Grikscheit et al. 1993).

In addition to the advantages specifically related to $\mathrm{MGC}$, the benefits commonly associated with on-line communication in general hold as well. It is more convenient and time effective for customers, it may facilitate their expression of opinions, conversation history can simply be retrieved, and consumers can easily keep in contact. This latter possibility of forming relationships with other customers and with the contact facilitator may draw consumers back to the site on a frequent and regular basis (McWilliam 2000). Companies can reach more geographically dispersed 
and different market segments. It may gain crucial customer information for following-up with customized offerings, for launching new products, for product development, and for evaluating chat sessions.

In sum, MGC may provide customers and companies with certain advantages that are unique to the specific combination of moderation and on-line group communication. Therefore, it may develop into an important marketing tool. In moderated group communication, three factors seem to be of specific influence, i.e., the consumer, the group, and the moderator. In the next section, we will elaborate on how these factors may influence customers' evaluations in commercial chat groups.

\subsection{Development of a Theoretical Research Model}

With respect to customers' evaluations in on-line environments, customer satisfaction seems to be as critical as an effectiveness parameter as in off-line environments (e.g., Buskin 1998; Szymanski and Hise 2000). In addition to the accumulating body of research evidence, the importance of satisfaction is also explicitly recognized by practitioners (Ernst and Young 1999; Jupiter Research 2001). Frequently, a distinction is made between overall e-satisfaction and encounter e-satisfaction (Shankar et al. 2000). In this study, the focus is on the latter, i.e., satisfaction with the discrete chat session. In this way, we conceptualize participant chat session satisfaction as a post consumption and evaluative response. Although the antecedents to customer encounter satisfaction are well documented in off-line contexts (e.g., Oliver 1997), customer sarisfaction with respect to e-retailing in general and MGC in particular, has not been subjected to conceptual development or empirical study (Szymanski and Hise 2000).

To provide initial evidence for the determinants of satisfaction with chat sessions, we adopt a number of theoretical lenses and review the literature from marketing, $\mathrm{CMC}$, group dynamics, and leadership that advances satisfaction as an effectiveness measure. In line with these disciplines, three types of antecedents can be discerned that may influence satisfaction. First of all, research has identified consumer characteristics as antecedents to consumer evaluations of (technology mediated) service delivery (Bitner 1992; Dabholkar 1996; Zeithaml et al. 1993). A second group of antecedents pertains to the group characteristics: intra-group processes that take place among the individual members of a group (Campion et al. 1996). These reflect factors like group cohesion and group-efficacy. Finally, the behavior of the moderator in the group may impact customer satisfaction (e.g., Bass 1997; Mason 1997; Price et al. 1995a). In the chat sessions under study, the moderator not only moderates the interaction but (s)he also provides information and expert advice. Therefore, the term advisor seerns more appropriate.

Furthermore, within each of these three groups of antecedents, research has suggested a classical dichotomy that has been confirmed across settings, time, and culture: task-related versus social-related (Beatty et al. 1996; Forsyth 1999; Waldersee et al. 1995). Task-related antecedents refer to the goal of the interaction and social- 
related antecedents to the social aspects of the interaction. Commercial MGC is essentially a social environment with a goal-oriented connotation and therefore, both dimensions will be reflected in our study variables.

\subsubsection{Consumer Characteristics}

Since satisfaction is an individual, subjective judgment, the idiosyncratic consumer characteristics that the consumer brings to the interaction will influence chat session satisfaction. As the extent of customer participation and input in chat sessions is substantial, the influence of customer characteristics and, hence, subjectivity might be significant too. In the technology adoption and marketing literature, it is proposed that, in case of new services, consumer characteristics can affect both how consumers evaluate the service interaction and how they perform during the encounter, e.g., their actual input (e.g., Dabholkar 1996; Lockett and Littler 1997). In this study, we define consumer characteristics as unique attributes of the customer that (s)he brings to the interaction. The characteristics may explain individual differences in perceptions of the same event. Four types of variables have been advanced as important customer characteristics in relation to (technology-based) service delivery: the social benefits that consumers associate with the use of interactive on-line services, the functional benefits of such services, self-efficacy perceptions of customers, and customers' feelings of comfort with social (on-line) environments (Dabholkar 1996; Dellaert 2000; Hoffman 2001; Ramaswami et al. 1998; Savicki et al. 1998). Whereas functional benefits and self-efficacy may be labeled as task-related characteristics, social benefits and social comfort are social antecedents.

\section{Social and Functional Benefits}

The concept of benefits rests on the idea that consumers use products and services on the basis of the benefits they desire (Gutman 1982; Haley 1968; Reynolds and Gutman 1984). Many researchers suggest two primary categories of benefits: social and functional benefits (Adelman et al. 1994; Beatty et al. 1996; Berry 1995; Bitner 1995, Gwinner et al. 1998). Social benefits relate to the fact that consumers may be interested because they value the social aspects of the interactive services and they enjoy the company of a salesperson or other customers on-line, which has been identified as a reason to participate in chat sessions (Rothaermel and Sugiyama 2001; Utz 2000). On the other hand, consumers may use interactive services because of the convenience they offer or because of the benefits of input delivered by other customers, i.e., the functional benefits. Several service studies found significant relations between benefits and customer satisfaction (e.g., Gwinner et al. 1998; Reynolds and Beatty 1999). Also, research of on-line consumer behavior demonstrates the importance of the benefits that customers derive from on-line interpersonal interactions (Dellaen 2000).

The chat session as a commercial tool is fairly new and a situation that many consumers probably have not yet experienced. In such cases, people tend to make judgments about the new situation based on similar or related phenomena. Empirical studies have shown the existence of generalized judgments and its influence on the 
evaluation of a new situation (Dabholkar 1996; Lockett and Littler 1997; Park and Lessig 1981). Therefore, we argue that the benefits customers associate with the use of interactive services in general will positively influence customer's chat session sarisfaction. We hypothesize:

\section{H: Social benefits associated with the use of interactive services will positively influence participant chat session satisfaction.}

$H_{2}$ : Functional benefits associated with the use of interactive services will positively influence participant chat session satisfaction.

\section{Self-Efficacy}

The technology adoption literature suggests that consumers' self-efficacy is important in computer-mediated interactions (Eastin and LaRose 2000; Webster and Martocchio 1992). Self-efficacy is defined as "people's judgment of their capabilities to organize and execute actions required to attain designated types of performances" (Bandura 1986 p. 391). Bandura's theory (1977) proposes that efficacy beliefs are task specific. In other words, this concept focuses on one's belief of being able to perform a specific task. It has been demonstrated that self-efficacy is positively related to satisfaction offline, as well as in virtual environments (Staples et al. 1998). Although self-efficacy may refer to several aspects (e.g., Webster and Martocchio 1992) we define selfefficacy, in the context of MGC, as the consumer's judgment of his or her knowledge and skills regarding the product or the service. For instance in the example of Pristine Real Time Trading, it relates to the knowledge and skills regarding investing. Since sharing and exchanging product knowledge is a substantial aspect of commercial chat sessions, we argue that the extent to which customers feel they are knowledgeable with respect to the topic of the chat session will influence their satisfaction. We formulate the following hypothesis:

\section{H: Self-efficacy beliefs will positively influence participant chat session satisfaction.}

\section{Social Comfort}

In addition to knowledge and skills associated with the product or service, it seems important to examine users' comfort with on-line group interaction and asking other customers for advice. Hence, a person might believe (s)he has skill and knowledge with respect to investing, however may not feel comfortable in sharing this knowledge. Similarly, one might not want to demonstrate ignorance by asking others for advice on a particular topic. So, whereas self-efficacy relates to the content of the chat session, comfort refers to the social environment of MGC. In an off-line setting, Butcher et al. (2001) found that social comfort, i.e., the customer's feeling of relaxation arising from the social interaction, significantly influences encounter satisfaction. Wanberg et al. (2000) demonstrate that a person's feeling of discomfort may form an attitudinal barrier to ask others for advice. In the context of commercial $\mathrm{MGC}$, a consequence of feelings of social discomfort might be that a customer 
becomes a 'lurker', absorbing information but not actively participating in the group process of asking and sharing information. People who feel comfortable asking questions are likely to be more satisfied since their specific questions and concerns will be addressed. We formulate the following hypothesis:

\section{$H_{*}: \quad$ Social comfort will positively influence participant chat session satisfaction.}

As stated above, the basic idea is that customer satisfaction with the chat session is not only dependent on the input associated with the individual, but also with that of the group. The influence of group characteristics is discussed in the next section.

\subsubsection{Group Characteristics}

In this study, we define group characteristics as perceptions of customers regarding several aspects of the group process during the chat session. Specifically, we focus on four variables: group task communication style, group social communication style, group cohesion, and group-efficacy. Whereas task communication style and groupefficacy refer to the task-related aspects of the chat session, social communication style and cohesion are social antecedents.

\section{Group Communication Style}

In research on off-line groups, the distinction between task and social communication has often been made (Barry and Stewart 1997). In CMC research, of which chat is an example, this distinction is also common (Burke and Chidambaram 1995; Whitworth et al. 2000). Different concepts have been used to describe the dichotomy of taskoriented versus social-oriented (Bales 1950; Deutsch and Gerard 1955; Hogg 1992; Spears and Lea 1992; Sproull and Kiesler 1986). A group with a social communication style shows solidarity, agreement, and focuses on personal relationships and the social aspects of chatting. A group with a task-oriented communication style focuses on the task and on getting and sharing task-related information.

In research on off-line groups, group task communication has been associated with performance, whereas group social communication has been associated with satisfaction (e.g., Forsyth 1999). In CMC research on the other hand, the results regarding this relation between group communication and satisfaction are varied. For instance, researchers argue that social aspects are hardly communicated in CMC. Social information processing theory (e.g., Walther 1992) indicates that social communication slows down while communicating via computers because of the limited bandwidth and the requirement of typing. Also, social presence theory suggests that fewer non-verbal cues will lead to lower social presence (Short et. al. 1976). Their focus is on task communication; CMC enables more exchange of information, which leads to a better advice and therefore results in greater satisfaction (Miller and Monge 1986). However, the finding that CMC is perceived as less social than face-to-face communication is not found in all available studies (e.g., Whitworth et al. 2000). It has been contended that social communication is an essential ingredient of on-line interactions by serving as feedback regarding the relations in the group and 
communicating empathy (Preece 1999). Further, Kahai and Cooper (1999) found that task as well as social communication both influence satisfaction. In line with this result, we formulate the following hypotheses:

\section{Hs: Group task communication style will positively influence participant chat session satisfaction.}

\section{H6: Group social communication style will positively influence participant chat session satisfaction.}

\section{Group Cohesion}

Recently, research on group CMC has proposed to extend the classical task versus social dichotomy by adding a cohesiveness dimension (Reid et al. 1996; Whitworth et al. 2000), thereby matching an earlier three-way division (Benne and Sheats 1948). In a study of computer-mediated groups using the task and socio-emotional dichotomy of Bales (1950), the authors concluded that, with regard to social inputs, it is important to differentiate acts that express agreement and emotional state from those linked to group formation and cohesiveness (Reid et al. 1996). A similar result was found in an earlier study of CMC using Bales' system (Hiltz et al. 1986). Also in off-line environments, this nuance in social inputs has been suggested (Hogg 1992; Spears and Lea 1992). Therefore, in this study, we focus on group cohesion in addition to social communication.

Group cohesion is typically analyzed in terms of affective bonds among group members and members' desire to remain in a group (e.g., Kidwell et al. 1997). Many studies in several disciplines have demonstrated the importance of group cohesiveness in influencing group processes and outcomes, especially satisfaction (e.g., Forsyth 1999). Reflecting upon these results, we contend that group cohesion may positively influence chat session satisfaction:

\section{H: Group cohesion will positively influence participant chat session satisfaction.}

\section{Group-Efficacy}

The research that demonstrates the importance of group communication and cohesion also stresses that these variables are only some of the dimensions affecting the interaction (Williams and Spiro 1985). Another theoretical construct that has regularly appeared in research on groups as an important influencer of satisfaction is group-efficacy (Riggs et al. 1994). Whereas group cohesion relates to the social aspects of chat, group-efficacy refers to task aspects. Although not often researched in the context of $\mathrm{CMC}$, we argue that group-efficacy beliefs may be important in the context of chat sessions as well. In addition, it was found that efficacy beliefs in reference to the self are independent from efficacy beliefs in relation to the group of which one is a member (Bandura 1986; Riggs et al. 1994). Group-efficacy beliefs refer to an individual's assessment of the group's collective ability to perform task-related behaviors. For example, in the context of MGC in which customers and the advisor discuss about investing, group-efficacy refers to the customer's judgment of the 
group's knowledge and ability regarding investing. The added value of chat sessions comes partly from the relevant and interesting input of other customers ( $\mathrm{Hagel}$ and Armstrong 1997). Therefore, the extent to which customers feel that other participants are able to offer interesting information will influence their satisfaction. This is reflected in the following hypothesis:

\section{Hs: Group-efficacy will positively influence participant chat session satisfaction.}

The role of the advisor is an important and beneficial input for commercial MGC. In the next section, we discuss its potential influence on customers' evaluations.

\subsubsection{Advisor Characteristics}

Many studies suggest that the role of the moderator or advisor is crucial for the success of customer interaction (Bitner et al. 1990; van Dolen et al. 2002). Especially in settings in which customers participate in the service delivery, the advisor must develop mechanisms for managing its participants to ensure efficiency and satisfaction as perceived by all customers involved in the chat session. In this study, we focus on the advisor's management of the interaction by his or her communication style: social-oriented and task-oriented.

\section{Communication Style}

In earlier research, the distinction between task-oriented and social communication has not only been made with respect to the group but also with respect to the one who is leading the group (e.g., Fiedler and House 1988; Forsyth 1999; Mann 1959). Again, a number of different concepts have been used, closely related to this dichotomy (Bales 1958; Blake and Mouton 1982; Sheth 1976). An advisor with a taskoriented communication style is highly goal-oriented and focuses on fulfilling responsibilities and on satisfying concerns for a productive outcome. Social communication is more personal (Bass 1990), and focuses on interpersonal relationships and on the process of satisfying group members' emotional needs.

The leadership literature regarding the effect of communication style on specific outcomes provides evidence that a social style is positively related to satisfaction, whereas a task-oriented style highly is related to performance, i.e., achieving goals (e.g., Bass 1990). Services studies also suggest that customers are more likely to associate satisfaction with the provider's expression of social behavior than with the provider's task behaviors (Roberts and Aruguette 2000). Task behaviors are more likely associated with compliance, recall of information, and performance measures than with satisfaction (Hall et al. 1988).

The importance of a social-oriented communication style of the advisor to create satisfaction might become even more salient in MGC. CMC research suggests that the role of the moderator of on-line activities typically involves special responsibilities and authorities (Mason 1997), compared to face-to-face interactions. Also, Berge (1992) notes that the on-line moderator takes on various roles; (s)he has to focus not only on the task but also has to be a facilitator, manager, expert, 
marketer, and helper. In addition, chat sessions are voluntary. Many voluntary group meetings fail because leaders want to run the group as they see fit. Volunteers usually will not tolerate this type of leadership for very long (Johnson 1994). A task-oriented advisor is likely to manage the group by keeping them focused on the task. A socialoriented advisor will be less forceful and support socializing if that seems to be what the group wants. In line with this and the results of the leadership and service literature, we formulated the following hypothesis:

\section{Ho: Participants in groups with an advisor with a social communication style will be more satisfied with the chat session than participants in groups with a task-oriented advisor.}

In addition to the influence of the consumer, group, and advisor characteristics on satisfaction, we posit two additional relationships in our theoretical research model. Firstly, research of groups has demonstrated that predictor-criterion relationships regarding group characteristics may vary between individual perceptions and grouplevel (shared) perceptions (van Yperen and Snijders 2000). Secondly, there may not only be a direct influence of the advisor on satisfaction, the effects of the characteristics of the individual and the group on satisfaction might be influenced by the advisor as well. Both issues will be discussed in the next section.

\subsubsection{Refinement of the Theoretical Research Model}

Regarding the assessment of group characteristics, most researchers studying groups use individual perceptions to measure group processes (Kenny et al. 1998). Nonetheless, chatting in a group, as communication in any other group, involves more persons and is social by definition. Consequently, observations do not refer to a person, but rather to multiple persons embedded within a social context. Consider the influence of the perceived group cohesion during a chat session on participant satisfaction. This perception may represent a perception that is unique to the individual. In other words, the perception results from a subjective assessment of the participant which is affected by demographic background, a trait that the participant brings to the chat session or the specific role of the individual within the chat group (Klein et al. 2001; van Yperen and Snijders 2000). At the same time, group members process information not only at the individual-level by reviewing information, but they also process information at the group-level through group discussion (Hinsz et al. 1997; Kerr et al. 1996a; Larson and Christensen 1993). Yet, how a person perceives, depends not only on that person but also on the partners with whom the person interacts (Kenny et al. 1998). Consequently, it may be that the perception of group cohesion is in fact interpersonally determined and that the rating of group cohesion is related to the group. In other words, the customer satisfaction appraisal is determined by the shared opinions on cohesion of his or her chat group members as well as by his or her own subjective perceptions. What would make the feature quasiobjective is the inter-subjectivity- the fact that there is consensus among several individuals in their perceptions indicates an actual presence of cohesion within the group. 
Individual perceptions correspond to subjective appraisal processes and need to be assessed because it may provide useful insight for customization which is especially feasible in an e-commerce environment. Individual variation between customers may stem from actual individual differences among customers caused by for instance diversity in needs, expectations, knowledge, and an individual's values. Group-level relationships may provide relevant information regarding the influence and management of group dynamics within chat groups. If there are relationships at the group-level due to group intra-action that are different from relationships at the individual-level, decisions that are based solely on individual-level perceptions may have an adverse effect on chat session satisfaction.

In order to separate these conceprually different factors, one should treat the individuals as the unit of analysis and simultaneously treat the group as the unit of analysis. The individual data correspond to individual appraisal processes, while the group data correspond to the situational context. One may consider a research design which includes individuals and groups as units of analysis as a hierarchical structure. We refer to a hierarchy as consisting of units grouped at different levels. That is, participants are nested within a chat group. For this data structure, multi-level statistical techniques (Bryk and Raudenbush 1992) can help to distangle the effects of subjective experiences (leading to within-group differences) from those of the group context (leading to between-groups differences). Consistent with the terms used in most multi-level analysis research, we will refer to the first effect as the individuallevel effect and to the latter as the group-level effect.

Previous research on groups has convincingly demonstrated that predictorcriterion relationships may differ across the levels (Bolon 1999; Ostroff 1993). Multilevel analysis allows us to compare whether similar or different processes are involved at the individual- and the group-level. Consistency in the predictor-criterion relationships at both levels is an important evidence of the validity of the perceptions of the individual (Ostroff 1993). Although many researchers have proposed homology of relationships across levels of analysis (Lindsley et al. 1995), it can also be hypothesized that different processes operate at the different levels of analysis (Ostroff 1993). Research on CMC argues that communication via computers reduces the power of the group over the individual, which implies that individual-level variables would have more influence than group-level variables (Kraut et al. 1992).

Regarding the four group characteristics (as described in paragraph 4.3.2), the purpose of the present study is the investigation of the extent to which satisfaction with the chat session is associated with differences between individuals within chat groups, and the extent to which satisfaction is associated with differences between chat groups. Concretely, this means that we use individual and group assessments of our group predictors to find out whether data at the group-level significantly add explained variance to the individual-level data with regard to satisfaction. This purpose is reflected in the following research question:

$R Q_{\text {I: }}$ To what extent will chat session satisfaction be influenced by the customer's subjective experience of the four group characteristics and to what extent by the shared perceptions of the four group characteristics? 
The advisor may influence the relationship between consumer and group characteristics, and satisfaction in several ways. Two major frameworks used to explain interpersonal influences are congruity theory and group role models. Both categorize antecedents in terms of the social and task dichotomy. Related to these theories is the discussion about economic versus social exchange by researchers from several disciplines (Carman 1980; Levi-Strauss 1969; Thibaut and Kelley 1959). According to the congruity theory, satisfaction is a function of evaluative congruity, which is a cognitive matching process in which a perception is compared to an evoked referent cognition for the purpose of evaluating a stimulus object/action (Sirgy 1983; Sirgy and Tyagi 1986). Regarding congruity, communication research suggests that congruence in inputs of people during an interaction is important. Dissonance of communication styles is a dysfunctional outcome of the mismatch between the style of the advisor and the group (Soldow and Thomas 1984). A conceptual congruence framework of Miles et al. (1990) suggests that either both the communication style of the advisor and the customers should be task-oriented or both should be relation-oriented. They suggest that in initial encounters, as is the case with the chat sessions under study, this similarity in styles will be most effective. Related to congruity theory is the similarity principle, i.e., we like people who are similar to us in some way (Newcomb 1961, 1963). This effect has been obtained in studies of several groups (e.g., Hill and Stull 1981; Kandel 1978) and suggests that the characteristics of the consumer, group, and advisor should exhibit a relatively high degree of similarity. According to this line of reasoning, chat session satisfaction is positively influenced when a customer or a group with social characteristics interacts with a social-oriented advisor. In the same way, a customer or a group with taskrelated characteristics will be more satisfied with a task-oriented advisor.

Another perspective on task and social inputs within groups is taken by researchers of group role models. An essential feature of these role models is the idea of complementary roles in a group and a tendency for groups to develop both task and socio-emotional roles (Benne and Shears 1948; Forsych 1999; Mudrack and Farrell 1995). The complementarity principle refers to the tendency for group members to like people who are dissimilar to them in ways that complement their personal qualities (Kerckhoff and Davis 1962; Levinger et al. 1970; Meyer and Pepper 1977). An effective group, in terms of performance and satisfaction, is a team that has a full complement of roles active within it. It is emphasized that there should be balance between the social and task roles within a group to fulfill both the task and social needs of the group (Bales 1950, 1958; Forsyth 1999; Hare 1976). Groups that maintain the balance evaluate their interactions more positively (Kahai and Cooper 1999). Regarding the chat sessions under study, this implies that satisfaction is created when the task as well the social aspects are simultaneously covered within the group. Balance will be established when the advisor's task-oriented style is complementary to the consumer or group social characteristics or when the advisor's social-orientation is complementary to the consumer or group task characteristics. Take for instance groups with a task-oriented advisor; since the advisor is focusing on the goal of the meeting, the social needs have to be fulfilled by the group by, for instance, creating feelings of group cohesion. Similarly, in the case of a social-oriented advisor, self- or 
group-efficacy may become important to assure that also task-related information is exchanged. It also could be that the balance of social and task aspects is created by different roles within the group, independently from the role of the advisor.

Concluding, the influence of the advisor on the relationship between consumer and group characteristics, and satisfaction might be different according to the congruity theory and the group role models. Therefore, we develop a tentative research question regarding this influence:

$R Q_{2:}$ What influence, if any, will the communication style of the advisor (task versus social) have on the effect of the consumer characteristics and group characteristics (subjective and shared perceptions) on satisfaction?

A summary of our theoretical research model is given in figure 4-1.

Figure 4-1: Theoretical Research Model

\section{Task-oriented advisor}

\section{Social-oriented advisor}

Consumer characteristics

Task $-\left[\begin{array}{l}\text { Functional beneits } \\ \text { Self-efficacy }\end{array}\right.$

Social $\left\{\begin{array}{l}\text { Social benefits } \\ \text { Social comfort }\end{array}\right.$

Group characteristics perceived by the individual

Task $-\left[\begin{array}{l}\text { Task communication } \\ \text { Group-efficacy }\end{array}\right.$

Social $-\left[\begin{array}{l}\text { Social communication } \\ \text { Group cohesion }\end{array}\right.$

Group characteristics shared by the group

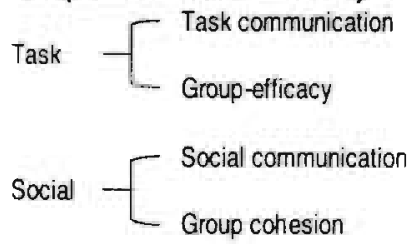




\subsection{An Empirical Study}

\subsubsection{Method}

To test our research hypotheses and questions, we organized chat sessions in which respondents chatted with an advisor and others. The objective was to gather information about two financial investment funds and to obtain financial advice. In this setting, we manipulated the style of the advisor. In one half of the sessions the advisor behaved according to a social-oriented script and in the orher half, a taskorientation was taken.

The context of financial advising was selected for several reasons. First, we felt that we should use a service that most people, both males and females, could relate to (but not necessarily have experience with). Pre-tests indicated that investing is a topic that most respondents could relate to, because they personally invested money, they knew someone else who invests, or because they just heard or read about it.

Secondly, many chat sessions on this topic actually take place on the Internet (e.g., www.financialchat.com; www.sns.nl). Although these are mostly general interest chat sessions and not organized, commercial chat sessions, the popularity indicates the relevance of the topic to consumers. In addition, this shows that investing is a topic about which people like to know the opinion of other consumers and to share their own knowledge. As a result, it was anticipated that most respondents would find the context of chatting in groups about investing both realistic and believable. Thirdly, these kind of financial group seminars are also organized in an off-line, faceto-face setting and have proved to be very successful (Direct Marketing 2001; O'Connor 1998). Finally, chat sessions are currently being initiated by many financial service firms to attract current customers looking for information as well as new customers (Information Week 2001; Jupiter Research 2001).

It was decided to use a laboratory experiment over a field study for several reasons. Although chat is among the most popular activities on the net, providing service via chat is rather new. In testing a new and as yet widely unavailable service option on the Internet, a study of potential customers and their perceptions was thought to be appropriate. Secondly, given the comprehensive model being tested, the questionnaire was too long to be administered in a field study to customers actually using this service. Furthermore, people experienced in chatting would probably self-select into the sample, creating a non-respondent bias. In addition, this approach allowed manipulation of the style of the advisor, something not easily replicated in field experiments (Dabholkar 1996; Jackson et al. 1984).

\subsubsection{Procedure}

For each experimental chat session, small groups (4 to 7 persons) were invited to a research laboratory. On arrival, each participant was placed in a separate experimental cubicle, where (s)he was seated in front of a computer screen. All information was transferred via the computer. The experiment started with an 
introduction on how to use the computer and the chat program, and about the nature of the study. It was explained that they were going to chat about investment funds together with other customers and an advisor of a bank. To eliminate possible brand bias regarding the bank, we explained that the bank preferred to stay anonymous. A questionnaire was administered electronically to each respondent measuring the control and consumer variables. After answering the questions, each participant was presented with the same scenario. It was explained that (s)he planned to invest 1500 euro (a part of an inheritance) and that (s)he made an appointment with the bank to get more information about two investment funds (s)he was interested in and to get investment advice. A short description of the funds was given. Two funds which are currently available (a Global Life Society equity and a Global Property equity fund) were chosen. A financial expert told us that these were equally suited to experienced and inexperienced investors. In the scenario, it was written that a week before the appointment the advisor of the bank called about a new service offered by the bank; a chat session together with other consumers who were interested in the funds. The scenario stated that the participant agreed to participate.

After all respondents had read the scenario, the chat session began. In half of the groups, the advisor was social-oriented and in the other half, the advisor was taskoriented. For the role of advisor, we hired and trained an investment specialist to behave either social- or task-oriented. The social- and task-oriented conditions were based on a review of the communication style and leadership style literature (Bales 1950; Williams and Spiro 1985). Many of the aspects of the style that were manipulated were consistent with the behaviors identified by Bales (1950) and Williams and Spiro (1985). Regarding the task-oriented style, the advisor was trained to be highly goal-oriented and purposeful. He was concerned with efficiency and structuring the session. The advisor gave direction and information, repeated, clarified, and evaluated. In the social condition, the advisor was more personal and social, even to the extent of sometimes ignoring the task at hand. He made jokes, showed understanding, and rewarded the input of the customers. The groups were restricted to chat for at maximum 45 minutes. During pre-tests, we discovered that this was the average time the groups needed to cover all relevant questions and issues. At the end of the chat session, a questionnaire was administered electronically to each respondent. After answering the questions, the participants were debriefed about the purpose of the research.

In order to standardize the manipulation of the style of the advisor as much as possible, scripts were developed, which the advisor used during every session. These scripts were different for the social and task treatment, but the same for every group within each treatment (figure 4-2). First, the advisor started with a standard introduction. Secondly, during a session three standard interactions with one of the participants occurred. In fact, in order to control these interactions, this participant was one of the researchers, who acted as a participant during the whole session. Thus, every group experienced the same behaviors of the advisor. The actions of the participant were always the same in all groups, but the response of the advisor differed per treatment. Thirdly, since all conversation in a session could not be controlled, standard sentences were developed for each treatment separately. The 
advisor used these as appropriate for different situations. To be sure that this more spontaneous behavior was in line with the treatments, responses were practiced with the advisor while chatting with him about investment funds. Training of the advisor continued until he had reasonable understanding of the differences in behavior, was able to use scripts and standard sentences, and the standardized interactions ran smoothly. Finally, the advisor closed the session following a standard script.

\section{Figure 4-2: Task versus Social Treatment}

Task-oriented

\section{Introduction:}

The advisof structures the session: he sets goals, explains his role, stresses the importance of staying goal-oriented, states that he will give a solid advice, underscores the time maximum of 45 minules, and sels an agenda for the session.

During the session:

1) Participants were called by number.

2) Three standard interactions. For example:

$\mathrm{Nr}$ 3: This is rather funny, chatting about investments. Isn't it possible to do this more often...or we could start an investment club or something like that..or invest together....

Advisor: I think this is a topic which is not relevant to this particular session. Now we are talking about investing in our investment products.

3) Standard sentences. For example:

I will summarize what you said, Keep in mind our objective, Let me clarify this point, We have 10 minutes left.

\section{Closing of the session:}

The advisor explains what the bank can offer the participants, expresses that he tried to give as much information as possible, that an irvestment via his bank would be a good choice, and that he will send all of participants a personal advice and offer by e-mail.

\section{Social-oriented}

\section{Introduction:}

The advisor is personal and social: he shows his appreciation with the customer's participation, explains that his role is to help them, expresses his hope that they will enjoy it and that this session will be the start of a longstanding relationship with the bank, and he introduces himself, including personal intormation (married, kids).

\section{During the sesslon:}

1) Participants were called by name.

2) Three standard interactions. For example:

Robin: This is rather funny, chatting about investments. Isn't it possible to do this more often...or we could start an investment club or something like that..or invest together....

Jim: I think that is a great idea! Other groups did that belore and often it is a success. Perhaps it is a good idea to exchange email addresses at the end of this session... What do you think?

3) Standard sentences. For example:

I think we are doing a good job, I like your idea!, I understand what you mean, That's a good remark!

\section{Closing of the session:}

The advisor praises the input of the customers, expresses his own enjoyment, and his hope that it was enjoying and useful for them, gives opportunity for extra questions via e-mail or an appointment, and focuses on meeting again in the near future.

\subsubsection{Pre-Test}

The scenario, the scripts, and the behavior of the advisor were developed and trained based on extensive pre-testing. Several versions of the scenario were developed with different amounts of detail in each regarding the situation and the investment products. The realism of each scenario was tested by asking students to read a 
particular version and then rate the realism using two 7-point Likert scales (the situation as described is realistic and it was not difficult to imagine myself in the situation). The scenario with the highest rating was used. This scenario was judged to be highly realistic (mean 6).

Regarding the manipulation of the style of the advisor, we first tested a number of scripts to identify the behaviors that appropriately represented the social and task communication style of the advisor. After reading a script, pre-test subjects were given a short questionnaire containing items designed to assess the validity of the manipulations. Based on these pre-tests the scripts were modified and tested again. This process continued through several iterations, until we were reasonably certain that the manipulations did work in creating a treatment effect and the scripts were interpreted as intended. Once the written scripts were judged satisfactory, they were pre-tested along with the style of the advisor during test chat sessions using a sample of undergraduate and graduate students. After each chat session, these subjects (not the same who participated earlier) responded to a series of items assessing the validity of the manipulations. After completing the pre-test questionnaire, subjects were also asked to comment on the believability and realism of the script and behavior of the advisor. Based on these pre-tests, additional modifications were made to the scripts and the behavior of the advisor. Also this process continued through several iterations, until we were reasonably certain that the manipulations (scripts and behavior of the advisor) did create a treatment effect. Furthermore, these pre-tests showed that none of the subjects identified one of the participants as a member of the research project during the standardized interactions in the chat session. Also postexperiment interviews with subjects indicated this result.

\subsubsection{Sample}

Participants in this computer-led experiment were 212 students from a large Dutch University. They received course credits for their participation. The sample consisted of $54 \%$ men and $46 \%$ women. The age ranged from 17 to 38 with an average of 22 . The level of experience in investing was quite low with a mean rating of 2.96 on a scale of 1 to 7 . The level of experience in chatting was higher, rated 4.22 (on a scale of 1 to 7). For each chat session small groups (4 to 7 persons) were invited to the laboratory simultaneously, who formed one chat group. In total 40 groups were formed. Each group was randomly assigned to the treatment (social versus task). Of the total respondents, 20 groups, consisting of 106 respondents, received the social style treatment and 20 groups, consisting of 106 respondents, received the task style treatment.

\subsubsection{Questionnaire Development}

All scale items of the survey were measured on 7-point Likert-scale ranging from 'totally disagree' to 'totally agree'.

Chat session satisfaction: Satisfaction with the chat session was measured on a nine item, equally weighted scale. We used all items as suggested by Evans et al. (2000), i.e., 
I am satisfied with the financial advice I was given; I am satisfied with the way in which my customer needs were addressed; I am satisfied with the financial advisor; I am satisfied with this way of personal interaction; I am satisfied with the social contact that took place; I am satisfied with the advisor as a financial expert; I am satisfied with this type of financial advisory service. We complemented this scale with two items: Based on my experience, I am satisfied with this advisory service; In general, I am satisfied with this service provider. Cronbach's alpha is 95 .

Consumer characteristics: The scale measuring self-efficacy beliefs (6 items) was based upon an instrument developed by Riggs et al. (1994). The social benefits and the functional benefits were both measured with four items for each scale as suggested by Reynolds and Beatty (1999). The operationalization of social comfort was based upon an instrument developed by Wanberg et al. (2000). In the context of our study, this scale comprises four items and measures whether the respondents are comfortable with asking other people for on-line advice regarding their financial issues.

Group characteristics: The scales measuring group task (4 items) and group social communication style (4 items) were based on an instrument developed by Williams and Spiro (1985). Group cohesion was measured using seven items adapted from a scale developed by Rosenfeld and Gilbert (1989). The six items measuring groupefficacy beliefs were based upon a scale developed by Riggs et al. (1994).

Prior to conducting the main experiment, the questionnaire was extensively pretested and many items were slightly reworded and the scales were refined. Since none of the scales was specifically developed for chat groups or interaction on the Internet, all scales had to be adapted to our specific context. Consequently, it was necessary to validate all scales for the present purpose. We employed two techniques to test the factor structure and item loadings of the scale-constructs of the independent variables. We initially examined coefficient alphas of all constructs. In addition, principal component analyses (varimax rotation) were employed to investigate the structure of the constructs. With respect to the consumer characteristics, a four-factor structure was achieved with items clearly loading on the a priori dimensions. Another principle component analysis concerning the group characteristics yielded a four-factor structure with items loading on the expected dimensions. In addition, the items of the constructs were subjected to confirmatory factor analysis (CFA) using LISREL Jöreskog and Sörbom 1993) to assess the critical measurement properties of the scales. The indices of the proposed four factor model for the items of the consumer characteristics provided a good fit (GFI $=.91 ; \mathrm{AGFI}=.88$; $\mathrm{RMSEA}=.045 ; \mathrm{NNFI}=.96$; $\mathrm{CFI}=.97$ ), revealing unidimensionality of the scales.

In addition, a CFA was performed on the items of the group characteristics and suggested changes in the items of group cohesion and group-efficacy. All validation checks were rerun and it was found that the CFA results did produce the best measures. The indices of the final four factor model provided an acceptable fit $(\mathrm{GFI}=.90 ; \quad \mathrm{AGFI}=.86 ; \quad \mathrm{RMSEA}=.042 ; \quad \mathrm{NNFI}=.97 ; \mathrm{CFI}=.97)$ clearly indicating unidimensionality of the measures. For both proposed four-factor models the fit indices, construct reliabilities of the scales, and confirmatory factor loadings with tvalues for each item are represented in table 4-1. 
Table 4-1: Results of Confirmatory Factor Analyses

Measures

Factor loadings t-value

Consumer characteristics

Fit indices: (GFI=.91; $A G F I=.88 ;$ RMSEA $=.045 ; \mathrm{NNFI}=.96 ; \mathrm{CF}=.97$ )

Social benefits $(n=4 ; \alpha=82)$

I enjoy the company of other customers on-line

The social aspect of advisory service chat sessions is important to me

I enjoy spending time with new interactive services

I value the social aspects of interactive chat services

Functional benefits $(n=4 ; \alpha=87$ )

I make better decisions because of advisory service chat sessions 12.12

I benefit from the information these type of chat sessions offers me 13.34

I value the convenience that new interactive services provides me with 14.30

Advisory service chat sessions are useful

10.30

Self-efficacy ( $n=6 ; \alpha=.89$ )

I have confidence in my ability to invest

13.57

I doubt my ability to invest a

I have all the skilis needed to invest very well

14.55

I consider myself a capable investor

12.46

11.79

My future regarding investing is limited because of my lack of skills a

I am very proud of my investing skills and abilities

7.15

Social comfort $(n=4 ; \alpha=.84)$

I am comfortable asking people on-line for advice regarding my financial issues

11.75

I don't mind asking others on-line if they have any tips regarding financial matters

12.80

I am comfortable asking other people on-line for their assistance in my financial practices

11.88

I don'? like to ask people on-line for financial advice because it can make them feel embarrassed a

\section{Group characteristics}

Fit indices: (GFI=.90; $\mathrm{AGFI}=.86$; RMSEA $=.042 ; \mathrm{NNFI}=.97 ; \mathrm{CFI}=.97$ )

Group task communication ( $n=4 ; \alpha=.81$ )

The group was very focused on getting financial advice

10.39

The group was more interested in a social conversation than in gathering information ${ }^{\mathrm{a}}$

The group wanted to stick to the main purpose of the interaction, information gathering

10.19

The group was more interested in getting advice than in a social conversation

10.20

Group social communication $(n=4 ; \alpha=.84)$

The group members often displayed positive feelings toward each other during the discussion

10.46

The group was easy to talk with

The group indicated support for the views of the group members

12.40

The group was friendly

12.53

Group cohesion ( $n=7 ; \alpha=.91)$

I liked the chat group I was in

10.77

I would like future chat groups to include similar members

13.70

I enjoyed interacting with this group

11.38

There was a feeling of group unity and cohesion

13.29

I felt attracted to this group

Many in the group fitted my idea of good group member

The chat group was composed of people who fit together

\section{Group-efficacy ( $n=6 ; a=.80$ )}

The chat group had above average investment ability

The members of this group had excellent investment skills

This group was not very effective a

This group was not able to perform as well as it should a

Together we possessed the skills necessary to invest well

I had confidence in the group's ability to invest 
Construct reliabilities of all scales were tested by means of Cronbach's alpha. Coefficients of all measures were at least .80 , which implies that reliability is deemed acceptable. Next, within-method convergent validity was examined by investigating the significance and magnitude of the item loadings. All items loaded significantly on their respective construct (minimum $t-v a l u e ~=6.46$ ) where all items had a standardized loading of at least .48. In addition, discriminant validity was evaluated by testing whether pairs of constructs were correlated less than unity. Chi-square difference tests with one degree of freedom were used to test for unity between pairs of constructs. All tests were significant at the .05 significance level.

Manipulation checks: The scales used for the manipulation check for the communication style of the advisor, task-oriented ( 4 items) versus social-oriented ( 7 items), were based on an instrument developed by Williams and Spiro (1985).

In addition, the variables experience in investing and experience in chat served as control variables.

\subsection{Multi-Level Analysis and Model Building}

For this study, multi-level modeling is used, since our data can be characterized as a hierarchically nested data structure, i.e., customers within chat groups (Bryk and Raudenbush 1992). A detailed explanation of multi-level modeling and the interpretation of a multi-level model can be found in Chapter 2, paragraph 2.4. In the context of this study, a two-level model was specified for the dependent variable chat session satisfaction.

To compare within-group and between-groups coefficients of the variables, we divided them into the group mean and the within-group deviation variable. The individual-level of the model concerns all consumer antecedents and all within-group deviation scores of the group characteristics. The group-level reflects all group means of the group characteristics. The coefficient of the group-means measures the betweengroups effect, whereas the coefficient of the within-group deviation scores measures the within-group effect. For chat session satisfaction this results in the model:

SATISFACTION ${ }_{i}=\gamma_{00}+\gamma_{10}$ EXPINV $_{i}+\gamma_{20}$ EXPCHAT $_{4}+\gamma_{30}$ SOCBENEFITS $_{4}+\gamma_{40}$ FUNCBENEFITS $_{4}+\gamma_{50}$ SELF-EFF $_{i}+$ $\gamma_{60} \mathrm{SOCCOMFORT}_{4}+\gamma_{70} \mathrm{TASKCOMM}_{4}+\gamma_{00} \mathrm{SOCIALCOMM}_{4}+\gamma_{90} \mathrm{COHESION}_{4}+\gamma_{10} \mathrm{GROUP}-\mathrm{EFF}_{4}+$ $\gamma_{01}$ TASKCOMM $+\gamma_{0}$ SOCIALCOMM $_{1}+\gamma_{03}$ COHESION $+\gamma_{01}$ GROUP-EFF $+u_{0}+u_{11}+u_{2}+u_{3}+u_{4}+u_{5}+$ $u_{5}+u_{71}+u_{5}+u_{9}+U_{10}+e_{i}$

where $i$ stands for individuals; $j$ indicates groups; SATISFACTION $N_{\text {refers }}$ to the degree of chat session satisfaction of customer $i(i=1, \ldots n c)$ in group $j(j=1, \ldots n G) ;$ EXPINV, EXPCHAT, are experience in chat and experience in investing at the individual-level respectively; SOCBENEFITS, FUNCBENEFITS, SELF-EFFi, SOCCOMFORT, are social benefits, functional benefits, self-efficacy, and social comfort at the individual-level, respectively; TASKCOMM, SOCIALCOMM, COHESION, GROUP-EFF, are group task communication, group social communication, group cohesion, and group-efficacy at 
the individual-level, respectively; TASKCOMM, SOCIALCOMM, COHESION, GROUP-EFF are group task communication, group social communication, group cohesion, and groupefficacy at the group-level, respectively. The section of the model incorporating the regression coefficients $\gamma_{00}, \ldots \gamma_{04}$ is the fixed part of the model, $\mathrm{e}_{\mathrm{ii}}$ is the individual-level error term, and $\mathrm{u}_{0}, \ldots \mathrm{u}_{10} ;+\mathrm{e}_{\mathrm{ij}}$ is the random part of the model.

\subsection{Results}

Manipulation checks were made for the communication style of the advisor, taskversus social-oriented, using an independent samples t-test. The results show that the treatment works well. In the groups with a task-oriented advisor, the means of the manipulation check items are 5.54 for task-orientation and 3.78 for social-orientation $(\mathrm{t}=-13.33, \mathrm{p}<.001)$. In the groups with a social-oriented advisor, these means are 3.78 for task-orientation and 5.60 for social-orientation $(t=14.77, p<.001)$. Regarding chat session satisfaction and the group characteristics, group-level variance and individuallevel variance were decomposed. Group-level variance and total individual-level variance were produced directly by MLwiN. The results in table 4-2 indicate that a substantial part of the variance concerns between-groups variance. Regarding chat session satisfaction, this finding indicates that a multi-level approach is appropriate. Regarding the group characteristics, determination of between-groups variance is particularly important when relationships that involve aggregate variables are tested. Intraclass correlations ranged from .21 to .37 . From these results, it can be concluded that the perceptions of all group variables are partly shared by the other customers in the chat group. Therefore, it was appropriate to add them to the model as group-level variables'.

Means, standard deviations, individual-level and group-level correlations for groups with a social-oriented advisor and groups with a task-oriented advisor are presented in table 4-3. To test the hypotheses and to examine whether the communication style of the advisor had an effect on the relationship between the consumer and group characteristics, and satisfaction $\left(\mathrm{RQ}_{2}\right)$, separate analyses for the groups with a task- and social-oriented advisor were conducted. Multi-level models are considered as models that may be subject to multi-collinearity. Therefore, ordinary regression analyses were conducted to investigate multi-collinearity by means of the Variance Inflation Factor (VIF). VIF's of the predictor variables were lower than 2.9 , hence no severe multi-collinearity problems were to be expected.

\footnotetext{
'Regarding the individual consumer characteristics (and the control variables), we did not expect any between-groups variance. We conceptualized these variables as general constructs which are related to the individual consumer and not as perceptions of the particular chat session. Therefore, the individual consumer variables were measured before the chat session took place. All other variables were measured after the chat sessions. Although it could be that randomly, some groups had more self-efficacious people than other groups for instance. However, the results show that the consumer variables do not have any significant between-groups variance (not reported in table). Because these variables do apparently have no group part, theoretically and empirically, they are only included as individual-level effects.
} 
Table 4-2: Variance Attributed to Group Factors and the Customer's Subjective Assessment

\begin{tabular}{lccc}
\hline & Group-level & Individual-level & Intraclass correlation * \\
\hline Group characteristics & $22 \%$ & $74 \%(4)$ & .23 \\
Chat session satisfaction & $27 \%$ & $59 \%(14)$ & .31 \\
Group task communication & $33 \%$ & $56 \%(11)$ & .37 \\
Group social communication & $25 \%$ & $68 \%(7)$ & .27 \\
Group cohesion & $23 \%$ & $62 \%(15)$ & .27 \\
Group-efficacy & $23 \%$ & \\
\hline
\end{tabular}

Note: Values between parentheses: percentage of the individual-level variance attributed to measurement error.

a ICC-coefficients are corrected for unreliability.

Table 4-3: Means, Standard Deviations, and Correlations

\begin{tabular}{|c|c|c|c|c|c|c|c|c|c|c|c|c|}
\hline \multicolumn{13}{|c|}{ Groups with a social-oriented advisor } \\
\hline Variables & Mean (s.d.) & 1 & 2 & 3 & 4 & 5 & 6 & 7 & 8 & 9 & 10 & 11 \\
\hline 1. Satișfaction & $4.68(1.27)$ & & & & & & & & .10 & 37 & .16 & .33 \\
\hline 2. Experience in investing & $2.89(1.80)$ & -.28 & & & & & & &. .13 & -.12 & -.03 & -.03 \\
\hline 3. Experience in chat & $4.37(1.67)$ & .13 & .02 & & & & & & .01 & -.03 & .05 & -.01 \\
\hline 4. Social benefits & $4.03(1.01)$ & .27 & -.02 & .18 & & & & & -.14 & .04 & -.01 &. .19 \\
\hline 5. Functional benefits & $4.98(1.05)$ & .40 & -.02 & .18 & .57 & & & & -.02 & .08 & .16 & .02 \\
\hline 6. Self-efficacy & $3.92(1.27)$ & -.22 & .66 & .15 & .18 & .16 & & & .07 & .07 & .08 & -.02 \\
\hline 7. Social comfort & $5.56(1.07)$ & .07 & .06 & -.03 & .07 & .08 & .09 & & .17 & .12 & .23 & .13 \\
\hline 8. Group task commun. & $4.91(1.24)$ & .23 & .14 & .06 & .04 & .01 & .02 & .22 & & .16 & .29 & .55 \\
\hline 9. Group social commun. & $5.18(.73)$ & .32 & -.02 & .20 & $\cdot .12$ & .10 & -.01 & .24 & .05 & & .49 & .50 \\
\hline 10. Group cohesion & $4.66 \quad(.94)$ & .45 & -.05 & .01 & .20 & .22 & -.09 & .05 & .23 & .31 & & .49 \\
\hline 11. Group-elficacy & $4.46(1.07)$ & .45 & .08 & .09 & .20 & .09 & .02 &. .04 & .30 & .30 & .50 & \\
\hline \multicolumn{13}{|c|}{ Groups with a task-oriented advisor } \\
\hline Variabies & Mean (s.d.) & 1 & 2 & $\overline{3}$ & 4 & 5 & 6 & 7 & 8 & 9 & 10 & 11 \\
\hline 1. Satisfaction & $3.48(1.55)$ & & & & & & & & .04 & .16 & .11 & .02 \\
\hline 2. Experience in investing & $3.03(1.79)$ & .01 & & & & & & & .09 & -.03 & -.15 & .05 \\
\hline 3. Experience in chat & $4.08(1.82)$ & .08 & .11 & & & & & & .03 & .02 & .07 & .01 \\
\hline 4. Social benefits & $4.02(1.34)$ & .44 &. .13 & .22 & & & & & -.11 & .14 & .08 & -.05 \\
\hline 5. Functional benefits & $5.14(1.01)$ & .26 & -.16 & .25 & .55 & & & & .12 & .09 & .05 & .02 \\
\hline 6. Self-efficacy & $3.64(1.26)$ & .15 & .66 & .11 & .06 & -.01 & & & .04 & -.01 & .04 & .20 \\
\hline 7. Social comfort & $5.60(1.00)$ & .32 & .05 & .06 & .21 & .19 & -.06 & & .09 & .19 & .15 & .07 \\
\hline 8. Group task commun. & $4.82(1.06)$ & -.06 & .25 &. .02 & .03 & .13 & -.09 & .08 & & -.02 & .11 & .21 \\
\hline 9. Group social commun. & $4.25(1.17)$ & .39 & .03 & -.12 & .04 & .11 & -.05 & .12 & .06 & & .74 & .51 \\
\hline 10. Group cohesion & $3.43(1.25)$ & .55 & -.03 & .18 & .31 & .31 & .21 & .13 & .24 & .48 & & .42 \\
\hline 11. Group-efficacy & $3.67(1.12)$ & .24 & .07 & .07 & .12 & .04 & .19 & .14 & .31 & .44 & .56 & \\
\hline
\end{tabular}

Note: Individual-level correlations are in the lower triangle and group-level correlations are in the upper triangle. Correlations in the upper triangle are the correlations between the group averages of the group variables. All correlations $>.18$ are significant at $p<.05$ (two-tailed).

Table 4-4 presents our multi-level analyses for groups with a social- and a task-oriented advisor. Regarding $R Q_{1}$, we had to estimate to what extent satisfaction is influenced by the individual's subjective experience and to what extent by the shared perceptions of the group characteristics. Therefore, first, the control variables were included into the model (step 1). Secondly, the four consumer characteristics were added (step 2). Thirdly, the within-group deviation scores of the four group characteristics were added (step 3). Finally, the group means of the four group characteristics were included (step 4). 
Table 4-4: Results of the Multi-Level Analyses

\begin{tabular}{|c|c|c|c|c|}
\hline & Social & & Task & \\
\hline & Coefficients (SE) ${ }^{a}$ & Bootstrap & Coefficients (SE) " & Bootstrap \\
\hline \multicolumn{5}{|l|}{ Step 1 (control variables) } \\
\hline \multicolumn{5}{|l|}{ Control variables } \\
\hline Experience in investing & $-.07(.06)$ & $-.07(.06)$ & $-.14(.10)$ & $-.14(.10)$ \\
\hline Expenience in chat & $.02(.05)$ & $.02(.05)$ & $-.01(.07)$ & $-.01(.08)$ \\
\hline Increase in model fit & $x^{2}(2)=7.7$ & & $x^{2}(2)=.6$ & \\
\hline \multicolumn{5}{|l|}{ Step 2 (individual-level) } \\
\hline \multicolumn{5}{|l|}{ Consumer characteristics } \\
\hline Social benefits & $.24(.10)^{\mathrm{b}}$ & $.23(.10) \div$ & $.34(.11)^{d}$ & $.31(.11)^{\circ}$ \\
\hline Functional benefits & $.27(.09)^{d}$ & $.27(.08):$ & $-.18(.15)$ & $-.18(.19)$ \\
\hline Self-efficacy & $-.16(.08)^{d}$ & $.16(.08)^{\mathrm{d}}$ & $.26(.15)^{c}$ & $.27(.15)$ \\
\hline Social comfort & $.04(.08)$ & $.03(.10)$ & $.36(.12)^{d}$ & $.35(13)^{\circ}$ \\
\hline Increase in model fit & $x^{2}(4)=24.9^{\circ}$ & & $x^{2}(4)=27.9 \mathrm{e}$ & \\
\hline \multicolumn{5}{|l|}{ Step 3 (individual-level) ${ }^{\mathrm{C}}$} \\
\hline \multicolumn{5}{|l|}{ Group characteristics } \\
\hline Group task communication style & $.17(.08)^{d}$ & $.17(.09)^{\mathrm{d}}$ & $-.29(.18)$ & $-.32(.20)$ \\
\hline Group social communication style & $.33(.15)$ & $.33(.15)^{d}$ & $.41(.15)^{e}$ & $.41(.17)^{d}$ \\
\hline Group cohesion & $.24(.10)^{d}$ & $.25(.11)^{3}$ & $.59(.15)^{d}$ & $.59(.14)^{\circ}$ \\
\hline Group-efficacy & $.32(.10)^{d}$ & $.30(.10)^{\mathrm{d}}$ & $-.24(.16)$ & $-.21(.15)$ \\
\hline Increase in model fit & $\chi^{2}(4)=47.0$ & & $x^{2}(4)=35.10$ & \\
\hline \multicolumn{5}{|l|}{ Step 4 (group-level) } \\
\hline \multicolumn{5}{|l|}{ Group characteristics } \\
\hline Group task communication style & $-.08(.19)$ & $-.07(.22)$ & $.25(.20)$ & $.24(.22)$ \\
\hline Group sociai communication style & $.82(.41)^{d}$ & $.88(.52)^{c}$ & $.46(.29)$ & $.47(.34)$ \\
\hline Group cohesion & $-.39(.43)$ & $-.50(.48)$ & $-.21(.31)$ & $-.16(.35)$ \\
\hline Group-efficacy & $.65(.30)^{\circ}$ & $.61(.35)^{c}$ & $.28(.25)$ & $-.29(.30)$ \\
\hline Increase in model fit & $x^{2}(4)=11.2^{\circ}$ & & $x^{2}(4)=3.4$ & \\
\hline Total increase in model fit & $x^{2}(14)=90.8^{\circ}$ & & $x^{2}(1.4)=67.00$ & \\
\hline
\end{tabular}

Note: "Unstandardized coefficients with their standard errors. "Within-group deviation score $X_{i}-X_{i ;}{ }^{c} p<.05$ (one-tailed); ${ }^{\circledR} p<01$ (one-tailed); ${ }^{\circ} p<.05$.

None of the random slopes was significant, which implies that in this context inclusion of a random intercept-only is most appropriate (Snijders and Bosker 1999). The fixed effects of single predictor variables were tested by means of one-tailed $\mathrm{t}$ tests (i.e., the coefficient divided by its standard error). Furthermore, simulations have been conducted to test accuracy of the parameter estimates. Parametric bootstrapping was applied (bootstrap resampling involves the repeated drawing of samples with replacement, from cases actually observed, followed by fitting the model to each such sample). Particularly in small samples, the results obtained by this resampling method have been shown to be better than those obtained from simply applying IGLS to the one original sample (Efron 1987; Fenwick. 1979; Tukey 1958). Our bootstrapping results are based on respectively 500 replications.

\subsubsection{Consumer Characteristics}

The results indicate that the social benefits variable is significant for groups with a social-oriented advisor and groups with a task-oriented advisor. Therefore, $\mathrm{H}_{1}$ is accepted. The functional benefits variable is only significant for groups with a social- 
oriented advisor, so $\mathrm{H}_{2}$ is only accepted for those groups. $\mathrm{H}_{3}$ is accepted for groups with a task-oriented advisor, but not for groups with a social-oriented advisor. In the latter groups, self-efficacy is significant and negatively related to satisfaction. Social comfort $\left(\mathrm{H}_{4}\right)$ is only significant for groups with a task-oriented advisor.

\subsubsection{Group Characteristics}

The group characteristics were measured at two levels ( $\left.R Q_{1}\right)$; the individual's subjective experience of group characteristics (individual-level coefficients) and the shared perceptions of group characteristics (group-level coefficients). Group task communication style is only significant at the individual-level for groups with a social-oriented advisor, so $\mathrm{H}_{5}$ is only accepted for those groups. With respect to groups with a social-oriented advisor, the results reveal that for group social communication the group-level coefficient is significant and positively related to chat session satisfaction, while also a significant relationship exists at the individual-level. The group-level coefficient is significantly higher compared to the within-group deviation coefficient ${ }^{2}$. So, the effect of group social communication operates at both levels. With respect to groups with a task-oriented advisor, the analysis reveals that group social communication only has an individual-level effect. In all, $\mathrm{H}_{b}$ is accepted for both conditions. For both conditions, group cohesion has an individual-level effect. Therefore, $\mathrm{Hz}$ is accepted. Finally, for groups with a social-oriented advisor, group-efficacy has a significant effect for both the within-group deviation score and the group mean with a significantly higher group-level coefficient. For groups with a task-oriented advisor, group-efficacy is not significant. $\mathrm{H}_{8}$ can be partly accepted.

\subsubsection{Advisor Characteristics}

To explore whether there are differences in chat session satisfaction between the groups with a social-oriented advisor and the groups with a task-oriented advisor, we conducted ANOVA and found a statistically significant difference $(F=39.77$, $p<.001)$. The means of satisfaction are 4.68 for the groups with a social-oriented advisor and 3.48 for the groups with a task-oriented advisor. Ho can be accepted.

\subsubsection{Research Questions Results}

From the results as discussed in relation to the hypotheses, we conclude that chat session satisfaction is influenced by both the individual's subjective and shared perceptions of group characteristics in socially moderated groups, and only by the subjective experiences of group characteristics in task-oriented groups ( $\left.R Q_{1}\right)$. Furthermore, the results reveal that the communication style of the advisor (social versus task) influences the effect of the variables (individual and group perceptions) on participant satisfaction with the chat session $\left(\mathrm{RQ}_{2}\right)$.

\footnotetext{
${ }^{2}$ An explanation how to test this difference is given in Chapter 2 footnote 3 .
} 


\subsubsection{Summary}

In sum, we find that the hypotheses are largely confirmed, but between treatment groups, the effects of the variables on participant satisfaction subtlety differ. The results are summarized in table $\mathbf{4 - 5}$.

Table 4-5: Summary of Results

\begin{tabular}{|c|c|c|c|c|c|c|c|c|c|c|c|}
\hline & \multicolumn{4}{|c|}{ Consumer characteristics } & \multicolumn{4}{|c|}{ Group characteristics } & \multicolumn{3}{|c|}{ Group characteristics } \\
\hline & \multirow[b]{2}{*}{$\begin{array}{l}\text { Social } \\
\text { benefits }\end{array}$} & \multirow[b]{2}{*}{$\begin{array}{l}\text { Functional } \\
\text { benefits }\end{array}$} & \multirow[b]{2}{*}{$\begin{array}{l}\text { Sell- } \\
\text { efficacy }\end{array}$} & \multirow[b]{2}{*}{$\begin{array}{l}\text { Social } \\
\text { comfort }\end{array}$} & \multicolumn{4}{|c|}{ Individual-'ével } & \multicolumn{3}{|c|}{ Group-level } \\
\hline & & & & & $\begin{array}{l}\text { Group } \\
\text { task : }\end{array}$ & $\begin{array}{l}\text { Group } \\
\text { social : }\end{array}$ & $\begin{array}{l}\text { Group } \\
\text { cohesion }\end{array}$ & $\begin{array}{l}\text { Group. } \\
\text { efficacy }\end{array}$ & $\begin{array}{l}\text { Group Group } \\
\text { task = social }\end{array}$ & $\begin{array}{l}\text { Group } \\
\text { cohesion }\end{array}$ & $\begin{array}{l}\text { Group- } \\
\text { efficacy }\end{array}$ \\
\hline Social & $x$ & $x$ & $-x$ & & $x$ & $x$ & $x$ & $x$ & $x$ & & $x$ \\
\hline Task & $x$ & & $x$ & $x$ & & $x$ & $\mathrm{x}$ & & & & \\
\hline
\end{tabular}

Refers to the communication style of the group; $X=$ significant.

\subsection{Discussion}

The purpose of this study was to investigate the factors that determine customer satisfaction with moderated on-line chat sessions in a commercial context. In addition, we took into account two relevant contingencies: the style of the advisor and group-level processes. While our findings indicate positive relationships between consumer, group, and advisor characteristics, and satisfaction, the exact nature of the predictor-criterion relationships varies across styles and levels. This suggests that the role of the advisor is of influence and that during chat sessions processes at the grouplevel develop which influence chat session satisfaction.

\subsubsection{Consumer Characteristics}

With respect to the consumer characteristics, our findings indicate a positive relationship between social benefits and satisfaction for both styles of the advisor. This suggests that the fundamentally social nature of chat sessions is in line with the social benefits that customers associate with interactive services, independent of the role of the advisor.

The variable functional benefits, on the other hand, is only significant in groups with a social-oriented advisor. It seems that although the task-oriented advisor is more focused on efficiency and the goals of the meeting, this does not confirm customers' ideas of functional benefits. It might be that customers' beliefs of functional benefits with respect to MGC refer to the stories and experiences of other customers and that a social-oriented advisor creates more an atmosphere of sharing which corresponds with these beliefs.

Feelings of social comfort in asking others on-line for advice is only significant for task-oriented advisors. A task-oriented advisor with his or her concern for production will not specifically assist customers to ask their questions. Therefore, it is important 
that customers themselves do feel comfortable to speak up in groups, otherwise it might be that their task-related questions will not be answered.

Consumers with knowledge and skills with respect to the content of chatting (e.g., self-efficacy) are satisfied in groups with a task-oriented advisor, but not in groups with a social-oriented advisor. Note that this latter negative influence is contrary to our hypothesis. This might be understandable given that in groups with a task-oriented advisor the focus is more on intormation exchange, so self-efficacious consumers can use their skills. For knowledgeable people, it might be less satisfying when the advisor also focuses on social conversation and the negative effect may reflect that.

In sum, with the exception of social benefits, the findings of the consumer variables show that the different styles of the advisor do fulfill different beliefs of benefits and require different skills of customers. For chat group composition, this implies that a firm should match the characteristics of the individual consumer with the style of the advisor or the advisor should adapt his or her style to the characteristics of the customer.

\subsubsection{Group Characteristics}

With respect to the group characteristics, it was found that for both the social- and task-oriented moderated sessions, group social communication and group cohesion contribute positively to satisfaction. For task-oriented groups, both aspects are important at the individual-level. For social-oriented groups, group cohesion is important at the individual-level and group social communication is important at both levels. This result challenges research that argues that social aspects are hardly communicated in CMC (e.g., Hiltz et al. 1986) and supports research that argues that social communication takes place and is an essential ingredient in CMC (Preece 1999; Walther and Burgoon 1992). Furthermore, this result supports research on group $\mathrm{CMC}$ that proposed to extend the classical task versus social dichotomy by adding a cohesiveness dimension (Reid et al. 1996; Whitworth et al. 2000).

Group-efficacy contributes positively to chat session satisfaction at both levels, but only for groups with a social-oriented advisor. It is important to note the different influence of group-efficacy compared to self-efficacy on satisfaction for groups with a social-oriented advisor. Whereas consumers, who belief that they are skilled and knowledgeable, are less satisfied in these groups, the customer's judgment of the group's knowledge is positively related to chat session satisfaction. This result is in line with the contention that efficacy beliefs in reference to the self are independent from efficacy beliefs in relation to the group of which one is a member (Bandura 1986; Riggs et al. 1994).

The additional shared experiences of social communication and group-efficacy for groups with a social-oriented advisor might be caused by group dynamics that seem to develop in these groups. Social-oriented advisors allow and enhance much more social talk, focus on relationships, and take care of each group member. Therefore, customers may have more opportunities to exchange knowledge as well as personal ideas, to express support and positive feelings, and to create a unique shared learning 
experience. In that way, the moderator creates a situation in which the group might agree on the group's collective feeling of support and effective performance, resulting in chat session satisfaction. A task-oriented advisor will not particularly pay attention to each group member, will not stimulate social talk, and even try to reduce it. In these groups, experiences of group characteristics will be limited to the subjective experience of the individual customer.

Group task communication style is only significant for socially moderated groups at the individual-level. This result seems to be in line with the positive effect of groupefficacy in these groups. It appears that while the advisor focuses on social aspects, the group regulates the task aspects of the session, like sharing knowledge available with other customers and staying focused on getting financial advise.

In sum, the results of the group characteristics show that social antecedents are important in creating satisfaction irrespective of the style of the advisor. Task antecedents are important in case of a social-oriented advisor. Furthermore, for groups with a task-oriented advisor customer's perceptions of satisfaction are influenced by individual, subjective experiences (individual-level effects). On the other hand, it seems that in groups with a social-oriented advisor, group processes arise that create shared experiences (group-level effects) in addition to the individual experience, and both influence satisfaction.

\subsubsection{Advisor Characteristics}

Regarding the influence of the communication style of the advisor on satisfaction, the results show that groups with a social-oriented advisor are more satisfied than groups with a task-oriented advisor. This is in line with previous research which suggests that customers are more likely to associate satisfaction with the provider's expression of social behavior than with the expression of task behavior (e.g., Bass 1990).

\subsubsection{Complementary Roles}

Some researchers argue that similarity within groups is preferable (Levinger et al. 1970; Magaro and Ashbrook 1985), whereas others find that the members of effective and satisfying groups possess compatible characteristics and fulfill complementary roles (Forsyth 1999; Kerckfhoff and Davis 1962; O'Connor and Dyce 1997). Our findings clearly provide support for the latter contention of complementary roles within a group. In case of a task-oriented advisor, predominantly social antecedents are significant and for groups with a social-oriented advisor, social as well as task. antecedents are significant. This suggests that groups strive to obtain a balance between the social and task roles within a group. This means that when the advisor is task-oriented, the group regulates the socio-emotional aspects during the chat session. Similarly, in case the advisor is social-oriented, the group performs task behaviors. This is in line with earlier findings stemming from the team literature (e.g., Neuman and Wright 1999) and might be indicative of the fact that conceptualizing chat groups as teams may be relevant. From the firm's perspective, the goal of chat group sessions is to have the group learn and build a preference for the brand, product or service, 
i.e., learning as a 'team' performance outcome. Neuman and Wright (1999) underscore the difference between teams and groups. Teams can be characterized by high task interdependence, high role differentiation, high task differentiation, and distributed expertise. Each team member has specialized knowledge and skills, members are interdependent and create unique interpersonal demands on each other to accomplish task performance. In short, for high team performance, team members' skills should complement one another and the members need to share their expertise. It could be argued that due to the fact that in chat groups there is distributive knowledge, coordination, and simultaneous interaction, teams and chat groups have in common that specific participant behaviors or traits are predictive of performance. Finally, the finding of the significant task antecedents in the groups with a socialoriented advisor suggests that customers do not only participate in commercial chat session for social and chit-chat reasons, but appreciate task aspects too.

\subsubsection{Suggestions for Future Research}

The theoretical research model developed here and its testing by empirical analysis contributes to the understanding of factors that are associated with an individual's satisfaction with commercial MGC. It can be seen as an attempt to empirically research the mainly anecdotal evidence that participation in on-line interactive services can significantly impact consumer evaluations. The study points to several topics for future research. To begin with, this study was a 'laboratory experiment'. As a consequence, the generalizability of the findings would be limited with regards to real-life settings. Furthermore, the use of an experimental design is subject to other inherent limitations pertaining to a possible lack of realism. Even though the results of the realism checks of the scenario as well as the manipulation checks of the advisor's behavior show successful manipulation, there may be a difference between simulation and real experience, affecting the way in which respondents react to the situation. Therefore, the generalizability of our findings should be examined within a real-life business-to-consumer setting on the Internet. Furthermore, evaluative judgments have been restricted to a single service episode in this study. Future experiments or field research might investigate how these judgments develop over time and how they may influence constructs like return intentions and loyalty or apply to other products or services.

Future research should also provide insight on the expectations of customers with respect to commercial MGC. The chat session as a commercial tool is fairly new and many consumers are probably inexperienced. Therefore, we focused on beliefs associated with interactive services in general and not specifically on expectations with respect to MGC. When customers get more accustomed to commercial MGC and hear about it from others, they inevitable will form expectations about this specific way of service provision that will influence their evaluative judgments.

In this study, we assumed a strict separation between social and task behaviors of the advisor. Outside the laboratory, however, it might be that advisors display a combination of both styles (Spiro and Weitz 1990). The manipulation of these two extremes, however, enables us to disentangle the influence of the two different styles 
and therefore allowed us to assess the validity of different models of chat group moderation. Nevertheless, future research should investigate the effects of advisors with a mixture of communication styles. If a combination of both styles is the most satisfying to customers, than an additional question suggested for future research is whether one advisor can perform both styles. Some researchers argue that a very few individuals can simultaneously perform both task and socio-emotional styles (e.g., Bales 1958). They suggest that in most groups both task and social aspects should be covered by pluralistic leadership (Waldersee et al. 1995). However, other researchers argue that people are able to behave in both ways simultaneously and dual leaders could produce other dysfunctional effects (Blake and Mouton 1982; Misumi and Peterson 1985).

Furthermore, it would be interesting to investigate the role of MGC within a multi-channel strategy of a firm. For instance, is MCG preferred by customers instead of one-on-one face-to-face encounters with service providers or is it preferred in addition to these encounters? Would electronic one-on-one encounters be satisfactory after a MGC session? Research on new media also shows that the use of new media creates a desire among people for more frequent communication which is satisfied by greater use of all existing communication channels (Lind and $\mathrm{Zmud}$ 1995). Future research should explore the influence of MCG on all other communication channels of a firm.

Finally, from our study it has become clear that predictor-performance relationships appear to be consistent across levels and styles of the advisor for some variables, while significant variations are found for other variables. Future research may extend the present study and investigate other types of consumer and group characteristics as well as other types of advisor styles to determine whether these contingencies are based on underlying structural patterns.

\subsubsection{Managerial Implications}

Our findings suggest a number of issues for firms that want to implement $M G C$ as a marketing tool. To begin with, our findings indicate that customers associate social as well as functional benefits with on-line interactive services; they feel that they make better decisions, benefit from the information these type of services offer, and enjoy the social aspects. With respect to MGC specifically, it seems that sessions with a social-oriented advisor confirm both these beliefs and result in satisfaction.

Furthermore, our findings emphasize the importance of matching the moderator with target customers and the purpose of the session. If the firm has insight into customer characteristics in advance, it seems to be desirable that the chat session is moderated by an advisor with the best fitting style. To moderate sessions satisfactorily in case customers' profiles are unknown, the purpose is broader, or when there is a mix of customer profiles, advisors needs to adapt their behavior. Spiro and Weitz (1990) propose training programs which focus on 'adaptive selling', taking identification of customer types and appropriate strategies into account. Training is necessary, but not sufficient; the unique combination of behavioral traits, e.g., a sense of humor, will be of influence too. Since these qualities are largely innate, also moderator selection should be considered carefully (Prince and Davies 2001). 
In addition, our results suggest that groups create a balance between the social and task roles within a group, resulting in satisfaction. This emphasizes the potential value of chat group composition (Neuman and Wright 1999). In other words, participant selection requires attention to the appropriate, heterogeneous, mix of participants for chat session satisfaction. Additionally, since shared perceptions were of influence for groups with a social-oriented advisor, company strategies that aim at influencing these shared perceptions might be effective in creating satisfaction. Specifically, it appears to be of importance to focus on shared perceptions of group social communication and group-efficacy. To enhance these group effects, 'visualizing of information' might be an appropriate strategy. Donath et al. (1999) suggest several graphical interfaces to enhance group processes, for instance the use of chat circles. Entering the session, each user is assigned a uniquely identified circle, visible on the screen for the moderator and all participants. During the session, a customer's overall level of activity is conveyed through the brightness of one's circle. Additionally one can use space. Circles can move close to each other to express support and positive feelings. One can imagine that at the end of a session, a group of bright (e.g., active) circles which are close to each other might create a positive feeling shared by the group. To enhance group-efficacy, one can highlight specific remarks and classify statements into color-coded categories, visible to the entire group. Information presented in an aggregated form gives individual users as well as the group overview and makes learning and evaluating easier (Avery et al. 1999). These strategies may not only enhance group dynamics but also provide feedback to the group about the regulation of socio-emotional and task aspects within the group.

To conclude, it seems that the companionship inherent to MGC can help on-line retailers to overcome the social gap that exists with respect to the on-line shopping experience. Human interaction can be an important part of the buying experience; orher humans provide information, help make purchase decisions, and give customers the possibility of developing a relationship with the advisor and/or orher customers. MGC with its presence of other customers and the advisor seems to bring back this interpersonal experience. Customers appreciate the knowledge of other group members, they enjoy interacting within a group, and appreciate the exchange of social communication. 


\section{Chapter 5}

\section{Moderated Group Chat: An Investigation of Alternative Models of Satisfaction}

We examine customer satisfaction with on-line moderated group chat (MGC) used as a new marketing tool. Three alternative models of satisfaction with MGC are proposed: an attribute-based model, an overall affect model, and a group characteristics model. The attribute-based model includes customer perceptions of control, enjoyment, reliability, speed of delivery, and ease of use. The overall affect model incorporates consumer feeling toward the use of technology and the need for real-life contact on-line. The group characteristics model is based on perceptions of task climate, social climate, group involvement, group similarity, and group receptivity. In addition, we take two contingencies relevant to MGC into account: 1) the style of the advisor, and 2) group-level processes. While our findings indicate that both attributes and group characteristics have a significant impact on customer satisfaction, the exact nature of the predictor-criterion relationships varies across the contingencies of advisor style and group-level processes. This suggests that for chat sessions in a marketing context attention should be paid to the role of the advisor and the fact that the formation of chat session satisfaction may be the result of processes that operate at the individual-level and/or at the group-level. 


\subsection{Introduction}

Due to its explosive growth and proliferation, the Internet has evolved from a virtual billboard for efficient information exchange and a virtual storefront for enabling sales transactions to a conduit for the delivery of services (Bergeron 2001). Interestingly, the infusion of technology in electronic (e-)services is changing the nature of the service delivery process in different ways. Thus far, the main focus in the service research literature has been on leveraging the Internet's potential for customization and flexibility through the increasingly active involvement of customers in the service delivery process. A multitude of services may now be initiated and distributed by the customer without direct or indirect contact with employees or other customers (Dabholkar 2000; Meuter et al. 2000). In many service industries, such as banking, brokerage, tourism and travel, successful self-service business models have already been developed and implemented (Barnes et al. 2000). In a sense, the ' $\mathrm{e}$ ' in the eservice encounters reflects the efficiency and ease of use commonly associated with these technology-mediated, self-service encounters.

However, whereas the use of on-line (and on-site) technology-based self-service seems effective, it has also been advocated that it may be desirable to accompany the focus on 'high tech' by an emphasis on 'high touch' in service delivery (Naisbitt et al. 2001). According to Albrecht and Zemke (2001 p. 8), relying too much on the implementation of technology-based self-service runs the risk of creating a 'commoditized sameness' that makes it difficult to provide the competitive differentiation and experiential value commonly associated with the service delivery process. Some customers may prefer the social aspects of interactions with employees and other customers as a value-added option (Barnes 1997; Ledingham 1984; Prendergast and Marr 1994), while others may have a need for human contact as a result of privacy and confidentiality concerns frequently associated with technologybased self-service (Bitner et al. 2000; Information Week 2001). Increasingly, therefore, customers are demanding real-time integration and human service in addition to automated cyber sale transactions and software agents. Research company NFO found that $13.7 \%$ of Internet users would buy products on-line if they could have real-time interaction with a sales person and additionally, $35 \%$ of shoppers would buy more products with on-line dialogues or 'multi-logues' (NFO Interactive 1999). From this viewpoint, the connotation of ' $e$ ' in e-service contains reference to the significance of the experiential value in on-line service environments (Mathwick et al. 2001).

In order to address the consequences of the recent shift in semantics of on-line service delivery, firms are exploring the potential of interactive and collaborative ebusiness functionalities that allow customers to interact with employees and other customers simultaneously and hence make the encounter less sterile. One increasingly popular use of innovative real-time customer contact options is company-hosted Internet Relay Chat (IRC), which allows for synchronous communication and information exchange. For example, catalog retailer Lands' End enables shoppers to consult a sales person and/or 'shop with a friend' during the electronic encounter. Petsmart.com allows customers to chat with other customers and a pets expert during scheduled on-line chat events and many financial service providers (e.g., American 
Express) are experimenting with chat services (Information Week 2001). Practitioners that experimented with IRC as a marketing instrument report above average visitorbuyer conversion rates (Business Week 2001). Other benefits of using IRC to leverage service effectiveness that are frequently mentioned are information targeting and service customization, real-time feedback gathering, cross-selling, and the creation of emotional bonds (Bergeron 2001; Kenny and Marshall 2000; Muniz and O'Guinn 2001; Rifkin 2000; Wolfinbarger and Gilly 2000).

Given that commercial IRC is a relatively new service delivery mode, firms need strategic direction regarding customer acceptance and evaluation, in order to design and promote this new channel accordingly. Therefore, there seems to be a need for research that integrates the dynamics of interpersonal encounters within a technology-based service context. In other words, the emerging body of research on technology-based self-service (e.g., Bitner et al. 2000; Dabholkar 2000; Hoffman 2001; Meuter et al. 2000) needs to be complemented by an empirical examination of technology-based interpersonal services. In this examination, it seems specifically relevant to take two unique characteristics of these services into account. An IRC in a commercial context is frequently moderated and research in on-line and off-line groups has shown that moderator behavior can influence an individual's and a group's evaluations (Barry and Stewart 1997; Fiedler and House 1988; Forsyth 1999). Furthermore, as IRC involves many-to-many communication and groups constitute a social environment, individual perceptions and group-level (shared) perceptions are likely to have different effects on customers' evaluations. Therefore, we need to explicitly consider the influence of moderator behavior, as well as the differential effects of individual and group perceptions on customers' evaluations. Taking these two characteristics of commercial IRC into account, the objective of this chapter is to investigate the factors that determine customers' evaluations of on-line chat sessions in a commercial context. Following the recent call for more replication research in marketing (e.g., Easley et al. 2000) and in order to anchor the study of new phenomena within the existing research tradition, we replicate and extend previous research on technology-based service delivery by Dabholkar (1996).

The chapter is structured as follows. We develop a conceptual foundation for explaining customer satisfaction in commercial chat groups in which we propose three alternative models. Next, we empirically assess these models, using multiple levels of analysis. We conclude with a discussion of results, and theoretical and managerial implications. Yet, we first summarize the IRC domain as described in Chapter 4, paragraph 4.2.

\subsection{The Domain of Commercial IRC}

There is a variety of IRC applications aimed at enhancing electronic selling and service environments. Figure 5-1 presents our conceptualization of present IRC options, based on a review of trade press, technology performance evaluations and academic literature (e.g., Business Week 2001; Levine et al. 2000; W; 1 lsh and Godfrey 2000). 
Figure 5-1: Categories of Commercial IRC

\begin{tabular}{|c|c|c|}
\hline & Dyadic & Many-to-many \\
\hline Customer-initiated & $\begin{array}{l}\text { 1) Customer service in response to the } \\
\text { customer. typically a 'Help me' question. }\end{array}$ & $\begin{array}{l}\text { 3) Open chat rooms: provide customers with a social } \\
\text { environment to share ideas, without an active role of the firm. }\end{array}$ \\
\hline Company-initiated & $\begin{array}{l}\text { 2) Customer service initiated by the } \\
\text { company: typically a "How can I help } \\
\text { you?" question. }\end{array}$ & $\begin{array}{l}\text { 4) Moderated group chat: customers actively discuss and } \\
\text { exchange information with other customers, moderated by a } \\
\text { customer service employee. }\end{array}$ \\
\hline
\end{tabular}

The rows represent the party who initiated the interaction: the customer versus the company. The columns represent the communication structure of the interaction: dyadic (dialogue) versus many-to-many ('multi-logue'). The first category of commercial IRC represents dyadic, customer-initiated chat. Examples of retailers using this service are Eddie Bauer, $\mathrm{J}$ Crew and Recreational Equipment Inc. (Information Week 2001). The second type of commercial IRC is also dyadic, but company-initiated. Companies watch visitors and push a dialog box to them (Bannan 2001). The third use of commercial IRC consists of the open chat rooms. For example, Recreational Equipment Inc. enables customers to swap tips on gear or adventure trips with other customers. Finally, a rapidly growing category of commercial IRC is moderated group chat (MGC). An example of this IRC application can be found at American Express, which organizes chat events as part of their on-line consumer financial services and as part of their corporate services. In addition, they organize events for specific customer groups like Small Business Owners and Blue-card members. Also, non-profit organizations as Debt Counselors of America, organize chat sessions to provide on-line financial advice. Related to MGC are on-line training sessions and seminars, which are often organized in a business-to-business context.

In the current study, we focus on MGC. A description of the unique advantages of MGC for customers and firms can be found in Chapter 4, paragraph 4.2. Service delivery via MGC creates a service experience involving two important components: technology and interpersonal aspects. Interpersonal aspects involve the consumer, the group, and the moderator. The next section elaborates on how these components may influence customers' evaluations of customer service in commercial chat groups.

\subsection{Development of a Conceptual Foundation}

With respect to the customer's evaluation of the chat session, the focus of this study is on satisfaction. It is well established that customer satisfaction is a critical outcome measure of face-to-face service encounters, technology-based self-service encounters, and encounters in on-line environments (Bitner et al. 1990; Keaveney and Parthasarathy 2001; Meuter et al. 2000; Szymanski and Hise 2000). Thus, customer satisfaction may be a crucial evaluative judgment outcome in technology-based interpersonal services as well. In this study, the focus is on customer satisfaction with 
the moderated chat session encounter and the objective is to gain an in-depth understanding of its determinants. We define chat session satisfaction as a customer's overall evaluation of the advisory chat service, including the financial advisor, the social contact, the financial advice, and the technology characteristics. Although the antecedents to customer encounter satisfaction are well documented in off-line contexts (e.g., Oliver 1997), relatively little is known about the levels of customer encounter satisfaction and their drivers with respect to e-retailing in general and MGC in particular (Szymanski and Hise 2000). Such research would provide specific diagnostic information to design this new channel.

Commercial MGC represents a unique form of service delivery and the dimensions of service delivery in traditional models may not apply or may have to be extended. From the computer-mediated communication (CMC) literature (e.g, Trevino and Webster 1992), as well as the research on customer-technology interfaces (e.g., Dabholkar 1996; Dabholkar and Bagozzi 2002), there is accumulating empirical evidence that both (dispositional) consumer characteristics (e.g., need for interaction) and technology characteristics (e.g., perceived ease of use) may explain individual satisfaction variance. However, as the advent of chat has created a new social space in which persons interact, satisfaction may also depend on the characteristics of the group (e.g., Forsyth 1999; Kahai and Cooper 1999).

The purpose of this study is to propose and test alternative models of chat session satisfaction. Drawing on Dabholkar's (1996) research on technology-based selfservice, we depart from two alternative models to explain chat session satisfaction: an attribute-based model and an overall affect model. In addition, we propose a third model: the group characteristics model, which includes factors like group similarity and social climate. In addition to comparing the three models, the proposed models are tested under different conditions (e.g., Dabholkar and Bagozzi 2002) in order to investigate the impact of the moderator's style of interaction on customers' evaluations (e.g., Bass 1997; Mason 1997; Price et al. 1995a).

\subsubsection{Attribute-Based Model}

The attribute-based model is based on a cognitive approach to decision-making. Customers evaluate relevant attributes associated with their experience with MGC in order to form cognitive evaluations of the chat session. In this sense, attributes are features of an experience that are noted or found meaningful by individuals (Mohammed et al. 2000). In the context of technology-based self-service, Dabholkar (1996) suggests five attributes of service delivery that are important to customers: speed of delivery, ease of use, reliability, enjoyment, and control. Other research on self-service as well as research on face-to-face interactions support the role of these attributes in influencing customers' evaluations (e.g., Bateson 1985; Dabholkar 1994; Davis et al. 1992; Foley et al. 1990; Hui and Tse 1996; Lockett and Littler 1997; Parasuraman et al. 1991; Winsted 1997). Recent research has also demonstrated that these attributes are important aspects of on-line shopping and computer interaction (e.g., Novak et al. 1999).

In addition to Dabholkar (1996), Hoffman and Novak. (1996), and Zeithaml et al. 
(2000) underscore the importance of perceived control. They found that customers evaluate the increased control they experience while shopping on-line as an important aspect of their electronic experience. Wolfinbarger and Gilly (2001) suggest that an important reason for people to choose on-line service options, is to feel in control. Dabholkar (1996) and Guiry (1992) suggest that control is a factor which is intrinsically important to most people, regardless of the channel of service delivery. In this study, perceived control is defined as the amount of control that a customer feels (s)he has over the process or outcome of a service delivery chat session (cf., Bateson and Hui 1987). In line with previous research, we hypothesize:

\section{$H_{1:} \quad$ Perceived control in MGC will bave a positive effect on participant chat session satisfaction.}

We define perceived enjoyment as the extent to which participants feel that service delivery via chatting is enjoyable. The importance of perceived enjoyment is underscored in the context of technology adoption and usage (Dabholkar 1994, 1996; Davis et al. 1992; Igbaria et al. 1996), as well as in the context of e-commerce (Novak et al. 1999; Wolfinbarger and Gilly 2001; Childers et al. 2001). In general, these studies suggest that perceived enjoyment positively affects the evaluation of the customer's technology mediated experience. In line with this research, we hypothesize:

\section{H2: Perceived enjoyment in MGC will have a positive effect on participant} chat session satisfaction.

Although Dabholkar (1996) failed to find a significant relationship between reliability and expected service quality, her earlier (1994) study found 'performance', defined as reliability of the technology-based self-service, to be a significant determinant of attitude. Zeithaml et al. (2000) also found that customers consider reliability when they evaluate their electronic service experience. Moreover, it has been argued that perceived reliability is especially important for newer technologies and service delivery options based on technology (Evans and Brown 1988; Webster and Hackley 1997). Therefore, we expect reliability to have an impact on chat session satisfaction; the technology could be unpredictable and it might crash. Customers put effort in the service delivery and in case the communication fails this probably will influence the customer's evaluation. We define reliability as the extent to which participants feel that service delivery via chatting is reliable. We hypothesize:

\section{$H_{3:} \quad$ Perceived reliability in MGC will have a positive effect on participant chat session satisfaction.}

Earlier findings with respect to speed of service delivery are mixed. While Dabholkar (1996) did not find a significant relationship between speed and service quality, the inclusion of waiting time in her study may have masked the effect of 
speed. In the case of e-service, Zeithaml et al. (2000) report a significant impact of speed on customers' evaluations. We define perceived speed as the customer's perceptions of the time it took to get the service provided via chatting. Customers today are highly sensitive to the speed of service delivery. They appreciate the timesaving inherent in on-line service delivery; there is no need to travel to the store and to wait in line, when they can sit down at the computer at home (Wolfinbarger and Gilly 2001). If communication in MGC is nor going smoothly and customers have to wait to get responses to questions, they will be less satisfied. This leads to the following hypothesis:

\section{$H_{t}:$ Perceived speed of delivery in MGC will have a positive effect on participant chat session satisfaction.}

Ease of use has also been advanced as an important aspect of computer interactions in many contexts. Perceived ease of use has been found to be a significant predictor of technology use (Agarwal and Prasad 1999; Dabholkar 1994, 1996; Davis et al. 1989; Vankatesh and Davis 2000). In the case of e-service, Childers et al. (2001) found that the ease of use of new interactive media positively influences customers' evaluations of the web-shopping experience. Also, Wolfinbarger and Gilly (2001) found ease of use to be an important aspect of on-line shopping. We define perceived ease of use as the extent to which participants feel that service delivery via chatting is easy. With respect to the context of MGC, we formulate the following hypothesis:

\section{Hs: Perceived ease of use in MGC will have a positive effect on participant chat session satisfaction.}

\subsubsection{Overall Affect Model}

The overall affect model, as suggested by Dabholkar (1996), is based on an affective approach where consumers would use overall predispositions (Dabholkar 1994; Johnson 1984) in their decision-making and their evaluation of mediated commerce modes. In the context of our study, this rationale implies that customers use overall predispositions to form perceptions of the MGC. Dabholkar (1996) suggests two general dispositions that are important to potential customers using technology-based service delivery: attitude toward using technological products and the need for interaction with a service employee.

Lockett and Littler (1997) found general attitude toward technological change to influence the adoption of on-line banking. Other empirical studies also have shown the existence of generalized judgments and its influence on the evaluation of a new situation (Dabholkar 1996; Park and Lessig 1981; Schillewaert et al. 2000). Modahl (2000) concluded that, with respect to on-line shopping, demographic factors such as age and gender do not matter anywhere near as much as the customer's attitudes toward technology. Dabholkar argues that the use of many forms of technology- 
based self-service represent a new situation to customers. In such cases, customers tend to make judgments about the new situation based on similar or related phenomena. As a commercial tool MGC is fairly new and a service delivery mode that many consumers may not have extensive experience with. In this study, we define attitude as a participant's general feeling toward using technology-based interactive e-services. We hypothesize:

\section{H6: Attitude toward using technology-based interactive e-services in general will have a positive effect on participant chat session satisfaction.}

Contrary to the positive influence of attitude, Dabholkar (1996) posits need for interaction with the service employee to have a negative influence on the expected quality of technology-based self-service options in which no human interaction takes place. Meuter et al. (2000) found support for a similar construct called 'avoiding service personnel.' Studies have shown that people have different perceptions of technology-based products dependent on the importance of retail contact to them (Forman and Sriram 1991). Forman and Sriram (1991) state that there are relatively large consumer groups who value social interaction when shopping. MGC brings back the human element to those services on the Internet which excluded the human aspect like automated transactions and software agents. It is well known that motivations of customers to engage in on-line retail shopping include both utilitarian and hedonic dimensions (Childers et al. 2001). On the one hand, people might appreciate shopping on-line because of the lack of social interaction, whereas on the other hand they might like on-line shopping because of the possibility of contact with others, the service employee as well as other customers (Albrecht and Zemke 2001; Wolfinbarger and Gilly 2001). According to Jupiter Research more than $90 \%$ of offline shoppers want some sort of human interaction while they shop on-line and Forrester research reports that $37 \%$ of Internet consumers request information or help (Bannan 2001). In this study, need for interaction concerns the extent to which users feel a need for real-life human contact, with other customers or with the service provider, in e-services. We believe that need for interaction will have an important influence on chat session satisfaction. Therefore, we hypothesize:

\section{Hr: Need for interaction with the service employee and other customers will have a positive effect on participant chat session satisfaction.}

\subsubsection{Group Characteristics Model}

The notion of group characteristics and their influence on an individual's evaluation of group interactions has received ample attention in the literature of $\mathrm{CMC}$, group dynamics, and decision-making (e.g., Barry and Stewart 1997; Forsyth 1999; Kahai and Cooper 1999). It is well known that presence and behavior of other customers are important influencers of a customer's experience (Arnould and Price 1993; 
Grönroos 1992; Grove and Fisk 1997; Parasuraman et al. 1991). In the context of MGC, this implies that characteristics of the group are likely to influence a customer's evaluation.

The research literature on group processes and outcomes asserts that three types of characteristics affect group members' evaluations, such as satisfaction (e.g., Day et al. 1995; Forsyth 1999; Kahai and Cooper 1999; Milliken and Martins 1996; Vallaster and Koll 2002; Watson and Kumar 1992): cognitive variables, affective variables, and communication-oriented variables. A cognitive variable relates to the instrumental task of the group and we conceptualize this variable as task climate. Affective variables relate to the social aspects of the group. In this study, we focus on social climate. Communication-oriented variables relate to the properties of the communication within the group. We conceptualize this variable as communication interactivity while measuring it by three dimensions: group involvement, group similarity, and group receptivity (Burgoon et al. 1999). We first discuss the general construct of group climate, and the distinction between task and social climate. Next, we discuss the third factor, communication interactivity, and its three dimensions.

The construct of group climate or 'atmosphere' has been used to capture the perceptually meaningful practices and procedures within the group, which are determinant for individual group members' evaluations (cf., Michela et al. 1996). The climate construct has been developed to account for the shared perception of relatively objective characteristics of people's psychological environments, varying from the efficiency of information processing to the supportive behavior of others. It is important to note that psychological environments may have different climates, varying from ethics (Dickson et al. 2001) to service (Schneider and Bowen 1995) to safety (Zohar 2000), each of which is associated with a different aspect of its functioning. Dickson et al. (2001) propose that climate is associated with desirable outcomes both at the individual and aggregate level, particularly when people find themselves in temporary and/or novel circumstances characterized by the absence of internalized core norms. Furthermore, recent work in areas like service climate (Schneider and Wheeler 1992) suggests that it is constructive to identify forms of climate that are conceptually congruent with the environment's outcomes.

Since performance evaluations (such as satisfaction) often take instrumental targets as well as affective aspects into account (cf., Oliver 1997), a distinction between task and social climate has been frequently made (Flap and Volker 2001; Gray 2001; Michela et al. 1996). Task climate reflects the orientation of an entity on instrumental parameters, such as information, time and costs, overall productivity, and efficiency. It is related to a cognitive evaluation of task performance. If chat group participants view the atmosphere as conducive to the processing of information, this will influence their evaluation of the chat experience. As such, a task climate may lead to higher satisfaction of participants in chat groups. In addition, a supportive atmosphere among group members also contributes to favorable performance evaluations (e.g., Adelman et al. 1987; Herbert and Coghen 1993). With regard to face-to-face service delivery, it has been shown that the inter-customer support and bonding, characteristic of a social climate, contribute to customer satisfaction (Adelman et al. 1994). Furthermore, research on on-line interactions has 
demonstrated that the social behavior of people in chat rooms is a decisive performance factor (Preece 1999). Finally, Gray (2001) empirically demonstrates that the performance of ad-hoc project groups is positively associated with both task climate and social climate. Therefore, we hypothesize that both task and social climate are significant antecedents of chat group satisfaction:

\section{Hs: Perceived task climate of the chat group will bave a positive effect on participant chat session satisfaction.}

\section{H: $\quad$ Perceived social climate of the chat group will have a positive effect on participant chat session satisfaction.}

As stated above, we focus on communication interactivity in addition to task and social climate. The use of climate measures, whether domain-specific (e.g., service) or pertaining to lower aggregation levels (e.g., workgroups and project teams) inevitably incorporates a collection of a system's general practices and procedures, and runs the risk of subsuming measures of unique attitudes and behavior (Ott 1989). Therefore, in order to strategically focus the study of chat groups on the unique aspects of multiway interaction and 'multi-logue', we propose to incorporate elements of communication interactivity. In the CMC literature, interactivity has been advanced as a paramount communication variable (Burgoon et al. 1999; Rafaeli 1993). It has been conceptualized as a multi-dimensional and experiential construct, consisting of a number of properties reflecting the communication process between senders and receivers. Salient properties that create the experience of interactivity are interaction involvement, similarity, and receptivity (Burgoon et al. 1999). Interaction involvement concerns the extent to which users perceive the group as engaged in the interaction, i.e., whether the interaction creates a sense of presence, of 'here and now in the group' (Burgoon et al. 1999). It has been demonstrated that participant involvement is an important determinant of evaluations in face-to-face (e.g., Forsyth 1999) and mediated group interactions (Burgoon et al. 1999). Therefore, we hypothesize:

\section{Ho: Perceived involvement of the chat group will have a positive effect on participant chat session satisfaction.}

The influence of group similarity on participant evaluations is underscored in studies of several disciplines (e.g., Burgoon et al. 1999; Dryer and Horrowitz 1997; Forsyth 1999; Graves and Powell 1995; Newcomb 1981). Group similarity concerns the extent to which participants perceive the group members as akin to themselves. This may be rooted in sharing similar beliefs and interests, as well as a preference for the same TV program (Forsyth 1999). Similarity with other people reassures us that our beliefs are accurate (Festinger 1954), creates a feeling of unity and serves as a signal that interaction will be free of conflict (e.g., Insko and Schopler 1972). In the context of face-to-face service encounters, the general presumption is that perceived similarity with the salesperson is likely to influence the customer's evaluation of the 
encounter positively (e.g., Crosby et al. 1990; Wiener and Mowen 1985). From research on CMC, which has a small contextual base of visual and audio cues, it appears that the more participants viewed themselves as similar to their interaction partners, the more they rated the interface as attractive, useful, and credible (Burgoon et al. 1999). Accordingly, we argue that in case customers interact in a chat group in which they perceive other participants as similar to them, they will be more satisfied:

\section{Hu: Perceived similarity with the participants of the chat group will have a positive effect on participant chat session satisfaction.}

Group receptivity is defined as the extent to which the group members listen to and are open to one another's ideas. With respect to face-to-face service delivery, a salesperson perceived as listening is associated with customer satisfaction (Ramsey and Sohi 1997). In the context of CMC, Burgoon et al. (1999) found group receptivity to be valuable for creating perceptions of friendliness among users. Furthermore, it was found that the more participants saw their interaction partner as receptive, the more they enjoyed working with the partner and the more they were satisfied with the partner's contribution. Along these lines, we expect the group's receptivity to be important to participant satisfaction with the chat session:

\section{Hi2: Perceived receptivity of the chat group will have a positive effect on participant chat session satisfaction.}

\subsubsection{Refinement of the Conceptual Foundation}

A goal of the study is to compare and evaluate alternative explanatory models. In Dabholkar's (1996) study, it was found that the consumers favored the attribute-based model in forming evaluations of service quality for technology-based self-service options. This was based on the finding that cognitive evaluations of service delivery attributes explained a substantial portion of the variance in expected service quality. Although the overall affect model was also supported, it did not add further explanatory power to the attribute-based model. Dabholkar (1996) stated that these results are in line with consumer decision-making theory wherein unfamiliarity with a situation encourages cognitive evaluations (Bettman and Park 1980; Park and Lessig 1981). Since MGC is also a new situation to many customers, we would expect the attribute-based model to be favored over the overall affect model. However, in the context of MGC, the group characteristics model might be preferred by customers, since the group forms a critical aspect of this innovative way of service delivery. We develop a research question regarding this comparative influence:

$R Q_{1:}$ Which model will have the greatest explanatory power: the attribute-based model, the overall affect model, the group characteristics model, or a combination of the models? 
Another objective of the study is related to the assessment of group characteristics. As discussed in Chapter 4, paragraph 4.3.4, perceptions of customers who chat in a group may not only refer to a person, but also to the group. One purpose of the present study is the investigation of the extent to which satisfaction with the chat session is associated with the customer's subjective experience, and the extent to which it is associated with the shared perceptions of the group. This purpose is reflected in the following research question:

\section{RQ2: To what extent will chat session satisfaction be influenced by the customer's subjective experience and to what extent by the shared perceptions of the variables?}

A third goal of the study is to determine the advisor's influence on the effect of the variables (individual and group perceptions) on participant satisfaction with the chat session. A group that performs well, in terms of satisfaction, is a group that has a full complement of roles active within it. There should be a balance between the different roles within a group to fulfill both the task and the social needs of the group (Bales 1950, 1958; Forsyth 1999; Hare 1976). Groups that maintain the balance evaluate their interactions more positively (Kahai and Cooper 1999). There might be several possibilities to create balance. Balance might be established when the advisor's style is complementary to the attributes, predispositions, and processes within the group. It also could be that the balance within the group is created by different roles within the group, independently from the role of the advisor. We develop a research question regarding this possible influence of the advisor on the relationships between the independent variables and chat session satisfaction:

\section{$R Q_{3}$ : What influence, if any, will the communication style of the advisor (task and social) have on the effect of the variables (subjective and shared perceptions) on participant chat session satisfaction?}

\subsection{An Empirical Study}

For an elaborate discussion of the research method, procedure, pre-test, and sample issues we refer the reader to Chapter 4 , as this study is based on the same database. Below a brief synopsis of the most salient details is given.

\subsubsection{Method}

To test our research hypotheses and questions, we organized chat sessions in a laboratory experimental setting. In the experiments, respondents chatted with an advisor and others in the context of financial advising. 


\subsubsection{Procedure}

For each experimental chat session, small groups ( 4 to 7 persons) were invited to a research laboratory. The experiment started with an introduction, then each participant was presented with the same scenario and the chat session began. In half of the groups, the advisor was social-oriented and in the other half, he was taskoriented. In order to standardize the manipulation of the style of the advisor as much as possible, scripts were developed, which the advisor used during every session. Samples of these scripts can be found in Chapter 4, figure 4-2.

\subsubsection{Pre-Test}

The scenario, the scripts and the behavior of the advisor were developed and rained based on extensive pre-testing. The pre-testing continued through several irerations, until we were reasonably certain that the manipulations (scripts and behavior of the advisor) did create a treatment effect.

\subsubsection{Sample}

Participants in this experiment were 212 students from a large Dutch University. In total 40 groups were formed. Each group was randomly assigned to the treatment. Of the total respondents, 20 groups (106 respondents) received the social style treatment and 20 groups (106 respondents) received the task style treatment.

\subsubsection{Questionnaire Development}

All scale items of the survey were measured on 7-point Likert-scale ranging from 'totally disagree' to 'totally agree'.

Chat session satisfaction: We used all items as described in Chaprer 4 paragraph 4.4.5. Attributes: The items measuring control (4 items), enjoyment ( 4 items), reliability (4 items), speed of delivery (4 items), and ease of use (4 items) of the investment advisory service were based upon instruments developed by Dabholkar (1996).

Overall affect: The scales measuring attitude toward technology based interactive e-services (4 items) and need for live interaction ( 4 items) were also based on instruments developed by Dabholkar (1996).

Group characteristics: The three items measuring task climate and the five items measuring social climate were based upon a scale developed by Fiedler (1967). Group involvement ( 4 items), group similarity ( 3 items), and group receptivity ( 3 items) were measured using items adapted from scales developed by Burgoon and Hale (1987). We employed two techniques to test the factor structure and item loadings of the scaleconstructs of the independent variables. We initially examined coefficient alphas of all constructs. In addition, principal component analyses (varimax rotation) were employed to investigate the structure of the constructs. Three separate principle component analyses concerning the attribute-based model, the overall affect model, 
and the group characteristics model respectively, yielded a five-factor, a two-factor, and a five-factor structure with items loading on the expected dimensions. In addition, the items of the constructs were subjected to confirmatory factor analysis (CFA) using LISREL (Jöreskog and Sörbom 1993) to assess the critical measurement properties of the scales. The indices of the proposed five factor model for the items of the attribute-based model, the proposed two factor model for the overall affect model, and the five factor model for the group characteristics model provided a good fit, revealing unidimensionality of the scales. For all three proposed factor models, the fit indices, construct reliabilities of the scales, and confirmatory factor loadings with t-values for each item are represented in table 5-1. Construct reliabilities of all scales were tested by means of Cronbach's alpha. Coefficients of all measures were at least .75 , which implies that reliability is deemed acceptable. Next, within-method convergent validity was examined by investigating the significance and magnitude of the item loadings. All items loaded significantly on their respective construct (minimum $t$-value $=7.33$ ) where all items had a standardized loading of at least .55 . In addition, discriminant validity was evaluated by testing whether pairs of constructs were correlated less than unity. Chi-square difference tests with one degree of freedom were used to test for unity between pairs of constructs. All tests were significant at the .05 significance level.

Table 5-1: Results of Confirmatory Factor Analyses

Measures

Factor loadings t-value

Attribute-based model

Fit indices: (GFI=.91; $\mathrm{AGFl}=.87 ; \mathrm{RMSEA}=.045 ; \mathrm{NNFI}=.97 ; \mathrm{CFI}=.97$ )

Control $(n=4 ; \alpha=.89)$

I feel much control over the advisory process when using chat

Through this advisory service I have a direct influence on getting the information I need $\quad .81$

This advisory service enables to get a grip on the necessary investment intormation

Chat will give me more control over the service process

Enjoyment $(n=4 ; \alpha=.90)$

This investment advisory service is enjoyable

This investment advisory service is fun

This investment advisory service is entertaining

Reliability $(n=3 ; a=.80$ )

This investment advisory service delivers what it promises

This investment advisory service is something l expect to work well

This investment advisory service is reliable

Spoed of dellvery $(n=4 ; a=89)$

This investment advisory service is a fast way of service delivery

This investment audvisory service takes a long time s

This investment advisory service is time efficient

This investment advisory service takes too much time " 
Table 5-1: Results of Confirmatory Factor Analyses (continued)

\begin{tabular}{|c|c|c|}
\hline Measures & Factor losdings & t-value \\
\hline \multicolumn{3}{|l|}{ Overali affect model } \\
\hline \multicolumn{3}{|l|}{ Fit indices: (GFI=.98; $\mathrm{AGFl}=.96 ; \mathrm{RMSEA}=.024 ; \mathrm{NNFl}=.99 ; \mathrm{CFl}=1.00)$} \\
\hline \multicolumn{3}{|c|}{ Attitude $(n=4 ; a=.77)$} \\
\hline \multicolumn{3}{|c|}{ How would you describe your feelings toward using technology-based interactive e-services in general? } \\
\hline Good & .59 & 7.96 \\
\hline Pleasant & .55 & 7.33 \\
\hline Beneficial & .68 & 9.41 \\
\hline Favorable & .80 & 11.07 \\
\hline \multicolumn{3}{|l|}{ Need for interaction ( $n=3 ; \alpha=.75$ ) } \\
\hline Feal-life human contact in e-services makes the process enjoyable for the customer & .66 & 9.10 \\
\hline In e-services, I like interacting with the person who provides the service & .81 & 10.89 \\
\hline On-ine personal interaction by the service employee is not very important for me a & .62 & 8.54 \\
\hline \multicolumn{3}{|l|}{ Group characteristics model } \\
\hline \multicolumn{3}{|l|}{ Fit indices: (GFl=.92; AGFI=.88; RMSEA=.041; NNFI=.97; CFl=.97) } \\
\hline \multicolumn{3}{|l|}{ Task climate $(n=3 ; \alpha=.88)$} \\
\hline This group was not very effective a & .82 & 13.53 \\
\hline The group climate during the chat session was productive & .82 & 13.54 \\
\hline The group climate during the chat session was successful & .88 & 14.99 \\
\hline \multicolumn{3}{|l|}{ Social climate $(n=5 ; \alpha=.88)$} \\
\hline The group climate during the chat session was friendly & .74 & 11.74 \\
\hline The group climate during the chat session was accepting & .72 & 11.23 \\
\hline The group climate during the chat session was warm & .76 & 12.21 \\
\hline The group climate during the chat session was cooperative & .80 & 12.88 \\
\hline The group climate during the chat session was supportive & .77 & 12.19 \\
\hline \multicolumn{3}{|l|}{ Involvement $(n=4 ; a=.85)$} \\
\hline The group was intensively involved in our conservation & .73 & 11.38 \\
\hline The group was interested in talking & .71 & 11.05 \\
\hline The group showed enthusiasm while talking & .75 & 11.87 \\
\hline The group seemed to find the conversation stimulating & .83 & 13.63 \\
\hline \multicolumn{3}{|l|}{ Similarity ( $n=3 ; \alpha=.85$ ) } \\
\hline The group was different than me a & 70 & 10.89 \\
\hline The group made me feel we had a lot in common & .89 & 14.93 \\
\hline The group made me feel they were similar to me & .86 & 14.30 \\
\hline \multicolumn{3}{|l|}{ Receptivity ( $n=3 ; \alpha=83$ ) } \\
\hline The group was willing to listen to me & .73 & 11.17 \\
\hline The group was unresponsive to my ideas a & 81 & 12.89 \\
\hline The group was open to my ideas & 84 & 13.42 \\
\hline
\end{tabular}

a Reverse coded.

\subsection{Multi-Level Analysis and Model Building}

For this study, multi-level modeling is used, since our data can be characterized as a hierarchically nested data structure, i.e., customers within chat groups (Bryk and Raudenbush 1992). A detailed explanation of multi-level modeling and the interpretarion of a multi-level model can be found in Chapter 2, paragraph 2.4. In the present study, a two-level model was specified for the dependent variable chat session satisfaction. To compare within-group and between-groups coefficients of the 
variables, we divided them into the group mean and the within-group deviation variable. The individual-level of the model concerns all within-group deviation scores of the variables. The group-level reflects all group means of the variables. The coefficient of the group-means measures the between-groups effect, whereas the coefficient of the within-group deviation scores measures the within-group effect (Bryk and Raudenbush 1992). The multi-level model for chat session satisfaction is formulated as follows for the attribute-based model:

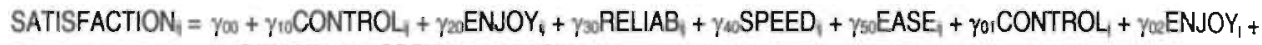

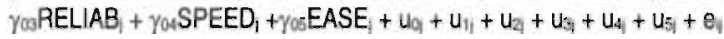

The multi-level model for chat session satisfaction is formulated as follows for the overall affect model:

SATISFACTION ${ }_{i}=\gamma_{00}+\gamma_{10}$ ATTITUDE $_{i}+\gamma_{20}$ NEED $_{i}+\gamma_{01}$ ATTITUDE $_{1}+\gamma_{00}$ NEED $_{i}+u_{09}+u_{11}+u_{2}+e_{i}$

The multi-level model for chat session satisfaction is formulated as follows for the group characteristics model:

SATISFACTION $=\gamma_{00}+\gamma_{10}$ TASKCLIM $_{1}+\gamma_{20}$ SOCCLIM $_{1}+\gamma_{30}$ INVOLV $_{1}+\gamma_{40}$ SIMIL $_{i}+\gamma_{50}$ RECEP $_{i}+\gamma_{01}$ TASKCLIM $_{1}+$

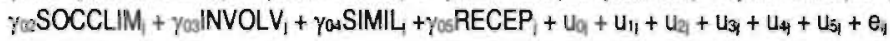

where $i$ stands for individuals; $j$ indicates groups; SATISFACTIONa $N_{q}$ refers to the degree of chat session satisfaction of customer $i(i=1, \ldots n c)$ in group $j(j=1, \ldots n G)$; CONTROL, ENJOY, RELIAB ${ }_{3}$, SPEED$_{1}$, EASE $_{\text {i }}$ are control, enjoyment, reliability, speed of delivery, and ease of use at the individual-level respectively; CONTROL, ENJOY, RELIAB, SPEED, EASE; are control, enjoyment, reliability, speed of delivery, and ease of use at the group-level respectively; $A T T I U D E_{i}, N_{N E E D_{i j}}$ are attitude toward technology-based interactive eservices and need for live interaction at the individual-level respectively; ATITUDE, NEED; are attitude toward technology-based interactive e-services and need for live interaction at the group-level respectively; TASKCLIM, SOCCLIM, INVOLV task climate, social climate, group involvement, group similarity, and group receptivity at the individual-level, respectively; TASKCLIM, SOCCLIM, INVOLV, SIMIL, RECEP, are task climate, social climate, group involvement, group similarity, and group receptivity at the group-level, respectively.

\section{$5.6 \quad$ Results}

The results of the manipulation checks show that the treatment worked well. In the groups with a task-oriented advisor, the items are 5.54 for task-orientation and 3.78 for social-orientation $(t=-13.33, p<.001)$ and in the groups with a social-oriented advisor, these means are 3.78 for task-orientation and 5.60 for social-orientation $(t=14.77, p<.001)$. 
Table 5-2: Variance Attributed to Group Factors and the Customer's Subjective Assessment

\begin{tabular}{lccc}
\hline & Group-level & Individual-level & Intraclass correlation " \\
\hline Variables & $22 \%$ & $74 \%(4)$ & .23 \\
Satistaction & $9 \%$ & $86 \%(5)$ & .10 \\
Control & $15 \%$ & $79 \%(6)$ & .16 \\
Enjoyment & $8 \%$ & $80 \%(12)$ & .10 \\
Reliability & $17 \%$ & $78 \%(5)$ & .18 \\
Speed & $17 \%$ & $71 \%(12)$ & .20 \\
Ease of use & $0 \%$ & $77 \%(23)$ & .00 \\
Attitude & $0 \%$ & $75 \%(25)$ & .00 \\
Need for interaction & $25 \%$ & $66 \%(9)$ & .28 \\
Task climate & $26 \%$ & $65 \%(9)$ & .29 \\
Social climate & $19 \%$ & $69 \%(12)$ & .22 \\
Group involvement & $0 \%$ & $85 \%(15)$ & .00 \\
Group similarity & $10 \%$ & $75 \%(15)$ & .12 \\
Group receptivity & & 75 & \\
\hline
\end{tabular}

Note: Values between parentheses: percentage of the individual-level variance attributed to measurement error. a ICC-coefficients are corrected for unreliability.

Group-level variance and individual-level variance of all variables were decomposed to examine within-group agreement and between-groups differences. Results in table 5-2 indicate that attitude, need for interaction ${ }^{1}$, and group similarity do not have any group-level variance. Because perceptions of these variables were apparently not shared by other members of the group they are only included as individual-level effects. For the other variables, a small to substantial part concerns between-groups variance. Intra-class correlations range from .10 to .29 , so it can be concluded that the perceptions of these variables were partly shared by the other customers in the chat group. Therefore, it was appropriate to add them to the model as group-level variables. Regarding chat session satisfaction, the intra-class correlation indicates that a multi-level approach is appropriate. Multi-level models are considered as models that may be subject to multi-collinearity. Therefore, ordinary regression analyses were conducted to investigate multi-collinearity by means of the Variance Inflation Factor (VIF). The VIF's of the predictor variables were lower than 2.8, hence no severe multi-collinearity problems were to be expected (Kleinbaum et al. 1988). To test the hypotheses and research questions, separate analyses for the groups with a task- and social-oriented advisor were conducted. Means, standard deviations, individual-level and group-level correlations between the variables for groups with a social-oriented advisor and groups with a task-oriented advisor are respectively presented in table 5-3.

\footnotetext{
'Regarding the two predispositions, we did not expect any between-groups variance. We conceprualized these variables as general constructs which are related to the individual consumer and not as perceptions of the particular chat session. Therefore, attitude and need for interaction were measured before the chat session took place. Though it could be that randomly, some groups had more people with a positive attitude than other groups for instance. However, the results show that the predispositions do not have any significant between-groups variance.
} 
Table 5-3: Means, Standard Deviations, and Correlations

\begin{tabular}{|c|c|c|c|c|c|c|c|c|c|c|c|c|c|c|}
\hline \multicolumn{15}{|c|}{ Groups with a social-oriented advisor } \\
\hline Variables & Means (s.d.) & 1 & 2 & 3 & 4 & 5 & 6 & 7" & $8=$ & 9 & 10 & 11 & $12 a^{a}-a b a$ & $\sqrt{13}$ \\
\hline 1. Satisfaction & $4.70(1.30)$ & & .48 & .24 & .53 & .47 & .51 & & & .44 & .39 & .35 & & .26 \\
\hline 2. Control & $4.24(1.48)$ & .57 & & .40 & .84 & .68 & .68 & & & .68 & .56 & .52 & & .09 \\
\hline 3. Enjoyment & $5.42(1.03)$ & .46 & .48 & & .44 & .33 & .49 & & & .26 & .36 & .20 & & -.01 \\
\hline 4. Reliability & $4.24(1.26)$ & .57 & .76 & .53 & & .71 & .69 & & & .70 & .63 & .55 & & 20 \\
\hline 5. Speed & $4.92(1.46)$ & .38 & .46 & .19 & .47 & & .75 & & & .56 & .48 & .33 & & 11 \\
\hline 6. Ease of use & $5.04(1.39)$ & .26 & .37 & .40 & .27 & .36 & & & & .60 & .71 & .38 & & .26 \\
\hline 7. Attitude & $5.15(.90)$ & .17 & .11 & .33 & .14 & .04 & .11 & & & & & & & \\
\hline 8. Need for interaction & $5.21(1.03)$ & .34 & .34 & .40 & .42 & .26 & .20 & .20 & & & & & & \\
\hline 9. Task climate & $4.75(1.31)$ & .34 & .43 & .24 & .37 & .24 & .17 & -.07 & 13 & & .57 & .86 & & .51 \\
\hline 10. Social climate & $5.50 \quad(.92)$ & .18 & .30 & .53 & .31 & .17 & .27 & .08 & .08 & .33 & & .51 & & .14 \\
\hline 11. Involvement & $5.59(.94)$ & .32 & .30 & .40 & .32 & .22 & .22 & .24 & .24 & .44 & .51 & & & .54 \\
\hline 12. Similarity & $3.74(1.11)$ & .16 & .13 & .27 & .13 & -.01 & .02 &. .04 & .08 & .23 & .27 & 19 & & \\
\hline 13. Receptivity & $4.77(1.19)$ & .09 & .21 & .24 & .19 & .06 & .10 & .02 & .02 & .26 & .41 & .27 & .32 & \\
\hline \multicolumn{15}{|c|}{ Groups with a task-oriented advisor } \\
\hline Variables & Means (s.d.) & 1 & 2 & 3 & $\overline{4}$ & 5 & 6 & 79 & $8^{\circ}$ & 9 & 10 & 11 & $12^{a}$ & 13 \\
\hline 1. Satisfaction & $3.45(1.59)$ & & .32 & .15 & .27 & .15 & .09 & & & .22 & .22 & .10 & & .25 \\
\hline 2. Control & $3.94(1.39)$ & .65 & & .54 & .58 & .50 & .51 & & & .44 & .57 & .24 & & .51 \\
\hline 3. Enjoyment & $4.48(1.40)$ & .57 & .52 & & .28 & .39 & .37 & & & .03 & .53 & .54 & & .29 \\
\hline 4. Reliability & $3.85(1.27)$ & .62 & .53 & .51 & & .52 & .23 & & & .43 & .49 & -.01 & & .51 \\
\hline 5. Speed & $4.61(1.51)$ & .54 & .47 & .55 & .40 & & .47 & & & .43 & .42 & .03 & & .12 \\
\hline 6. Ease of use & $4.61(1.46)$ & .40 & .38 & .31 & .42 & .41 & & & & -.00 & -.01 & .08 & & .18 \\
\hline 7. Attitude & $5.31 \quad(.92)$ & .16 & .17 & .26 & .16 & .27 & .10 & & & & & & & \\
\hline 8. Need for interaction & $5.11(1.17)$ & .22 & .25 & .23 & .21 & .15 & .05 & .23 & & & & & & \\
\hline 9. Task climate & $3.81(1.38)$ & .37 & .28 & .41 & .37 & .37 & .18 & .05 & .08 & & .61 & -.01 & & .38 \\
\hline 10. Social climate & $4.41(1.09)$ & .35 & .29 & .42 & .38 & .35 & .26 & .08 & .17 & .57 & & .43 & & .53 \\
\hline 11. Involvement & $4.77(1.02)$ & .27 & .12 & .32 & .33 & .16 & .14 & -.06 & .08 & .57 & .60 & & & .34 \\
\hline 12. Similarity & $3.32(1.33)$ & .46 & .40 & .29 & .43 & .22 & .17 & .25 & .14 & .47 & .44 & .37 & & \\
\hline 13. Receptivity & $4.31(1.09)$ & .38 & .26 & .38 & .19 & .18 & .21 & .10 & -.01 & .33 & .38 & .29 & .43 & \\
\hline
\end{tabular}

Note: Individual-level correlations are in the lower trangle and group-level correlations are in the upper triangle. Correlations in the upper triangle are the correlations between the group averages. a Since these variables do not have any between-groups variance, they are not included in our research as group-level variables. All correlations $>.18$ are signiticant at $p<.05$ (two-tailed).

Note that in table 5-3, speed of delivery is highly correlated with ease of use at the group-level and reliability with control at the group- and individual-level. These intercorrelations are not entirely unexpected because the constructs are closely related and also found to be highly correlated in Dabholkar's (1996) study. The reason for the high correlation between task climate and group involvement at the group-level is not as clear. It might be that this correlation has a conceptual basis; Forsyth (1999) for instance suggests that high inputs (e.g., task climate) are strongly related to high commitment. It is also possible that this correlation does not have a conceptual basis; it has been argued that high correlations at the group-level are not an uncommon phenomenon in hierarchical models (Ostroff 1993).

Table 5-4, 5-5, and 5-6 present the results of our multi-level analyses regarding chat session satisfaction for the separate analyses for groups with a social- and a taskoriented advisor. Regarding $\mathrm{RQ}$, we had to estimate to what extent chat session satisfaction is influenced by the individual's subjective experience, and to what txtent 
by the shared perceptions of the variables. Therefore, first, the within-group deviation scores of all variables were added to the model (step 1). Secondly, the group means of variables were included (step 2). None of the random slopes was significant, which implies that in this context inclusion of a random intercept-only is most. appropriate (Snijders and Bosker 1999). The fixed effects of single predictor variables were tested by means of one-tailed t-tests (i.e., the coefficient divided by its standard error). Simulations have been conducted to test accuracy of the parameter estimates. Parametric bootstrapping was applied. In tables 5-5, 5-6, and 5-7, the results of bootstrapping based on 500 replications are indicated.

\subsubsection{Attribute-Based Model}

The results in table 5-4 indicate that, at the individual-level, control, tnjoymenr, reliability, and speed of delivery are significant for both, groups with a social-oriented advisor and groups with a task-oriented advisor. Therefore, $\mathrm{H}_{2} \mathrm{H}_{2} \mathrm{H}$, and $\mathrm{H}_{1}$ are accepted. The group-level coefficient of control is significantly higher compared to the within-group deviation coefficient of control for groups with a task-oriented advisor, so, the effect operates at both levels. Reliability is significant for both groups, but only the group-level coefficient for socially moderated groups is significantly higher compared to the within-group deviation coefficient. For these groups, the effect operates at both levels. Ease of use is significant for groups with a socialoriented advisor, but only at the group-level. So, $\mathrm{H}_{5}$ is only accepted for those groups.

Table 5-4: Results of the Multi-Level Analyses: Attribute-Based Model

\begin{tabular}{|c|c|c|c|c|}
\hline & Social & & Task & \\
\hline & Coefficients (SE) a & Bootstrap & Coefficients (SE)" & Bootstrap \\
\hline \multicolumn{5}{|c|}{ Step 1 (individual-level) b } \\
\hline \multicolumn{5}{|c|}{ Attributes } \\
\hline Control & $.28(.08)^{d}$ & $.28(.09)^{*}$ & $.42(.09)^{4}$ & $.42(.10)^{d}$ \\
\hline Enjoyment & $.30(.09)^{\circ}$ & $.30(.10)^{d}$ & $.21(.09)^{d}$ & $.19(.08)^{d}$ \\
\hline Reliability & $.21(.10)^{8}$ & $.20(.09)^{d}$ & $.39(.09) \mathrm{di}$ & $.40(.10)^{\sigma}$ \\
\hline Speed & $.16(.07)^{4}$ & $.16(.07)^{\circ}$ & $.20(.08)$ & $.20(.09)^{d}$ \\
\hline Ease of use & $-.05(.07)$ & $-.05(.08)$ & $.05(.08)$ & $.06(.14)$ \\
\hline Increase in model fit & $\chi^{2}(5)=87.7^{\circ}$ & & $x^{2}(5)=105.2^{\circ}$ & \\
\hline \multicolumn{5}{|l|}{ Step 2 (group-level) } \\
\hline \multicolumn{5}{|l|}{ Attributes } \\
\hline Control & $.03(.17)$ & $.01(.08)$ & $.77(.20)^{4}$ & $.79(.22)^{\circ}$ \\
\hline Enjoyment & $-.20(.25)$ & $-.23(.33)$ & $-.02(.15)$ & $-.01(.17)$ \\
\hline Reliability & $.68(.21)^{\circ}$ & $.68(.23)^{t}$ & $.42(.23)^{2}$ & $.42(.26)^{c}$ \\
\hline Speed & $.06(.13)$ & $.09(.26)$ & $-.07(.14)$ & $-.08(.20)$ \\
\hline Ease of use & $.46(.15)^{a}$ & $.43(.16)^{\circ}$ & $-.14(.13)$ & $-14(1.14)$ \\
\hline Increase in model fit & $X^{\prime}(5)=41.4^{\circ}$ & & $x^{2}(5)=24.7^{i}$ & \\
\hline
\end{tabular}

Note: a Unstandardized coefficients with their standard errors. "Within-group deviation score $X_{1}-X_{6}{ }^{2} p<.05$ (one-tailed); ${ }^{\mathrm{D}} \mathrm{p}<.01$ (one-tailed): ${ }^{8} \mathrm{p}<.05$. 


\subsubsection{Overall Affect Model}

Table 5-5 shows that atritude is not significant for any group, so $\mathrm{H}_{6}$ has to be rejected. Furthermore, the results reveal that need for interaction is significant for groups with a social-oriented advisor and for groups with a task-oriented advisor. Therefore, $\mathrm{H}_{7}$ is accepted.

Table 5-5: Results of the Multi-Level Analyses: Overall Affect Model

\begin{tabular}{lllll}
\hline & Social & & Task & \\
\hline Step 1 (individual-level) & & & \\
Predispositions & Coefficients (SE) & Bootstrap & Coefficients (SE) & Bootstrap \\
$\quad$ Attilude & & & & \\
$\quad$ Need for interaction & $.17(.12)$ & $.17(.15)$ & $.22(.18)$ & $.22(.15)$ \\
Increase in model fit & $.43(.11)^{\circ}$ & $.42(.10)^{\circ}$ & $.29(.14)^{\circ}$ & $.28(.14)^{\circ}$ \\
\hline
\end{tabular}

Note: " Unstandardized coefficients with their standard errors. ${ }^{5}$ Within-group deviation score $X_{i}-X_{j} ;{ }^{c} p<01$ (one-tailed); ${ }^{6} p<.05$.

Table 5-6: Results of the Multi-Level Analyses: Group Characteristics Model

\begin{tabular}{|c|c|c|c|c|}
\hline & Social & & Task & \\
\hline & Coefficients (SE) & Bootstrap & Coefficients (SE) ${ }^{a}$ & Bootstrap \\
\hline \multicolumn{5}{|c|}{ Step 1 (individual-level) $\mathrm{b}$} \\
\hline \multicolumn{5}{|c|}{ Group characteristics } \\
\hline Task climate & $.28(.11)^{c}$ & $.28(.11)^{\circ}$ & $.15(.14)$ & $.17(.17)$ \\
\hline Social climate & $.08(.15)$ & $.08(.15)$ & $.21(.16)$ & $.20(.15)$ \\
\hline Group involvement & $.34(.13)^{\mathrm{c}}$ & $.35(.13)^{c}$ & $-.05(.18)$ & $-.01(.02)$ \\
\hline Group similarity & $.10(.10)$ & $.08(.09)$ & $.43(.12)$ & $.41(.12)^{6}$ \\
\hline Group receptivity & $-.08(.10)$ & $-.07(.07)$ & $.31(.15)^{\circ}$ & $.30(.14)^{c}$ \\
\hline Increase in model fit & $x^{2}(5)=25.6^{d}$ & & $x^{2}(5)=40.3^{\circ}$ & \\
\hline \multirow{2}{*}{\multicolumn{5}{|c|}{$\begin{array}{l}\text { Step } 2 \text { (group-level) } \\
\text { Group characteristics }\end{array}$}} \\
\hline & & & & \\
\hline Task climate & $.68(.28)^{c}$ & $.71(.33)^{c}$ & $.44(.22)^{c}$ & $.45(.22)^{c}$ \\
\hline Social climate & $.59(.26)^{c}$ & $.55(.25)^{e}$ &. $.04(. .46)$ & $.03(.11)$ \\
\hline Group involvement & $.47(.47)$ & $-.48(.44)$ & $.30(.33)$ & $.27(.25)$ \\
\hline Group receptivity & $.28(.26)$ & $.25(.20)$ & $.54(.25)^{c}$ & $.53(.26)^{6}$ \\
\hline Increase in model fit & $x^{2}(4)=19.0^{\circ}$ & & $x^{2}(4)=16.6^{d}$ & \\
\hline
\end{tabular}

Note: "Unstandardized coefficients with their standard errors. Within-group deviation score $X_{i}-X_{j}{ }^{c} p<.01$ (one-tailed); ${ }^{\circ} p<.05$.

\subsubsection{Group Characteristics Model}

The results in table 5-6 indicate that, at the individual-level, task climate and group involvement are significant in socially moderated groups. Therefore, $\mathrm{H}_{s}$ and $\mathrm{H}_{10}$ are accepted for those groups. Group similarity and group receptivity are significant for groups with a task-oriented advisor, so $\mathrm{H}_{11}$ and $\mathrm{H}_{12}$ are accepted for those groups. At the group-level, task climate is significant for both groups, and the group-level coefficient is significantly higher compared to the within-group deviation coefficient. 
Social climate is significant in socially moderated groups at the group-level only and group receptivity is significant for task-oriented groups. The group-level coefficient of group receptivity is significantly higher compared to the within-group deviation coefficient, so the effect operates at both levels. Therefore, at the group-level, $\mathrm{Hs}$ is accepted for both styles, $\mathrm{H}_{9}$ for the social treatment and $\mathrm{H}_{12}$ for the task treatment. Interestingly, there is no between-groups variance for group similarity. This implies that group members do not share perceptions of group similarity.

\subsubsection{Research Questions Results}

With respect to $R Q_{1}$, table 5-7 shows that for both styles of the advisor the attributebased model and the group characteristics model have good fits, as the difference between the deviance statistics for the models are significant compared to the intercept-only model. The overall affect model has a good fit only for the socially moderated groups. The attribute-based model has the best model fit and explains most of the variance of chat session satisfaction. The combined model including all attributes and predispositions (model D) as specified independent variables shows that the increase in explained variance on including the overall affect variables was merely incremental over the variance explained by the attribute-based model alone (model A). Also, the increase in model fit of model D compared to model $A$ is nonsignificant. The combined model using all attributes, predispositions, and group characteristics (model E) as independent variables shows an increase in explained variance on including the group characteristics over the variance explained by the attribute-based and overall affect model together (model D). Also, the increase in model fit of model $\mathrm{E}$ compared to model $\mathrm{D}$ is significant.

Table 5-7: A Test of Alternative Models for Different Advisor's Styles

Cornbined models

$\begin{array}{lllll}\text { (A) } & \text { (B) } & \text { (C) } & \text { (D) } & \text { (E) } \\ \begin{array}{l}\text { Attribute-based } \\ \text { model }\end{array} & \begin{array}{l}\text { Overall affect } \\ \text { model }\end{array} & \begin{array}{l}\text { Group } \\ \text { characteristics } \\ \text { model }\end{array} & \begin{array}{l}\text { Attribute and } \\ \text { overall affect }\end{array} & \begin{array}{l}\text { Attribute, overall affect, } \\ \text { group characteristics }\end{array} \\ & & & \end{array}$

Social-oriented

Increase in model fit

Explained variance

$x^{2}(10)=129.1^{2 . d}$

$x^{2}(2)=19.1^{\text {a.d }}$

$x^{2}(9)=44.6^{\text {a.d }}$

$x^{2}(2)=1.9^{\circ}$

$x^{2}(9)=22.9$ cd

Individual-level

Group-level

Task-oriented

Increase in model fit

Explained variance

Individual-level

Group-leve|

$72.8 \%$

$88.7 \%$

$36.9 \%$

$9.5 \%$

$41.4 \%$

$70.7 \%$

\section{$73.3 \%$}

$88.9 \%$

$78.5 \%$

$91.1 \%$

$x^{2}(10)=129.9^{\text {ad }} \quad x^{2}(2)=7.0^{\text {add }} \quad x^{2}(9)=56.8^{\text {a.d }} \quad x^{2}(2)=.7^{\circ} \quad x^{2}(9)=19.5^{\text {cdd }}$

The difference between the deviance statistics ( $\triangle$ Deviance) has an $\chi^{2}$-distribution (with the number of added predictors as degrees of freedom) under $H_{b}$ that the model does not predict significantly better than the intercept-onily model; ${ }^{\circ} \mathrm{H}_{0}$. the model does not predict significantly better than model $(\mathrm{A}) ;{ }^{\circ} \mathrm{H}_{0}$ the model does not predict significantly better than model (D); ; $p<.05$. 
Regarding $R Q_{2}$, we conclude that chat session satisfaction is influenced by both the individual's subjective experience as well as by the shared perceptions of attributes and group characteristics. Furthermore, the results as discussed in relation to the hypotheses, reveal that the communication style of the advisor (social-oriented versus task-oriented) influences the effect of the variables (individual and group perceptions) on participant satisfaction with the chat session $\left(\mathrm{RQ}_{3}\right)$.

To estimate which group characteristics explain additional variance in chat session satisfaction (and to what extent), we added the group characteristics to the attributebased model. Because of the relatively small sample size, simultaneously adding all ten group characteristics to the attribute-based model would lead to unreliable parameter estimates. Therefore, we separately added the group characteristics parameters to the model to test their significance. Finally, we included the significant group characteristics parameters jointly and it appeared that they remain significant. The results are presented in table 5-8.

Table 5-8: Multi-Level Analyses: Attrlbute-Based Model Extended by Group Characteristics

\begin{tabular}{|c|c|c|c|c|}
\hline & Social & & Task & \\
\hline & Coefficients (SE) ${ }^{a}$ & Bootstrap & Coefficients (SE) ${ }^{\mathrm{a}}$ & Bootstrap \\
\hline \multicolumn{5}{|l|}{ Step 1 (individual-level) $^{3}$} \\
\hline \multicolumn{5}{|l|}{ Attributes } \\
\hline Control & $.27(.08)^{\mathrm{d}}$ & $.28(.10)^{d}$ & $.39(.08)^{d}$ & $.39(.10)$ \\
\hline Enjoyment & $.22(.09)^{d}$ & $.23(.10)$ & $.26(.09)^{d}$ & $.26(.08)$ \\
\hline Reliability & $.17(.10)^{\mathrm{c}}$ & $.18(.10)=$ & $.29(.09)^{0}$ & $.28(.08):$ \\
\hline Speed & $.14(.06)^{d}$ & $.14(.07)^{\mathrm{d}}$ & $.17(.07)^{\circ}$ & $.16(.07):$ \\
\hline Ease of use &. $.01(.06)$ & $-.01(.04)$ & $.04(.07)$ & $.02(.04)$ \\
\hline Increase in model fit & $\chi^{2}(5)=87.7^{e}$ & & $x^{2}(5)=105.2$ & \\
\hline \multicolumn{5}{|l|}{ Step 2 (group-level) } \\
\hline \multicolumn{5}{|l|}{ Attributes } \\
\hline Control & $.08(.15)$ & $.09(.21)$ & $.70(.21)^{\mathrm{d}}$ & $.70(.22)^{\circ}$ \\
\hline Enjoyment & $-.10(.23)$ & $-.04(.07)$ & $.03(.15)$ & $.04(.22)$ \\
\hline Reliability & $.55(.19)^{d}$ & $.51(.18)^{d}$ & $.54(.21)^{3}$ & $.56(.24)^{\mathrm{d}}$ \\
\hline Speed & $.06(.11)$ & $.07(.14)$ & $.24(.16)$ & $-.25(.17)$ \\
\hline Ease of use & $.28(.14)^{d}$ & $25(.12)^{d}$ & $.02(.13)$ & $-.03(.16)$ \\
\hline Increase in model fit & $x^{2}(5)=41.4^{0}$ & & $y^{\prime}(5)=24.7^{\circ}$ & \\
\hline \multirow{2}{*}{\multicolumn{5}{|c|}{$\begin{array}{l}\text { Step } 3 \\
\text { Group characterlstics }\end{array}$}} \\
\hline & & & & \\
\hline Task climate (individual) ${ }^{\triangleright}$ & $.20(.07)^{d}$ & $.20(.08) \pi$ & & \\
\hline Group involvement (individual) ${ }^{b}$ & $.15(.08)^{c}$ & $.14(.07)^{d}$ & & \\
\hline Group similarity (individual) ${ }^{\circ}$ & & & $.15(.07)^{d}$ & $.16(.08)^{\circ}$ \\
\hline Group receptivity (individual) ${ }^{\mathrm{b}}$ & & & $19(.09)^{d}$ & $.20(.10)^{\circ}$ \\
\hline Task climate (group) & $.30(.10)^{0}$ & $.32(.12)^{\mathrm{c}}$ & $.30(.15)^{d}$ & $.28(.14)^{-1}$ \\
\hline Increase in model fit & $x^{2}(3)=17.1^{\circ}$ & & $x^{\prime}(3)=5.5^{e}$ & \\
\hline
\end{tabular}

Note: a Unstandardized coefficients with their standard errors. ${ }^{\circ}$ Within-group deviation score $X_{i} X_{i} ;{ }^{c} p<.05$ (one-tailed); ${ }^{0} p<01$ (one-tailed): ${ }^{0} p<.05$.

The table indicates that for the socially moderated groups, task climate and group involvement at the individual-level are significant. For the task-oriented groups, group similarity and group receptivity at the individual-level are significant. Task 
climate at the group-level is significant for all groups. A comparison with the estimation of the group characteristics model reveals that only social climate at the group-level for the socially moderated groups and group receptivity at the group-level for the task-oriented groups are no longer significant. A comparison with the estimation of the attribute-based model reveals that the group-level coefficients of reliability for the groups with a social- and a task-oriented advisor, are significantly higher compared to the within-group deviation coefficients. All orther results stay the same for both, socially moderated and task-oriented groups ${ }^{2}$.

\subsection{Discussion}

Currently, a number of companies are experimenting with $\mathrm{MGC}$ as a marketing tool and in order to provide guidance to these efforts, our research empirically assessed three alternative models for explaining customer satisfaction with this new phenomenon. In addition, we took into account two relevant contingencies: the style of the advisor and group-level processes. While our findings indicate positive effects of attributes, predispositions, and group characteristics on customer satisfaction, the exact nature of the predictor-criterion relationships varies across styles and levels. This suggests that the role of the advisor is of influence and that processes develop at the group-level during chat sessions which influence chat session satisfaction.

\subsubsection{A Comparison of Models}

Consumers appear to favor the attribute-based model in forming evaluations of MGC, based on the finding that this model explains most of the variance of chat: session satisfaction. The overall affect model is partly supported, but is does not add further explanatory power to the attribute-based model. This is in line with Dabholkar's (1996) research, in the context of technology-based self-service options. The group characteristics model is also supported and including the group characteristics in a combination of the attribute-based and overall affect model increases the model fit. Furthermore, our findings are in line with carlier research on. small groups which suggests that group characteristics have an important influence on individual evaluations (e.g., Kahai and Cooper 1999; Vallaster and Koll 2002). The study tests the models under different conditions to investigate the impact of the style of the advisor on customer satisfaction with the chat session. The preference for the attribute-based model is consistent across all conditions.

\footnotetext{
2 We also tested to see whether the predispositions: of the overall affect model were significant in explaining chat session satisfaction in addition to the attributes. This was not the case. This is in line with the results of model (D) in table 5-7.
} 


\subsubsection{Individual- and Group-Level Effects}

Chat session satisfaction is influenced by both the individual's subjective experience as well as by the shared perceptions of customers. For all three models, we find that the customer's individual perceptions are important. Effects of shared perceptions on chat session satisfaction, however, are found for attributes and group characteristics, but not for the predispositions. This latter result is understandable, given that predispositions are conceptualized as general constructs of the individual consumer and lack any group-level content. To avoid bias caused by perceptions of the particular chat session, the predispositions were measured before the chat session took place. Although it might have happened that, for instance, some groups had more people with a positive artitude than other groups, this was not the case. We discuss specific individual- and group-level effects on chat session satisfaction in relation to the models.

\subsubsection{Style of the Advisor}

The results reveal that the communication style of the advisor influences the effect of the variables on chat session satisfaction. Specifically, the style affects the group-level effects of the attributes. Additionally, the results of the group characteristics model show that most of the independent variables which influence chat session satisfaction in socially moderated groups, do not influence chat session satisfaction in taskoriented groups, and vice versa. It would appear that the style of the advisor influences group processes that take place; it influences the effect of shared perceptions as well as customer perceptions of group characteristics. The specific differences will be discussed in relation to the separate models.

\subsubsection{Attribute-Based Model}

\section{Individual-Level Effects}

With respect to the individual hypotheses in the attribute-based model, the study found that customer perceptions of control, enjoyment, reliability, and speed (at the individual-level) were important determinants of satisfaction in socially and task moderated groups. Ease of use at the individual-level, on the contrary, was not significant for any group. This suggests that satisfaction with MGC stems from the fact whether customers perceived they were in control over the service process, whether their expectations with regard to reliability are met, and whether the service delivery is enjoyable and fast. Perceptions of control might be created by the fact that it is easier for customers to be open and honest on-line (Whitty 2002). For example, dissatisfaction with the service can be expressed more readily than in a face-to-face encounter (Wolfinbarger and Gilly 2001) and customers even can decide not to participate any longer in the discussion. The fun aspect might be created by the human element of MGC; real-life human interaction on the Internet is one of the most popular applications of the world wide web and is often associated with fun (e.g., Hoffman and Novak 1996). With respect to reliability and speed, our findings 
differ from those of Dabholkar (1996). Whereas Dabholkar focused on on-site technology, the fact that MCG enables customers to stay at home while obtaining investment advice from various 'experts' may be perceived to be an efficient way of gathering information. Interestingly, the presence of other customers, who also ask questions, seems not to be perceived as slowing down the service delivery process. With respect to reliability, our study does not refer to the machine only, but to the entire investment advisory service; chatting with other customers and the advisor in a controlled environment. It might be that this human aspect as well as the secured setting influence customer perceptions of reliability of the service, in addition to wellworking technology.

\section{Group-Level Effects}

The influence of shared experiences (i.e., group-level evaluations) of the attributes on satisfaction differs for the two styles of moderation; reliability is significant for both conditions, but ease of use is significant only for socially moderated groups and control only for task-oriented groups. These shared experiences might be caused by group dynamics that seem to develop in the groups. A social-oriented advisor is flexible with respect to how the interaction flows. It might be that this 'easy-going' attitude creates the shared experience of ease of use within the group, resulting in satisfaction. Customers in task moderated groups exhibit lower ratings on this aspect. Task-oriented advisors are much more structured and demanding to customers and, therefore, these sessions may be perceived as more difficult. However, this perception does not influence customer satisfaction. Interestingly, within groups with this structured moderating style, customers share perceptions of control over the service process that result in satisfaction. In these groups, customers get the information they ask for without social chit-chat, which might create a shared feeling of control among customers that they get the service they need. Finally, all groups, independent of moderating style share perceptions of reliability.

\subsubsection{Overall Affect Model}

\section{Individual-Level Effects}

Although the overall affect model did not add to the variance explained by the attribute-based model, the results did build on previous research. 'The study found that only need for interaction is significant, irrespective of the style of the advisor. This suggests that the personal aspect of MGC is in line with the customers' need for real-life human contact in e-services. This result challenges research that argues that lack of social experience is an important determinant to shop on-line (e.g., Wolfinbarger and Gilly 2001) and supports research that argues that social, personal interaction is an essential aspect of positive on-line experiences (e.g., Preece 1999). 


\subsubsection{Group Characteristics Model}

\section{Individual-Level Effects}

The influence of the customer's subjective experience of the group characteristics on satisfaction differs for the two styles of the advisor. The study found that the customer's subjective perception (e.g., the individual-level) of group involvement and task climate are important determinants of satisfaction in socially moderated groups. It seems that these groups are more intensively involved in the conversation and this results in satisfaction. This is understandable given that a social-oriented moderator stimulates people to talk and to share ideas enthusiastically. With respect to task climate, it seems that groups appreciate balance between the social and task aspects within a group. That is, the group likes the social-oriented style of moderation, but at the same time, the group likes an atmosphere that is encouraging to the processing of information. Interestingly, customers in a socially moderated group perceive the climate as more productive than customers in a task moderated group.

Group similarity and group receptivity are important to satisfaction in task moderated groups. The importance of group similarity for these groups might be caused by the advisor's focus on efficiency. Dissimilarity of ideas might cause conflicts (e.g., Insko and Schopler 1972). Similarity among people, on the other hand, is suggested to enhance an efficient and smooth interaction. This is in line with the goals of the session as stated by the advisor and therefore this might result in satisfaction. At the same time, customers in groups with a task-oriented advisor appreciate that other customers are open to their ideas as is reflected by the significant effect of group receptivity. It might be that because a task-oriented advisor is not especially keen on this, it is important that customers are responsive to each other. Finally, social climate at the individual-level was not significant for any group.

\section{Group-Level Effects}

With respect to the influence of shared experiences (i.e., group-level evaluations), the results show that social climate is significant only for socially moderated groups and group receptivity only for task-oriented groups. However, these effects do not remain significant in the combination of the attribute-based model and the group characteristics model. On the other hand, task climate is significant for both conditions and remains significant in the combination of models. We might conclude that customers within groups share perceptions of a climate of productivity and effectiveness. These shared perceptions are important determinants of satisfaction, irrespective of the style of the advisor. This suggests that customers do not only participate in commercial chat sessions for social reasons but appreciate instrumental aspects as well. Finally, group similarity did not contain group-level variance which implies that customers do not share perceptions of similarity of the group. 


\subsubsection{Suggestions for Future Research}

The experiment and questionnaire approach was thought appropriate for this study for reasons explained, although generalizability of the findings is limited with regards to real-life settings. Certainly, there is a difference between simulation and real experience, and a real experience of a MGC might evoke more reliable responses from customers. Future research could test the models in an actual service encounter.

In this study, the only situational influence addressed was the style of the advisor. Other situational influences like the number of chat members may be investigated in future research. On-line chat sessions often involve more than seven persons (the maximum of our study) and group size might influence the individual members' evaluations (Lascu et al. 1995; Salomon and Globerson 1989). Furthermore, different formats may be tried. For example, a small group of customers that actively chats while others only follow the discussion (like an audience attending a forum discussion).

In our study, we assumed a strict separation between social and task behaviors of the advisor, but it may very well be that, outside the laboratory setting, behavior of advisors contains a combination of both styles (Spiro and Weitz 1990). The manipulation of these two extremes, however, enables us to disentangle the influence of the two different styles. Future research could investigate the effects of a mixture of styles. Additionally, it would be interesting to explore customer attributions. Research has shown that customers' evaluations are influenced by attributions for success or failure in interpersonal interactions (e.g., Bitner et al. 2000). With MGC, customers might have several sources of attribution: the technology, themselves, the other participants and the advisor. It might be relevant to investigate to what extent customers attribute the success or failure of a chat session to the different sources.

Further studies can continue to replicate and extend models for technology-based services, as was done in our study by testing the models as suggested by Dabholkar (1996). In addition, the models developed in this study may be tested in other service contexts. As indicated by Dabholkar (1996), it is possible that the overall affect model would fit better for certain types of services, for instance where strong emotions are aroused (e.g., health care). Indeed, a study of Preece (1999) on on-line medical support groups suggests that this might be the case.

Finally, the attributes and group characteristics included in this study may impact evaluations of satisfaction differently in other contexts. For instance, within chat groups that focus on medical or personal problems an individual's perception of social climate may be an important determinant of customer satisfaction with the chat session (Preece 1999). On the other hand, a larger group may not be evaluated quite as highly on the group involvement factor, as it might become more difficult to participate actively (e.g., Forsyth 1999). Also certain attributes and group characteristics, that we did nor include in our framework, may be relevant. For instance, the physical environment in which customers chat might be of influence. It is possible that the customer who is chatting at home is not alone, but that actually a couple is chatting. It also might be that the customer is doing several things at the same time, like chatting and sending e-mails, or browsing. Future research could investigate whether and how these factors influence customers' evaluations of MGC. 


\subsubsection{Managerial Implications}

Commercial IRC is a relatively new service delivery mode and the results of our study provide firms with information for strategic direction. Specifically, we explore customers' evaluations of MGC to help firms design this new channel accordingly. Given that the attribute-based model explains most of the variance in satisfaction suggests that firms can design and promote attributes of MGC that will lead to higher satisfaction. Had the overall affect model accounted for most of the variance in satisfaction, this would have suggested that firms would need to focus on selecting customers with a need for real-life human interaction on-line. Furthermore, our study shows that group characteristics are important. This suggests that firms would need a focus on the management of group processes during the chat session.

The finding that the customer's individual experience of control, reliability, speed, and enjoyment strongly influence chat session satisfaction, irrespective the style of the advisor, clearly suggests that these attributes should be underscored in MGC design and promotion. Firms should use a technology that is reliable and quick. Furthermore, service design must ensure that customers have and keep the feeling that they are in control over the service process. This feeling might be related to the lack of pressure to buy or agree, since there is no face-to-face contact. This may be increased by giving customers the possibility to leave the chat room or to be present passively, as an audience, instead of requiring active participation. Also, the fun element might be inherent to $\mathrm{MGC}$, created by the other human beings at present, although this also might be enhanced by, for instance, using colorful and humorous aspects in the design. In general, it seems that the very nature of MGC has several features which influence people's evaluation of this service delivery mode and these features should be underscored in promotion of MGC. At the same time, some of these aspects should be increased by building it into the service design.

Furthermore, it seems important to pay attention to group characteristics. The differential effects of the group characteristics on chat session satisfaction across styles of the advisor emphasize that managers need to fine-tune the moderating style in accordance with the group. These differential effects also appear with respect to the group-level effect of the attributes. So, in general it seems that for different styles of the advisor, different group dynamics develop that influence satisfaction. Therefore, it seerns crucial to match moderating styles with the group processes a firm may want to develop and with the purpose of the session. This matching might be realized by selecting an advisor with the best fitting style and by training the advisor to adapt his or her behavior in accordance with the group processes that develop (Prince and Davies 2001; Spiro and Weitz 1990). For instance, in case a firm wants to develop a chat session in which people are highly involved, it seems that the best fitting style would be a social-oriented advisor. Further, to stimulate specific group characteristics and group-level effects, tools might be installed within the chat mode. Especially tools providing group feedback that aims at communal goals and group processes instead of individual actions might be effective. For instance, for task climate, one can highlight key moments, color threads of subjects, circle stand-alone messages which still have to be answered, and classify text into color-coded categories. In this way, the patterns 
and texture of the discussion within the group are reflected in the patterns and texture of the interface. This allows the group to monitor which topics are already dealt with and to assess their productivity as a group. Also, clear rules and regulations might be helpful in stimulating group processes. Particularly in the implementation of new marketing tools, customers may need a frame of reference to guide their behavior. Therefore, it seems important to develop policies and guidelines of MGC. For instance, suggestions for turn-taking might ensure that all customers get a chance to share their ideas, which may increase involvement, as well as feelings of receptivity. Finally, careful attention should be paid to the composition of chat groups. It seems valuable to focus on similarity of customers and to target those customers with a high need for interaction with real-life personnel. However, too much similarity may impair a group's task climate by enhancing group think (e.g., Forsyth 1999), so management must be sensitive in achieving the appropriate balance. 

Chapter 6

\section{Conclusion}




\subsection{Synopsis}

The research in this dissertation is driven by the importance of customer encounters and the satisfaction derived from these encounters for both customers and firms. Since an important aspect, of a firm's performance rests on its capability to turn interactions with customers into satisfying experiences, the focus in this dissertation has been on the factors that drive customer satisfaction. We studied face-to-face and electronic encounters. Face-to-face encounters will continue to be a critical channel to deliver services and to sell products. In addition, the advent of the Internet has led to a considerable extension of the number of customer touch points, resulting in the fact that on-line encounters between firm and customers have become an integral aspect of the marketing effort of many companies.

In Chapter 1, we specified that the overall aim of this dissertation was to uncover antecedents that are important in enhancing customer encounter satisfaction in face-to-face and electronic settings in a retail context. Next, we developed more specific objectives for the individual chapters based on our general objective. In Chapter 2, the focus has been on the effect of interpersonal perceptions in dyadic, face-to-face encounters. Chapter 3 dealt with the effects of humor on dyadic, face-to-face encounters and electronic encounters. In Chapter 4, we paid attention to the influence of consumer, group, and advisor characteristics in many-to-many, electronic (chat) encounters. Based on the same data-base, Chapter 5 dealt with the influence of different (consumer) decision-making models in many-to-many, electronic encounters. The common theme across all chapters has been the perspective on identifying those factors that can be used to explain the key construct of customer encounter satisfaction. The chapters varied in that different theoretical backgrounds, and various methods and techniques were used. Figure $6-1$ summarizes the main characteristics of the research in this dissertation.

Figure 6-1: Main Characteristics of the Dissertation Research

\begin{tabular}{lllll}
\hline Subject & Chapter 2 & Chapter 3 & Chapter 4 & Chapter 5 \\
\hline $\begin{array}{l}\text { Theoretical } \\
\text { background }\end{array}$ & $\begin{array}{l}\text { Effect of } \\
\text { interpersonal } \\
\text { perceptions }\end{array}$ & $\begin{array}{l}\text { Effect of humcir } \\
\text { Interpersonal } \\
\text { perception research }\end{array}$ & $\begin{array}{l}\text { Effect of consumer, group, } \\
\text { and advisor characteristics }\end{array}$ & $\begin{array}{l}\text { Explanatory value } \\
\text { of different decision- } \\
\text { making models }\end{array}$ \\
Data & Field survey & Experiment & $\begin{array}{l}\text { Marketing, computer- } \\
\text { Decision-making } \\
\text { mediated communication, } \\
\text { group dynamics, and } \\
\text { leadership theories }\end{array}$ & $\begin{array}{l}\text { Experiment + survey } \\
\text { Encounter mode }\end{array}$ \\
Face-to-face & $\begin{array}{l}\text { Face-to-face }+ \\
\text { web-site }\end{array}$ & Chat & Experiment + survey \\
Interaction structure & Dyads & Dyads & Groups & Chat \\
\hline
\end{tabular}


In this concluding chapter, we will attempt to tie together the results that have been presented in the separate chapters. First, in section 6.2, we present the main conclusions of the chapters in relation to the objectives that were specified in the introduction of this thesis. Subsequently, we present an integral perspective based on our findings in section 6.3. We attempt to develop a vision on creating customer satisfaction in various kinds of customer-firm encounters, which goes beyond the conclusions that were already drawn on the basis of the individual chapters. We end this chapter and the dissertation by offering a number of perspectives for future research.

\subsection{Main Conclusion of the Chapters}

\subsubsection{Chapter 2}

The questions with respect to the dyadic, face-to-face encounter we set out to answer in Chapter 2, were: 1) to what extent is customer satisfaction influenced by the customer's onu experience of the encounter and to what extent by the employee's experience of the encounter (and vice versa for employee satisfaction)?, and 2) are customers' and employees' perceptions based on their own unique experience during the encounter or are these perceptions based on stable characteristics of the employee?

With respect to the first question, we conclude that both customer and employee satisfaction are determined not only by their own perceptions, but also by the perceptions of those with whom they are interacting. Furthermore, we conclude that the influence of employee performance on customer and employee satisfaction is unique to a specific encounter, but at the same time it seems to reflect a stable form of employee behavior.

\subsubsection{Chapter 3}

While focusing on dyadic, face-to-face encounter and self-service electronic encounters, the objectives of Chapter 3 were to: 1) discuss the conceptualization of humor and to study the influence of different types of bumor on customes encaunter evaluations in face-to-face and electronic encounters, and 2) take into account the interplay between bumor and service encounter outcomes.

From two experimental studies, we conclude that the type of humor (related versus unrelated) in a face-to-face encounter is more important than the outcome, whereas in electronic encounters, the outcome of the service encounter is more important. In addition, we report that in electronic encounters, related humor can weaken the negative effect of an unfavorable service outcome.

\subsubsection{Chapter 4}

In Chapter 4, we studied many-to-many, electronic encounters in the form of chat sessions. The objectives of this chapter were to: 1) develop a theoretical researcb madel, 
grounded in several research fields, that can be used to explain customer satisfaction with MGC in a marketing context, and 2) empirically test this theoretical research model while taking various contingencies into account: the style of the advisor and individual versus shared perceptions.

Based on a broad literature review, we propose a theoretical research model that encompasses three groups of characteristics: consumer, group, and advisor characteristics. Our findings indicate a positive influence of consumer, group, and advisor characteristics on satisfaction. Furthermore, the results show that the exact nature of the predictor-criterion relationships varies across styles and levels.

\subsubsection{Chapter 5}

In Chapter 5, we examined chat sessions as well. The specific objectives were to: 1) replicate and extend earlier research on two models of technology-infused encounters to the context of MGC, 2) develop a group characteristics model, grounded in the group decisionmaking literature, and 3) empirically test all three models while taking two contingencies into account: the style of the advisor and individual versus sbared perceptions.

Based on earlier research in the field of self-service technology, we examine an attribute-based model and an overall affect model. We extend previous research by developing a third model, i.e., a group characteristics model. This model incorporates five group characteristics: task climate, social climate, group involvement, group similarity, and group receptivity. Our findings indicate that both attributes and group characteristics have a significant impact on customer satisfaction. In addition, we find that the exact nature of the predictor-criterion relationships varies across the contingencies of advisor style and group-level processes.

\subsection{An Integrated Perspective}

The four chapters explore various kinds of encouncers through different kinds of theoretical lenses. Notwithstanding these different perspectives, there are a number of unifying principles that all chapters have in common. In this section, we discuss these principles and the consequences that they might have for the design, management and research of customer-firm encounters.

\subsubsection{Interpersonal Influence}

In Chapter 2, we emphasize the fundamentally interpersonal nature of encounters. Thi presence of an effect caused hy the belief of the interaction partner is perhaps the must fundamental indication of interdependence in interactions. This effect of interpersonal influence is substantiated by the group-level effects as found in Chapter 4 and 5. This signifies that customers share perceptions and that these shared perceprions influence customer satisfaction. The interpersonal effects as found in the different stuties may reflect truly influence processes; people let each other know, 
verbally or non-verbally, how they perceive the interaction and this influences the judgment on the part of the customer (e.g., Mead 1986). This implies that customers are sensitive to their social context.

The influence of the social context in which customers are interacting implies that customers' perceptions change when they are with different persons, in face-to-face as well as in interpersonal, moderated electronic encounters. In order to effectively manage and design customer encounters, this interpersonal influence should be taken into account.

Also, academic researchers should take the interpersonal nature of encounters into account. Much of the perceptions research is one-sided: the research object (either the customer or the employee) perceives the 'target', but the perceptions of the target are not taken into consideration. Moreover, the two form impressions about each other that might be of influence and these influences should be included in perceptions research, too. Only research taking the interpersonal interdependence into account captures the richness of the social context of the customer-firm encounter.

If we assume that the customer-firm encounter is a major factor in determining customer preference structures, theories of interpersonal influence can provide valuable insights, may suggest appropriate methods of analysis for understanding faceto-face and electronic encounters, and can indicate how to engineer optimal encounters. These theories can be expected to help explain and predict why customers find particular customer-firm encounters more satisfying than others.

\subsubsection{Social and Task Antecedents}

In Chapters 2 and 4, we make the assumption that antecedents of customer satisfaction can be classified according to the classical dichotomy of task-related versus social-related antecedents. Both chapters provide support for the complementary value of these antecedents in the encounter. Whereas Chapter 2 focuses on both task and social aspects as performed by the contact employee, in Chapter 4 these aspects might be fulfilled by the employee and the group members.

From Chapter 2, we may conclude that the customer's perceptions of the employee's task performance are of stronger influence in explaining satisfaction than the perceptions of social competence. Interestingly, in Chapter 4, we find that: customers are more satisfied while interacting with a social-oriented advisor. This might be explained by the interaction structure. Since customer-firm interactions are generally purposeful encounters, one of the interaction partners has to 'lead' and to initiate goal-oriented aspects. In traditional face-to-face encounters, it is usually recognized by both partners that this is part of the employee's job. In new interaction modes, as in MGC, these role descriptions might be less clear. Purposeful interactions between strangers require rules if the task is to be completed, and it seems that in online group interactions new roles are to be defined. Particularly in the implementation of new marketing tools, customers may need a frame of reference that guide their behavior. The difference may also be due to the setting of the studies. In Chapter 2, the customers are 'real' and they needed the information because they were considering a real purchase, whereas in Chapter 4 the respondents are part of a role-play. 
In the studies presented in Chapter 4 and 5, we assume a strict separation between social and task behaviors of the advisor. However, the research of Chapter 2 indicates that employees are able to perform a mixture of communication styles. Therefore, although some researchers argue that a very few individuals can simultaneously perform both task and socio-emotional styles, our results are in favor of researchers who argue that people are able to behave in both ways simultaneously. At the same time, our results show that both aspects of performance may be considered as relatively enduring and consistent characteristics that an employee (inevitably) brings to every encounter. The research suggests that task and social competence are attributes of the contact employee and that some salespersons may possess these competences to a greater extent than others.

\subsubsection{Unique and Shared Experiences}

This dissertation clearly suggests that a substantial part of customers' perceptions of face-to-face and moderated electronic encounters is based on their subjective, unique experience. Chapters 2, 4, and 5 demonstrate via the use of hierarchical modeling techniques that customer encounter satisfaction is based on subjective appraisal processes. At the same time, we conclude that there is a certain degree of intersubjectivity in perceptions. In Chapter 2, we find consensus among several customers in their perceptions of the employee, while the customers never have met and thus never have discussed employee performance with each other. This clearly supports an actual presence of a behavior of the employee. Furthermore, in this chapter, we find that the customer and the employee agree in their perceptions of employee performance. In Chapter 4 and 5, we conclude that customers share their perceptions of attributes of the on-line interactive service and the group characteristics. Overall, it might be concluded that perceptions as formed in interpersonal settings are uniquely related to the customer, but also seems to reflect some inter-subjectivity.

\subsubsection{Role of the Employee}

All chapters demonstrate the important value of the employee in creating customer satisfaction. In Chapter 2, both task and social competences of the employee are found to be important determinants of customer satisfaction. In Chapter 3, the type of humor used by the employee is found to be more important than the outcome of the service in face-to-face encounters.

Also, in moderated electronic encounters, the performance of the employee is found to be of influence on customers' evaluations. It does not only have a direct influence but it also affects the influence of consumer characteristics, group characteristics, and group dynamics on customer satisfaction; the advisor's style fulfills different beliefs of benefits, challenges different skills of customers, and influences group processes that take place. With the expanding number of electronic encounters that include human contact, the nature of electronic encounters change for reasons that have little to do with technological characteristics. 


\subsubsection{Nuances in Electronic Experiences}

The importance of the outcome of the service in self-service electronic encounters, as found in Chapter 3, might demonstrate that self-service via web-sites fulfills a need of customers to be goal-oriented. It has been argued that on-line shopping in its present stage may still be more likely to be goal-focused and driven by utilitarian motives rather than by experiential and hedonic ones. Goal-focused shoppers are transactionoriented; they shop only when they have a specific purpose in mind and desire to purchase what they want quickly (Wolfinbarger and Gilly 2001). Although it has been suggested that the more hedonic and social aspects of the electronic encounters play a crucial role too (Childers et al. 2001), this has not been found in Chapter 3 .

On the other hand, we argue that on-line shopping should nor be mainly regarded as a way of purchasing products in an efficient and timely manner. Our findings on electronic encounters in this dissertation create a more nuanced picture on on-line experiences. The results reported in Chapter 4 indicate that customers associare social as well as functional benefits with on-line interactive services. Interestingly, the findings of Chapter 5 demonstrate that the attributes which are often associated with self-service technology are also associated with MGC. For instance, the absence of retail associates has been associated with an increase of feelings of control by on-line shoppers, but we found that customers in MGC, which includes an employee, feel control over the service process as well. In MGC, customers feel that they make good decisions, benefit from the information these type of group-services offer, and additionally enjoy the social aspects. The activity of MGC seems to be perceived as enjoying and satisfying in its own right.

Consequently, we argue that the notion that on-line buyers do not desire 'high touch' services, as stated by Wolfinbarger and Gilly (2001), should be nuanced. It might be that this belief stems from the fact that many commercial web-sites just do not fully explore the interactive capabilities of the Internet. The Internet is the most conversational mass medium ever developed, yet the majority of sites today do more self-absorbed yammering than focusing on fine-tuned interaction (Kirsner 1997). New technologies may change this if we use them well. Till recently the experiential qualities of off-line shopping met needs that couldn't be met on web-sites. However, we argue that with the inventory of new interactive services that include human elements experiential needs can be met.

Jointly, the findings of Chapter 4 and 5 emphasize that a technology-oriented perspective that attempts to treat on-line shopping delivery modes as cold information systems, rather than hedonic and social environments, is likely to be fundamentally misguided. In general, this dissertation challenges research that suggests that socio-emotional communication is hardly possible in $\mathrm{CMC}$ and that online shoppers largely like the lack of social interaction while shopping on-line. However, it is important to note that the findings suggest that customers do not only participate in commercial chat sessions for social and chit-chat reasons but appreciate task aspects as well. Rather, while designing encounters, instrumental characteristics must be considered in conjunction with the social criterion. 
In sum, it seems that the very nature of MGC has several features that influence people's evaluation of this service delivery mode. It has attributes that are also associated with goal-oriented electronic self-service, it includes human elements which respond to the call of customers for the integration of technology with human touch, and it seems to create unique elements related to the group aspects that are hardly found in off-line settings.

\subsubsection{The Future of Electronic Encounters}

It has been suggested that face-to-face shopping will loose its social function as people use the Internet for the purpose of social interaction (Coleman and Blackmon 1999). It might also be that new interactive services create needs that can not be met off-line anymore; on web-sites cognitively and aesthetically rich shopping environments are created in ways not readily imitable in the non-electronic shopping world.

With the growth of new interactive electronic interaction modes, it is likely that customers' on-line shopping experiences change. Indeed, many of the unique aspects of the new media most likely create a novel, intrinsically enjoyable virtual environment that should be featured in the design of electronic encounters. The frequency with which on-line customers interact in groups cannot be found in offline contexts.

Furthermore, the nature of on-line groups seems not to be comparable to off-line groups. It is suggested that interacting in on-line groups offers the advantage of influencing individual as well as group perceptions, while minimizing the opportunity for individual customers to dominate the group. On-line group interactions evoke 'multi-logues' that are honest and somewhat less constrained by social conventions than off-line groups. Consequently, the virtual market place may not mirror the off-line market place of dyadic and group encounters, and new theories and managerial strategies have to be developed to effectively design electronic encounters. The on-line environment has unique capabilities that might be compromised by attempting to mirror the off-line experience too closely. The expansion of electronic encounters that includes the multi-dimensional, multisensation, and 'multi-logue' possibilities may create a compelling experience to customers.

In the years to come, we expect to see a new generation of conversational websites that offer the possibility for dynamic experiences. It is shown that customers are prepared to pay more for a service from a real human being on-line (Datamonitor 2002). It seems that more extreme differences between conventional retail channels and these new channels are taking shape, and it appears important for companies to gain an understanding of this in order to maximize their performance as they enter this uncharted territory. 


\subsection{Suggestions for Future Research}

We provided specific directions of future research at the end of each chapter. In this concluding paragraph, we would like to focus the discussion to some general directions of future research on customer satisfaction in customer-firm encounters of various kinds.

First of all, given the proliferation of electronic encounters, it is important to understand the factors that influence adoption of this new generation of customer touch points and to investigate the role of electronic encounters within a multichannel strategy of a firm. In this dissertation, we do not make comparisons in that respect between the face-to-face, self-service, and moderated electronic encounters. Further research could be designed specifically to allow comparisons of the cells within figure 1-1, Chapter 1. For instance, research could examine what motivates people to use electronic self-service encounters instead of face-to-face and/or moderated electronic encounters. Do customers prefer electronic encounters over one-on-one face-to-face encounters or do they view electronic encounters as complementary? Do electronic encounters have the same influence on important outcomes as face-to-face encounters? Do electronic self-service encounters have the same influence on important outcomes as moderated electronic encounters? Research on new media also shows that the use of new media creates a greater use of all existing communication channels (Lind and Zmud 1995). Understanding the choices of customers to participate in face-to-face encounters as well as to use (self-service) electronic encounters may help managers to develop an integrated strategy. Effective management of all customer-firm service delivery and product selling options can be an excellent means of creating competitive advantage. When the appropriate mix of these customer-firm options is better understood, effective management of these channels may increase profitability and success in the increasingly competitive marketplace.

Secondly, further work in interpersonal influence as demonstrated in Chapter 2 (e.g., partner effects), and in Chapter 4 and 5 (e.g., group-level effects) is needed since these effects are perhaps the quintessential indicators of interpersonal processes (Kenny and Cook 1999). Little research is done with respect to these effects in the marketing context and the surface has been barely scratched. In social psychology, this influence is described in the Actor-Partner Interdependence Model (APIM) (Kenny et al. 1998). It assumes that one person's score on an independent variable may influence not only that person's score on an outcome variable, but also that person's partner's score on an outcome variable. This model can be applied to both dyadic and group research. All too often, dyadic and group researchers estimate actor effects, but fail to study partner effects (Kenny and Cook 1999). Future research may also wish to consider which processes are operating behind the interpersonal effects.

Thirdly, future research needs to take into account the various levels of analysis. The dissertation emphasizes the value of a multi-level approach, since both individual-level and group-level variables were crucial in explaining variance in customer and employee encounter satisfaction. The different levels of analysis reflect qualitatively different perspectives; individual data correspond to subjective appraisal 
processes, while aggregated data correspond to the inter-subjective perceptions. The question whether individual reports of customer satisfaction are a function of group factors rather than a result of an individual's subjective perceptions merits research attention (van Yperen and Snijders 2000). Although partner effects are not usually estimated in multi-level models, because of their social psychological importance, they should be given consideration.

Fourthly, there are clearly next steps in the research of MGC with respect to the models as suggested in Chapter 4 and 5. For instance, a satisfaction model could be tested which includes the consumer characteristics as described in Chapter 4 with the attributes as presented in Chapter 5. Future research may also work on the refinement and combining of the group characteristics as suggested in Chapter 4 and 5. In total, we suggest nine group characteristics which might be of influence in MGC. As a next step a model could be tested with the best fitting group characteristics. These group characteristics could than be added to the consumer characteristics and attributes. Also, introducing the task and social competence variables as used in Chapter 2 in the context of MGC might be a useful extension of the research.

Finally, major research opportunities exist in terms of providing a better understanding of characteristics that drive perceptions of customer satisfaction in face-to-face encounters and electronic encounters. Our in-depth investigations of underlying mechanisms of interpersonal interaction and specific tools to create customer satisfaction with face-to-face encounters are theoretically fruitful in suggesting hypotheses that could be tested in future research. We focused on specific constructs of interpersonal perceptions research. However, this field suggests additional constructs which hardly have been investigated in the context of marketing but which might be of great influence too. For instance, assimilation (Does the customer see employees as alike?), reciprocity (Do the customer and the employee see each other similarly!), and meta-accuracy (Does the employee know bow (s)he is seen? ) are widely recognized as fundamental mechanisms underlying interpersonal encounters.

Also, a focus on the influence of the relevance of humor and the sense of humor of employees and customers may increase understanding how to enhance customer encounter satisfaction. Additional research on electronic encounters is required into how factors like the physical environment in which customers experience electronic encounters, the design characteristics of interactive shopping sites, role clarity, motivation, and customer ability affect on-line shopping behavior. As a general conclusion on future research on customer satisfaction in close encounters, we can only hope this dissertation has contributed to more insight and stimulates others to explore this field. By developing an in-depth understanding of the subtle processes that shape satisfaction in the close encounters between firms and customers, we hope that companies can respond in innovative ways to the old adagio of staying close to the customer. 


\section{References}

Aaker, D.A. and R. Jacobson (1994). The Financial Information Content of Perceived Quality. Journal of Marketing Research, 31 (2), 191-201.

Adelman, M.B., A.C. Ahuvia and C. Goodwin (1994). Beyond Smiling: Social Support and Service Quality. In: Service Quality: New Directions in Theory and Practice, Rust, R.T. and R.L. Oliver (Ed.), 139-171, Sage Publications, Thousand Oaks, CA.

Adelman, M.B., M.R. Parks and T.L. Albracht (1987). Beyond Close Relationships: Social Support and Weak Ties. In: Communicating Social Support, Albracht, T.L., M.B. Adelman and Associates (Ed.), 126-147, Newbury Park, CA.

Agarwal, R. and J. Prasad (1999). Are Individual Differences Germane to the Acceptance of New Information Technologies? Decision Sciences, 30 (2), 361-392.

Albrecht, K. and R. Zemke (2001). Service America in the New Economy. McGraw-Hill, New York.

Albright, L., D.A. Kenny and T. Malloy (1988). Consensus in Personality Judgments at Zero Acquaintance. Joumal of Personality and Social Psychology, 55 (2), 387-395.

Albright, L., T. Malloy, W. Dong, D.A. Kenny. X. Fang. L. Winquist and D.D. Yu (1997). Cross-Cultural Consensus in Personality Judgments. Journal of Personality and Social Psychology, 72 (3). 558-569.

Alden, D.L. and W.D. Hoyer (1993). An Examination of Cognitive Factors Related to Humbrousness in Television Advertising. Journal of Advertising, 12, (2), 29-37.

Alden, D.L., W.D. Hoyer and C. Lee (1993). Identifying Global and Culture-Specitic Dimensions of Humor in Advertising: A Multinational Analysis. Joumal of Marketing. 57 (2), 64-75.

Anderson, E.W. (1996). Customer Satistaction and Price Tolerance. Marketing Letters. 7 (3), $19-30$.

Anderson, E.W. (1998). Customer Satisfaction and Word-of-Mouth. Joumal of Senvice Research, 1 (1). 1-14.

Anderson, E.W. and C. Fornell (1994). A Customer Satisfaction Research Prospectus. In: New Directions in Theory and Practice, Rust, R.T. and R.L. Oliver (Ed.), 241-268, Sage Publications, Thousand Oaks. CA.

Anderson, E.W. and C. Fornell (2000). The Customer Satisfaction Index as a Leading Indicalor. In: Handbook of Senvices Marketing and Management, Swartz, T.A. and D. lacobucci (Ed.), 255-267, Sage Publications. Thousand Oaks. CA.

Anderson, J.C. and D.W. Gerbing (1988). Structural Equation Modeling in Practice: A Review and Recommended TwoStep Approach. Psychological Bulletin, 103 (May), 347-362.

Anderson E.W. and M. Sullivan (1993). The Antecedents and Consequences of Customer Satisfaction for Firms. Marketing Science, 12 (2), 125-143.

Anderson, E.W., C. Fornell and R. Lehmann (1994). Customer Satisfaction, Market Share, and Profitability. Joumal of Marketing, 56 (3), 53-66.

Anderson, E.W., C. Fomell and R.T. Rust (1997). Customer Satisfaction, Productivity, and Profitability: Differences between Goods and Services. Marketing Science, 16 (2), 129-145.

Amould, E.J. and L.L. Price (1993). River Magic: Extraordinary Experience and the Extended Service Encounter. Joumal of Consumer Research, 20, 24-44.

Assael. H. (1995). Consumer Behavior and Marketing Action. 5th edition, South Western College Publishing, Pacific Grove, CA.

Avery, C., P. Resnick and R. Zeckhauser (1999). The Market tor Evaluations. American Economic Review, 89, 564-584.

Babin, B.J., W.R. Darden and M. Griffin (1994). Work and/or Fun: Measuring Hedonic and Utilitarian Shopping Value. Joumal of Consumer Research, 20 (4), 644-656.

Bales, R.F. (1950). A Set of Categories for the Analysis of Small Group Interaction. American Sociological Feview, 15, $257-263$.

Bales, R.F. (1958). Task Roles and Social Roles in Problem-Solving Groups. In: Readings in Social Psychology:

Maccoby, E.E., T.M. Newcomb and E.L. Hartley (Ed.), 437-447, Holt, New-York.

Bandura, A. (1977). Sell-efficacy: Toward a Unilying Theory of Behavioral Chanige. Psychological Review, 84 (2), 191-215.

Bandura, A. (1986). Social Foundations of Thought and Action: A Social Cognitive Theory. Prentice-Hall, Englewood Clifts, NJ.

Bannan, K.J. (2001). Burning up the Wires; Web Chat Spins a New Line on Customer Service. PSINet e-Business,

Winter, 48-51. Available: http://www.psinet.

Barnes, B. (1995). The Elements of Social Theory. UCL Press, London, UK.

Bames, J. (1997). Closeness, Strength and Satisfaction: Examining the Nature of Relationships between Providers of Financial Services and their Retail Customers. Psychology and Marketing. 14 (4), 765 790.

Barnes. J.G., P.A. Dunne and W.J. Glynn (2000). Self-Senvice and Technology: Unanticipated and Unintended Effects on Customer Relationships. In: Handbook of Services Marketing and Management, Swartz, T.A. and D. lacobucci (Ed.), 89-102, Sage Publications, Thousand Oaks, CA.

Barret, M. (1997). Alternative Delivery Systems: Supermarkets, ATMs, Telephone Banking, PCs, and On-Line Banking. Bankers' Magazine, 180 (3), 44-51. 
Barry, B. and G.L. Stewart (1997). Composition, Process, and Performance in Seli-Managed Groups: The Role of Personality. Joumal of Applied Psychology, 82 (1), 62-78.

Barua, A., S. Ravindran and A. Whinston (1997). Effective Intra-Organizational Information Exchange. Joumal of Information Science, 23 (3), 239-248.

Bass, B.M. (1990). Bass and Stogdilf's Handbook of Leadership: Theory, Research, and Managerial Applications. $3^{\mathrm{a}}$ edition, The Free Press, New York.

Bass, B.M. (1997). Personal Selling and Transactional/Transformational Leadership. Joumal of Personal Selling \& Sales Management, 17 (3), 19-28.

Bateson, J.E.G. (1985). Self-Service Consumer: An Exploratory Study. Journal of Retailing, 61 (3), 49-76.

Bateson, J.E.G. and M.K.M. Hui (1987). Perceived Control as a Crucial Perceptual Dimension of the Service Experience: An Experimental Study. In: Add Value to Your Service, Surpenant, C.F. (Ed.), 187-192, American Marketing Association, Chicago, IL.

Baym, N.K. (1995). The Performance of Humor in Computer-Mediated Communication. Joumal of Computer Mediated Communication, 1 (2). Available: http://www.ascusc.org/jcmc/vol1/issue2/baym.html.

Beatty, S.E., M. Mayer, J.E. Coleman, K.E. Reynoids and J. Lee (1996). Customer-Sales Associate Retail Relationships. Journal of Retailing, 72 (3), 223-247.

Beck, C.T. (1997). Humor in Nursing Practice: A Phenomenological Study. International Journal of Nursing Studies, 34 (5), 346-352.

Benne, K.D. and P. Sheats (1948). Functional Roles of Group Members. Joumal of Social Issues, 4 (2), $41-49$.

Berge, Z. (1992). The Role of the Moderator in a Scholarly Discussion Group (SDG). Available: http:/star.ucc.nau.edu/-mauri/moderate/zlbmod.html.

Bergeron, B. (2001). The Eternal E-customer. McGraw-Hill, New York.

Berlyne, D.E. (1972). Laughter, Humour, and Play. Handbook of Social Psychology, 3, 795-852.

Berry, L.L. (1995). Relationship Marketing of Senvices: Growing Interest, Emerging Perspectives. Journal of the Academy of Marketing Science, 23 (4), 236-245.

Bettencourt, L.A. and S. Brown (1997). Contact Employees: Relationship among Workplace Fairness, Job Satisfaction and Prosocial Service Behaviors. Joumal of Retailing, 73 (1), 39-61.

Bettencourt, L. and K. Gwinner (1996). Customization of the Service Experience: The Role of the Front-Line Employee. Intemational Joumal of Service Industry Management, 7, 3-20.

Bettman, J.R. and C.W. Park (1980). Effects of Prior Knowledge and Expenience and Phase of the Choice Process on Consumer Decision Processes: A Protocol Analysis. Joumal of Consumer Research, 7 (3), 234-248.

Bickart, B. and R.M. Schindler (2001). Internet Forums as Influential Sources of Consumer Information. Joumal of Interactive Marketing, 15 (3), 31- 40.

Bitner, M.J. (1992). Servicescapes: The Impact of Physical Surroundings on Customers and Employees. Journal of Marketing, 56 (2), 57-71.

Bitner, M.J. (1995). Building Service Relationships: It's All About Promises. Joumal of the Academy of Marketing Science, $23(4), 246-251$.

Bitner, M.J. and A.R Hubbert (1994). Encounter Satisfaction versus Overall Service Satisfaction versus Service Quality. In: Service Quality: New Directions in Theory and Practice, Rust, R.T. and R.L. Oliver (Ed.), 72-94, Sage Publications, London, UK.

Bitner, M.J., B.H. Booms and L.A. Mohr (1994). Critical Service Encounters: The Employee's Viewpoint. Joumal of Marketing, 58 (4), 95-107.

Bitner, M.J., B.H. Booms and M.S. Tetreault (1990). The Service Encounter: Diagnosing Favorable and Unfavorable Incidents. Joumal of Marketing, 54 (1), 71-84.

Bitner, M.J., S. Brown and M.L. Meuter (2000). Technology Infusion in Service Encounters. Joumal of the Academy of Markeling Science, 28 (1), 138-149.

Blake, R.R. and J.S. Mouton (1982). How to Choose a Leadership Style. Training and Development Joumal, 36, 39-46.

Bloch, M. and A. Segev (1996). The Impact of Electronic Commerce on the Travel Industry. Available: hitp:/haas.berkeley.edu/-citm/trav-projtravel.htm.

Bloch, P.H. and G.D. Bruce (1984). Product Involvement as Leisure Behavior. In: Advances in Consumer Behavior, T.C. Kinnear (Ed.), 11, 197-202. Association for Consumer Research, Ann Arbor, MI.

Blocklyn, P. (1988). Making Magic: The Disney Approach to People Management. Personnel, December, 28-33.

Boles, J.C. and B.J. Babin (1996). On the Front Lines: Stress, Conflict, and the Consumer Service Provider. Joumal of Business Research, 37, 41-50.

Bolon, D.S. (1999). Level of Analysis Considerations in Organizational Citizenship Behavior Research: An Empincal Investigation of Individual and Work Group Effects among Hospital Employees. Health Management Research, 12. 92-108. 
Bolton, R.N. (1998). A Dynarnic Model of the Duration of the Customer's Relationship with a Continuous Service Provider:

The Role of Customer Satisfaction. Marketing Science, 17 (1), 45-65.

Bopp, K.D. (1990). How Patients Evaluate the Quality of Ambuiatory Medical Encounters: A Marketing Perspective. Joumal of Health Care Marketing, 10 (1), 6-15.

Borkenau, P. and A. Liebler (1992). Trait Inferences: Sources of Validity at Zero Acquaintance. Joumal of Personality and Social Psychology, 62 (4), 645-657.

Boruch, F. (1995). Your Work Can Be Child's Play. Human Resource Magazine, 40 (August), 60-64.

Bowen, D.E. and B. Schneider (1985). Boundary Spanning Role of Employees and the Service Encounter. Some Guidelines for Management and Research. In: The Service Encounter. Managing Employee/Customer Interaction in the Service Business, Czepiel, J.A., M.F. Solomon and C.F. Surprenant (Ed.), 127-147, Lexington Books, Lexington, MA.

Bray, J.H. and S.E. Maxwell (1993). Multivariate Analysis of Variance. In: Experimental Design and Methods, Lewis-Beck, M.S. (Ed.), 337-408, Sage Publications, London, UK.

Bremmer, J. and H. Roodenburg (1997). A Cultural History of Humour. Polity Press, Cambridge, UK.

Bressler, S.E. and C.E. Grantham (2000). Communities of Commerce. McGraw-Hill, New York.

Brown, D. and J. Bryant (1983). Humor in the Mass Media. In: Handbook of Humor Research, McGhee, P.E., and J.H.Goldstein (Ed.), $2^{\text {nd }}$ edition, Springer-Verlag, New York.

Brown, S.W. and T.A. Swartz (1989). A Gap Analysis of Professional Service Quality. Joumal of Marketing, 53 (2), 92-98.

Bryant, J., J.S. Crane, P.W. Comisky and D. Zillmann (1980). Relationship between College Teachers' Use of Humor in the Classroom and Students' Evaluations of their Teachers. Joumal of Educational Psychology, 72 (4), 511-19.

Bryk, A.S. and S.W. Raudenbush (1992). Hierarchical Linear Models: Applications and Data Analysis Methods. Sage Publications, Thousand Oaks, CA.

Bui, K.T., L.A. Peplau and C.T. Hill (1996). Testing the Rusbult Model of Relationship Commitment and Stability in a 15Year Study of Heterosexual Couples. Personality and Social Psychology Bulletin, 22 (10), 1244-1257.

Burbach, H.J. and C.E. Babbitt (1993). An Exploration of the Social Functions of Humor among College Students in Wheelchairs. Journal of Rehabilitation, 59 (1), 6-9.

Burgoon, J.K. and J.L. Hale (1987). Validation and Measurement of the Fundamental Themes of Relational Communication. Communication Monographs, 54, 19-41.

Burgoon, J.K., B. Bengtsson, J. Bonito, A. Ramirez and N.E. Dunbar (1999). Designing Interfaces to Maximize the Quality of Collaborative Work. In: Proceedings of the Hawail Intemational Conference on Computers and System Sciences, Maui, HI.

Burke, K. and L. Chidambaram (1995). Developmental Differences between Distributed and Face-to-Face Groups in Electronically Supported Meeting Environments: An Exploratory Investigation. Group Decision and Negotiation, 4 (3), 213-233.

Business Week Ebiz (2001), Chat Me Up......Please. By O' Crockett, R., March 19.

Buskin, J. (1998). Tales from the Front: A Firsthand Look at Buying On-Line. The Wall Street dournal, December 7.

Butcher, K., B. Sparks and F. Oçallaghan (2001). Evaluative and Relational Influences on Service Loyalty. International Joumal of Service Industry Management, 12 (4), 310-327.

Campion, M.A., E.M. Papper and G.J. Medker (1996). Relations between Work Team Characteristics and Effectiveness: A Replication and Extension. Personnel Psychology, 49, 429-452.

Cappella, J.N. (1997). Behavioral and Judged Coordination in Adult Informal Social Interactions: Vocal and Kinetic Indicators. Joumal of Personality and Social Psychology, 72 (2), 119-131.

Carman, J.M. (1980). Paradigms for Marketing Theory. Research in Marketing, 3, 1-36.

Chapman, A.J. (1983). Humor and Laughter in Social Interaction and Some Implications for Humor Research. In: Handbook of Humor Research, McGhee, P.E. and J.H. Goldstein (Ed.), Springer-Verlag, New York.

Chapman, A.J. and H.C. Foot (1976). Humour and Laughter. Theory, Research and Applications. Johr Wiley \& Sons, Ltd., New York.

Chase, A.B. (1978). Where Does the Customer Fit in a Service Operation? Harvard Business Feview, 56 (6), 137-142.

Chattopadhyay, A. and K. Basu (1990). Humour in Advertising: The Moderating Role of Prior Brand Evaluation. Joumal of Marketing Research, 27 (4), 466-476.

Childers, T.L., C.L. Christopher, J. Peck and S. Carson (2001). Hedonic and Utilitarian Motivations for Online Retail Shopping Behavior. Joumal of Retailing, $77(4), 511-535$.

Cohen, M. (1990). Caring tor Ourselves Can Be Funny Business. Holistic Nursing Practices, 4, 1-11.

Coleman, J.G. (1992). All Seriousness Aside: The Laughing-Leaming Connection. International Joumai of Instructionai Media, 19 (3), 269-276.

Coleman, C. and D. Blackmon (1999). Retailers Strive for Shopping Synergy. The Wall Street Joumal, December 20, B1-B6.

Crosby, L.A. K.R. Evans and D. Cowles (1990). Relationship Quality in Services Selling: An Interpersonal Influence Perspective. Joumal of Marketing, 54 (1), 68-81.

Curtis, P. (1997). MUDding: Social Phenomena in Text-Based Virtual Realities. In: Culture of the Internet, Kiesler, S.

(Ed.), Lawrence Earbaum, New York. 
Czepiel, J.A. (1990). Service Encounters and Service Relationships: Implications for Research. Journal of Business Research, 20 (January), 13-21.

Czepiel, J.A., M.R. Solomon and C.F. Surprenant (1985). The Service Encounter. Lexington Books̄, Lexington, New York.

Dabholkar, P.A. (1994). Incorporating Choice into an Attitudinal Framework: Analyzing Models of Mental Comparison Processes. Journal of Consumer Research, 21 (1), 100-118.

Dabholkar, P.A. (1996). Consumer Evaluations of New Technology-Based Self-Service Options: An Investigation of Alternative Models of Service Quality. International Joumal of Research in Marketing, 13, 29-51.

Dabholkar, P.A (2000). Technology in Service Delivery: Implications for Self-Service and Service Support. In: Handbook of Services Marketing and Management, Swart, T.A. and D. lacobucci (Ed.), 89-102. Sage Publications, Thousand Oaks, CA.

Dabholkar, P.A. and S. Walls (1999). Service Evaluation and Switching Behavior for Experiential Services: An Empirical Test of a Broader Conceptual Framework. In: Proceedings of the Frontiers in Services Conference, Rust, R.T., S.W. Brown, and V. Zeithaml (Ed.), 56, Nashville, TN.

Dabholkar, P.A. and R.P. Bagozzi (2002). An Attitudinal Model of Technology-Based Self-Service: Moderating Eflects of Consumer Traits and Situational Factors. Joumal of the Academy of Markeling Science, 30 (3), forthcoming.

Danet, B., T. Wachenhauser, A. Cividalli, H. Bechar-Israeli and Y. Rosenbaum-Tamari (1995). Curtain Time 20:00 GMT: Experiments in Virtual Theater on Internet Relay Chat. Journal of Computer-Mediated Communication, 1 (2). Available: htp://www.ascusc.org/jcmo/volt/issue2/contents.html.

Datamonitor (2002). Online Customer Management and Cross-selling in Financial Services. DMFS 1441. Available: hitp://www.datamonitor com.

Davis, F.D., R.P. Bagozzi and P.R. Warshaw (1989). User Acceptance ol Computer Technology: A Comparison of Two Theoretical Models. Management Science, 35 (8), 982-1003.

Davis, F.D., R.P. Bagozzi and P.R. Warshaw (1992). Extrinsic and Intrinsic Molivation to Use Computers in the Workplace. Joumal of Applied Social Psychology, 22 (14), 1109-1130.

Day, D., M. Dosa and C. Jorgensen (1995). The Transfer of Research Information within and by Multicultural Teams. Information Processing \& Management, 31 (1), 89-100.

Deighton, J., D. Romer and J. McQueen (1989). Using Drama to Persuade. Joumal of Consumer Research, 16 (3), 335-343.

Dellaert, B.G.C. (2000). Tourists' Valuations of other Tourists' Contributions to Travel Web Sites. Presented at the ENTER 2000 Conference, May, Barcelona.

DePaulo, B.M. (1992). Nonverbal Behaviour and Self-Presentation. Psychological Bulletin, 111 (2), 203-243.

DePaulo, B.M. and A. Rosenthal (1982). Measuring the Development of Sensitivity to Nonverbal Communication, In: Measuring Emotions in Infants and Children, Izard, C.E. (Ed), Cambridge University Press, New York.

Deutsch, M. and H.B. Gerard (1955). A Study of Normative and Informational Social Influences upon Individual Judgment. Journal of Abnomal and Social Psychology, 51,629-636.

Dickson, M.W., D.B. Smith, M.W. Grojean and M. Ehrhart (2001). An Organizational Climale regarding Ethics: The Outcome of Leader Values and the Practice that Reflect them. The Leadership Quarterly, 12, 197-217.

Direct Marketing (2001). "Social" Seminars Help Financial Advisors Reach Senior Market. 64, (1), 15.

Dolen van, H.L. (2000). De Klassieke Canon. Ambo, Amsterdam.

Dolen van, W.M., J.G.A.M. Lemmink, J. Mattsson and I. Rhoen (2001). Affective Consumer Responses in Service Encounters: The Emotional Content in Narratives of Critical Incidents. Joumal of Economic Psychology, 22, 359-376.

Dolen van, W.M. J.C. de Ruyter and J.G.A.M. Lemmink (2002). An Empirical Assessment of the Influence of Customer Emotions and Contact Employee Performance on Encounter and Relationship Satisfaction. Joumal of Business Research, forthcorning.

Donath, J., K. Karahalios and F. Viegas (1999). Visualizing Conversation. Joumal of Computer-Mediated Communication, 4 (4). Available: http://www ascusc: org/jcmcivol6/issue1/contents.

Dryer, D.C. and L.M. Horowitz (1997). When Do Opposite Markets Attract? Interpersonal Complementarity versus Similarity. Joumal of Applied Psychology, 72, 592-603.

Easley, R.W.. C.S. Madden and M.G. Dunn (2000). Conducting Marketing Science: The Role of Replication in the Research Process. Journal of Business Research, 48, 83-92.

Eastin, M.A. and P.L. LaRose (2000). Internet Self-Elficacy and the Psychology of the Digital Divide. Joumal of Computer Mediated Cornmunication, 6 (1). Available: http:/www.ascusc.org/jemcivol6/issuel/contents.html.

Efron, B. (1987). Better Bootstrap Confidence Intervals. Journal of the American Statistical Society, 82 (March), 171-185.

Endlich, E. (1993). Teaching the Psychology of Humor. Teaching of Psychology, 20, 181-183.

Emst and Young (1999). Intemet Shopping: An Emst and Young Special Repont. Enst and Young LLP.

Evans, K.R. and S.W. Brown (1988). Strategic Options for Service Defivery Systems. In: Proceedings of the AMA Summer Educators' Conference, Ingene, C.A. and G.L. Frazier (Ed.), 207-212, American Marketing Association, Chicago, IL.

Evans, K.R., T.J. Amold and J.A. Grant (1999). Combining Service and Sales at the Point of Customer Contact: A Retail Banking Example. Joumal of Service Research, 2, 34-49. 
Felson, R. (1992). Coming to See Ourselves: Social Sources of Self-Appraisal. Advances in Group Processes, 9 (2), 185-205. Fenwick, I. (1979). Techniques in Market Measurement: The Jackknife. Journal of Marketing Research, 16 (3), 410-414. Festinger, L. (1954). A Theory of Social Comparison Processes. Human Relations, 7, 117-140.

Fiedler, F.E. (1967). A Theory of Leadership Effectiveness. McGraw-Hill, New York.

Fiedier, F.E. and House, R.J. (1988). Leadership Theory and Research: A Report of Progress. in: International Review of Industrial and Organizational Psychology, Cooper, C.L. and I. Robertson (Ed.), 3, 73-92, John Wiley, London, UK.

Flap, H. and B. Volker (2001). Goal Specific Social Capital and Job Satisfaction, Effects of Different Types of Networks on Instrumental and Social Aspects of Work. Social Networks, 23, 297-320.

Foley, J.D., V.L. Wallace and P. Chan (1990). The Human Factors and Computer Graphics Interaction Techniques. In: Human-Computer Interaction, Preece, J. and L. Keller (Ed.), 68-121, Prentice Hall, Hertlordshire, UK.

Ford, G.T., D.B. Smith and J.L. Swasy (1988). An Empirical Test of the Search Experience and Credence Attributes Framework. Advances in Consumer Research, 15, 239-243.

Forman A.M. and V. Sriram (1991). The Depersonalization of Retailing: Its Impact on the 'Lonely' Consumer. Joumal of Retailing, 67 (2), 226-243.

Fomell, C. (1992). A National Customer Satisfaction Barometer. The Swedish Experience. Journal of Marketing, 56 (1), 1-21.

Fornell, C., M.D. Johnson, E.W. Anderson, J. Cha and B. Bryant (1996). The American Customer Satisfaction Index (ACSI): Assessing the Financial impact of Quality Initiatives. In: Proceedings of the vuran Institute's Conference on Managing for Total Quality, 76-102, Juran Institute, Wilton, CT.

Forsyth, D.R. (1999). Group Dynamics. $3^{\text {st }}$ edition, Wadsworth Publishing Company, Belmont, CA

Fox, W.S. (1993). Computerized Creation and Diffusion of Folkloric Materials. Folklore Fonum, 16, 5-20.

Freud, S. (1905, 1960). Jokes and Their Relation to the Unconscious. Routledge \& Kegan Paul Ltd., London.

Garcia, A.C. and J.B. Jacobs (1999). The Eyes of the Beholder: Understanding the Turn-Taking System in QuasiSynchronous Computer-Mediated Communication. Research on Language and Social Interaction, 32 (4), 337-367.

Goffman, E. (1959). The Presentation of Self in Everyday Life. Doubleday, New-York.

Goldstein, H., J. Rasbach, I. Plewis, D. Draper, W. Browne, M. Yang, G. Woodhouse and M. Healey (1998). A User's Guide to MiwiN. Multilevel Models Project Institute of Education, University of London, London.

Goodwin, C. and D.D. Gremler (1996). Friendship over the Counter: How Social Aspects of Service Encounters Influence Consumer Service Loyalty. Advances in Service Marketing and Management, 5, 247-282.

Graves, L.M. and G.N. Powell (1995). The Effect of Sex Similarity on Recruiters' Evaluation of Actual Applicants: A Test of the Similarity-Attraction Paradigm. Personal Psychology, 48, 85-98.

Gray, R.J. (2001). Organizational Climate and Project Success. International Joumal of Project Management, 19, 103-109.

Grayson, K. (1998). Customer Response to Emotional Labor in Discrete and Relational Service Exchange. Intennational Joumal of Service industry Management, 9, 103-125.

Grayson, K. and D. Shulman (2000). Impression Management in Services Marketing. In: Handbook of Services Marketing and Management, Swartz, T.A. and D. lacobucci (Ed.), Sage Publications, Thousand Oaks, CA.

Gremler, D.D. and K.P. Gwinner (2000). Customer-Employee Rapport in Service Relationships. Joumal of Service Research, 3 (1), 82-104.

Grikscheit, G.M., H.C. Cash and C.E. Young (1993). The Handbook of Selling: Psychological, Managerial, and Marketing Dynamics. $2^{\text {so }}$ edition, Wiley Publishers, New York.

Grönroos, C. (1984). A Service Quality Model and its Marketing Implications. European Journal of Marketing, 4 (18), $36-44$.

Grônroos, C. (1990). Relationship Approach to Marketing in Services Contexts: The Marketing and Organizationa: Behavior interlace. Joumal of Business Research, 20 (January), 3-11.

Grônroos, C. (1992). Service management: Managernent, Strategy and Marketing in Senvice Compettion, ISL Förlag, Göteborg.

Grônroos, C. (1997). Value-Driven Relational Marketing: From Products to Resources and Competencies. Joumal of Marketing, 13 (5), 407-419.

Grönroos, C. (2000). Service Reflection: Service Marketing Comes of Age. In: Handbook of Services Marketing and Management. Swart. T.A. and D. lacobucci (Ed.), 13-16, Sage Publications, Thousand Oaks, CA.

Grove, S.J. and R.P. Fisk (1997). The Impact of other Customers on Service Experiences: A Critical Incident Examination of "Getting Along." Joumal of Retailing, 73 (1), $63-85$.

Grove, S.J., R.P. Fisk and M.J. Dorsch (1998). Assessing the Theatrical Components of the Service Encounter. A Cluster Analysis Examination. Services Industries Joumal, 18 (July), 116-134.

Guiry, M., (1992). Consumer and Employee Roles in Service Encounters. In: Advances in Consumer Research, Sherry, J.F. and B. Sternthal (Ed.), 19, 666-672.

Gupta, S. and M. Vajic (2000). The Contextual and Dialectical Nature of Experiences: In: New Service Development: Creating Memorable Experiences, Fitzsimmons, J.A. and M.J. Fitzsimmons (Ed), 33-51, Sage Publications, Thousand Oaks, CA.

Gutek, B.A. (2000). Senvice Relationships, Pseudo-relationships, and Encounters. In: Handbook of Services Marketing and Management, Swart, T.A. and D. lacobucci (Ed.), 371-380, Sage Publications, Thousand Oaks, CA. 
Gutek, B.A., A.D. Bhappu, M. Liao-Troth and B. Cherry (1999). Distinguishing between Service Relationships and Encounters. Journal of Applied Psychology, 84 (2), 218-233.

Gutman, J. (1982). A Means-End Chain Model Based on Consumer Categorization Processes. Journal of Marketing, 46 (2), 60-72.

Gwinner, K.P., D.D. Gremler and M.J. Bitner (1998). Relational Benefits in Services Industries: The Customer's

Perspective. Joumal of the Academy of Marketing Science, 26 (2), 101-114.

Hagel, J. and A.G. Armstrong (1997). Net Gain. Harvard Business School Press, Boston, MA.

Haley, R.I. (1968). Benefit Segmentation: A Decision-Oriented Research Tool. Joumal of Marketing, 32 (3), 30-35.

Hall, J.A., D.L. Roter and N.R. Katz (1988). Meta-Analysis of Correlates of Provider Behaviour in Medical Encounters.

Medical Care, 26, 657-675.

Hampes, W.P. (1992). Relation between Intimacy and Humor. Psychological Reports, 71, 127-130.

Handy, C. (1995). Trust and the Virtual Organization. Harvard Business Review, 73 (3), 40-50.

Hanna, N., G.L. Gordon and R.E. Ridnour (1994). The Use of Humor in Japanese Advertising. Joumal of Intemational Consumer Marketing, 7 (1), 85-106.

Hare, A.P. (1976). Handbook of Small Group Research. $2^{\text {nd }}$ edition, Free Press, New York.

Hartine, M.D. and O.C. Ferrell (1996). The Management of Customer-Contact Service Employees: An Empirical Investigation. Joumal of Marketing, 60 (4), 52-70.

Hatfield, E., J. Cacioppo and R.L. Rapson (1993). Emotional Contagion. Current Developments in Psychological Science, $2(1), 96-99$.

Herbert, T.B. and S. Coghen (1993). Stress and Immunity in Humans: A Meta-Analytic View. Psychosomatic Medicine; $55,364-379$.

Hezel, R.T., J. Bryant and L. Harris (1982). The Relationship between Humor and Educational Information: Lectures and Leaming. Unpublished Manuscript.

Hill, C.T. and D.E. Stull (1981). Sex Differences in Effects of Social and Value Similarity in Same-Sex Friendship. Journal of Personality and Social Psychology, 41, 488-502.

Hiltz, S.R., K. Johnson and M. Turoff (1986). Experiments in Group Decision Making. Human Communication Research, 13, 225-252.

Hinsz, V.B., R.S. Tindale and D.A. Vollrath (1997). The Emerging Conceptualization of Groups as Information Processors. Psychological Bulletin, 121 (1), 43-64

Hirschman, E.C. and M.B. Holbrook (1982). Hedonic Consumption: Emerging Concepts, Methods and Propositions. Journal of Marketing, 46 (3), 92-101.

Hochschild, A.A. (1983). The Managed Heart. University of Califomia Press, Berkeley, CA.

Hoffman, D.L. (2001). Consequences of the Web for Customers and Firms: Developing a Research Agenda for Intemet Marketing. Presentation at the American Marketing Association Faculty Consortium on Electronic Commerce, Texas, July, 14-17.

Hoffman, D.L. and T.P. Novak (1996). Marketing in Hypermedia Computer-Mediated Environments: Conceptual Foundations. Journal of Marketing, 60 (3), 50-68.

Hofmann, D. (1997). An Overview of the Logic and Rationale of Hierarchical Linear Models. Journal of Management, 23 (6), 723-744.

Hogg, M.A.(1992). The Social Psychology of Group Cohesiveness. Harvester Wheatsheaf, London, UK.

Hui, M.K. and D.K. Tse (1996). What to Tell Consumers in Waits of Different Lengths: An Interactive Model of Service Evaluation. Joumal of Marketing, 60 (2), 81-90.

lacobucci, D., K.A. Grayson and A.L. Ostrom (1994). The Calculus of Service Quality and Customer Satisfaction: Theoretical and Empirical Differentiation and Integration. In: Advances in Services Marketing and Management, Swartz, T.A., D.E. Bowen and S.W. Brown (Ed.), 3, 1-67, JAI Press, Greenwich, CT.

Igbaria, M., S. Parasuraman and J. Baroudi (1996). A Motivational Model of Microcomputer Usage. Joumal of Management Information Systems, 13 (1), 83-103.

Informationweek (2001). Citybank to Create Virtual Communities to Service Customers. July 23. Available $\mathrm{http} / / \mathrm{ww}$ w. informationweek.com.

Insko, C.A. and J. Schopler (1972). Experimental Social Psychology. Academic Press, New York.

Jackson, D.W., J. Keith and A.K. Burdick (1984). Purchasing Agents' Perceptions: A Situational Approach. Joumal of Marketing, 48 (4), 75-83.

Johnson, D.W. (1994). Joining Together: Group Theory and Group Skills. Allyn and Bacon, Boston, MA.

Johnson, M.D. (1984). Consumer Choice Strategies for Comparing Noncomparable Alternatives. Joumal of Consumer Research, 11 (3), 741-753.

Johnson, M. and G.M. Zinkhan (1991). Emotional Responses to a Professional Service Encounter. Joumal of Services Marketing, 5, 5-16.

Johnson, R.A. and D.W. Wichern (1998). Applied Mullivariate Statistical Analysis. Prentice Hall, Englewood Clitts, NJ. 
Johnson, M., G.M. Zinkhan and G. Ayala (1998). Recommending a Service Provider: Some Factors which Influence the Probability of Referral. Journal of Services Marketing, 12 (5), 397-415.

Jonge de, J., G. van Breukelen, J. Landeweerd and F. Nijhuis (1999). Comparing Group and Individual Level Assessments of Job Characteristics in Testing the Job Demand-Control Model: A Multi-Level Approach. Human Relations, 52 (1), 95-122. Jöreskog K., and D. Sôrbom (1993). LISREL 8: A Guide to the Program and Applications. SPSS, Chicago, IL. Jupiter Research (2001). Integrated Finance: Composing a Symphony out of the Discord.

Kahai, S.S. and R.B. Cooper (1999). The Effect of Computer-Mediated Communication on Agreernent and Acceptance. Journal of Management Information Systems, 16 (1), 165-188.

Kandel, D.B. (1978). Similarity in the Real Life Adolescent Friendship Pairs. Joumal of Personality and Social Psychology, 36, 306-312.

Kaplan, R.S. and D.P. Norton (1992). The Balanced Scorecard-Measures that Drive Performance. Harvard Business Review, 70 (1), 71-79.

Kaye, K. (1999). Comic Relief Spikes Peets Coffee \& Tea. Available: http://www.channelseven.com/adinsight/case_studies. Keaveney, S.M. and M. Parthasarathy (2001). Customer Switching Behavior in On-Line Services: An Exploratory Study on the Role of Selected Attitudinal, Behavioral, and Demographic Factors. Joumal of the Academy of Marketing Science, 29 (4), 374-390.

Kenny, D. (1996a). Interpersonal Perception: A Social Relations Analysis. The Guilford Press, New York.

Kenny, D. A. (1996b). Models of Non-Independence in Dyadic Research. Joumal of Social and Personal Relationships, 13 (2), 279-294.

Kenny, D. and W. Cook (1999). Partner Effects in Relationship Research: Conceptual Issues, Analytic Difficulties, and Illustrations. Personal Relationships, 6 (4), 433-448.

Kenny D. and J.F. Marshall (2000). Contextual Marketing: The Real Business of the Internet. Harvard Business Review, 78 (6), 119-125.

Kenny, D., D. Kashy, and N. Bolger (1998). Data Analysis in Social Psychology. In: The Handbook of Social Psychology, Gilbert, D., S. Fiske and G. Lindzey (Ed.), 233-265, McGraw-Hill, New York.

Kenny, D., C. Homer, D. Kashy and L. Chu (1992). Consensus at Zero Acquaintance: Replication, Behavioral Cues, and Stability. Joumal of Personality and Social Psychology, 62 (1), 88-97.

Keppel, G. (1991). Design and Analysis: A Researcher's Handbook. Prentice Hall, Englewood Clifts, NJ.

Kerckhoff, A.C. and K.E. Davis (1962). Value Consensus and Need Complementarity in Mate Selection, American Sociological Review. 27, 295-303.

Kerr, N.L., R.J. MacCoun and G.P. Kramer (1996). Bias in Judgment: Comparing Individuals and Groups. Psychological Review, 103, 687-719.

Kidwell. R.E., K.W. Mossholder and N. Bennett (1997). Cohesiveness and Organizational Citizenship Behavior: A MultiLevel Analysis Using Work Groups and Individuals. Joumal of Management, 23 (6), 775-793.

Kirsner, S. (1997). Close Encounters: The Most Effective Web Sites Offer Users a Conversation, NotaMonologue.Cl Web Business Magazine. Available: http:/www.cio.com/archive/webbusiness.

Klein, D., J. Bryant and D. Zillman (1982). Relationship between Humor in Introcluctionary Textbooks and Students' Evaluations of the Text's Appeal and Effectiveness. Psychological Reports, 50 (February), 235-241.

Klein K.J., A.B. Conn, D.B. Smith and J.S. Sorra (2001). Is Everyone in Agreement? An Exploration of Within-Gioup Agreement in Employee Perceptions of the Work Environment. Joumal of Applied Psychology, 86 (1), 3-16.

Kleinbaum, D.G. L.L. Kupper and K.E. Muller (1988). Applied Regression Analysis and other Mulfivariable Methods. $2^{\text {nd }}$ edition, PWS-KENT Publishing Company, Boston, MA.

Kozlowski, S.W.J. and K.J. Klein (2000). A Multilevel Approach to Theory and Research in Organizations: Contextual, Temporal, and Emergent Processes. In: Multilevel Theory, Research, and Methods in Organizations, Klein, K.J and S.W.J. Kozlowski (Ed.). Society for Industrial and Organizational Psychology Frontiers Series, 3-90, Jossey-Bass, San Francisco, CA.

Kraut, R.E., J. Galegher, A.S. Fish and B.L. Chalfonte. (1992). Task Requirements and Media Choice in Coliaborative Writing. Human-Computer Interaction, 7, 375-407.

Krishnan, H.S. and D. Chakravarti (1990). Humour in Advertising: Testing Eflects on Brand Name and Message Claim Memory. In: Proceedings of the Summer Educators' Conference, Bearden, W. and A. Parasuraman (Ed.), 10-16, American Marketing Association, Chicago, IL.

LaFave, L. (1972). Humor Judgments as a Function of Reference Group and Identification Classes. In: Psychology of Humor, Goldstein, J.H. and P.E. McGhee (Ed.), Academic Press, New York.

LaFollette, H. and N. Shanks (1993). Belief and the Basis of Humor. American Philosophical Quarterly, 30 (4), 329-339.

Lapierre. J. (1996) Service Quality: The Construct, its Dimensionality and its Measurement. In: Advances in Service Marketing and Management, Swartz, T.A, D.E. Bowen and S.W. Brown (Ed.), 5, JAI Press, Greenwich, CT. 
Larson, J.R. and C. Christensen (1993). Groups as Problem Solving Units: Toward a New Meaning of Social Cognition. British Joumal of Social Psychology, 32, 5-30.

Larsson, J.R. and D.E. Bowen (1989). Organization and Customer: Managing Design and Coordination of Services. Academy of Management Review, 14 (2), 213-233.

Lascu, D.N., W.O. Bearden and R.L. Rose (1995). Norm Extremity and interpersonal Influences on Consumer Conformity. Journal of Business Research, 32, 201-212.

Lazare, A., S. Eisenthal and L. Wasserman (1975). The Consumer Approach to Patient Hood: Attending to Patient Request in a Waik-In Clinic. Archives of General Psychiatry, 22 (May), 553.

Leaf, C. (1998). The Death of Customer Service. Smart Money, (October), 131-137.

Ledingham, J.A. (1984). Are Consumers Ready for the Information Age? Joumal of Advertising Research, 24 (4), $31-37$.

Lefcourt, H.M. and R.A. Martin (1986). Humor and Life Stress: Antidote to Adversity. SpringerVerlag, New York.

Leiber, D. (1986). Laughter and Humor in Critical Care. Dimensions of Critical Care Nursing, 5, 162-167.

Lemmink, J. and J. Mattsson (1998). Warmth during Non-Productive Retail Encounters: The Hidden Side of Productivity. International Joumal of Research in Marketing, 15, 505-517.

Levesque, M. (1997). Meta-Accuracy among Acquainted Individuals: A Social Relations Analysis of Interpersonal Perception and Metaperception, Journal of Personality and Social Psychology, 72 (1), 66-74.

Levine, A., C. Locke, D. Searls and D. Weinberger (2000). The Cluetrain Manifesto: The End of Business as Usual. Persues Books, Cambridge, MA.

Levinger, G. D.J. Senn and B.W. Jorgensen (1970). Progress toward Permanence in Courtship: A Test of the KerckhoffDavis Hypothesis. Sociometry, 33, 427-433.

Levi-Strauss, C. (1969). The Elementary Structure of Kinship. Beacon Press, Boston, MA.

Lind, M. and R. Zmud (1995). Improving Interorganizational Effectiveness through Voice Mail Facilitation of Peer-to-Peer Relationships. Organization Science, 6 (4), 445-462.

Lindsley, D.H., D.J. Brass and J.B. Thomas (1995). Efficacy-Performance Spirals: A Multilevel Perspective. Academy of Management Review, 20, 645-678.

Locke, K. (1996). A Funny Thing Happened: The Management of Consumer Emotions in Service Encounters. Organizational Science, 7 (1), 41-59.

Lockett, A. and D. Litter (1997). The Adoption of Direct Banking Senvices. Joumal of Marketing Management, 13, $791-811$.

Lovelock, C.H. (1995). Technology, Servant or Master in the Delivery of Services. Advances in Service Marketing and Management, 4, 63-90.

Lytle, R.S. and M.P. Mokwa (1992). Evaluating Health-Care Quality: The Moderating Role of Outcomes. Journal of Health Care Marketing, 12 (1), 4-14.

Madden, T.J.and M.G. Weinberger (1984). Humour in Advertising: A Practitioner View. Journal of Advertising Research, $24(4), 23-29$.

Magaro, P.A. and R.M. Ashbrook (1985). The Personality of Societal Groups. Journal of Personality and Social Psychology, 48, 1479-1489.

Maltz, E. and A. Kohli (1996). Market Intelligence Dissemination across Functional Boundaries. Journal of Marketing Fesearch, $33(1), 47-61$.

Mann, J.H. (1959). A Review of the Relationships between Personality and Performance in Small Groups. Psychological Bulletin, 56, 241-270.

Martin, R.A. and H.M. Lefcourt (1983). Sense of Humor as a Moderator of the Relation between Stressors and Moods. Journal of Personality and Social Psychology, 45 (6), 1313-1324.

Martin, R.A. and H.M. Lefcourt (1934). Situational Humor Response Questionnaire: Quantitative Measurement of Sense of Humor. Joumal of Personality and Social Psychology, 47 (1), 145-155.

Martineau, W.H. (1972). A Model of the Social Functions of Humor. In: The Psychology of Humor, Goldstein, J.H. and P.E. McGhee (Ed.), 101-125, Academic Press, New York.

Mason, $\overline{\mathrm{H}}$ (1997). Moderating Educational Computer Conferencing. Available: http'/star ucc.nau.edu/ mauri/ papers/mason.html.

Mathwick, C., N. Malhotra and E. Aigdon (2001). Experiential Value: Conceptualization, Measurement, and Application in the Catalog and Internet Shopping Environment. Joumal of Retailing, 77 (1), 39-56.

McGhee, P.E. (19/4). Cognitive Mastery and Children's Humor. Psychological Bulletin, 81 (10), 721-730.

McKeown, M. (2002). Why They Don't Buy; Make your Online Customer Experience Work. Prentice Hall, London.

McLuhan, M. and Q. Fiore (1997). The Medium is the Message: An Inventory of Effects. HardWired, San Francisco, CA.

McWilliam, G. (2000). Building Stronger Brands through Online Communities. Sloan Management Review, 41 (3), 43-54.

Mead, G.H. (1934). Mind, Self, and Society. University of Chicago Press, Chicago, IL. 
Mead, N.A. (1986). Listening and Speaking Skills Assessment. In: Performance Assessment: Methods and Applications, Berk, R.A. (Ed.), Johns Hopkins University Press, Baltimore, MD.

Meuter, M.L. and M.J. Bitner (1998). Self-Service Technologies: Extending Service Frameworks and Identifying Issues for Research. American Marketing Association. Winter, 12-19.

Meuter, M., L. Ostrom, A.L. Roundtree, I. Robert and M. Bitner (2000). Sell-Service Technologies: Understanding Customer Satistaction with Technology-Based Service Encounters. Journal of Marketing, 64 (3), $50-64$.

Meyer, J.P. and S. Pepper (1977). Need Compatibility and Material Adjustment in Young Married Couples. Journal of Personality and Social Psychology, 35, 331-342.

Michela, J.L., M.P. Lukaszewski and J.P. Allegrante (1996). Organizational Climate and Work Stress: A General Framework Applied to inner-City Schoolteachers. In: Organizational Risk Factors for Job Stress, Sauter, S.L. and L.R. Murphy (Ed.), 61-80, American Psychological Association, Washington.

Miles, M.P., D.R. Arnold and H.W. Nash (1990). Adaptive Communication: The Adaptation of the Seller's Interpersonal Style to the Stage of the Dyad's Relationship and the Buyer's Communication Style. Joumal of Personal Selling \& Sales Management, 10 (February), 21-27.

Miller, K.I. and P.R. Monge (1986). Participation, Satisfaction, and Productivity: A Meta-Analytic Review. Academy of Management Journal, 29 (4), 727-753.

Milliken, F.J. and L.L. Martins (1996). Searching for Common Threads: Understanding the Multiple Effects of Diversity in Organizational Groups. Academy of Management Review, 21 (2), 402-433.

Mindness, H. (1971). Laughter and Liberation. Nash, Los Angeles, CA.

Misumi, J. and M.F. Peterson (1985). The Performance-Maintenance (PM) Theory of Leadership: Review of a Japanese Research Program. Administrative Science Quarterly, 30, 198-223.

Modahl, M. (2000). Now or Never: How Companies Must Change to Win the Battle for Internet Consumers. HarperBusiness, New York.

Mohammed, S., R. Klimoski and J.R. Rentsch (2000). The Measurement of Team Mental Models: We Have No Shared Schema. Organizational Research Methods, 3 (2), 123-165.

Molnos, A. (1998). A Psychotherapist's Harvest. Available:http://fox.klte.hu/-keresofi/psychotherapylindex.shtml.

Moran, C.C. (1996). Short-Term Mood Change, Perceived Funniness, and the Effect of Humor Stimuli. Behavioral Medicine, 22 (1), 32-39.

Moran, C.C. and M.M. Massam (1999). Differential Influences of Coping Humor and Humor Bias on Mood. Behavioral Medicine: An Interdisciplinary Joumal of Research and Practice, 25 (Spring), 36-42.

Mudrack, P.E. and G.M. Farrell (1995). An Examination of Functional Role Behavior and its Consequences for Individuals in Group Settings. Small Group Behavior, 26, 542-571.

Mulkay, M. (1988). On Humour. Polity Press, Cambridge, UK.

Muniz, A.M. and T.C. O'Guinn (2001). Brand Community. Joumal of Consumer Research, 27 (4), 412-433.

Murphy, K.L. and M.P. Collins (1999). Communication Conventions in Institutional Electronic Chats. Available: http:/www.firstmonday.dk/issues/issue2_11/murphy.

Myers, S.A., B.L. Ropog and R.P. Rodgers (1997). Sex Differences in Humor. Psychological Reports, 81, 221 -222.

Naisbitt, J., N. Naisbitt and D. Philips (2001). High Tech, High Touch: Technology and Our Accelerated Search for Meaning. Nicholas Brealey Publishing. Naperville, IL.

Nasar, J.L. (1989). Perceptions, Cognition, and Evaluation of Unaan Places. In: Public Places and Spaces, Altman, I. and E.A. Zube (Ed.), 31-56, Plenum Press, New York.

Neuman G.A., and J. Wright (1999). Team Effectiveness: Beyond Skills and Cogniwe Ability. Joumal of Applied Psychology, 84 (3), 376-389.

Newcomb, T.M. (1961). The Acquaintance Process. Holt, Rinehart and Winston, Newi York.

Newcomb, T.M. (1963). Stabilities Underlying Changes in Interpersonal Aftraction. Joumal of Abnormal and Socia! Psychology, 66, 376-386.

Newcomb, T.M. (1981). Heiderean Balance as a Group Phenomenon. Joumal of Personality and Social Psychology, 40, 862-867.

Newell, F. and K. Newell-Lemon (2001). Wireless Rules. McGraw-Hill, New York.

New York Times (1998). Intemet Chat Rooms Becoming a Popular Forum for Business. By. Arnaul, G., January 26. Available: http://www.nytimes.com.

NFO World Group (1999). NFO InDepth Interactive. Available: http://wrww.nfow.com/nfointeractive/info.asp.

Novak, T.P., D.L. Hoffman and Y.F. Yung (1999). Measuring the Customer Experience in Online. Environmerits: A Structural Modeling Approach. Marketing Science, 19 (1), 22-42.

O'Connor, J.M. (1998), Seminar Marketing: Beyond the Basics. Practice and Tec' moloyy: Institute of Certified Financial Planners.

O'Connor, B.P. and J. Dyce (1997). Interpersonal Rigidity, Hostility, and Complementarily in Musical Bands. Joumal of Personality and Social Psychology, 72, 362-372. 
O'Guinn, T.C. and R.J. Faber (1989). Compulsive Buying: A Phenomenological Exploration. Journal of Consumer Research, 16 (2), 147-158.

Oliver, R.L. (1997). Satisfaction: A Behavioral Perspective on the Consumer. McGraw-Hill, New York.

Oliver, R.L. (2000). Customer Satisfaction with Services, In: Handbook of Services Marketing and Management, Swartz,

T.A. and D. lacobucci (Ed.), 247-254, Sage Publicakions, Thousand Oaks, CA.

Oliver, R.L. and J.E. Swan (1989). Postpurchase Communications by Consumers. Joumal of Retailing, 64, 517-533.

Ostroff, C. (1993). Comparing Correlations Based on Individual-Level and Aggregated Data. Joumal of Applied Psychology, 78 (4), 569-582.

Ostrom, A and D. lacobucci (1995). Consumer Trade-ofts and the Evaluation of Services. Joumal of Marketing, 59 (1), $17-28$.

Ott, J.S. (1989). The Organizational Culture Perspective. Brooks/Cole, Pacific Grove, CA.

Parasuraman, A., L.L. Berry and V.A. Zeithaml (1991). Refinement and Reassessment of the SERVOUAL Scale. Joumal of Retailing, 67 (4), 420-450.

Parasuraman, A., V.A. Zeithaml and L.L. Berry (1985). A Conceptual Model of Service Quality and its Implications for Further Research. Joumal of Marketing, 49 (4), $41-50$.

Park, D. and C. Judd (1989). Agreement on Initial Impressions: Differences due to Perceivers, Trait Dimensions, and Target Behaviors. Joumal of Personality and Social Psychology, 56 (3). 493-505.

Park, C.W. and V.P. Lessig (1981). Familiarity and its Impact on Consumer Decision Biases and Heuristics. Joumal of Consumer Research, 8 (2), 223-230.

Parse, A. (1993). The Experience of Laughter. A Phenomenological Study. Nursing Science Quarterly, 6, 39-43.

Paulhus, D. and M. Bruce (1992). The Effect of Acquaintanceship on the Validity of Personality Impressions: A Longitudinal Study. Joumal of Personality and Social Psychology, 63 (5), 816-824.

Perdue, B.C. and J.O. Summers (1986). Checking the Success of Manipulations in Marketing Experiments. Joumal of Marketing Research. 23 (4), 317-326.

Perry, S.D. and S.A. Jenzowsky (1997). The Influence of Commercial Humor on Program Enjoyment and Evaluation. Joumalism and Mass Communication Quarterly, 74 (2), 388-400.

Pine, B.J. and J.H. Gilmore (1999). The Experience Economy. Harvard Business School Press, Boston, MA.

Powpaka, S. (1996). The Role of Outcome Quality as a Determinant of the Overall Service Quality in Different Categories of Service Industries. Joumal of Services in Marketing, 10 (2), 5-25.

Preece, J. (1999). Empathic Communities: Balancing Emotional and Factual Communication. Interacting With Computers, 12, 63-77.

Prendergast, G.P. and N.E. Marr (1994). Disenchantment Discontinuance in the Diffusion of Technologies in the Service Industry: A Case Study in Retail Banking. Joumal of Intemational Consumer Marketing, 7 (2). 25-40.

Price, L. E. Amould and S. Deibler (1995b). Consumers' Emotional Responses to Service Encounters: The Influence of the Service Provicter. International Joumal of Service Industry Management, 6 (1), 34-63.

Price, L., E. Amould and P. Tierney (1995a). Going to Extremes: Managing Service Encounters and Assessing Provider Performance. Joumal of Marketing, 59 (1), 83-97.

Prince, M. and M. Davies (2001). Moderator Teams: An Extension to Focus Group Methodology. Qualitative Market Research: An Intemational Journal 4 (4), 207-216.

Rafaeli, A (1999). Dress and Behavior of Customer Contact Employees: A Framework for Analysis. In: Advances in Services Marketing and Management, Swart, T., D. Bowen and S.W. Brown (Ed.), 175-211, JAI Press, Greenwich, CT.

Ramaswami, S.N., T.J. Strader and K. Brett (1998). Identifying Potential Customers for On-Line Financial Services. Journal of Internet Banking and Commerce, 3 (2). Available: http:/Www.arraydev.com/commerce/JIBC/9806-05.htm.

Ramsey, R.O. and R.S. Sohi (1997). Listening to Your Customers: The Impact of Perceived Salesperson Listening Behavior on Relationship Outcomes. Journal of the Academy of Marketing Science, 25 (2), 127-137.

Rapp, A. (1947). Toward an Eclectic and Multilateral Theory of Laughter and Humor. Joumal of General Psychology, 36, $217-219$.

Raudenbush, S.W. (1993). Hierarchical Linear Models and Experimental Design. In: Applied Analysis of Variance in Behavioural Science, Edwards, L.K. (Ed.), 459-496, Marcel Dekker, New York.

Reichheld, F.F. and W.E. Sasser (1990). Zero Defections: Quality Comes to Services. Harvard Business Review, 68 (5), $105-111$.

Reid, F.J.M., V. Malinek, C.J.T. Stott and J.S.B.T. Evans (1996). The Messaging Threshold in Computer-Mediated Communication. Ergonornics, 39 (8), 1017-1037.

Reno, R. and D. A. Kenny (1992). Effects of Selt-Consciousness and Social Anxiety on Self-Disclosure among Unacquainted Individuals: An Application of the Social Relations Model. Joumal of Personality, 60 (1), $79-94$.

Reynolds, K.E. and S.E. Beatty (1999). Cuslomer Benefits and Company Consequences of Customer-Salesperson Relationships in Retailing. Joumal of Retailing, 75 (1), 11-32.

Reynolds, T.J. and J. Gutman, (1984). Laddering: Extending the Repertory Grid Methodology to Construct AttributeConsequence-Value Hierarchies. In: Personal Values and Consumer Psychology, Pitts, R.E and A.G. Woodside (Ed.), 155-167, Lexington Books, Lexington, MA. 
Risch-Podie, A. and S. Schultz-Kleine (2000). Customer Participation in Service Production and Delivery. In: Handbook of Services Marketing and Management, Swart, T.A. and D. lacobucci (Ed), 111-126, Sage Publications, Thousand Oaks, CA.

Rifkin J. (2000). The Age of Access: The New Cutture of Hypercapitalism, Where All of Life Is a Paid-For Experience. Tarcher/Putnam, New York.

Riggs, M.L., J. Warka, B. Babasa, R. Betancourt and S. Hooker (1994). Development and Validation of Self-Efficacy and Outcome Expectancy Scales for Job-Related Applications. Educational and Psychological Measurement, 54, 793-802.

Roberts, C.A. and M.S. Aruguette (2000). Task and Socio-Emotional Behaviours of Physicians: A Test of Reciprocity and Social Interaction Theories in Analogue Physician-Patient Encounters. Social Science and Medicine, 50, 309-315.

Rosenfeld, L.B. and J.R. Gilbert (1989). The Measurement of Cohesion and its Relationship to Dimensions of SelfDisclosure in Class-Room Settings. Small Group Behavior, 20, 291-301.

Rothaermel, F.T. and S.Sugiyama (2001). Virtual Internet Communities and Commercial Success: Individual and Community-Level Theory Grounded in the Atypical Case of TimeZone.com. Journal of Management, 27, 297-312.

Ruyter de, K. and M. Wetzels (1998). On the Complex Nature of Patient Evaluations of General Practice Service. Journal of Economic Psychology, 19, 565-590.

Salomon, G. and T. Globerson (1989). When Teams Do not Function the Way they Ought to. Intemational Journal of Educational Research, 13, 89-98.

Savicki, V., M. Kelley and E. Oesterreich (1998). Effects of Instructions on Computer-Mediated Communication in Singleor Mixed-Gender Small Task Groups. Computers in Human Behavior, 14 (1), 163-180.

Schiffman, L.G. and L.L Kanuk (1994). Consumer Behavior. $5^{\mathrm{m}}$ edition. Prentice-Hall, New York.

Schillewaert, N., M.J. Aheame, R.T. Frambach and R.K. Moenaert (2000). The Acceptance of Technology in the Sales Force. E-Eusiness Research Center Working Paper, 07-2000.

Schlesinger, L.A. and J. Zomitsky (1991). Job Satisfaction, Service Capability, and Customer Satisfaction: An Examination of Linkages and Management Implications. Human Resource Planning, 14 (2), 141-149.

Schneider, B. (1980). The Service Organization: Climate is Crucial. Organizational Dynamics, 9, 52-65.

Schneider, B. and D.E. Bowen (1985). Employee and Customer Perceptions of Service in Banks: Replication and Extension. Joumal of Applied Psychology, 70 (3), 423-433.

Schneider, B. and D.E. Bowen (1995). Winning the Senvice Game. Harvard Business School Press, Boston, MA.

Schneider, B. and J.K. Wheeler (1992). A Passion for Service: Using Content Analysis to Explicate Service Climate Themes. Joumal of Applied Psychology, 77 (5), 705-717.

Scott, C., D.M. Klein and J. Bryant (1990). Consumer Response to Humor in Advertising: A Series of Field Studies Using

Behavioral Observation. Joumal of Consumer Research, 16 (March), 498-501.

Services Marketing Newsletter (1989). Recent Study Shows Gap betwoen Customers and Service Employees on

Customer Service Perceptions, 5 (1).

Shade, R.A. (1996). License to Laugh: Humor in the Classroom. Teachers Ideas Press, Englewood, CO.

Shankar, V., A.K. Smith and A. Rangaswamy (2000). The Relationship between Customer Satișlaction and Loyalty in On-

Line and OH-Line Environments. E-Business Research Center Working Paper, 02-2000.

Sharma, A. (1997). Salesperson Attributes and the Customer-Salesperson Interaction: Implications for Relationship Marketing. Research in Marketing, 13, 185-209.

Shemwell, D., U. Yavas and Z. Bilgin (1998). Customer-Service Provider Relationships: An Empirical Test of a Model of

Service Quality, Satisfaction and Relationship-Oriented Outcomes. Intemational Journal of Service Industry Management, 9, 155-168.

Sherny, J.F. (1990). A Sociocultural Analysis of a Midwestern Flea Market. Joumal of Consumer Research, 17 (1), 13-30.

Sheth, J.N. (1976). Buyer-Seller Interactions: A Conceptual Framework. In: Advances in Consumer Fesearch, Anderson,

B.B. (Ed), 382-386, Association for Consumer Research, Cincinnati, $\mathrm{OH}$.

Short, J., E. Williams and B. Christie (1976). The Social Psychology of Telecommunication. Wiley, London, UK.

Shostack, G.L. (1985). Planning the Service Encounter. In: The Service Encounter, Czepiel, J.A., M.R. Solomori and C.F.

Surprenant (Ed.), 243-254, Lexington Books, Lexington, MA.

Shrauger, S. and T. Schoeneman (1979). Symbolic Interactionist View of Self-Concept: Through the Looking Glass

Darkly. Psychological Bulletin, 86 (4), 549-573.

Sirgy, M.J. (1983). Social Cognition and Consumer Behavior. Praeger Publishers, New York.

Sirgy, M.J. and P.K. Tyagi (1986). An Attempt toward an Integrated Theory of Consumer Psychology and DecisionMaking. Systems Research, 3 (3), 161-175.

Sivadas, E., R. Grewal and J. Kellaris (1998). The Internet as a Micro Marketing Tool: Targeting Consumers through

Preferences Revealed in Music Newsgroup Usage. Joumal of Business Research, 41 (3), 179-186.

Snetsinger, W. and B. Grabowski (1994a). Use of Humorous Visuals to Enhance Computer-Based-Instruction. Visual Literacy in the Digital Age: Selected Readings from the 25 Conference of International Visual Literacy Association.

Beauchamp, D.G., R.A. Braden and J.C. Baca (Ed.), 262-270. 
Snetsinger, W. and B. Grabowski (1994b). The Use of Humor in a CBI Science Lesson to Enhance Retention. Presentation at the 1994 Convention of the Association for Educational Communications and Technology, Nashville. TN.

Snijders, T. and P. Bosker (1999). Multilevel, Analysis: An Introduction to Basic and Advanced Multilevel Modeling. Sage Publications, London, UK.

Snodgrass, S. (1992). Further Effects of Role versus Gender on Interpersonal Sensitivity. Journal of Personality and Social Psychology, 62 (2), 154-158.

Soldow, G.F. and G.P. Thomas (1984). Relational Communication: Form versus Content in the Sales Interaction. Journal of Marketing. (1), 84-94.

Solomon, J.C. (1996). Humor and Aging Well: A Laughing Malter or a Matter of Laughing? (Aging Well in Contemporary Society, Part 2: Choices and Processes). American Behavioural Scientist, 39 (3), 249-271.

Solomon, M.R., C. Surpenant, J.A. Czepiel and E.G. Gutman (1985). A Role Theory Perspective on Dyadic Interactions: The Service Encounter. Joumal of Marketing, 49 (1), 99-111.

Spears, R. and M. Lea (1992). Social Influence and the Influence of the "Social" in Computer-Mediated Communication. In: Contexts of Computer-Mediated Communication, Lea, M. (Ed.), 30-65, Harvester Wheatsheaf, London, UK.

Speck, P.S. (1987). On Humor and Humor in Advertising. Unpublished Doctoral Dissertation, Texas Tech University, Lubbock, TX.

Speck, P.S. (1991). The Humorous Message Taxonomy: A Framework for the Study of Humorous Ads. In: Current Issues in Research and Advertising, Leigh, J.H. and C.R. Martin (Ed.), 13, 1-44, Division of Research, Michigan Business School, University of Michigan, Ann Arbor, Ml.

Spiegeiman, P. (2000). Live Customer Interaction and the Internet Join in 'Internation'. Direct Marketing (4), 38-41.

Spiro, R.L. and B.A. Weitz (1990). Adaptive Selling: Conceptualization, Measurement, and Nomological validity. Journal of Marketing Research, 27 (1), 61-69.

Spolts, H.E., M.G. Weinberger and A.L. Parsons (1997). Assessing the Use and Impact of Humor on Advertising Effectiveness: A Contingency Approach. Joumal of Advertising, 26 (3), 17-32.

Sproull, L. and S. Kiesler (1986). Reducing Social Context Cues: Electronic Mail in Organizational Communication. Management Science, 32, 1492-1512.

Staples, D.S., J.S. Hulland and C.A. Higgins (1998). A Self-Efficacy Theory Explanation for the Management of Remote Workers in Virtual Organizations. Joumal of Computer-Mediated Communication, 3 (4). Available: http://www.ascusc.org/jcmc/vol3/issue $4 /$ contents.html.

Suls, J. (1983). Cognitive Processes in Humor Appreciation. In: Handbook of Humor Research, McGhee, P.E. and J.H. Goldstein (Ed.), 39-58, Springer-Verlag, New York.

Svebak, S. (1974). Revised Questionnaire on the Sense of Humor. Scandinavian Journal of Psychology, 15, 328-331.

Swan, J.E. and L.J. Comb (1976). Product Performance and Customer Satisfaction: A New Concept. Joumal of Marketing, $40(2), 25-33$.

Swartz, T.A. and S.W. Brown (1991). An Evolution of Research on Professional Service Quality. In: Service Quality: Multidisciplinary and Multinational Perspectives, Brown, S.W., E. Gummesson and B. Gustavsson (Ed.), 237-250, Lexington Books, Lexington, MA.

Switt, W.B. and A.T. Swift (1994). Humor Experts Jazz Up the Workplace. Human Resource Magazine, 39 (March), $72-75$.

Sypher, W. (1956). Comedy. Doubleday \& Co, New York.

Szymanski, D.M. and R.T. Hise (2000). E-Satisfaction: An Initial Examination. Joumal of Retailing, 76 (3), 309-322.

Tabachnik, B.G. and L.S. Fidell (1996). Using Multivariate Statistics. Harper Collins, New York.

Thibaut, J. and H.H. Kelley (1959). The Social Psychology of Groups. John Wiley and Sons, New York.

Thorson, J.A. and F.C. Powell (1993). Development and Validation of a Multidimensional Sense of Humor Scale. Journal of Clinical Psychology, 49 (1), 13-23.

Tidwell, J. and K. Wickre (2001). In the Key of C: Content and Community Co-Mingle. EContent Magazine, September. Available: http:/www.econtentmag.com/Magazine/Features/tidwell9_01b.html.

Trevino, L., K. and J. Webster (1992). Flow in Computer-Mediated Communication: Electronic Mail and Voice Mail Evaluation and Impacts. Communication Research, 19, 539-573.

Tukey, J.W. (1958). Bias and Confidence in Not-Quite Large Samples. Annals of Mathematical Statistics, 29 (June), 614.

Umesh, U.N.. R.A Peterson, M. McCann-Nelson and R. Vaidyanathan (1996). Type IV Error in Marketing Research: The Investigation of ANOVA Interactions. Journal of the Academy of Marketing Science, 24 (1), 17-26.

Utz, S. (2000). Social Information Processing in MUDs: The Development of Friendships in Virtual Worlds. Joumal of Online Behavior, 1 (1). Available: http://www.behavior.net/JOB/v1n1/utz. html.

Vallaster, C. and O. Koll (2002). Participatory Group Observation: A Tool to Analyze Strategic Decision Making. Qualitative Market Research: An international Joumal, 5 (1), $40-57$.

Vankatesh, V. and F.D. Davis (2000). A Theoretical Extension of the Technology Acceptance Model: Four Longitudinal Field Studies. Management science, 46 (2), 186-204.

Vinton, K. L. (1989). Humor in the Workplace: It Is More than Telling Jokes. Small Group Behavior, 20 (2), 151-166. 
Vronay, D., M. Smith and S. Drucker (1999). Streaming Media Interfaces for Chat. Microsoft Research Paper, Redmond, WA 98052 .

Waldersee, R., R. Simmons and G. Eagleson (1995). Pluralistic Leadership in Service Change Programs: Some Preliminary Findings. In: Best Papers Proceedings: Acaderny of Management, August, Madison Omnipress, Vancouver, Canada.

Walsh, J. and S. Godfrey (2000). The Internet: A New Area in Customer Service. European Management Joumal, 18 (1), 85-92. Walther, J.B. (1992). Interpersonal Effects in Computer-Mediated Communication: A Relational Perspective. Communication Research, 19 (1), 52-90.

Walther, J.B. and J.K. Burgoon (1992). Relational Communication in Computer-Mediated Interaction. Human Communication Research, 19 (1), 50-88.

Wanberg, C., R. Kanfer and J.Y. Banas (2000). Predictors and Outcomes of Networking Behavior among Unemployed Job Seekers. Journal of Applied Psychology, 85, 491-503.

Watson, W.E. and K. Kumar (1992). Differences in Decision-Making regarding Risk Taking: A Comparison of Culturally Diverse and Culturally Homogeneous Task Groups. International Journal of Intercultural Relations, 16, 53-65.

Webster, F.E. (1994). Executing the New Marketing Concept. Marketing Management, 3(1), 9-18.

Webster, J. and P. Hackley (1997). Teaching Effectiveness in Technology-Mediated Distance Learning. Academy of Management Journal, 40 (6), 1282-1309.

Webster, J. and J.J. Martocchio (1992). Microcomputer Playfulness: Development of a Measure with Workplace Implications. MIS Quarterly, June, 201-226.

Weinberger, M.G. and C.S. Gulas (1992). The Impact of Humor in Advertising: A Review. Joumal of Adventising, 21 (4), 35-59.

Weisfield, G.E. (1993). The Adaptive Value of Humor and Laughter. Ethnology and Social Biology, 14 (2), 141-169.

Weitz, B.A., H. Sujan and M. Sujan (1986). Knowledge, Motivation, and Adaptive Behavior: A Framework for Improving Selling Effectiveness. Joumal of Marketing, 50 (4), 174-191.

Westbrook, R.A. and R.L. Oliver (1991). The Dimensionality of Consumption Emotion Patterns and Consumer Satisfaction. Journal of Consumer Research, 18 (June), 84-91.

Whitty, M.T. (2002). Liar, Liar! An Examination of How Open, Supportive and Honest People Are in Chat Rooms. Computers in Human Behaviour, forthcoming.

Whitworth, B., B. Gallupe and R.J. McQueen (2000). A Cognitive Three Process Model of Computer-Mediated Groups: Theoretical Foundations for Groupware Design. Group Decision and Negotiation, 9 (5), 431-456.

Wicker, F.W., W.L. Barron and A.C. Willis (1980). Disparagement Humor: Dispositions and Resolutions. Joumal of Personality and Social Psychology, 39 (4), 701-709.

Wiener, J.L. and J.C. Mowen (1985). Source Credibility; On the Independent Effect of Trust and Expertise When Attractiveness Is Held Constant. Working paper, 85-3, Oklahoma State University, Stillwater, OK.

Wiliarns, H. (1986). Humor and Healing: Therapeutic Effects in Geriatrics. Gerontion, 1, 14-17.

Williams, K.C. and R.L. Spiro (1985). Communication Style in the Salesperson-Customer Dyad. Joumal of Marketing Research, 22, 434-442.

Wilson, C.P. (1979). Jokes: Form, Content Use and Function. Academic Press Inc., New York.

Winsted, K.F. (1997). The Service Experience in Two Cuttures: A Behavioral Perspective. Joumal of Retailing, 73 (3), 337-360.

Wikin, S.L. (1999). Taking Humor Seriousiy. Social Work, 44 (2), $101-104$.

Wolfinbarger, M. and M. Gilly (2001). Shopping Online for Freedorn, Control, and Fun. Califomia Management Review, 43 (2). 34-56.

Yperen van, N. (1998). Informational Support, Equity, and Burn-Out: The Moderating Effect of Self-Efficacy. Joumal of Occupational and Organizational Psychology, 71(1), 29-33.

Yperen van, N. and T. Snijders (2000). A Multilevel Analysis of the Demands-Control Model: Is Stress at Work Determined by Factors at the Group Level or the Individual Level? Joumal of Occupational Health Psychology, 5, 182:-190.

Zeithaml, V. and M.J. Bitner (1996). Services Marketing. McGraw Hill, New York.

Zerthaml, V.A., A. Parasuraman and L.L. Berry (1993). The Nature and Determinants of Customer Expectations of Service. Journal of the Academy of Marketing Science, 21 (1), 1-12.

Zeithaml, V.A., A. Parasuraman and A. Malhotra (2000). A Conceptual Framework for Understanding E-Service Quality: Implications for Future Research and Managerial Practice. Marketing Science Institute, Working Paper 00-115, Cambridge, MA.

Zillman, D. and J. Bryant (1983). Uses and Effects of Humor in Educational Ventures. In: Handbook of Humor Research, McGhee, P.E. and J.H. Goldstein (Ed.), 173-193, Springer-Verlag, New York.

Ziv, A. (1988). Teaching and Leaming with Humor. Experiment and Replication. Joumal or Experimental Education, 57 (1), 5-15.

Zohar, D. (2000). A Group-Level Model of Safely Climate. Joumal of Applied Psychology, 85 (4), 587-597. 



\title{
Appendix A
}

\section{Humor Treatment for Face-to-Face Encounters: Excerpts of Related versus Unrelated Humor ${ }^{a}$}

\author{
Related humor \\ Customer: Good afternoon, I would like to book a holiday. \\ Travel agent: Ahh, You are here for some vitamin V (i.e., V=Vacation). \\ Customer: I would like to go in the week of March 12th. \\ Travel agent: Would you like to escape from Camival or would you want to slide down the mountains in your Carnival outfit? \\ Travel agent: There's an entertainment program in the bus, so you just might need your outfit. \\ Customer: Yes, indeed, I would like to go by bus instead of car, royal class, together with my boytriend. \\ Travel agent: Let me see whether there are still two seats available.....because 2 persons on 1 seat certainly is no fun \\ and definitely is no royal class at all (laughter).
}

Travel agent: Which hotel would you prefer... Of course, we could put an igloo on the slopes if you want to.... This would get you very close to the slopes! But perhaps that is a bit too nippy?!

Customer: Would you think insurance is necessary?

Travel agent: Well, it can be very slippery out at the slopes!

\section{Unrelated humor}

(Travel agent stumbles over chair)

Travel agent: $0000 \mathrm{~h}$, I am sorny, I act like Miss Bean!

Travel agent: Could you give me your name and date of birth for the booking form?

Customer: My name is J. van Leeuwen and my partner's name is R. Williams (i.e., a well known singer).

Travel agent: That's a good catch! Is he the real Hobbie Williams?

Customer: No (laughter).

Travel agent: Is he also a good singer...or only in the shower?

Customer: Well, actually he is a good singer, but his name is Rudolph...but he's not a reindeer.

Travel agent: And what's the date of birth?

Customer: Mine is May 7th, 1976.

Travel agent: And Rudolph's?

Customer: April 1st, 1975.

Travel agent: You are kidding me.... Williams and also born on April fool's day.

Customer: No, I am not kidding you (laughter).

Travel agent: Well, it would be a very good one, though. Let me call and see whether there is still room available for you and Robbie.....uh Rudolph (laughter).

Travel agent (while waiting on the phone): Lately, I had such a strange experience: they put me on hold and than they accidentally transierred the call to a Comedy Joke-line.

Customer: Your kidding me!

Travel agent: No I am not.... That is what I would call a practical joke.

Travel agent (talking to another service employee on the phone): I would like to make a reservation for $\mathrm{J}$. van Leeuwen and R. Williams. No, it is not the real one....but he was born on April faol's day.... No really, it is not a joke (laughter).

(Customer's cell phone rings: the tune is from Rudolph the Red Nose Reindeer).

Travel agent: Is that your car dealer calling for your annual moose test?

${ }^{3}$ The examples are all idiomatically translated from Dutch texts. 


\section{Appendix B}

\section{Humor Treatment for Electronic Encounters: Site Samples of Related Humor}

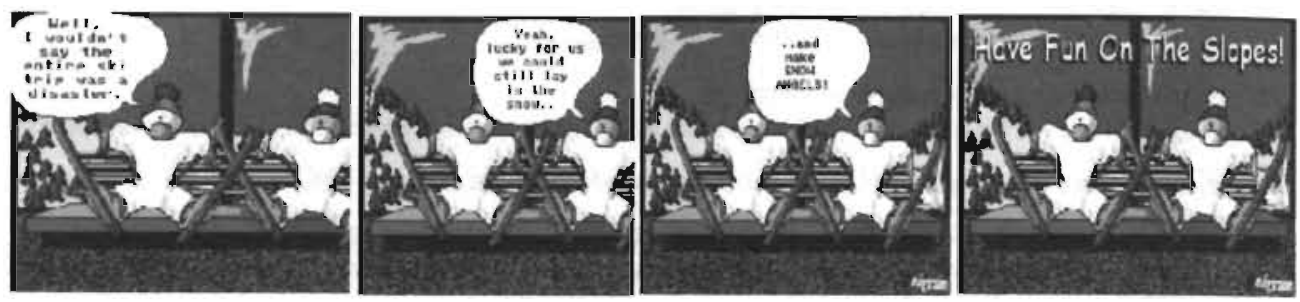

1) Cartoon with Figures in Plaster Cast
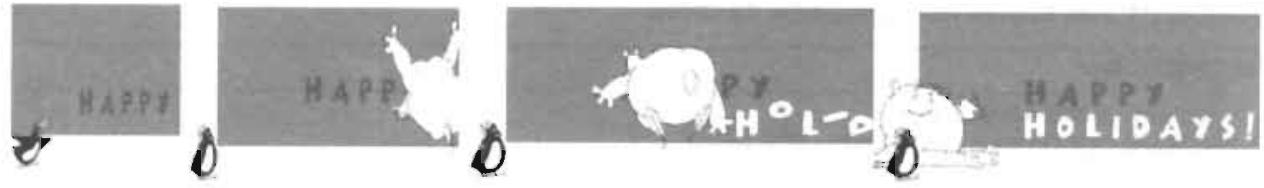

2) Animated Picture
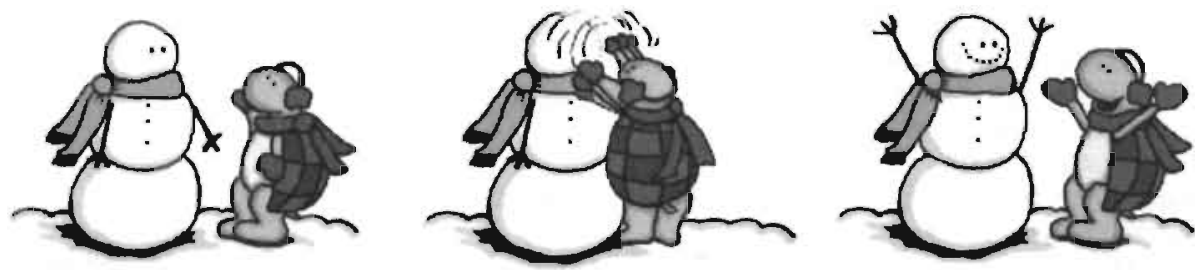

3) Funnies as Dispersed over the Web-site
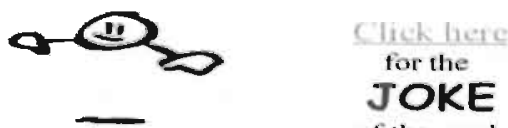

of the week

4) Joke of the Week 


\section{Appendix B (continued)}

\section{Humor Treatment for Electronic Encounters: Site Samples of Unrelated Humor}
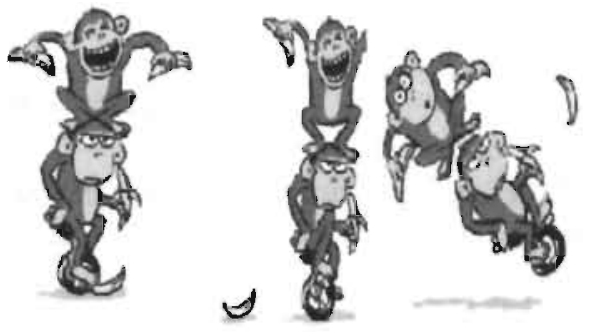

I car always count on you when the chinps are down.

$$
\text { Tha-ks! }
$$
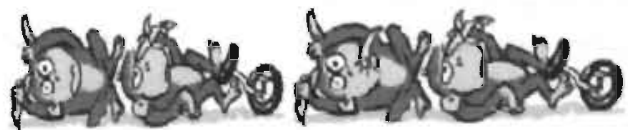

1) Cartoon with Monkeys Slipping on Banana
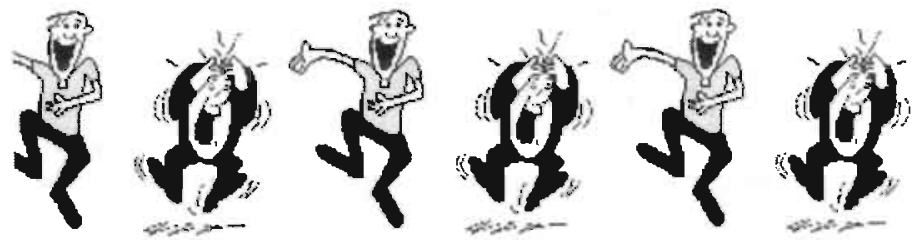

2) Animated Picture
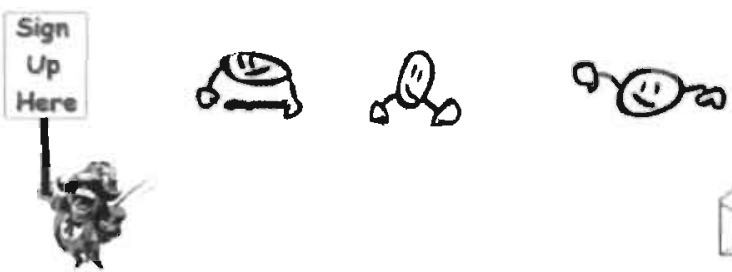

If you have filled out all the fields containing a SMILEY (e) you can submit this bonking form:

\section{Book this trip!}

3) Funnies as Dispersed over the Web-site

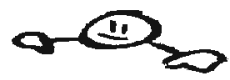

4) Joke of the Week

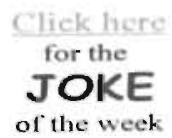





\section{Close Encounters of Various Kinds}

\section{Empirical Studies of Customer-Firm Interactions}

\section{Nederlandse Samenvatting}

\section{Inleiding}

In een markt die wordt gekenmerkt door een sterke concurrentie en door veeleisende klanten, is het scheppen van klanttevredenheid voor bedrijven van crucial belang. Tevreden klanten zijn loyaal, zorgen voor positieve mond-tot-mondreclame en creëren daarom een goede reputatie van het bedrijf. Niet alleen voor bedrijven is klanttevredenheid van belang, maar ook voor de consumenten zelf. Zij ervaren tevredenheid als plezierig en bovendien hoeven zij niet in te zitten over het indienen van een klacht of over het terugbrengen van het product. Daarnaast geeft tevredenheid met de aanschaf aan klanten het gevoel dat zij in staat zijn om goede beslissingen te nemen. Het is daarom voor een bedrijf van belang om te zorgen dat elke interactie met een klant naar diens tevredenheid verloopt. Met interacties bedoelen we in dit proefschrift een tijdsperiode waarin een klant direct contact heeft met het bedrijf. We kunnen verschillende interacties onderscheiden. Zo zijn er persoonlijke interacties, waarin de klant en de verkoper beiden fysiek aanwezig zijn en in levenden lijve met elkaar communiceren. In de Angelsaksische literatuur worden dit 'face-to-face encounters' genoemd. Met de komst van het Internet zijn nieuwe vormen van interacties ontstaan, de zogeheten elektronische interacties. In deze interacties staat zelfbediening vaak centraal; de klant koopt een product of dienst via een web-site, zonder assistentie van een verkoper. Als voorbeeld geven we het kopen van een boek bij Amazon.com.

Een gevolg van de self-service op het Internet is dat het menselijke contact tussen de klant en het bedrijf tot een minimum blijft beperkt of zelfs helemaal verdwijnt. Hoewel sommige klanten het gebrek aan contact juist waarderen, blijkt dat er bij andere klanten en in bepaalde elektronische verkoopsituaties toch een sterke behoefte is aan persoonlijk contact. Deze klanten hebben behoefte aan sociaal contact of koesteren speciale wensen die zij liever tijdens een persoonlijk gesprek aan de orde stellen. Verder wijst onderzoek uit dat er een grotere kans is dat kijken kopen wordt als er een bepaalde vorm van menselijk contact plaats vindt. Als reactie hierop onderzoeken steeds meer bedrijven de mogelijkheden die interactieve technologieën bieden om klanten met verkopers te laten communiceren. Een van die mogelijkheden is het commercieel chatten in groepsverband. Dit zijn elektronische interacties waarbij groepen klanten met elkaar en met een verkoper chatten over een bepaald product of een bepaalde service. Het bedrijf initieert deze chatsessies en de verkoper vervult een actieve rol tijdens het chatten. Een voorbeeld hiervan zijn de chatsessies 
die de financiële dienstverlener American Express organiseert voor zijn klanten om zo de introductie van nieuwe producten te ondersteunen.

De centrale doelstelling van deze dissertatie is te onderzoeken welke factoren de klanttevredenheid bepalen in face-to-face en elektronische verkoopsituaties. Hiertoe formuleren we de volgende onderzoeksvragen:

1) Wat is het effect van interpersoonlijke percepties op klanttevredenheid in face-to-face verkoopsituaties? (hoofdstuk 2)

2) Wat is het effect van humor op klanttevredenheid in face-to-face verkoopsituaties en in elektronische zelfbediening? (hoofdstuk 3)

3) Hoe beïnvloeden de kenmerken van de klant, de groep, en de verkoper klanttevredenheid bij het chatten in groepsverband? (hoofdstuk 4)

4) Hoe beïnvloeden verschillende modellen van besluitvorming klanttevredenheid bij het chatten in groepsverband? (hoofdstuk 5)

\section{Face-to-Face Verkoopgesprekken: Een Dyadisch Perspectief}

In hoofdstuk 2 onderzoeken we verkoopgesprekken vanuit een invalshoek die gebaseerd is op de onderzoekstraditie van de interpersoonlijke perceptie, afkomstig uit de sociale psychologie. Dit houdt in de eerste plaats in dat we niet alleen klanttevredenheid bestuderen, maar ook de tevredenheid van de verkoper over het gesprek. Ten tweede analyseren we zogeheten 'partner-effecten', waarbij we nagaan in welke mate de percepties van de verkoper de klanttevredenheid beïnvloeden en in welke mate de percepties van de klant de tevredenheid van de verkoper beinvloeden. Ten slotte onderzoeken we of percepties van de klant en de verkoper zijn gebaseerd op unieke ervaringen gedurende het gesprek of op stabiele kenmerken van de verkoper.

In een studie die plaatsvond in een meubelzaak zijn de meningen van klanten en verkopers gemeten. De resultaten tonen aan dat factoren die klanttevredenheid bepalen ook de tevredenheid van de verkoper beïnvloeden. Verder hebben we vastgesteld dat de klanttevredenheid niet alleen wordt bepaald door de mening van de klant over de verkoper, maar ook door het beeld dat de verkoper van zichzelf heeft. Op eenzelfde manier wordt de tevredenheid van de verkoper beïnvloed door het beeld dat de verkoper van zichzelf heeft en door de mening van de klant. Tot slot toont onze studie aan dat de percepties van de klant en de verkoper niet alleen worden gevormd door hun unieke ervaring tijdens het verkoopgesprek, maar ook door relatief stabiele kenmerken van de verkoper.

\section{Het Effect van Humor in Face-to-Face en Elektronische Verkoopsituaties}

In hoofdstuk 3 onderzoeken we het effect van humor op klanttevredenheid in face-toface gesprekken en in de elektronische zelfbediening. Hierbij brengen we het verband tussen het gebruik van humor en de uitkomst van de service in kaart. In het onderzoek maken we een onderscheid tussen gerelateerde en ongerelateerde humor. Gerelateerde humor is gedefinieerd als humor die betrekking heeft op het product of de service. Zo heeft in het geval van het boeken van een vakantie een gerelateerde 
grap van de verkoper betrekking op de reis. Ongerelateerde humor staat los van het product of de service. Onder uitkomst verstaan we het resultaat van het verkoopgesprek, waarbij we een onderscheid maken tussen een positieve (de reis kan worden geboekt) of een negatieve uitkomst (de reis kon niet worden geboekt).

Het effect van beide typen humor en van het resultaat van de service wordi gemeten door middel van een experiment. De verkoopsituatie betreft het boeken van een wintersportvakantie hetzij via een persoonlijk verkoopgesprek. hetzij via een website. Door de experimentele opzet van onze studie kunnen we naast tevredenheid ook meten in hoeverre klanten de interactie plezierig hebben gevonden en of zij van plan zijn als klant terug te keren naar het reisbureau of naar de web-site.

De resultaten tonen aan dat gerelateerde humor de kans op een positieve evaluatie van klanten in de face-to-face verkoopsituatie vergroot. Dit effect wordt niet gevonden voor de web-site. Verder constateren we dat het resultaat van de service het oordeel van de klant beïnvloedt in het face-to-face gesprek én in de elektronische zelfbediening. Bovendien stellen we vast dat in persoonlijke verkoopgesprekken de invloed van de humor belangrijker is dan het resultaat van de service, terwijl voor het boeken van een reis via de web-site het resultaat belangrijker is. Tot slot signaleren we interactie-effecten voor de elektronische verkoopsituatie. Dit duidt erop dat in het geval de reis niet kan worden geboekt op de web-site, het gebruik van gerelateerde humor het effect van deze negatieve uitkomst deels zou kunnen compenseren.

\section{Chat als Marketing Instrument: De Ontwikkeling van een Theoretisch Model}

In hoofdstuk 4 introduceren we serviceverlening via chatten in groepsverband. In het Engels wordt dit moderated group chat genoemd, afgekort MGC. We definiëren MGC, als een on-line, synchrone interactie van een groep klanten, waarbij een actieve rol voor een adviseur van het bedrijf is weggelegd en het doel commercieel is. Op basis van theorieën vanuit marketing, communicatie, groepsdynamica en leiderschap ontwikkelen we een theoretisch onderzoeksmodel. Vervolgens onderzoeken we empirisch welke factoren van dit model klanttevredenheid met MGC bepalen.

Het theoretische model bestaat uit drie groepen variabelen: klant-, groeps- en adviseurkenmerken. De klantkenmerken worden gemeten aan de hand van vier variabelen: de sociale voordelen die klanten associëren met het gebruik van interactieve elektronische services, de functionele voordelen die klanten associëren met het gebruik van interactieve elektronische services, de mate waarin een klant zichzelf in staat acht om te kunnen chatten over een bepaald product of een bepaalde service, en de mate waarin klanten zich comfortabel voelen in een sociale (on-line) omgeving. We meten de groepskenmerken aan de hand van de volgende variabelen: de taakgerichte communicatie binnen de groep, de socialgerichte communicatie binnen de groep, groepscohesie, en de mate waarin de groep in staat is om taakgericht gedrag te vertonen. Met betrekking tot de kenmerken van de adviseur maken we onderscheid tussen een taakgerichte en een sociaalgerichte communicatiestijl.

Naast de invloed van deze factoren op klanttevredenheid gaan we na wat het effect is van twee belangrijke aspecten van MGC. Ten eerste bepalen we hoe de stijl van de adviseur de relatie tussen de verschillende klant- en groepskenmerken en 
klanttevredenheid beïnvloedt. Ten tweede testen we of de effecten van de kenmerken verschillen voor de individuele klant en voor de groep. Met andere woorden: we onderzoeken of een perceptie van de klant uniek is of dat de perceptie gedeeld wordt door de hele groep.

Onze resultaten tonen aan dat de kenmerken van de klant en van de groep de klanttevredenheid positief beïnvloeden, maar dat deze effecten verschillen voor de chatgroepen met een taakgerichte adviseur, vergeleken bij de groepen met een sociaalgerichte adviseur. Verder blijkt dat er verschillen zijn tussen waarnemingen van de individuele klant en waarnemingen van de groep. Deze resultaten wijzen erop dat tijdens de commerciële chatsessies de rol van de adviseur van groot belang is en dat er bepaalde groepsprocessen ontstaan die de klanttevredenheid beïnvloeden.

\section{Chat als Marketing Instrument: Een Onderzoek naar Alternatieve Modellen van Klanttevredenheid}

In hoofdstuk 5 onderzoeken we drie alternatieve modellen voor klanttevredenheid met MGC: een attributen-model, een algemeen affect-model, en een groepsmodel. De eerste twee zijn bestaande modellen, maar deze zijn nog niet eerder getest in de context van groeps-chat. Het laatste model is speciaal voor deze studie ontwikkeld.

Het attributen-model gaat ervan uit dat de klanten een aantal belangrijke aspecten van groeps-chat evalueren om zich vervolgens een mening over MGC te vormen. Die aspecten hebben betrekking op de controle, het plezier, de betrouwbaarheid, de snelheid, en het gemak, zoals klanten het ervaren tijdens het chatten. In het affectmodel wordt verondersteld dat klanten algemene predisposities hebben en die gebruiken om hun mening over MGC te vormen. In het model worden twee predisposities gemeten, zowel het gevoel van de klant met betrekking tot het gebruik van technologie als de behoefte aan contact met mensen in on-line verkoopsituaties. Het groepsmodel gaat ervan uit dat bepaalde kenmerken van de groep de tevredenheid van de klant met MGC beïnvloeden. In deze studie hebben we de volgende vier groepskenmerken gemeten: het taak en sociale klimaat in de groep, de betrokkenheid van de groep, de gelijkheid van de groep, en de ontvankelijkheid van de groep. Evenals in hoofdstuk 4 onderzoeken we bovendien de invloed van de stijl van de adviseur en bekijken we of de effecten verschillen met betrekking tot de individuele klanten en tot de groepen.

Onze resultaten laten zien dat zowel het attributen-model als het groepsmodel een significante invloed heeft op klanttevredenheid. Maar zoals in hoofdstuk 4 het geval was, constateren we ook nu weer dat de modellen verschillen voor groepen met een taakgerichte verkoper vergeleken bij groepen met een sociaalgerichte verkoper. Ook blijkt opnieuw dat er verschillen zijn tussen de waarnemingen van de individuele klant en die van de groep. Dit houdt in dat bij het commerciële gebruik van de chatsessies aandacht moet worden besteed aan de rol van de adviseur en aan het feit dat klanttevredenheid een resultaat is van individuele evaluatieprocessen van de klant alsmede van groepsprocessen die tijdens het chatten ontstaan. 


\section{Conclusie}

Het onderzoek van dit proefschrift geeft te zien dat in persoonlijke verkoopgesprekken én in MGC interpersoonlijke beïnvloeding plaatsvindt. Verder blijkt dat niet alleen sociale maar ook takgerichte factoren de klanttevredenheid beïnvloeden in beide verkoopsituaties. Het proefschrift toont tevens aan dat percepties van klanten niet alleen worden gevormd door hun eigen, subjectieve mening, maar dat er ook een bepaalde mate van overeenstemming is in de percepties van de verschillende klanten. De studies in alle hoofdstukken bevestigen het belang van de rol van de verkoper in het creëren van klanttevredenheid. Tot slot stellen we dat het idee dat on-line kopers geen menselijk contact verlangen moet worden genuanceerd. In de komende jaren verwachten we de opkomst van een nieuwe generatie van commerciële web-sites die de mogelijkheid geven tot interactieve en interpersoonlijke interacties. 



\section{Curriculum Vitae}

Willemijn M. van Dolen was born on May 7, 1972 in Amsterdam, the Netherlands. After completion of the secondary school at St. Ignatius Gymnasium in Amsterdam, she studied at the Faculty of Behavioral and Social Sciences at the University of Groningen, the Netherlands. She specialized in Social \& Organizational Psychology as well as in Psychology of Personality and obtained her Master's Degree in 1996. During her studies, she worked for three years as a teaching assistant at the University of Groningen and several Higher Education Institutions. In 1995, she joined the Dutch School of Criminal Investigation and Crime Control as a researcher. She started as a consultant at a recruitment agency in 1996. As of June 1998, she became a Ph.D. candidate at the department of Marketing and Marketing Research, Faculty of Economics and Business Administration, Maastricht University, the Netherlands. In 2001, she spent one year as a visiting scholar at the University of California, Berkeley, USA. Her main research interests include customer satisfaction, employee performance, customer emotions, interpersonal influence, and chat-selling. Her work has been published in Journal of Economic Psychology, Journal of Business Research, in several conference proceedings, and is forthcoming in International Journal of Service Industry Management and Journal of Retailing. 


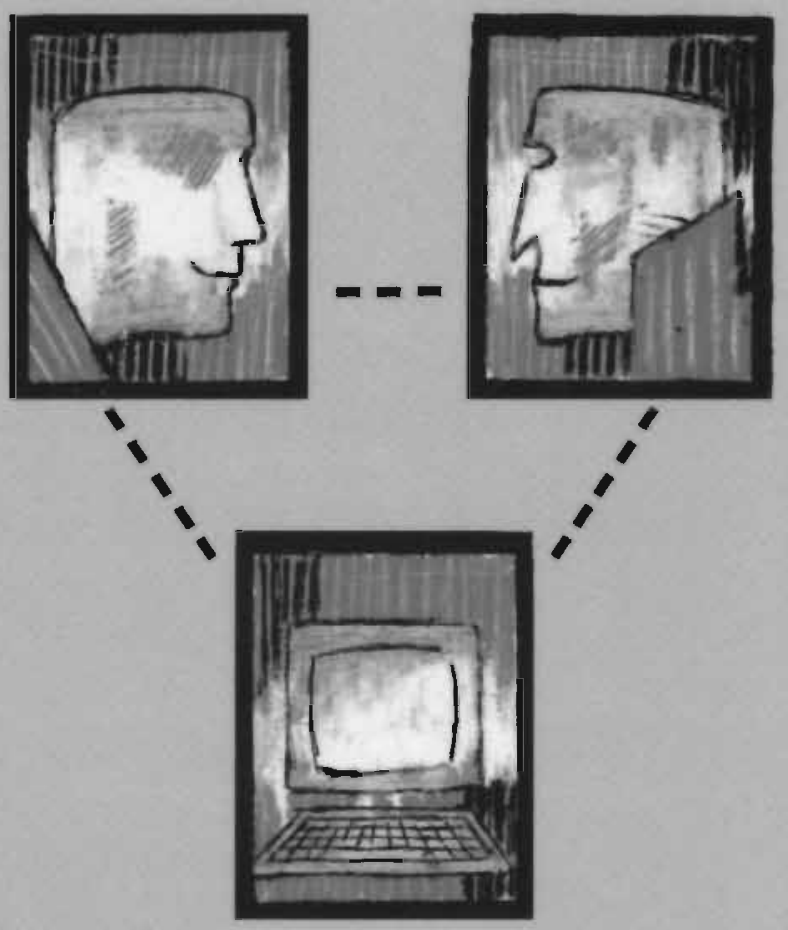

